\title{
Ma Ángeles Llopis Nebot \\ Pensamiento reflexivo en el Prácticum I del alumnado de Grado de Maestro en Educación Primaria a través de diarios online
}

Directores:

Dr. Jordi Adell Segura

Dra. Ma Lidón Moliner Miravet

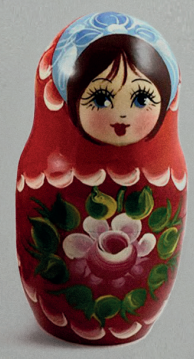


Programa de Doctorado en Educación Secundaria (R.D. 1393/07)

UNIVERSITAT JAUME I

Ma Ángeles Llopis Nebot

\section{Pensamiento reflexivo en el}

Prácticum I del alumnado de Grado de Maestro en Educación Primaria a través de diarios online

Directores:

Dr. Jordi Adell Segura

Dra. Ma Lidón Moliner Miravet

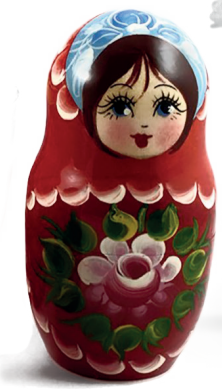


Diseño y maquetación de portada y tesis: Jose V. Martínez (hando.es)

Cada uno de los capítulos que contiene esta tesis doctoral, así como las imágenes incluidas, si no se indica lo contrario, se encuentra sujetos a la Licencia Reconocimiento-NoComercial-SinObraDerivada 4.0 Internacional de Creative Commons. Para ver una copia de esta licencia, visite http://creativecommons.org/ licenses/by-nc-nd/4.0/ o envíe una carta Creative Commons, PO Box 1866, Mountain View, CA 94042, USA.

\section{creative
commons $(9)(9) \odot$}


"Las cosas nunca son como a primera vista las figuramos, y así ocurre que cuando empezamos a verlas de cerca, cuando empezamos a trabajar sobre ellas, nos presentan tan raros y hasta tan desconocidos aspectos, que de la primera idea no nos dejan a veces ni el recuerdo."

La familia de Pascual Duarte

Camilo José Cela 



\section{Informe}
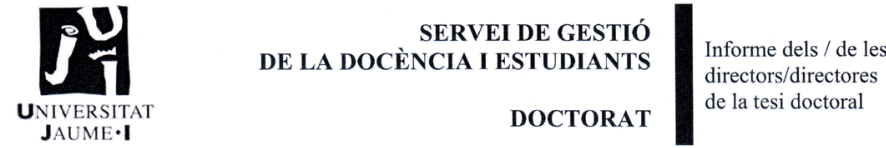

D'acord amb l'article 19 de la Normativa dels Estudis de Doctorat de la Universitat Jaume I (26-

1-2012) que regula el procediment per a l'elaboració i defensa de les tesis doctorals segons el RD 99/2011, i com a directors/directores de la tesi doctoral presentada per $\mathrm{M}^{\mathrm{a}}$ Ángeles LLopis amb el títol Pensamiento reflexivo en el Practicum I del alumnado de grado de maestro en

educación primaria a través de diarios on-line

de l'òrgan responsable del programa de doctorat departament d'educació emet el següent INFORME:

La tesis doctoral de la estudiante $\mathrm{M}^{\mathrm{a}}$ Ángeles LLopis Nebot cumple con las directrices establecidas en el programa de doctorado en el que se inscribe la tesis.

Este trabajo contribuye en el avance de las investigaciones de innovación educativa.

Los diferentes apartados de la tesis son claros y pertinentes. En el marco teórico se abordan cuestiones básicas como el pensamiento reflexivo o el Espacio Europeo de Educación Superior. A través de un estudio de caso se analizan las reflexiones del estudiantado del grado de maestro/a en la asignatura del Prácticum I. El apartado metodológico detalla el diseño de la investigación apartonado cuidadosamente los elementos básicos de este apartado. En la siguiente sección se presentan los resultados de los dos grupos participantes (control y experimental) y se aportan citas que complementan los resultados obtenidos. Finalmente se aportan las conclusiones más relevantes y los límites y las futuras líneas de investigación.

Así pues, a partir de esta tesis doctoral se desvelan las claves para mejorar una asignatura de vital importancia desde un enfoque reflexivo.

El/ La director/a de la tesi
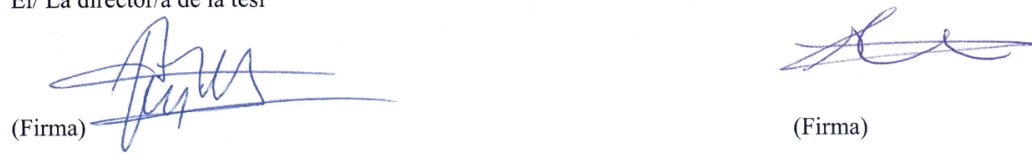

(Firma)

JDRBI ADELL SEGURA

Castelló de la Plana, 28 ..... d junio ... de 20.17
(Firma)

Nom i cognoms

Gon rohinen rinavet 



\section{Agradecimientos}

Quiero manifestar todo mi agradecimiento a aquellas personas que han estado de una u otra forma apoyando este proyecto.

En primer lugar agradezco a Jordi Adell y a Lidón Moliner, mis directores de tesis, su dedicación y sus valiosos consejos así como la absoluta confianza que han tenido en mí a pesar de ir siempre contrareloj. Sois un amor.

En mis agradecimientos, aunque ya no esté, no puede faltar Marisa Sanchiz. En este camino has sido y eres importante. Tu calidad humana y entrega siempre me servirán de ejemplo e inspiración.

A mis padres, por su infinita paciencia, generosidad y apoyo no solo en esta tesis sino en la vida entera.

A Jose, por su cariño y su humor, por soportar durante todo este tiempo las renuncias que conlleva la vida del doctorando y por ayudarme a mejorar infinitamente el aspecto de este trabajo.

A Esther, por su incondicional amistad y por toda una vida de aventuras. A este tren me he subido sola pero cuando puedas, cuando quieras, aquí estoy para echarte una mano.

Por supuesto muchas gracias los profesionales que han dedicado desinteresadamente su tiempo y esfuerzo a este trabajo doctoral. Quienes me ayudaron a validar la entrevista, quienes motivaron a los alumnos para que participaran y quienes se ofrecieron a revisar y mejorar la tesis. Sin duda os debo una.

Gracias a todos los alumnos y alumnas que participaron en la investigación y que compartieron sus experiencias a pesar de su siempre escaso tiempo.

Gracias también a mi familia, carnal y política, hermano, tios, cuñadas, cuñados y queridísimos sobrinos, por vuestra presencia, cariño y ánimos hasta la meta.

También quiero agradecer a los miembros de nuestro recién nacido grupo GREAT no solo los ánimos y los consejos que me habéis dado en el presente sino, especialmente, los que me daréis en el futuro.

Y por último, mi más sincero agradecimiento a la web Sci-Hub y a todos aquellos investigadores que comparten de forma libre su conocimiento. 



\section{Índice}

Agradecimientos . . . . . . . . . . . . . . . . . . . . . . . . .7

PARTE I. JUSTIFICACIÓN DE LA INVESTIGACIÓN. . . . . . . . . . . . . . . 15

PARTE II. MARCO TEÓRICO . . . . . . . . . . . . . . . . . . . . . . . . . . . . . 17

1. Unión Europea y cambios en la Educación Superior . . . . . . . . . . . . . . 17

1.1 Configuración del Espacio Europeo de Educación Superior . . . . . . . . . . 17

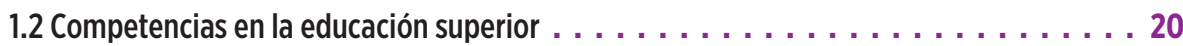

2. El Grado de Maestro o Maestra en Educación Primaria . . . . . . . . . . . . . . . 25

2.1 La asignatura de Practicum en el Grado de Maestro en Educación Primaria . . . . . . . . 27

2.2 Hacia un Practicum reflexivo . . . . . . . . . . . . . . . . . . 30

3. Aproximación filosófica y epistemológica de la práctica reflexiva . . . . . . . . 34

3.1 John Dewey: de la acción rutinaria a la acción reflexiva . . . . . . . . . . . . 37

3.2 Donald Schön: el pensamiento práctico . . . . . . . . . . . . . . . . . . . . . . 40

4. Consideraciones terminológicas sobre la reflexión y la práctica reflexiva . . . . . 43

4.1 Aproximación al concepto de reflexión . . . . . . . . . . . . . . 43

4.1 .1 La dirección de la reflexión . . . . . . . . . . . . . . . . . . . . . . . . . . . . 47

4.2 Aproximación al concepto de práctica reflexiva $\ldots \ldots \ldots \ldots \ldots \ldots \ldots \ldots 48$

5. La reflexión como proceso cíclico. . . . . . . . . . . . . . . . . . . . . . 54

5.1 El modelo experiencial de Kolb . . . . . . . . . . . . . . . . . . . . . . 54

5.2 El ciclo reflexivo de Gibbs . . . . . . . . . . . . . . . . . . . . . . . . . . . . . 56

5.3 EL modelo ALACT de Korthagen (2001) . . . . . . . . . . . . . . . . . . . 59

5.4 El modelo de Wareing: Me, my, more, must. . . . . . . . . . . . . . . . . . . 61

6. Niveles de reflexión docente. . . . . . . . . . . . . . . . . . . . . . . . . . . 64

7. Métodos para fomentar la práctica reflexiva . . . . . . . . . . . . . . . . 71

7.1 Métodos que se apoyan en la tecnología . . . . . . . . . . . . . . . . 72

7.1 .2 El diario reflexivo online . . . . . . . . . . . . . . . . . . . . . . . . 73

7.2 Métodos basados en la interacción humana . . . . . . . . . . . . . . . . . . . 75

7.2 .1 Apoyo del tutor y/o supervisor . . . . . . . . . . . . . . . . . 75

7.2 .2 Apoyo del grupo de iguales $\ldots \ldots \ldots \ldots \ldots \ldots \ldots \ldots \ldots \ldots$

7.2 .3 Apoyo mixto . . . . . . . . . . . . . . . . . . . . . . . . . . 78

8. Críticas al paradigma del pensamiento reflexivo $\ldots \ldots \ldots \ldots \ldots \ldots \ldots . \ldots 80$

8.1 Críticas teórico-conceptuales . . . . . . . . . . . . . . . . . . 80 
8.2 Críticas a la metodología $\ldots \ldots \ldots \ldots \ldots \ldots \ldots \ldots \ldots \ldots . \ldots . \ldots . \ldots . \ldots \ldots$

8.3 Críticas a los fines de la reflexión. . . . . . . . . . . . . . . 84

8.4 Críticas éticas. . . . . . . . . . . . . . . . . . . . . . . . . . 85

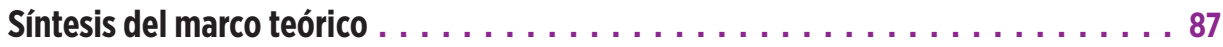

PARTE III. MARCO EXPERIMENTAL . . . . . . . . . . . . . . . 89

9. Contexto de la investigación. . . . . . . . . . . . . . . . . . . 89

10. Planteamiento del problema . . . . . . . . . . . . . . . . . . . . . 95

11. Objetivos. . . . . . . . . . . . . . . . . . . . . 97

12. Preguntas de investigación . . . . . . . . . . . . . . . 98

13. Diseño de la investigación. . . . . . . . . . . . . . . . . . . . 99

13.1 Paradigma y perspectiva teórica. . . . . . . . . . . . . . . . . . . . 101

13.2 Enfoque o método. . . . . . . . . . . . . . . . . . . . . . 103

13.2 .1 Criterios de calidad . . . . . . . . . . . . . . . . . . . . . . . . . 104

13.3 Selección de la muestra. . . . . . . . . . . . . . . . . . . . . . . . . 106

13.4 Intervención y seguimiento $\ldots \ldots \ldots \ldots \ldots \ldots \ldots \ldots \ldots \ldots \ldots \ldots \ldots$

13.5 Métodos de recogida de información . . . . . . . . . . . . . . . . . . . . 110

13.5.1 Entrevista semiestructurada . . . . . . . . . . . . . . . . . 110

13.5.2 Diarios online (e-diarios) . . . . . . . . . . . . . . . . . . . 113

13.6. Técnicas de investigación e instrumentos de análisis. . . . . . . . . . . . 115

13.6.1 Análisis de contenido . . . . . . . . . . . . . . . . . . . . . 115

13.6.2 Software de análisis de datos cualitativos MAXQDA v.12 . . . . . . . . . 116

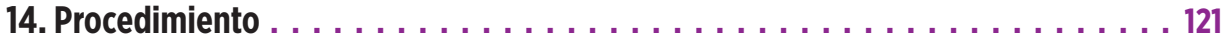

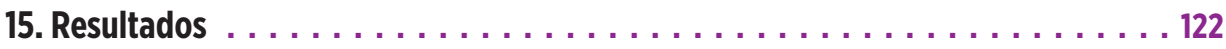

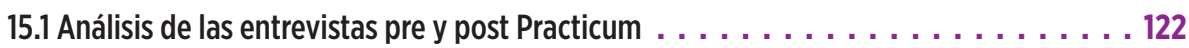

15.1.1 Resultados de las entrevistas para el grupo experimental . . . . . . . . . 122

15.1.2 Resultados de las entrevistas para el grupo control . . . . . . . . . . . 125

15.1 .3 Síntesis de resultados en ambos grupos para la entrevista reflexiva . . . . . . . 130

15.2 Análisis del diario reflexivo online. . . . . . . . . . . . . . . . . . 130

15.2.1 Análisis de los niveles de reflexión de los e-diarios . . . . . . . . . . . 131

15.2.1.1 Resultados de los diarios online para el grupo experimental . . . . . . . . . 131

15.2.1.2 Resultados de los diarios online para el grupo control . . . . . . . . . . 134

15.2.1.3 Síntesis de resultados en ambos grupos para los e-diarios reflexivos. . . . . 140

15.2.2 Análisis de los temas emergentes. . . . . . . . . . . . . . . . . . . . 141

15.2 .3 Síntesis de resultados para los temas emergentes $\ldots \ldots \ldots \ldots \ldots \ldots . \ldots \ldots$ 
15.3 Triangulación de instrumentos y resultados . . . . . . . . . . . . . 155

15.3.1 Síntesis de la triangulación de instrumentos y resultados. . . . . . . . . . 160

Síntesis del marco experimental . . . . . . . . . . . . . . . . . . . 162

16. Conclusiones y discusión . . . . . . . . . . . . . . . . . . 163

16.1 Discusión sobre los objetivos y las preguntas de investigación $\ldots \ldots \ldots \ldots \ldots \ldots$

16.2 Conclusión final . . . . . . . . . . . . . . . . . . . . . . . . . 180

16.2 .1 Limitaciones de la investigación. . . . . . . . . . . . . . . . . . . . . . . 181

16.2 .2 Consideraciones éticas. . . . . . . . . . . . . . . . . . . . . . . 183

16.2 .3 Líneas futuras de investigación . . . . . . . . . . . . . . . . . . . . . . . 184

PARTE IV. Referencias. . . . . . . . . . . . . . . . . . . . . . . . . . . . . . . . . 187

Anexos y apéndices . . . . . . . . . . . . . . . . . . . . . . . . . . . . 221 


\section{Tablas y figuras}

\section{Índice de tablas}

Tabla 1 Objetivos propuestos por el Plan Bolonia . . . . . . . . . . . . . . . . . . . . . . . . . . . . . . . . . 19

Tabla 2 Competencias genéricas o transversales en la educación superior . . . . . . . . . . . . . . . . . . . 21

Tabla 3 Definiciones de reflexión en orden cronológico . . . . . . . . . . . . . . . . . . . . . . . . . . . 44

Tabla 4 Definiciones de práctica reflexiva en orden cronológico . . . . . . . . . . . . . . . . . . . . . 49

Tabla 5 Procesos, propósitos y fundamentos de la práctica reflexiva. . . . . . . . . . . . . . . . . 50

Tabla 6 Niveles de reflexión categorizados por diversos autores . . . . . . . . . . . . . . . . . . . . . 65

Tabla 7 Actividades y objetivos del Practicum I . . . . . . . . . . . . . . . . . . . . . . . . . . . . . . . 91

Tabla 8 Evaluación del Practicum I y II según el tipo de prueba . . . . . . . . . . . . . . . . . . . . . . . . . . 92

Tabla 9 Resumen de los elementos que determinan el diseño de la investigación . . . . . . . . . . . . . . . 99

Tabla 10 Dimensiones clave del paradigma socio-crítico . . . . . . . . . . . . . . . . . . . . . . . . . . . 102

Tabla 11 Criterios de inclusión y exclusión de la muestra. . . . . . . . . . . . . . . . . . . . . . . . . . . . 107

Tabla 12 Esquema de intervención durante la fase experimental . . . . . . . . . . . . . . . . . . . . . . . . . . . . . . . . . . . . . . . . .

Tabla 13 Códigos utilizados para el análisis de los niveles de reflexión . . . . . . . . . . . . . . . . . . . . . . . . . . . . .

Tabla 14 Categorías generales y códigos de los temas emergentes . . . . . . . . . . . . . . . . . . . . . . . . . . . . . . . . . . . . . . . . . . . . . .

Tabla 15 Subcategorías en relación a las categorías generales . . . . . . . . . . . . . . . . . . . . . . . . . . . 120

Tabla 16 Resultados entrevista pre y post Practicum en el grupo experimental . . . . . . . . . . . . . . . . . . . . . . . . . . .

Tabla 17 Resultados entrevista pre y post Practicum para el grupo control . . . . . . . . . . . . . . . . . . . . . . . . . . . . . . . . . . .

Tabla 18 Resultados comparados entrevista inicial en grupo experimental y control . . . . . . . . . . . . . . . . . . . . .

Tabla 19 Resultados comparado de la entrevista final en el grupo experimental y control. . . . . . . . . . . 129

Tabla 20 Resultado niveles de reflexión en diarios online del grupo experimental. . . . . . . . . . . . . . . . 131

Tabla 21 Resultados niveles de reflexión en diarios online del grupo control . . . . . . . . . . . . . . . . 135

Tabla 22 Reflexiones en e-diarios del grupo expermiental vs grupo control . . . . . . . . . . . . . . . . . . . . . . . . . . . .

Tabla 23 Temas de reflexión del grupo experimental y del grupo control . . . . . . . . . . . . . . . . . . . . . 142

Tabla 24 Temas de reflexión agrupados . . . . . . . . . . . . . . . . . . . . . . . . . . . . . . . . . . . . . . . 143

Tabla 25 Triangulación de resultados según el método de recogida de información en

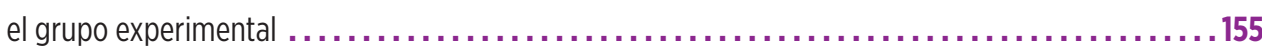

Tabla 26 Triangulación de resultados según el método de recogida de información en

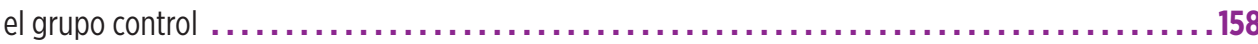




\section{Índice de figuras}

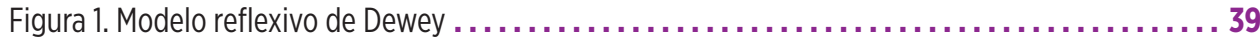

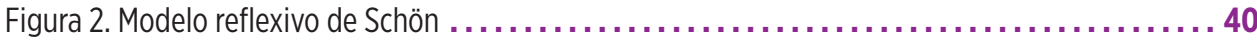

Figura 3. Habilidades y paradigmas que fundamentan la práctica reflexiva $\ldots \ldots \ldots \ldots \ldots \ldots \ldots 52$

Figura 4. Ciclo de aprendizaje experiencial de Kolb . . . . . . . . . . . . . . . . . . . . . . . . 55

Figura 5. Ciclo reflexivo de Gibbs. . . . . . . . . . . . . . . . . . . . . . . . . . . . . . . . . . . . . . . . 57

Figura 6. Modelo ALACT de reflexión. . .........................................6 60

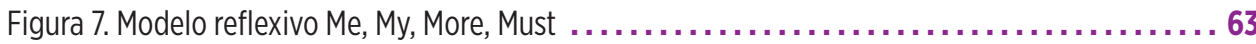

Figura 8. Niveles de reflexión sobre la práctica según Larrivee y Cooper (2005) . . . . . . . . . . . 67

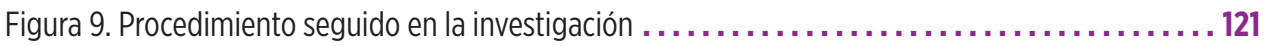

\section{Anexos y apéndices}

\section{Índice de anexos}

Anexo 1. Cuestionario de práctica refleciva de Larrivee (2008) $\ldots \ldots \ldots \ldots \ldots \ldots \ldots \ldots \ldots \ldots \ldots . .221$

Anexo 2. Documento de prácticas externas de la titulación de Maestro o Maestra de

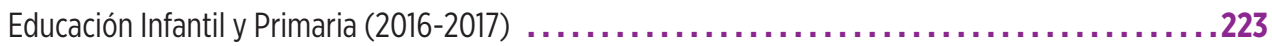

\section{Índice de apéndices}

Apéndice 1. Certificado de participación en la investigación . ......................... 259

Apéndice 2. Consentimiento informado .................................... 260

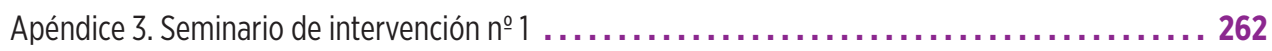

Apéndice 4. Guía del grupo experimental para elaborar el diario reflexivo $\ldots \ldots \ldots \ldots \ldots \ldots \ldots 265$

Apéndice 5. Entrevista reflexiva validada ..................................... 266 



\section{Parte I. Justificación de la investigación}

En la presente investigación se examina el proceso reflexivo del alumnado de tercer curso del Grado de Maestro Educación Primaria de la Universitat Jaume I de Castellón. Se pretende analizar cómo y hasta qué punto reflexiona dicho alumnado al llegar al Practicum I respecto aquello que compete a su futura profesión y averiguar, del mismo modo, si a lo largo de los cursos anteriores ha adquirido la competencia reflexiva, aspecto clave para desarrollarse en el futuro como profesional crítico.

También se pretende averiguar si aplicando una intervención específica se puede potenciar la capacidad reflexiva de dicho alumnado. A partir de los hallazgos se elaborarán una serie de orientaciones, a modo de conclusión, cuyo fin no es otro que favorecer entre el profesorado que imparte docencia en el Grado y especialmente entre el profesorado que supervisa alumnado de prácticas, la posibilidad de introducir cambios metodológicos que mejoren la adquisición de la competencia reflexiva en los futuros docentes.

Este trabajo coincide con un periodo de cambios en el plan de estudios de la titulación de Grado de Maestro en la UJl que afectará a la distribución de los créditos de Practicum de forma que el contacto entre teoría y práctica se iniciará desde el segundo curso. Se espera por lo tanto que los resultados obtenidos aporten algunas ideas clave que puedan influir en este proceso de renovación y que sirvan para potenciar y mejorar la competencia crítica del estudiantado.

La tesis tiene dos partes diferenciadas, una primera que comprende el marco teórico y una segunda parte dedicada al marco experimental. En los capítulos donde se expone la fundamentación teórica se revisa en toda su extensión las investigaciones previas y la literatura publicada en el campo de la práctica reflexiva. La parte empírica desarrolla la investigación llevada a cabo para abordar el caso particular de la práctica reflexiva en la Universitat Jaume I (UJI en adelante). 



\section{Parte II. Marco teórico}

\section{Unión Europea y cambios en la Educación Superior.}

\subsection{Configuración del Espacio Europeo de Educación Superior.}

La formación de la Unión Europea en 1993 inició en todos los países integrantes múltiples reformas en la estructura socio-económica de dichos estados destacando los cambios sucedidos a nivel económico (tratados de libre comercio, eliminación de aduanas, creación de fondos europeos, creación de moneda única, etc.), laboral (especialmente destacable la libre circulación de los ciudadanos ${ }^{1}$ europeos en busca del entorno laboral más óptimo) y educativo (convergencia de planes académicos, planes de movilidad dirigidos a alumnado y profesorado, etc.).

En 1996, a petición de la UNESCO, Jacques Delors elaboró el informe titulado La educación encierra un tesoro. En este informe se revisan tensiones educativas previsibles para el siglo XXI y se identifica la educación como instrumento clave de progreso para alcanzar los ideales de paz, libertad y justicia social. Este informe, contempla el aprendizaje a lo largo de la vida como un hecho basado en cuatro pilares fundamentales: aprender a conocer, aprender a hacer, aprender a convivir y aprender a ser.

El Informe Delors supone plantear nuevas directrices pedagógicas que apuntan hacia la necesidad de integrar todos los conocimientos y otras opciones de aprendizaje basadas en la adquisición de una serie de competencias capacitadoras para la vida y no tanto la mera cualificación técnica basada en el aprendizaje conceptual.

Las demandas del Informe Delors requieren un cambio en los núcleos formativos de los planes de estudios, un cambio que integre, como parte esen-

1 En la presente tesis de forma general y con el fin de agilizar su lectura se utilizará el masculino genérico para referirse a ambos sexos. 
cial, la adquisición y puesta en práctica de procesos reflexivos. Estos cambios son necesarios para examinar críticamente el propio proceso formativo (conocimientos, instrumentos) y evaluar si la formación recibida aporta finalmente habilidades, conocimientos y recursos acompañados de un grado de madurez personal para asumir responsabilidades futuras. Supone un cambio de paradigma educativo que sitúa al estudiantado como figura central, activa y reflexiva en su formación (Martínez-Clarés, Martínez-Juárez y Muñoz-Cantero, 2008).

El informe de la UNESCO tuvo especial consideración a partir de 1998, momento en el cual Italia, Francia, Reino Unido y Alemania firman la Declaración de La Sorbona, en la que reconocen la necesidad de crear un espacio común de educación superior. Un año después, la Declaración de Bolonia (1999), pondrá la primera piedra del proyecto por excelencia de la Unión Europea (en adelante UE) para reformar el sistema europeo universitario, la creación del Espacio Europeo de Educación Superior (en adelante EEES). El Proceso de Bolonia tiene como objeto la creación de un sistema universitario flexible apuntalado por tres pilares:

a. El European Credit Transfer System (en adelante ECTS) o Sistema Europeo de Transferencia de Créditos. Sistema que será paulatinamente adoptado por todas las universidades del EEES y que garantiza la homogeneidad y la calidad de los estudios en los países de la UE. Este sistema a su vez será clave para facilitar la movilidad del estudiantado entre los distintos países europeos.

b. La estructura de las titulaciones universitarias basadas en grado, de carácter más generalista y postgrado, con finalidad formativa especialista. Se menciona además la necesidad de orientar la educación superior hacia la adquisición de competencias más que de conocimientos.

c. Sistemas de acreditación. Con objetivo de vigilar la calidad de cada centro formativo y realizar seguimiento de su adecuación a los requisitos del EEES. En el Plan Bolonia se recogen una serie de objetivos dirigidos a los países de la UE (ver Tabla 1) que han sido fuente de amplio debate entre las instancias europeas de educación superior y en múltiples foros académicos. 


\section{Tabla 1}

Objetivos propuestos por el Plan Bolonia

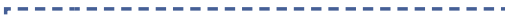

OBJETIVOS PROPUESTOS POR EL PLAN BOLONIA PARA LA EDUCACIÓN SUPERIOR

I. Adopción de un sistema de títulos comparables y equivalentes en todos los países para promover la empleabilidad de los ciudadanos europeos y la competitividad a escala internacional.

II. Adopción de un sistema de títulos comparables y equivalentes en todos los países para promover la empleabilidad de los ciudadanos europeos y la competitividad a escala internacional.

III. Adopción de un sistema universitario basado en dos ciclos principales: grado y postgrado. Para acceder al segundo ciclo será preciso haber completado el primer ciclo de estudios, con una duración mínima de tres años. El título concedido tras el primer ciclo corresponderá a un nivel de cualificación apropiado para acceder al mercado laboral europeo. El segundo ciclo debería culminar con la obtención de un título final o doctorado.

IV. Puesta a punto de un sistema de créditos como puede ser el sistema ECTS como medio apropiado para promover una mayor movilidad entre los estudiantes.

V. Promoción de la movilidad mediante la eliminación de los obstáculos al ejercicio efectivo del derecho a la libre circulación, tanto para estudiantes como para profesores, investigadores y personal administrativo.

VI. Promoción de la cooperación europea en materia de calidad educativa, a través del desarrollo de criterios y metodologías comparables.

VII. Promoción de la dimensión europea en la enseñanza superior, esto es, elaboración de programas de estudios, cooperación interinstitucional, programas de movilidad y programas integrados de estudios, formación e investigación.

Nota: Elaboración propia.

Miembros de la Comisión Europea fueron designados para realizar seguimiento materializado a través de diversos informes- del grado de desarrollo de la implementación, la efectividad y el impacto de las directrices de Bolonia en cada país. Desde estas instancias se ofrecía, además, soporte a los estados miembros en materia de políticas educativas (Comas, 2011). Sin embargo, las competencias en materia educativa quedaban delegadas en los propios estados miembros. Las instituciones universitarias asumen la responsabilidad y la libertad para impulsar planes transformativos y fijan sus propios plazos para adaptar los planes de estudio a la normativa europea. 
En España, la convergencia de las titulaciones a las propuestas europeas llega en 2007, con la aprobación del Real Decreto de Ordenación de Enseñanzas Universitarias Oficiales, por el cual se fija el sistema de titulaciones en tres niveles: grado, máster y doctorado.

En el año 2000, para apoyar la línea de acción del Plan Bolonia, surge el Proyecto Tuning (Tuning Educational Structures in Europe, 2003), cuyo objetivo principal es hacer comprensibles y comparables los planes de estudio para facilitar la adaptación y la calidad del sistema de titulaciones. Se vertebran así diversos estudios orientados a la concreción de competencias de aprendizaje genéricas y específicas en las distintas disciplinas universitarias y al desarrollo de perfiles profesionales basados en la innovación y la identificación de buenas prácticas.

\subsection{Competencias en la educación superior.}

El Proyecto Tuning (González y Wagenaar, 2006) define el concepto de competencia como "aquello que una persona es capaz o competente de ejecutar, el grado de preparación, suficiencia y/o responsabilidad para ciertas tareas” (p. 21). Esta definición, si bien un tanto elemental, servirá de punto de partida para una ingente cantidad de análisis en torno al concepto de competencia y servirá para el desarrollo de los libros blancos de las titulaciones en los que se establecerán las competencias a adquirir en el caso de cada grado (Riesco, 2008).

Desde el Proyecto Tuning se acuerda también una de las primeras clasificaciones de las competencias para las titulaciones en educación superior estableciendo una división entre competencias transversales y competencias específicas. Las competencias transversales, también llamadas genéricas (ver Tabla 2), deben ser adquiridas por cualquier graduado universitario independientemente de su titulación. Se adquieren a lo largo de todo el proceso académico y su utilidad es capacitar para hacer frente a las complejidades vitales en una multiplicidad de contextos y ámbitos. Las competencias específicas son las particulares de cada disciplina y explicitan los resultados de aprendizaje de cada asignatura. 


\section{Tabla 2}

Competencias genéricas o transversales en la educación superior

\begin{tabular}{|c|c|}
\hline COMPETENCIAS & COMPETENCIAS TRANSVERSALES \\
\hline \multirow{7}{*}{ INSTRUMENTALES } & Capacidad de análisis y síntesis \\
\hline & Capacidad de organización y planificación \\
\hline & Conocimientos de una lengua extranjera \\
\hline & Conocimiento de informática relativos al ámbito de estudio \\
\hline & Capacidad de gestión de la información \\
\hline & Resolución de problemas \\
\hline & Toma de decisiones \\
\hline \multirow{7}{*}{ PERSONALES } & Trabajo en equipo \\
\hline & Trabajo en un equipo de carácter interdisciplinar \\
\hline & Trabajo en un contexto internacional \\
\hline & Habilidades en las relaciones interpersonales \\
\hline & Reconocimiento de la diversidad y la multiculturalidad \\
\hline & Razonamiento crítico \\
\hline & Compromiso ético \\
\hline \multirow{8}{*}{ SISTÉMICAS } & Aprendizaje autónomo. Aprender a aprender \\
\hline & Adaptación a nuevas situaciones \\
\hline & Creatividad \\
\hline & Liderazgo \\
\hline & Conocimientos de otras culturas y costumbres \\
\hline & Iniciativa y espíritu emprendedor \\
\hline & Motivación por la calidad \\
\hline & Sensibilidad hacia temas medio-ambientales \\
\hline
\end{tabular}

Nota: Elaboración propia.

Las competencias transversales se dividen a su vez en competencias instrumentales, relacionadas con el saber, competencias personales, relacionadas con el saber ser (con mención especial para la competencia "razonamiento crítico") y competencias sistémicas, relacionadas con el saber hacer. Por su parte, las competencias específicas, se dividen en académicas o teóricas (saber), disciplinares o relativas a la 
práctica profesional (hacer) y comunicativas o indagadoras (saber hacer).

La clasificación de las competencias realizada por el Proyecto Tuning surge del análisis pormenorizado de las necesidades laborales en Europa y trata de definir un perfil formativo del estudiantado orientado a la inserción en el mundo profesional. Bajo este proyecto, se entiende como persona competente aquella que posee ciertos atributos que resultan necesarios para desempeñar su trabajo adecuadamente e incluye conocimientos, habilidades, actitudes y valores. Siguiendo a Pavié (2011), la propuesta Tuning consiste en un modelo holístico que pretende integrar y superar conceptualizaciones anteriores del término. Por conceptualizaciones anteriores, se está refiriendo el autor a las dos corrientes principales, ambas marcadamente mercantilistas, bajo las cuales se pretende definir el término competencia. Por un lado, la definición estadounidense, de tipo conductual, que considera competencia aquellos atributos o saberes aplicados que busca el empresario en sus futuros empleados. Por otro lado, la postura británica, de carácter funcionalista, que entiende competencia como el conjunto de habilidades y conocimientos aplicados al desempeño de un trabajo en función de las necesidades laborales precisas en un determinado contexto socio-económico. El enfoque holístico, pretende dar una visión no tan explícitamente orientada a la mejora de la productividad o a las necesidades del mercado laboral, sino que, a su vez, entiende que el sujeto también es competente cuando se apropia progresivamente de estructuras del conocimiento que le permiten cuestionar el contexto y que le capacitan para poderlo transformar.

En lo que se refiere a España, la convergencia hacia las directrices europeas corrió a cargo de diversos grupos de estudio y entidades como la Conferencia de Rectores de las Universidades Españolas (CRUE en adelante) y la Agencia Nacional de Evaluación de la Calidad y Acreditación (ANECA en adelante) o de organismos oficiales como el Ministerio de Educación y Ciencia (MEC en adelante). Cabe mencionar que para llevar adelante la conversión de titulaciones universitarias al sistema de adquisición de competencias se tomó como documento marco el modelo propuesto en el Proyecto Tuning añadiendo muy pocos matices.

El MEC (2006) entiende el término competencia de la siguiente manera: "Las competencias son una combinación de conocimientos, habilidades (intelectua- 
les, manuales, sociales, etc.), actitudes y valores que capacitarán a un titulado para afrontar con garantías la resolución de problemas o la intervención en un asunto en un contexto académico, profesional o social determinado" (p. 6).

Tanto el MEC (2006) como la ANECA (2006) mantienen la división primigenia entre competencias genéricas/transversales y específicas. $Y$ mantiene de forma idéntica la subdivisión de las competencias transversales, modificando únicamente la clasificación de las competencias específicas que pasan a denominarse académicas, disciplinares y profesionales.

La ANECA (2006) por su parte tiene un papel decisivo en la convergencia española al marco europeo. No solo valida y adapta todo aquello concerniente al nuevo planteamiento académico basado en la adquisición de competencias sino que participa activamente en la definición del perfil profesional de los futuros titulados españoles a través del diseño de los títulos oficiales de grado, publicando una serie de libros blancos de referencia donde estructura los contenidos generales en relación con las mencionadas competencias y asigna una serie de créditos ECTS mediante una valoración de horas de trabajo académico.

No pocos autores (Salinas, 2007; Martínez-Bonafé, 2005; Bolívar, 2011; Mulder, Weigel y Collings, 2011; Gimeno-Sacristán, 2008) discuten el significado del término competencia, su clasificación y su implementación. Salinas (2007), por ejemplo, se cuestiona si ciertamente en la educación superior se está asumiendo un enfoque constructivista e integrador del término competencia o a efectos prácticos no se ha superado la visión utilitaria y ligada a la productividad, de tradición estadounidense y británica. Martínez-Bonafé (2005) alude a la alegre asunción por parte de la ANECA de las competencias propuestas por Europa sin ningún tipo de reflexión crítica al respecto.

La crítica principal de los analistas mencionados y a la que se adscribe la presente tesis cuestiona cómo desde el aprendizaje por competencias, se está primando en el alumnado un pensamiento práctico, utilitarista, subordinado a las tendencias económicas y mercantiles predominantes a la vez que se elimina o reduce a su mínima expresión el espacio formativo dedicado a la capacidad reflexiva crítica, 
estrechamente relacionada con la adquisición de valores y responsabilidades sociales. A este respecto, especialmente destacable es el discurso y la obra de Philippe Perrenoud dirigido al ámbito educativo y en la que discrepa y propone competencias más allá de la visión de Bolonia (Perrenoud, 2004), vinculando estrechamente la función docente a la práctica reflexiva (Perrenoud, 2007) y a las características del contexto social (Perrenoud, 2012). 


\section{El Grado de Maestro o Maestra en Educación Primaria}

En el año 2003, la ANECA lanza una convocatoria a todas las universidades españolas solicitando la colaboración del profesorado en el diseño de los planes de estudio de las titulaciones de Maestro. Un total de 44 universidades participan en este proyecto denominado Adecuación de las titulaciones de Maestro al Espacio Europeo de Educación Superior (Maldonado, 2004), a partir del cual se crea una red de docentes universitarios que trabajan para realizar la adaptación de los planes de estudio a la convergencia europea tanto para los niveles de Educación Infantil como de Educación Primaria. Según expone Pinto (2005), dos fueron los ejes principales que vertebraron el proyecto. Por un lado, se establecen acuerdos respecto a la configuración estructural de la propia titulación (cursos, número de créditos ETCS, tipología de la titulación, especialidades, etc.) y por otro lado se delimitan las competencias profesionales que configuran el perfil de los maestros y se tratan cuestiones relativas al contenido formativo.

Los resultados del estudio de la red de docentes universitarios se plasmaron en el Libro Blanco de Magisterio (ANECA, 2005). En cuanto a la estructura de la titulación de maestro, el plan formativo recogido en el Libro Blanco establece la configuración de dos titulaciones (Grado de Maestro en Educación Infantil y Grado de Maestro en Educación Primaria), ambas de cuatro cursos de duración entre los cuales se distribuyen 240 créditos europeos. Se reparte el contenido de la titulación en aproximadamente un 30\% de formación psicopedagógica, un 50\% relativo a áreas de conocimiento y un $20 \%$ de formación práctica, siendo precisamente el aumento de créditos dedicados a la formación práctica una de las propuestas más destacables de este nuevo plan.

En cuanto a la determinación de competencias, en el Libro Blanco se recogen una serie de competencias específicas: las denominanadas genéricas, que son comunes en todos los perfiles de maestro, y las específicas de cada perfil o titulación.

Tras examinar el estudio de la ANECA, en España el MEC aprobará finalmente la Orden ECl/3857/2007 y la Orden ECl/3854/2007, ambas del 27 de diciembre por las que se establecen los requisitos para la verificación de los títulos universitarios ofi- 
ciales que habilitan para el ejercicio de la profesión de Maestro en Educación Primaria y Maestro en Educación Infantil, respectivamente.

La Orden ECl/3857/2007 define en el apartado 3 los objetivos y competencias profesionales que el estudiantado de Grado de Maestro en Educación Primaria (GMP en adelante) deberá adquirir y que se compendian a continuación.

1. Conocer las áreas curriculares de la Educación Primaria, la relación interdisciplinar entre ellas, los criterios de evaluación y el cuerpo de conocimientos didácticos en torno a los procedimientos de enseñanza y aprendizaje respectivos.

2. Diseñar, planificar y evaluar procesos de enseñanza y aprendizaje, tanto individualmente como en colaboración con otros docentes y profesionales del centro.

3. Abordar con eficacia situaciones de aprendizaje de lenguas en contextos multiculturales y plurilingües. Fomentar la lectura y el comentario crítico de textos de los diversos dominios científicos y culturales contenidos en el currículo escolar.

4. Diseñar y regular espacios de aprendizaje en contextos de diversidad y que atiendan a la igualdad de género, a la equidad y al respeto a los derechos humanos que conformen los valores de la formación ciudadana.

5. Fomentar la convivencia en el aula y fuera de ella, resolver problemas de disciplina y contribuir a la resolución pacífica de conflictos. Estimular y valorar el esfuerzo, la constancia y la disciplina personal en los estudiantes.

6. Conocer la organización de los colegios de educación primaria y la diversidad de acciones que comprende su funcionamiento. Desempeñar las funciones de tutoría y de orientación con los estudiantes y sus familias, atendiendo las singulares necesidades educativas de los estudiantes. Asumir que el ejercicio de la función docente ha de ir perfeccionándose y adaptándose a los cambios científicos, pedagógicos y sociales a lo largo de la vida.

7. Colaborar con los distintos sectores de la comunidad educativa y del entorno social. Asumir la dimensión educadora de la función docente y fomentar la educación democrática para una ciudadanía activa.

8. Mantener una relación crítica y autónoma respecto de los saberes, los valores y las instituciones sociales públicas y privadas.

9. Valorar la responsabilidad individual y colectiva en la consecución de un futuro sostenible.

10. Reflexionar sobre las prácticas de aula para innovar y mejorar la labor docente. Adquirir hábitos y destrezas para el aprendizaje autónomo y cooperativo y promoverlo entre los estudiantes. 
11. Conocer y aplicar en las aulas las tecnologías de la información y de la comunicación. Discernir selectivamente la información audiovisual que contribuya a los aprendizajes, a la formación cívica y a la riqueza cultural.

12. Comprender la función, las posibilidades y los límites de la educación en la sociedad actual y las competencias fundamentales que afectan a los colegios de educación primaria y a sus profesionales. Conocer modelos de mejora de la calidad con aplicación a los centros educativos.

La competencia genérica número diez hace mención explícita a la necesidad de reflexionar sobre el propio desempeño docente no solo para mejorar en la labor docente sino también para poder innovar en la práctica. Posteriormente, en esa misma Orden referido al módulo de Practicum y Trabajo Final de Grado (TFG en adelante), se establece como competencia "participar en la actividad docente y aprender a saber hacer, actuando y reflexionando desde la práctica” (p. 4).

Así, se menciona doblemente y de forma explícita la capacidad de reflexión como competencia necesaria para el futuro docente y se asocia particularmente al momento académico del Practicum. Se entiende que la formación docente orientada hacia la adquisición de competencias profesionales debe tener como punto de partida la propia experiencia y la reflexión sobre esta.

\subsection{La asignatura de Practicum en el Grado de Maestro en Educación Primaria}

El Practicum se considera un momento clave en la formación del profesorado. La necesidad de tomar contacto con la realidad del aula e integrar el conocimiento teórico con el práctico ha estado presente en los todos los programas académicos que forman futuros maestros desde sus orígenes (Lorenzo, 2010). Por ejemplo, en el Real Decreto 1440/1991 de 30 de agosto se describe el Practicum como:

Conjunto integrado de prácticas de iniciación docente a realizar en los correspondientes niveles del sistema educativo. Las prácticas deberán proporcionar el conocimiento del sistema escolar a través de conocimiento del centro concreto como unidad organizativa en sus distintas dimensiones y funciones, así como de la Comunidad Educativa. (p. 33.008) 
En los planes de estudio se recoge la obligatoriedad y necesidad del alumnado de magisterio de realizar prácticas relacionadas con su futura profesión a lo largo de su período formativo.

El Practicum, según Zabalza (2009), contribuye a desarrollar el currículum en la medida en que enriquece la formación del estudiantado mediante el ejercicio directo de la profesión, le permite profundizar y establecer nexos con sus conocimientos previos de carácter teórico y supone un ajuste de expectativas respecto al mundo laboral. Además, el Practicum completa la formación en competencias del alumnado y en particular fomenta la competencia reflexiva (Gómez, 2011).

En España, tras la incorporación del sistema educativo universitario al EEES, la cantidad de horas dedicadas al periodo de prácticas se ha visto incrementada de tal modo que las materias de Practicum y TFG llevan asignados al menos 50 créditos ECTS, es decir, aproximadamente un $20 \%$ de la carga lectiva total de la carrera. Las tendencias europeas en materia de Practicum, apuestan por un todavía mayor incremento de horas de formación práctica, llegando incluso a superar, como en el caso de algunas facultades de Gran Bretaña, al número de horas de formación teórica (Hilton, 2010; Murray y Wishar, 2011).

La Orden ECl/3857/2007, de 27 de diciembre, dedica su párrafo quinto a establecer las bases regulatorias del Practicum en España:

El Practicum se desarrollará en centros de educación primaria reconocidos como centros de formación prácticas mediante convenios entre las Administraciones Educativas y las Universidades. Tendrá carácter presencial y estará tutelado por profesores universitarios y maestros de educación primaria acreditados como tutores de prácticas. Los Practicums se realizarán en los tres ciclos de las enseñanzas de educación primaria (p. 53748).

Desde el MEC, también se regularán las competencias a adquirir durante el periodo de Practicum, su presencialidad y las características de la tutela del alumnado en lo concerniente tanto a los maestros de las escuelas como al profesorado universitario. 
Más allá de las formalidades que la legislación establece sobre el Practicum, González (2001) analiza los enfoques que las universidades han adoptado como forma de entender la asignatura del Practicum y describe cuatro escenarios o espacios clave:

a. El Practicum como un espacio de carácter práctico independiente del conocimiento teórico.

b. El Practicum como un espacio complementario entre teoría y práctica.

c. El Practicum como espacio para relacionar la teoría con la práctica.

d. El Practicum como una relación de carácter dialéctico, de contraste entre teoría y práctica.

Los dos primeros espacios establecen una división entre conocimientos teóricos y experiencia práctica. El primer caso considera que teoría y práctica son dos aspectos distintos e independientes en la formación docente y en el segundo, si bien ambos elementos se complementan, siguen perteneciendo a dos ámbitos diferenciados. Ambas concepciones son proclives a fomentar en el alumnado un "efecto lavado" (Darling-Hammond, 1999; Buchberger, 2000; Korthagen y Lagerwerf, 2001; Hobson Ashby, Malderez y Tomlinson, 2009; Egido y López, 2013), es decir el alumno adquiere la convicción de que la formación teórica estudiada en cursos anteriores no resulta útil para enfrentarse a la práctica y que la profesión se aprende verdaderamente en el aula junto al maestro supervisor, principalmente por imitación y por ensayo-error. Este efecto, no repercute únicamente en el rechazo del contenido más puramente teórico sino que también condiciona a la introducción de innovaciones en la metodología y en la evaluación. El Practicum que considera teoría y práctica como entes separados se convierte en un instrumento continuista y mantenedor del status quo dominante en la profesión docente.

El tercer espacio considera que la teoría y la práctica son campos interrelacionados y que la teoría puede verse reflejada en la práctica y viceversa. El estudiante se limita a identificar la presencia de elementos de una parte en la otra y de observar influencia directa que entre ambas partes se pueda ejercer. Quedaría a merced de otros agentes -los maestros supervisores presumiblemente- permitir al alumnado cuestionar, innovar y tener una retroalimentación profesional que fortaleciera el nexo teórico-práctico. 
Finalmente el cuarto escenario, además de relacionar teoría y práctica, induce a la toma de conciencia sobre el porqué de una determinada actuación en el aula y conlleva el cuestionamiento de los diferentes aspectos educativos tanto a nivel teórico como práctico. Esta relación dialéctica cimentaría la formación de un futuro profesional reflexivo y transformador. Esta situación sería tanto para Pérez (2001) como para Pérez, Benarroch, Jiménez, Smith y Rojas (2006), la principal finalidad del Practicum.

\subsection{Hacia un Practicum reflexivo}

Como se entrevé en el apartado anterior, dos paradigmas predominan a la hora de desarrollar el Practicum del GMP. El primero es el enfoque tradicional, de corte positivista y técnico, que presupone que el estudiante en prácticas aprende el modo de resolver situaciones profesionales aplicando una serie de competencias adquiridas previamente durante la formación teórica. Formación y experiencia que en este caso, están orientadas hacia la consecución de profesionales técnicos con conocimientos concretos, útiles para ser aplicados ante un problema laboral y obtener resultados óptimos y mesurables (Domingo, 2013).

El segundo de los paradigmas sería el crítico-reflexivo, que centra su interés no tanto en la medición de resultados sino en el propio proceso formativo. Desde este paradigma se asume que, dada la complejidad de la realidad educativa resulta difícil tener respuestas estandarizadas que sirvan en cualquier contexto. El saber profesional se adquiere analizando y reflexionando sobre cada demanda concreta e incluye a su vez la necesidad de debatir sobre aspectos éticos y cuestionar los supuestos pedagógicos asentados en educación.

El profesional que resulta del enfoque crítico, a diferencia del técnico, es alguien que cuestiona sus propias creencias sobre la enseñanza con el fin de mejorar la práctica educativa. La docencia, según Pavié (2011), implica un buen conocimiento de contenidos y de la didáctica de dichos contenidos, pero también implica un buen conocimiento del sí mismo. Es la reflexión sobre el ejercicio de su práctica y no la acumulación de un amplio repertorio de ejemplos, conocimientos y acciones lo que determina al alumno como futuro profesional (Montero, 2001). El resultado de este enfoque deviene 
en un profesional cuya formación resulta más integral, humana y rica (Domingo, 2013).

La ANECA realizó en 2005 un estudio entre el profesorado de los Departamentos de Educación de 18 universidades españolas. En dicho estudio se puso de manifiesto que las competencias relacionadas con el pensamiento crítico eran situadas por los docentes en los últimos puestos de la escala de valoración, a gran distancia de otro tipo de competencias de carácter técnico, relacionadas con el "saber" y que confirmaban el predominio en la educación superior de la visión técnica y conservadora del maestro en detrimento de otro tipo de planteamientos más críticos.

Doce años después de la investigación de la ANECA, la tendencia en educación superior y particularmente en el GMP parece ir superando el modelo de maestro como científico o técnico en favor del modelo de maestro como profesional reflexivo (Korthagen, 2010; Martinet, Raymond y Gauthier, 2004; Ur, 2006). Prueba de ello es la inclusión de la capacidad de reflexión y de análisis crítico como una competencia clave en un cada vez mayor número de programas académicos de formación del profesorado (Collin, Karsenti y Komis, 2013).

El modelo de maestro como profesional reflexivo (Wallace, 2002; Tigchelaar y Korthagen, 2004; Lunnenberg, Korthagen y Swennem, 2007; Alsina y Esteve, 2009) asume que analizar la experiencia es la fuente principal de conocimiento, que cada contexto de práctica es singular y supone per se una fuente de experiencia valiosa para el crecimiento profesional. El análisis de la experiencia debe abordar comparativamente al menos tres aspectos: el conocimiento extraído durante la práctica, los esquemas y concepciones previas relacionados con el ejercicio de la profesión docente y el saber formal, de carácter teórico, trasmitido académicamente.

Pérez (2001) en su tesis doctoral propuso el llamado Modelo Reflexivo de Supervisión, al que pronto se sumaron otros autores (Pérez, Benarroch, Jiménez, Smith y Rojas, 2006; Marhuenda, 2001; González, 2001; Parmigiani, 2001). Este modelo pretende aprovechar la relación que se establece durante el Practicum entre el tutor, el supervisor y el alumno. Estas tres figuras se deben involucrar activamente en el análisis de la teoría y de la práctica. Tutor y supervisor realizan un seguimiento estructurado, secuenciado y sistematizado del alumno, comprometiéndose a dedicar tiempo a la re- 
flexión conjunta y al abordaje de asuntos relacionados tanto con la teoría como con la práctica. El alumno, a su vez, debe ser un buen observador de todo aquello que sucede tanto en el aula como en la vida del centro y realizar una serie de actividades de carácter reflexivo como, por ejemplo, un diario de aprendizaje, donde exponga el fruto de dicha observación.

Pérez et al. (2006) analizan las dificultades que se han ido encontrando los autores propulsores del Modelo Reflexivo de Supervisión a la hora de implementarlo en el Practicum de sus respectivas facultades. Las dificultades más comunes halladas tienen que ver con la falta de preparación y de tiempo tanto del tutor como del supervisor y del alumno para llevar a cabo este seguimiento tan exhaustivo. Otras dificultades tienen que ver con la falta de conexión entre la universidad y la escuela por lo que las reflexiones desde una y otra no siempre guardan coherencia. Esto llevaría a una tercera dificultad, la discrepancia de roles del profesorado como práctico reflexivo o como técnico, ya comentada anteriormente. Finalmente, también encontraron que desde las instancias superiores de la Universidad, en general, se tiene poca consideración hacia la asignatura de Practicum lo cual impide introducir cambios que puedan repercutir en dedicar un mayor tiempo a la reflexión. Mérida, et al. (2003) extienden esta crítica hacia los propios Departamentos de Educación y reclaman una revisión de los criterios para asignar créditos de Practicum al profesorado. El Practicum debe considerarse como el eje vertebrador del currículum y no una simple materia con la que se completan créditos de carga docente.

Son múltiples los condicionantes que apremian en la educación superior hacia la realización de un Practicum cuyo eje principal sea la reflexión crítica. Las directrices europeas, las competencias clave introducidas en el currículum del GMP, el auge del paradigma del docente como profesional reflexivo y la propuesta de modelos reflexivos como el Modelo Reflexivo de Supervisión son solo algunos de estos factores. Así, no es extraño encontrar un campo amplio de investigación en este sentido, en el que los profesionales intentan incluir metodologías y herramientas cuyo objetivo es fomentar la reflexión. Algunas de las ideas más destacadas se exponen a continuación:

a. Narrar la experiencia en diarios reflexivos. Es quizá la actividad más consensuada como instrumento favorecedor de la reflexión (Latorre y Blanco, 2011; Jové et al., 2007). 
b. Elaborar informes periódicos sobre las prácticas que permitan al tutor y/0 al supervisor dar retroalimentación sobre la experiencia (Latorre y Blanco, 2011).

c. Realizar previamente a la estancia en prácticas entrenamiento en técnicas de observación con el objeto de mejorar en el alumno la obtención de información significativa (Latorre y Blanco, 2011).

d. Introducir el modelo del docente reflexivo desde el primer curso del GMP y en todas las materias formativas. Esto exigiría al profesorado universitario una revisión de su metodología, así como la elaboración de actividades promotoras del pensamiento crítico en el aula (Tigchelaar y Korthagen, 2004; Lunnenberg, Korthagen y Swennem, 2007).

e. Realizar seminarios periódicos de reflexión teorico-práctica donde se creen grupos de discusión (Bretonés, 2013; Liston y Zeichner, 1993; Zeichner y Liston, 1999; Jové et al., 2007).

f. Revisar las clases teóricas con el maestro supervisor y revisar las prácticas junto al tutor universitario para interrelacionar ambos tipos de aprendizaje y conocimientos (Johnston, 2000; Zeichner, 2010).

g. Utilizar el aprendizaje servicio como metodología facilitadora de la reflexión que contribuye a enlazar teoría y práctica (Koerner y Abdul-Tawwab, 2006).

h. Realizar análisis de vídeo-grabaciones propias y ajenas, acompañadas de una discusión posterior sobre lo observado (Jové et al., 2007).

i. Usar el relato etnográfico en los estudiantes y el análisis de incidentes críticos en el aula (Gutiérrez, Gorospe, De Aberasturi y Etxeberria, 2009).

j. Emplear recursos tecnológicos que faciliten el debate: foros de discusión, e-diarios, e-portfolios, escritura de blogs reflexivos, etc. (Gutiérrez et al., 2009).

Una vez examinadas las competencias que propone la ANECA para el GMP en general y para el Practicum en particular, se evidencia la necesidad de promover la competencia reflexiva como elemento clave de la formación del docente. Para ello, es posible tomar como ejemplo, algunas de las propuestas llevadas a cabo por los autores mencionados en este capítulo.

En el siguiente punto se analizarán los antecedentes epistemológicos que han resultado determinantes en la configuración del movimiento de la práctica reflexiva. 


\section{Aproximación filosófica y epistemológica de la práctica reflexiva}

Las primeras referencias directas según recogen Denton (2011) y Gutek (2005) se encuentran ya en el pensamiento griego de Sócrates, Platón y Aristóteles. Sócrates consideraba responsabilidad del maestro animar al discípulo a pensar por sí mismo para descubrir la verdad. Platón reconoce la importancia del dialogo para fomentar la reflexión y el pensamiento crítico y Aristóteles afirma que se debe reflexionar con la mente y con los sentidos.

En la Edad Media los religiosos San Agustín y Tomás de Aquino postulan que el verdadero aprendizaje es el que se refleja a través del pensamiento, consideran las propias experiencias y acciones el núcleo de la reflexión (Dupuis, 1985).

En la etapa de la llustración, el interés por el estudio de la mente humana hace que se consideren los procesos metacognitivos como agentes necesarios para la reflexión. Según Denton (2011) en esta etapa educadores como Rousseau, Basedow o Pestalozzi entienden la reflexión como un proceso de autoevaluación sobre experiencias y conocimientos pasados que preparan al individuo para la acción.

El siglo XX supone para la corriente del pensamiento reflexivo su momento de máxima eclosión y el comienzo de numerosas investigaciones desde diversos campos de las ciencias humanas y sociales. En la década de los noventa surge en Estados Unidos un movimiento desde el ámbito académico, promovido por investigadores de la enseñanza como Dondald Schön, que se esfuerzan por situar la reflexión como punto central de las reformas educativas. Este movimiento se nutre especialmente de las aportaciones de principio de siglo realizadas por John Dewey y pronto se extiende hacia otros continentes como Europa (especialmente en Reino Unido, Países Bajos, Noruega y España), Oceanía o Asia, entre investigadores y académicos que ven en la práctica reflexiva un planteamiento novedoso y atractivo.

Siguiendo a Domingo (2013), desde esta corriente pedagógica se rechaza la tradicional organización escolar jerárquica y la visión del maestro como técnico y se reivindica la figura del docente como profesional que reflexiona a sobre su propia experien- 
cia. El profesional reflexivo es un agente generador de teorías e hipótesis bajo las cuales se construye el conocimiento sobre la profesión docente. Desde este movimiento se reconoce explícitamente que el aprendizaje de la profesión no termina con la formación inicial sino que se prolonga durante toda la carrera docente.

Zeichner (1993), un firme defensor del maestro como profesional reflexivo, aboga por la necesidad de comprometer a la universidad con la formación de los estudiantes a este respecto. Dada la imposibilidad de ofrecer un acompañamiento perpetuo, los docentes universitarios deben preparar a las próximas generaciones para que aprendan a examinar críticamente su desempeño y para que adquieran un compromiso con su propio desarrollo profesional al finalizar la formación inicial.

Durante la etapa del modernismo, surgen diversas escuelas y corrientes filosóficas que constituirán el marco epistemológico en el que se fundamenta la corriente de la práctica reflexiva y que se pueden revisar en artículos como el de Bleakley (1999) o Ixer (2000). En esta tesis se va a desarrollar la propuesta de Procee (2006), posteriormente respaldada por Kori, Pedaste, Leijen, y Mäeots (2014), que no solo subsume las clasificaciones de los autores anteriores sino que las expone de forma más accesible al lector.

Procee divide en tres las tradiciones filosóficas principales bajo las cuales se ha abordado la reflexión: la escuela pragmática de Dewey, la teoría socio-crítica de la Escuela de Frankfurt de Habermas y el enfoque sistemático basado en la escuela kantiana.

La escuela pragmática, representada por autores como Dewey, Schön o Mead, defiende que la reflexión sobre la práctica es fundamental para el aprendizaje. Cada individuo debe ser consciente de sus propias acciones ya que solo mediante la toma de conciencia es posible superar el aprendizaje basado en el ensayo-error. Identifica la reflexión como el elemento que articula la teoría y la práctica.

Desde la teoría socio crítica, se indaga en cómo individuos y grupos adoptan una postura crítica en relación a una situación real. Desde esta postura se insta a pensar sobre los valores y perspectivas que subyacen a los comportamientos y las decisiones de personas o grupos y se anima al individuo a plantear nuevas hipótesis explicativas. El objetivo es liberar a la gente de su forma habitual de pensar y actuar. 
Inspirado por Habermas, en 1991, Mezirow da forma a la perspectiva transformacional. Bajo esta perspectiva se alude al proceso de llegar a ser críticamente consciente sobre cómo y por qué nuestras asunciones sobre el mundo limitan la forma en la que lo percibimos y condicionan nuestra relación con los demás. El aprendizaje sucede cuando descomponemos aquello aprendido y volvemos a construir nuevos conocimientos, habilidades y actitudes (Bolhuis y Simons, 1999).

El tercer enfoque se basa en la distinción realizada por Immanuel Kant entre comprensión y juicio. Mientras que la comprensión se relaciona con la capacidad de entender reglas lógicas, teorías y conceptos, el juicio está relacionado con la reflexión al ser el elemento capaz de conectar las experiencias con las reglas (Procee, 2006, p. 247).

Procee, basándose en la distinción de Kant, desarrolla lo que denomina "enfoque sistemático". Para este autor comprensión y juicio son ambos elementos clave en el campo educativo. El estudiantado tiene que aprender conceptos y teorías propios de su especialidad (comprender) pero también debe aprender a establecer la conexión entre dichos conocimientos y la realidad con la que opera (juicio) (p. 247-248).

Siguiendo a Procee, la conexión entre conocimiento y realidad puede ocurrir de dos maneras, o bien impulsada por conceptos pre-determinados (juicio determinante) o bien impulsadas por las experiencias (juicio reflexivo). El juicio determinante implica que la persona establece y aplica un conjunto de reglas o conceptos a la práctica particular. El juicio reflexivo se lleva a cabo cuando los conceptos o principios son limitados y deben ser desarrollados sobre la base de una práctica concreta.

Para Kori et al. (2014), aunque las tres interpretaciones de la reflexión están ampliamente reconocidas, es la perspectiva del pragmatismo la que más calado ha tenido en el mundo académico y en la que se suele fundamentar la investigación sobre la práctica reflexiva en educación.

Seguidamente se va a desarrollar la visión pragmática de la práctica reflexiva a través del estudio de sus dos principales impulsores, los autores John Dewey y Donald Schön. 


\subsection{John Dewey: de la acción rutinaria a la acción reflexiva.}

A comienzos del siglo XX, John Dewey dota de estructura formal y sistematizada al pensamiento reflexivo. En 1933, publica "How we think", una de sus obras más emblemáticas dirigida al mundo educativo, en la cual establece una distinción entre la acción rutinaria y la acción reflexiva. La acción rutinaria es descrita como la actuación dirigida por el impulso, conformada por hábitos de pensamiento y asunciones carentes de evidencia. Denota conformidad con lo tradicional, aceptación acrítica de lo establecido y falta de cuestionamiento hacia la autoridad (p. 7).

La acción reflexiva, por el contrario, sucede cuando el docente se encuentra con situaciones originales ante las cuales no puede aplicar soluciones estandarizadas o rutinarias. La acción reflexiva definida por Dewey supone la consideración activa, persistente y cuidadosa de toda creencia o práctica a la luz de los fundamentos que la sostienen y de las consecuencias a las que conduce (p. 9).

Para Dewey la acción reflexiva es una forma de pensamiento científico, lógico, racional, sistemático, riguroso y disciplinado (p. 12). El pensamiento reflexivo por lo tanto difiere del pensamiento rutinario en que supone reconocer un problema y aceptar la incertidumbre o el dilema que conlleva. Esta disonancia permite al maestro convertirse en un investigador activo, generador de hipótesis y crítico con sus propias conclusiones.

Dewey sintetiza cuatro características que determinan el acto reflexivo y cuatro cualidades por las que se define al profesional reflexivo.

El acto reflexivo, en primer lugar, es un proceso deliberado de pensamiento aplicado a la experiencia o a las ideas. En segundo lugar, reflexionar es una actividad que conlleva tiempo. En tercer lugar, la reflexión conduce al crecimiento cognitivo del cual resultan nuevas apreciaciones y una mejor comprensión de los hechos. Y finalmente, la reflexión es también un acto ético que debe condicionar las acciones futuras. 
Por otro lado, cuatro son las cualidades por las que se caracteriza al profesional reflexivo: sinceridad, franqueza, apertura mental o intelectual y responsabilidad (p. 30-33). La sinceridad está relacionada con la muestra de entusiasmo y curiosidad hacia la profesión docente. El profesional reflexivo se sincera con su propia actuación, afronta sus incertidumbres y es capaz de realizar cambios significativos en su desempeño.

La franqueza u honestidad con uno mismo, se refiere a la capacidad de introspección, y toma de conciencia sobre las propias acciones, pensamientos y emociones. Implica responsabilidad sobre los propios actos. El docente honesto examina los condicionantes que le afectan personalmente pero también considera los que afectan al contexto en el que desarrolla su trabajo. Se preocupa no tanto por la enseñanza (¿Qué he enseñado hoy?) como por el aprendizaje (¿Dónde ha habido aprendizaje hoy?).

El concepto de apertura mental, se traduce en una llamada interior a conocer todas las interpretaciones posibles de un problema y preguntarse por qué se hace lo que se hace en el aula. El docente reflexivo no teme ser cuestionado en sus creencias y métodos más sólidos sino que reconoce la posibilidad de cometer errores, se aviene a atender otros puntos de vista y a no verlos necesariamente como enfrentados.

Finalmente, la idea de responsabilidad remite al compromiso activo con la búsqueda de la verdad, con la asunción de que la propia visión del mundo influye en los significados otorgados a las experiencias y que, si se revisan dichos significados, es posible que la visión del mundo cambie. El docente responsable reflexiona sobre las consecuencias personales, académicas, sociales y políticas de sus actos.

Dewey entiende la práctica reflexiva desde una perspectiva técnica. Existe un continuo en el cual el estudiante posee un bagaje teórico-experiencial que le da ciertas claves para entender la práctica (ver Figura 1). Ante un hecho inesperado, recurrir a dicho bagaje no resulta eficaz. El alumno, en este caso, debe tomar una decisión y actuar de forma original. El resultado de la actuación será el objeto de reflexión previa y el resultado de todo el proceso se someterá a reflexión y será incorporado a su bagaje teórico-experiencial. 


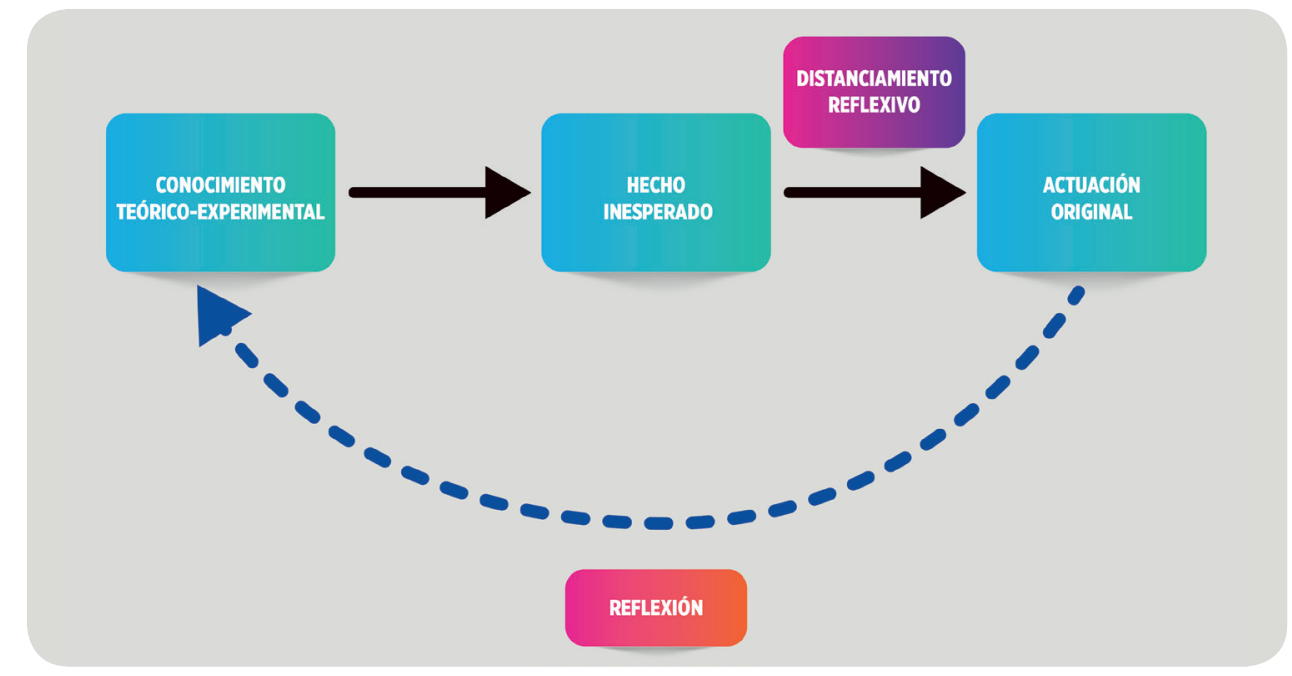

Figura 1. Modelo reflexivo de Dewey. Elaboración propia

Dewey (1916), busca a través de su modelo un equilibrio entre la rutina y la reflexión, entre pensamiento y acción, entre la sumisión absoluta y el rechazo ciego hacia lo establecido. La labor del docente es fomentar la actitud crítica en su alumnado y dicha actitud se obtiene mediante relación entre teoría y práctica a través de la reflexión. El conocimiento teórico se utiliza como herramienta para apoyar y dar soluciones a la práctica. La reflexión llega cuando surgen problemas dentro de la experiencia profesional que no han sido definidos previamente y por lo tanto se han de resolver sin una guía preconcebida. La reflexión sirve para encontrar una solución razonada a dichos problemas y requiere cierto distanciamiento entre la persona y la cuestión a reflexionar.

Entre las críticas más habituales realizadas hacia el modelo reflexivo de Dewey se halla su firme adhesión a la racionalidad técnica. A este respecto Hébert (2015) destaca la rigidez del modelo en el cual solo se inicia el proceso de reflexión cuando existe un problema a resolver. También discrepa sobre la evidente separación entre conocimiento y experiencia cuando, ante un conflicto, el docente debe primar el conocimiento teórico y racional sobre el práctico. El distanciamiento reflexivo frente a un problema no siempre es posible ya que las situaciones de aula exigen en la mayoría de ocasiones inmediatez en la respuesta. 


\subsection{Donald Schön: el pensamiento práctico.}

En sus primeros trabajos sobre reflexión, Donald Schön asume las ideas de Dewey referidas a la reflexión como proceso necesario, tanto para dar respuesta a problemas nuevos o inesperados como para unir teoría con práctica. Sin embargo, pronto advierte que la reflexión no sigue necesariamente el esquema lineal y técnico que Dewey planteaba. Schön (1987) observa que el aprendizaje sucede reflexionando tanto desde el conocimiento teórico ("saber de libro") como desde la observación y la actuación práctica, implicando esto último un conocimiento más tácito y espontáneo (p. 38).

En el modelo de reflexión propuesto por Schön (ver Figura 2) adquiere especial importancia lo que denomina "pensamiento práctico" considerado esencial para poder enlazar la práctica con la teoría. Desde el pensamiento práctico se sugiere que el saber está en la acción (Argyris y Schön, 1978; Schön, 1987). Tres ideas clave explican y describen el pensamiento práctico: el conocimiento en la acción ("knowing-inaction"), la reflexión en o durante la acción ("reflection-in-action") y la reflexión sobre la acción ("reflection-on-action").

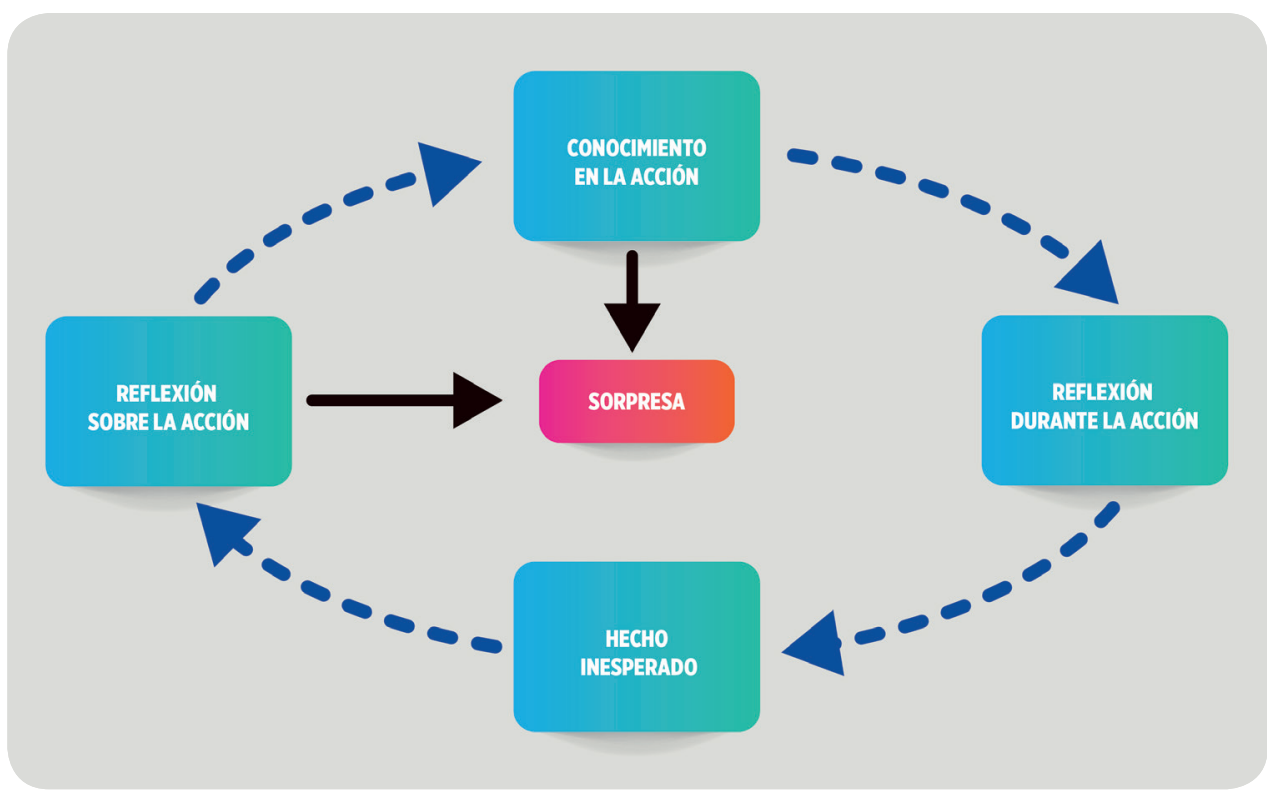

Figura 2. Modelo reflexivo de Schön. Recuperado de “El esquema de reflexión de la práctica” por Roma, J. (2007). La reflexión como eje central del desarrollo profesional. Educación médica, 10(1), 30-36 
El conocimiento en la acción (Schön, 1983, 1995) se refiere al saber personal acumulado a lo largo de la vida, extraído de las propias acciones y juicios, de carácter tácito y que actúa de forma espontánea e inherente a la actividad práctica. Incluye, por un lado, el conocimiento teórico propio de la formación académica y por otro el saber en la acción derivado de la práctica profesional. Este conocimiento no solo ayuda a entender ciertos fenómenos y problemas, sino que además aporta modelos prefijados para resolverlos con cierta garantía de éxito (Van Manen, 1991).

El segundo componente del modelo es la reflexión en la acción (Schön, 1983, p. 62). Este término hace referencia al propio pensamiento del individuo respecto a su desempeño mientras sucede la acción. Este tipo de reflexión se produce ante hechos inesperados, que causan sorpresa y que no permiten aplicar las respuestas prefijadas basadas en el conocimiento en la acción. En ese momento se establece un diálogo reflexivo interno y consciente del individuo sobre la situación problema y sobre su propia respuesta ante dicha situación. Esta reflexión se caracteriza por su inmediatez y por la captación rápida de matices y variables contextuales. Las estrategias y respuestas que se apliquen en ese momento constituirán una especie de experimento sobre la marcha de cuyo resultado se extraerán nuevas reflexiones.

Brockbank y McGill (2002) creen que conocimiento en la acción y reflexión en la acción son dos fases complementarias que formarían parte de una misma tarea siendo la primera una fuente de apoyo para la segunda.

Por último, la reflexión sobre la acción se refiere al análisis posterior a la acción. Esta reflexión es un componente esencial del aprendizaje permanente. Reflexionar sobre la acción pasada permite hacer y rehacer esquemas personales sobre la docencia y la educación. La reflexión sobre la acción permite considerar las características contextuales, permite examinar los procesos cognitivos utilizados para definir el problema, permite revisar metodología y fines pedagógicos, las creencias, teorías implícitas y esquemas de pensamiento del docente.

Schön evoluciona desde su concepción del profesional reflexivo basado en el paradigma técnico de Dewey hacia un paradigma transformacional. A través de la reflexión individual se obtiene conocimiento sobre las necesidades de la escuela, y al 
actuar sobre estas, se consigue que la organización educativa se adapte a la nueva realidad. A este efecto Schön lo denomina "cambiar la acción para cambiar el contexto".

Las críticas más habituales dirigidas hacia el modelo de Schön son las que hacen alusión al concepto de conocimiento tácito o intuitivo. Schön (1987) describe este conocimiento como "una forma natural de participar en la práctica" (p. 38). Se trata de una sensación instintiva o intuitiva que tiene los maestros expertos y que guía su práctica en ciertos momentos. Tanto McLaughlin, (1999) como Boyd, Boll, Brawner y Villaume (1998) se preguntan si existen docentes que carecen de esta intuición y si estos se considerarían profesionales no reflexivos. En caso afirmativo, se cuestionan si es posible enseñar a mejorar a dichos docentes una serie de capacidades cuya naturaleza es intuitiva.

La ambigüedad que rodea al término "tácito" hace que varios autores (Smyth, 1988; Fook y Askeland, 2006; Edwards y Thomas; 2010) tilden el modelo de Schön de ateórico e insuficientemente crítico.

Otro punto crítico hacia Schön se refiere al concepto de reflexión en la acción. Russel (2005), Eraut (1995) y Moon (1999b) encuentran que distinguir entre reflexión en la acción y reflexión sobre la acción puede resultar confuso. La reflexión en la acción se ve limitada al presente, esto es, existe un margen temporal donde es posible intervenir en la situación a través de la acción. Dado este margen temporal puede ser que la acción presente dure minutos, pero también horas, iincluso días! Depende en gran medida de las características de la práctica en cuestión. Así, ambos tipos de reflexión se superponen. De hecho, Moon (1999b) entiende que no solo ambos tipos de reflexión forman parte del mismo continuo temporal, sino que además son los mismos procesos cognitivos los que resuelven la situación rápida y casi inconsciente que los que actúan de forma lenta y consciente.

Para concluir, una tercera apostilla que Thompson y Thompson (2008) y Thompson y Pascal (2012) realizan al modelo reflexivo de Schön es la falta de un elemento reflexivo de carácter previsor, una "reflexión para la acción" referida al proceso de planificación de aquello que está por venir y que supondría mejorar los efectos de la metodología, los recursos y el tiempo disponible en educación. 


\section{Consideraciones terminológicas sobre la reflexión y la práctica reflexiva}

\subsection{Aproximación al concepto de reflexión}

En este punto de la tesis se va a profundizar en la definición y características del término reflexión. Si bien hay que advertir que ni siquiera en las revisiones de la literatura más reciente (Rose, 2016; Béres, 2017) se halla una definición de reflexión consolidada y aceptada por toda la comunidad científica, es posible en cambio reconocer ciertos atributos y elementos comunes sobre el término que la mayoría de investigadores aceptan.

En lengua inglesa, el término reflexión puede expresarse como reflection o como reflexion. Ambos conceptos se traducirían al castellano como reflexión, sin embargo, en inglés se establecen diferencias sustanciales entre ambas palabras.

El término reflection está directamente relacionado con la etimología de la palabra reflexión. Tiene esta su origen en el verbo latín reflectere. Su raíz, flectere, expresa volver o girar y su prefijo, re, significa hacia atrás.

Bengtsson (2003) refiere que la reflexión (reflection) actúa como un espejo que devuelve imágenes sobre la experiencia vital pasada y posibilita establecer conexiones con la experiencia presente para poder actuar sobre la actividad futura.

Reflexionar se concibe como el proceso activo de pensar en la propia experiencia para ser crítico con ella y aprender de ésta (Ryan, 2005). El concepto está ligado a hechos concretos, tanto si se reflexiona sobre la acción mientras sucede (reflexión en la acción) como si se hace posteriormente (reflexión sobre la acción).

El término reflexion, en cambio, hace referencia a la introspección. Thompson y Pascal, (2012) lo describen como una mirada profunda hacia cada interacción tanto en la docencia como en la vida cotidiana. Esta introspección sirve para conocer los propios pensamientos, sentimientos y comportamientos. Sirve para considerar el estado mental, el ser emocional y las motivaciones en un contexto determinado. La reflexión, en este caso, lleva a la autoconciencia sobre los patrones, visión del mundo, valores, socialización, ideología y prejuicios adquiridos bajo los cuales se crea la realidad social. 


\section{Tabla 3}

Definiciones de reflexión en orden cronológico

\begin{tabular}{|c|c|}
\hline AUTOR/ES & DEFINICIÓN \\
\hline Boyd y Fales (1983) & $\begin{array}{l}\text { Proceso de examinar y explorar internamente un tema que preocupa, provocado por la propia experiencia, que } \\
\text { crea y clarifica nuevos significados, terminando por producirse un cambio de la propia perspectiva conceptual. }\end{array}$ \\
\hline Boud, Keogh y Walker (1985) & $\begin{array}{l}\text { Importante actividad humana en la cual la gente reconquista su experiencia, piensa sobre ella, la medita } \\
\text { y la evalúa. Trabajar con la experiencia es lo importante en el aprendizaje. }\end{array}$ \\
\hline Kemmis (1985) & $\begin{array}{l}\text { Proceso dialéctico entre los propios pensamientos y la situación externa. El resultado de este proceso de } \\
\text { meta-pensamiento se traduce en la acción. Es un proceso de transformación personal a partir de la historia } \\
\text { y la experiencia acumulada que se sirve de diversas estrategias dirigidas a la acción o la toma de decisiones. }\end{array}$ \\
\hline Louden (1991) & $\begin{array}{l}\text { Proceso mental que sucede fuera del momento de la acción, mirando hacia delante o hacia atrás respec- } \\
\text { to a las acciones que han tenido lugar. }\end{array}$ \\
\hline Barnett (1992) & $\begin{array}{l}\text { Medio estimulante que permite al alumnado la auto-observación y el diálogo crítico respecto a pensa- } \\
\text { mientos y actos propios. }\end{array}$ \\
\hline Reid (1993) - Johns (1995) & $\begin{array}{l}\text { Ambos autores conciben la reflexión como proceso personal mediante el cual se revive una experiencia y } \\
\text { tras la cual se extrae un nuevo aprendizaje para el individuo implicado. }\end{array}$ \\
\hline atton y Smith (1995) & $\begin{array}{l}\text { Acto deliberado entre pensamiento y acción o entre pensamiento sobre la acción con el fin de mejorar la } \\
\text { respuesta ante un problema percibido. }\end{array}$ \\
\hline Zeichner y Liston (1996) & $\begin{array}{l}\text { Examen de las propias creencias, experiencias, actitudes, conocimientos, valores, oportunidades y res- } \\
\text { tricciones proporcionadas por el entorno laboral. Incluye el examen de aspectos socio-políticos y morales } \\
\text { de la enseñanza, factores que condicionarán actuaciones futuras. }\end{array}$ \\
\hline Valli (1997) & $\begin{array}{l}\text { Capacidad de mirar hacia atrás los acontecimientos, realizar juicios sobre estos y alterar el comporta- } \\
\text { miento docente a la luz de la destreza profesional, la investigación y el conocimiento ético. }\end{array}$ \\
\hline Pierson (1998) & $\begin{array}{l}\text { Proceso intersubjetivo útil que requiere el empleo a la vez de pensamiento calculador y contemplativo. } \\
\text { Implica sinceridad y compromiso al examinar los propios pensamientos, sentimientos y experiencias. }\end{array}$ \\
\hline Moon (1999c) & $\begin{array}{l}\text { Forma de procesamiento mental con un propósito y/o un resultado anticipado que se aplica a ideas } \\
\text { relativamente complicadas o desestructuradas para las cuales no hay solución obvia. }\end{array}$ \\
\hline Sanjurjo (2002) & $\begin{array}{l}\text { Toma de conciencia de las propias acciones y de los condicionantes contextuales que las determinan. } \\
\text { Permite indagar y volver la mirada hacia los propios actos y permite a su vez establecer relaciones entre } \\
\text { teoría y práctica o entre pensamiento y acción. }\end{array}$ \\
\hline Jay y Johnson (2002) & $\begin{array}{l}\text { Proceso a la vez individual y colaborativo. Incluye la experiencia y la incertidumbre. Consiste en identificar pre- } \\
\text { guntas y elementos clave de un tema significativo y en convertir los pensamientos en diálogo con uno mismo } \\
\text { o con los demás. A través de la reflexión se alcanza nuevas aclaraciones bajo las cuales se basan los cambios de } \\
\text { acción o disposición. Surgen nuevas preguntas de forma natural y el proceso sucede de forma espiral. }\end{array}$ \\
\hline Tate y Mills (2004) & $\begin{array}{l}\text { Experiencia de aprendizaje que comienza ante la reflexión crítica sobre el propio conocimiento experien- } \\
\text { cial y teórico, para lo cual hay que observar y comprender las diferentes perspectivas del problema. }\end{array}$ \\
\hline $\begin{array}{l}\text { Ng, Lan, y Thye (2004) } \\
\text { ing }\end{array}$ & $\begin{array}{l}\text { Proceso activo y deliberado de pensar dirigido a problemas prácticos, en el cual se consideran las creen- } \\
\text { cias subyacentes y el conocimiento previo para llegar a posibles soluciones (p. 202). }\end{array}$ \\
\hline De Dea Roglio y Light (2009) & $\begin{array}{l}\text { Detenerse, pensar profundamente de las propias experiencias, de forma que es importante apreciar el } \\
\text { pasado para influir en el presente y obtener un futuro mejor. }\end{array}$ \\
\hline Villalobos y Cabrera (2009) & $\begin{array}{l}\text { Implica todo un repertorio de conocimientos, actitudes, comportamientos y destrezas en el manejo } \\
\text { del aula. Incluye distintos diseños de la instrucción, establecimiento de estrategias e instrumentos de } \\
\text { evaluación y la interacción entre los estudiantes, los colegas y los padres y representantes. }\end{array}$ \\
\hline Archer (2010) & $\begin{array}{l}\text { Necesidad de interrelación entre los individuos y las estructuras sociales para comprender, mantener o } \\
\text { cambiar el curso de la acción elegido por las personas. }\end{array}$ \\
\hline $\begin{array}{l}\text { Nilsen, Nordström y Ellström } \\
(2012)\end{array}$ & $\begin{array}{l}\text { Mecanismo para traducir la experiencia en aprendizaje, examinando las propias actitudes, creencias y } \\
\text { acciones para llegar a conclusiones que posibiliten mejores elecciones o respuestas en el futuro. }\end{array}$ \\
\hline Mason y Klein (2013) & $\begin{array}{l}\text { Proceso cíclico de dar sentido y resolver problemas para mejorar la eficacia. Debe considerar factores } \\
\text { contextuales tales como los recursos, el currículum, las necesidades de los estudiantes, de las familias, de } \\
\text { la comunidad, la cultura de aula y sus propias creencias respecto a enseñar y aprender. }\end{array}$ \\
\hline
\end{tabular}

Nota: elaboración propia. 
Fook y Askeland (2006) definen la reflexión como la habilidad para reconocer la propia influencia en las situaciones. El maestro es sujeto activo en cada situación docente por lo tanto debe examinar el tipo de conocimiento que crea, la forma en cómo lo crea y las consecuencias de este conocimiento en el alumnado.

En su tesis doctoral Weber (2013) asevera que no existe una definición precisa de reflexión, estando por lo tanto de acuerdo con un gran número de autores (Collin, et al., 2013; Hickson, 2011; Larrivee, 2008; Lee, 2008; Marcos, Sanchez, y Tillema, 2011; Thorpe, 2004). En la Tabla 3 se puede revisar una amplia recopilación de definiciones y es posible hacerse una idea de cómo cada autor interpreta el acto reflexivo de forma diferente añadiendo o quitando elementos según su aplicación o campo de estudio.

Sin embargo Weber (2013), encuentra en la literatura científica una serie de elementos comunes que comparten la mayoría de definiciones de pensamiento reflexivo:

a. Es un proceso (Bates, Ramirez y Drits, 2009; Lee, 2008; Mahlios, Engstrom, Soroka y Shaw, 2008; Marcos et al. 2011; Nagle, 2008; Ostorga y Estrada, 2009; Pihlaja y Hoist, 2011; Thorsen y DeVore, 2013),

b. Es una habilidad que requiere ser enseñada (Francis, Tyson, y Wilder, 1999; Mulnix, 2012; Nagle, 2008; Russell, 2005; Stanley, 1998),

c. Implica la toma de decisiones (Ewart y Straw, 2005; Giovannelli, 2003; Larrivee, 2000, 2008; Ostorga y Estrada, 2009; Pihlaja y Hoist, 2011; Rosen, 2008; Van Manen, 1977),

d. Puede afectar positivamente al rendimiento de los estudiantes (Ewart y Straw; 2005; Minor, Onwuegbuzie, Witcher y James, 2002; Ostorga y Estrada, 2009).

A las características encontradas por Weber (2013), este trabajo incorpora otras tantas particularidades del concepto de reflexión que han ido surgiendo de manera recurrente durante proceso de búsqueda de documentación. Las características encontradas en literatura revisada se exponen a continuación:

e. Requiere intencionalidad (Hatton y Smith, 1995; Zeichner y Liston, 1996; Sanjurjo, 2002; Ng, Lan, y Thye, 2004).

f. Utiliza procesos metacognitivos (Kemmis, 1985; Barnett, 1992; Pierson, 1998; Moon, 1999c; 
Mason y Klein, 2013).

g. Implica investigación e indagación (Boyd y Fales, 1983; Valli, 1997; Moon, 1999c; Sanjurjo, 2002; Jay y Johnson, 2002).

h. Recurre a la experiencia individual (Boyd y Fales, 1983; Boud, Keogh y Walker, 1995; Kemmis, 1985; Reid, 1993; Johns, 1995; Valli, 1997; Jay y Johnson, 2002; Tate y Mills, 2004; De Dea Roglio y Light, 2009; Nilsen, Nordström y Ellström, 2012).

Entre las conceptualizaciones más recientes sobre la reflexión, se encuentra la de Ryan (2015), que intenta aunar varias de las propuestas de sus antecesores. Este autor entiende la práctica reflexiva como un acto transformativo. El docente, tras experimentar un acontecimiento inesperado, siente la necesidad de dar sentido a lo sucedido y de imaginar la posibilidad de una experiencia futura similar. Para dar sentido a los hechos utiliza recursos cognitivos básicos tales como el recuerdo de otras experiencias y conocimientos teóricos que le ayuden a entender y ordenar los hechos. Para imaginar la experiencia futura se deben alcanzar niveles más altos de abstracción que involucran la comprensión del contexto de aprendizaje, los problemas asociados a dicho contexto y la contribución personal a todo este escenario. Examinar de qué forma contribuye uno mismo a que los hechos sean como son requiere la revisión de experiencias pasadas y los conocimientos previos, pero también necesita cierta introspección para revisar los valores y filosofías propios y analizar las teorías personales en uso que se manifiestan durante el acto docente.

La reflexión para Ryan es una forma de ayudar al cambio y a la mejora educativa mediante la comprensión de la práctica y a través de la toma de conciencia plena sobre la profesión.

Más sencillo que acordar una definición de reflexión es identificar características que definen al profesional reflexivo. Zeichner y Liston (1996) reúnen cinco características que consideran clave en un profesional reflexivo y que Larrivee y Cooper (2005) asumen y amplían hasta diez. Así, el profesional reflexivo:

1. Reflexiona sobre la experiencia y aprende de ésta.

2. Es un investigador constante.

3. Solicita retroalimentación. 

4. Está abierto a puntos de vista alternativos.
5. Se responsabiliza de su aprendizaje.
6. Ajusta los conocimientos adquiridos a nuevos conocimientos.
7. Se observa a sí mismo en el acto de pensar.
8. Se compromete con la mejora continua de su práctica docente.
9. Se esfuerza por ajustar su comportamiento conforme a sus valores y creencias
10. Busca descubrir la verdad.

\subsubsection{La dirección de la reflexión}

Como se menciona en el punto 3.2 de esta tesis, fue Donald Schön en 1983 el primero en asentar términos relacionados con la direccionalidad de la reflexión al identificar la reflexión en la acción y la reflexión sobre la acción.

En la reflexión en la acción, el docente observa los hechos mientras suceden, relaciona la información que recibe y la compara con su experiencia y conocimientos previos. Finalmente, y de forma dinámica, es capaz de modificar su actuación para adecuarla a la demanda del aula. Se trata por lo tanto de una reflexión que sucede en el presente.

La reflexión sobre la acción, por el contrario, actúa sobre el pasado. El docente revisa la acción que ya ha sucedido dirigiendo la mirada hacia atrás y adoptando una metaposición respecto a los hechos. El objetivo de la reflexión sobre el pasado es la posibilidad de influir en la acción futura.

Killion y Todnem (1991), Ghaye (2010) y Farrell (2004, 2012) sostienen que existe un tipo de reflexión ex profeso para la acción (reflection-for-action). Esta dirección orientada hacia el futuro requiere conciencia previa sobre la necesidad de cambio. Implica reflexionar sobre las propias disonancias cognitivas entre lo que se cree y lo que se ejerce. Su marcado carácter proactivo y su clara intencionalidad de acción es lo que la diferenciaría de otras formas de reflexión.

Finalmente, York-Barr, Sommers, Ghere y Montie (2001) y Larrivee (2005), añaden una cuarta dirección de la reflexión denominada reflexión ha- 
cia dentro o interior (reflection-within). La reflexión interior es descrita como una mirada introspectiva a través de la cual el docente se cuestiona sus propios objetivos, intenciones y sentimientos respecto a cuestiones de enseñanza-aprendizaje. La reflexión hacia dentro es una idea similar al concepto de auto-reflexión.

Así, encontramos que la reflexión tiene cuatro direcciones, una para reflexionar en el momento presente (en), otra para reflexionar sobre hechos pasados (sobre), una tercera para reflexionar sobre el futuro (para) y una cuarta para la reflexión interna (hacia dentro).

\subsection{Aproximación al concepto de práctica reflexiva}

Probablemente la primera definición de práctica reflexiva tomada en consideración a la hora de teorizar es la propuesta de Dewey (1933). Dewey define práctica reflexiva como "Consideración activa, persistente y cuidadosa de cualquier creencia o forma supuesta de conocimiento a la luz de sus fundamentos y de las consecuencias que promueve" (p. 25).

Otros autores (Mezirow, 1981; Boud et al., 1895, Jarvis, 1992) influenciados por Dewey, conciben la práctica reflexiva de modo análogo, como un proceso de aprendizaje a través de la experiencia cuyo fin es adquirir nuevas percepciones sobre uno mismo o sobre la propia práctica. Incluso alguna definición más reciente, como la de Domingo (2013), no se aleja sustancialmente del planteamiento original al entender la práctica reflexiva como una postura intelectual metódica, relacionada con la práctica profesional que requiere intencionalidad y sistematicidad.

Paralelamente, surgen otras voces que sugieren que el termino práctica reflexiva puede ser interpretado de diferentes formas (ver la Tabla 4). 


\section{Tabla 4}

Definiciones de práctica reflexiva en orden cronológico

\begin{tabular}{|c|c|}
\hline & FINICION \\
\hline Dewey (1933) & $\begin{array}{l}\text { Consideración activa, persistente y cuidadosa de cualquier creencia o forma supuesta de } \\
\text { conocimiento a la luz de sus fundamentos y de las consecuencias que promueve. } \\
\text { Acto intencional, de cuestionamiento sistemático y de forma disciplinada y que en última } \\
\text { instancia lleva al cambio y al crecimiento profesional para los docentes. }\end{array}$ \\
\hline $\begin{array}{l}\text { Cruickshank y Applegate } \\
\text { (1981) }\end{array}$ & $\begin{array}{l}\text { Proceso que ayuda a los docentes a pensar en lo sucedido, por qué sucedió cierto evento y } \\
\text { qué más pudo haberse hecho para alcanzar ciertas metas }\end{array}$ \\
\hline Schön (1987) & Diálogo de pensamiento y acción a través del cual adquirimos más destrezas. \\
\hline Ross (1990) & Disposición para aceptar responsabilidades en la práctica profesional. \\
\hline Killion y Todnem (1991) & La práctica de analizar acciones, decisiones o productos enfocándose en el proceso. \\
\hline Lasley (1992) & $\begin{array}{l}\text { Capacidad para pensar de manera creativa, imaginativa y, eventualmente, autocrítica } \\
\text { acerca de la práctica pedagógica. }\end{array}$ \\
\hline & $\begin{array}{l}\text { Medio por el cual se puede desarrollar un mejor nivel de auto-conciencia sobre la natu- } \\
\text { raleza y el impacto del propio desempeño, esta conciencia crea oportunidades para el } \\
\text { crecimiento y desarrollo profesional. }\end{array}$ \\
\hline Hatton y Smith (1995) & $\begin{array}{l}\text { El uso de niveles de pensamiento de orden superior, tales como la exploración crítica y } \\
\text { la metacognición, las cuales nos permiten ver más allá de comportamientos y hechos } \\
\text { aislados y percibir un contexto más amplio para lograr una comprensión de esos compor- } \\
\text { tamientos y hechos. }\end{array}$ \\
\hline Bright (1996) & $\begin{array}{l}\text { Orientación crítica y cuestionadora que exige un profundo compromiso con el descubri- } \\
\text { miento y análisis de la información relacionada con la calidad de la acción profesional. }\end{array}$ \\
\hline Zeichner y Liston (1999) & $\begin{array}{l}\text { Asume la definición de Dewey (1933): } \\
\text { Consideración activa, persistente y cuidadosa de cualquier creencia o forma supuesta de } \\
\text { conocimiento a la luz de sus fundamentos y de las consecuencias que promueve. }\end{array}$ \\
\hline Cole y Knowles (2000) & $\begin{array}{l}\text { Proceso continuo de examinar y afinar de la práctica docente. Centrada de manera variable } \\
\text { en los contextos personales, pedagógicos, curriculares, intelectuales, sociales y/o éticos } \\
\text { asociados con el trabajo profesional. }\end{array}$ \\
\hline York-Barr et al. (2001) & $\begin{array}{l}\text { Forma de abordar la investigación que involucra un compromiso personal orientado hacia } \\
\text { el aprendizaje y mejoramiento continuo. }\end{array}$ \\
\hline Osterman y Kottkamp (2004) & $\begin{array}{l}\text { Proceso sistemático y comprensivo de recolección de información enriquecido por el } \\
\text { diálogo y el esfuerzo colaborativo. }\end{array}$ \\
\hline Domingo (2013) & $\begin{array}{l}\text { Postura intelectual metódica, relacionada con la práctica profesional y que requiere inten- } \\
\text { cionalidad y sistematicidad. }\end{array}$ \\
\hline
\end{tabular}

Nota. Elaboración propia. 
Osterman y Kottkamp (1993) realizan su particular propuesta:

Un medio por el cual se puede desarrollar un mejor nivel de auto-conciencia sobre la naturaleza y el impacto del propio desempeño, esta conciencia crea oportunidades para el crecimiento y desarrollo profesional (p. 2).

Esta definición es completada por los propios autores en años posteriores (Osterman y Kottkamp, 2004) identificando elementos de la práctica reflexiva vinculados a la colaboración social: "[la práctica reflexiva es] un proceso sistemático y comprensivo de recolección de información enriquecido por el diálogo y el esfuerzo colaborativo" (p.146). El elemento compartido y social se convierte en necesario para entender el acto reflexivo.

Catherine Beauchamp (2006) publicó un estudio en el cual examinó más de cincuenta definiciones de práctica reflexiva. En su trabajo Beauchamp no redacta una definición al uso de práctica reflexiva, sin embargo, identifica tres elementos especialmente presentes en la mayoría de conceptualizaciones revisadas. Estos tres elementos hacen referencia al proceso, el propósito y el fundamento de la práctica reflexiva y cada uno de ellos lleva una serie de actos asociados que pueden verse en la Tabla 5

\section{Tabla 5}

Procesos, propósitos y fundamentos de la práctica reflexiva

\begin{tabular}{|c|c|c|}
\hline PROCESO DE REFLEXIÓN & PROPÓSITO DEL PROCESO REFLEXIVO & FUNDAMENTOS DE LA REFLEXIÓN \\
\hline $\begin{array}{l}\text { " Examinar } \\
\text { " Pensar y comprender } \\
\text { " Resolver problemas } \\
\text { " Analizar } \\
\text { " Evaluar } \\
\text { " Construir } \\
\text { " Desarrollar } \\
\text { " Transformar }\end{array}$ & $\begin{array}{l}\text { » Prácticas } \\
\text { » Conocimiento social } \\
\text { » Experiencia } \\
\text { » Información } \\
\text { " Teorías } \\
\text { " Significados } \\
\text { " Creencias } \\
\text { " El sí mismo } \\
\text { » Cuestiones de interés }\end{array}$ & $\begin{array}{l}\text { » Pensar de forma diferente o de forma } \\
\text { más clara } \\
\text { » Justificar la propia postura } \\
\text { »Pensar sobre las acciones o las deci- } \\
\text { siones } \\
\text { »Cambiar pensamientos o conocimiento } \\
\text { » Actuar o mejorar la actuación } \\
\text { » Mejorar el aprendizaje del estudiantado } \\
\text { » Modificar el yo o la sociedad }\end{array}$ \\
\hline
\end{tabular}

Nota: Adaptado de "Processes in the definitions of reflection" por Beauchamp, C. (2006). Understanding reflection in teaching: A framework for analysing the literature. Unpublished doctoral thesis, Montreal: McGill University. 
La autora conjuga los tres elementos mencionados y a partir de estos describe la práctica reflexiva como un proceso que se sirve de la metacognición (examinar, pensar y comprender, resolver problemas, analizar, evaluar, etc.) y que sucede con respecto a un objeto determinado (prácticas, conocimiento social, experiencia, teorías, significados, creencias, etc.) con el fin de alcanzar un objetivo particular o razón de ser (pensar de forma más clara, justificar la propia postura, pensar sobre las acciones o las decisiones, etc.).

La propuesta de Beauchamp es recogida años después por Collin et al. (2013) quienes identifican un par de propiedades más asociadas con la práctica reflexiva: la reflexión fundamentada en la situación y la reflexión como suceso genérico o social. El primer término retoma la idea de Schön (1983) sobre la reflexión ligada al contexto. La reflexión surge a partir de la práctica, es modelada por acontecimientos específicos e inmediatos y por lo tanto no puede desvincularse de la situación que la provoca. El acto reflexivo proporciona respuestas que se pueden aplicar a situaciones particulares dadas en contextos similares al original.

La segunda propiedad aborda el término desde un enfoque sociológico. La práctica reflexiva es un proceso que realiza el individuo profesional pero también el individuo social. Por lo tanto, si se desea identificar qué aspectos guían un determinado comportamiento en el aula, debe considerar cuáles son los marcos sociales de referencia (roles de género, credos, estructura familiar, etc.). Difícilmente se pueden introducir cambios e innovaciones en educación si no se abordan los constructos sociales en los que se sustentan los patrones habituales de actuación.

Una última propuesta para esclarecer el término de práctica reflexiva es la que realiza Finlay (2008). Este autor establece un modelo descriptivo sustentado en tres paradigmas: la fenomenología existencial, la teoría crítica y el escepticismo. A su vez, tres habilidades fundamentan la práctica reflexiva: la reflexión, el pensamiento crítico y la autoconciencia y cada una de ellas está asociada a uno de los anteriores paradigmas. En la Figura 3 se puede ver un esquema sobre las habilidades y paradigmas mencionados. Así, en primer lugar, la habilidad de reflexión se identifica con la fenomenología existencial y la teoría crítica. La habilidad reflexiva bajo estos paradigmas permite interpretar los acontecimientos críticamente, fomentar la autoconciencia 
y la conciencia social, mejorar aspectos colaborativos y comunicativos que favorezcan el aprendizaje y establecer nexos entre teoría y práctica. En segundo lugar, la habilidad de autoconciencia se identifica con la fenomenología y se manifiesta en la capacidad cognitiva para pensar, conocer y ser sensible ante determinadas situaciones, además permite re-evaluar el conocimiento para llegar a una mejor comprensión. En tercer lugar, la habilidad de pensamiento crítico, relacionada con el escepticismo y la teoría crítica, permite identificar asunciones y desafiarlas, cuestiona cómo el contexto influye en los acontecimientos y adopta una postura escéptica al buscar alternativas y soluciones.

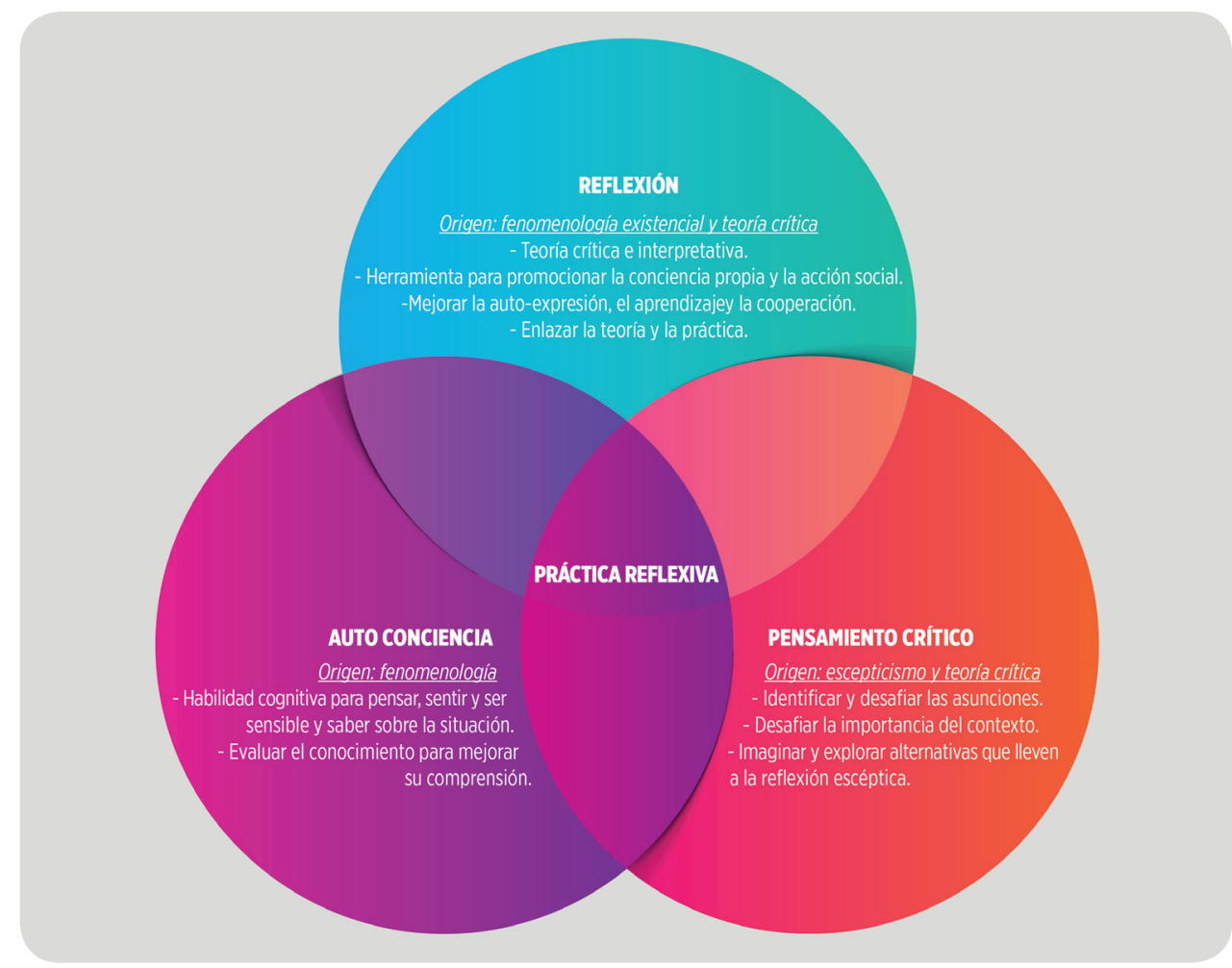

Figura 3. Habilidades que fundamentan la práctica reflexiva. Adaptado de "Skills underpinning the concept of reflective practice" por Finlay, L. (2008). Reflecting on 'Reflective practice'. Practice-Based Professional Learning Center, 52, 1-27. 
Al igual que sucede con el término reflexión, a los investigadores les ha resultado más cómodo identificar características del practicante reflexivo que asentar una definición sobre ésta. Por ejemplo, Barbara Larrivee (2000) cree que existen ciertas actitudes que favorecen la adopción de la práctica reflexiva en el terreno profesional. La primera actitud consiste en dedicar tiempo a la reflexión en solitario. Esta actitud permite crear un espacio apropiado revisar los propios sentimientos, frustraciones, inseguridades, sesgos y prejuicios que emergen en la práctica cotidiana.

La segunda actitud hace referencia a la tenacidad a la hora de solucionar problemas, implica flexibilidad y creatividad en la práctica docente, aprender de la experiencia y perseverar en la consecución de objetivos considerando que la realidad educativa es impredecible. La tercera condición del practicante reflexivo es cuestionar el statu quo y buscar la propia verdad de entre el saber convencional. Esta actitud implica valentía tanto individual como colectiva, requiere cierta habilidad para buscar alianzas entre compañeros de profesión y cierta diplomacia para enfrentarse a dos sectores educativos: los iguales que se han acomodado a rutinas y pensamientos establecidos y las estructuras jerárquicas de poder que pueden posibilitar o dificultar la introducción de metodologías innovadoras.

Zeichner y Liston (1996) se dirigen en su discurso directamente al estudiante en prácticas y le piden que observe atentamente lo que sucede en el aula con el fin de reconocer aquellas metodologías y técnicas que son más congruentes con su estilo personal, sus creencias y su forma de entender la enseñanza y la educación. Si al llegar al aula no indaga, si no integra sus habilidades y conocimientos, si no cuestiona lo que allí sucede y no establece vínculos con sus propias creencias y expectativas, en ese caso se está limitando a aplicar una serie de técnicas como si fueran trucos aprendidos. 


\section{La reflexión como proceso cíclico.}

La práctica reflexiva es entendida como un proceso cíclico que se inicia a partir de la experiencia y se cierra en la acción. Durante dicho proceso actúan una serie de estrategias cognitivas como la toma de conciencia, el análisis de los hechos o toma de decisiones que modulan la acción final y condicionan el inicio del nuevo ciclo.

Los modelos a los que más comúnmente se recurre para representar el ciclo de la reflexión son los propuestos por Kolb (1984), Gibbs (1988) y Korthagen (2001). En este trabajo se van a desarrollar brevemente los tres modelos, a la vez que se va a incluir un cuarto ciclo -propuesto por Wareing (2017)- tanto por su novedad, como por establecer diferencias notables respecto a los otros.

\subsection{El modelo experiencial de Kolb.}

El modelo reflexivo de Kolb (1984) se basa en el concepto de aprendizaje a través de la experiencia y se centra en explicar cómo la información se transforma en conocimiento. Directamente influenciado por Dewey y su visión instrumental de la práctica reflexiva, Kolb entiende que las decisiones deben tomarse de forma racional y consciente, para ello el individuo necesita recurrir a los conocimientos teóricos previos y a las experiencias anteriores. Cada nueva experiencia se suma al bagaje acumulado y el inicio del nuevo ciclo servirá para guiar la próxima decisión. En la Figura 4 se puede ver el esquema de aprendizaje experiencial planteado por Kolb.

El ciclo de aprendizaje experiencial de Kolb se describe a través cuatro fases:

1. Experiencia concreta. Es la primera toma de contacto con una nueva experiencia inesperada que causará alto impacto en el docente. El entorno físico y social en el cual suceden los hechos influirá directamente en cómo el docente percibe la situación.

2. Observación reflexiva. El docente revisa y reflexiona sobre la nueva experiencia y comienza a generar hipótesis causales sobre la experiencia. En este momento es fundamental mantener una actitud receptiva y de apertura mental. Lo que busca el docente en esta etapa es obtener 
una comprensión general de la situación y se basa principalmente en el examen de experiencias previas. La reflexión, por lo tanto, es parte del ciclo de aprendizaje y no un elemento independiente.

3. Conceptualización abstracta. En esta etapa se buscan aspectos teóricos que fundamenten la información reflexionada en la etapa anterior. El docente analizará la información, buscará explicaciones razonables y tratará de validar la hipótesis generada.

4. Experimentación activa. A partir de los análisis anteriores se llega a una comprensión de los hechos y se elaboran una serie de estrategias de actuación alternativas que pondrán en práctica cuando ocurran nuevas situaciones.

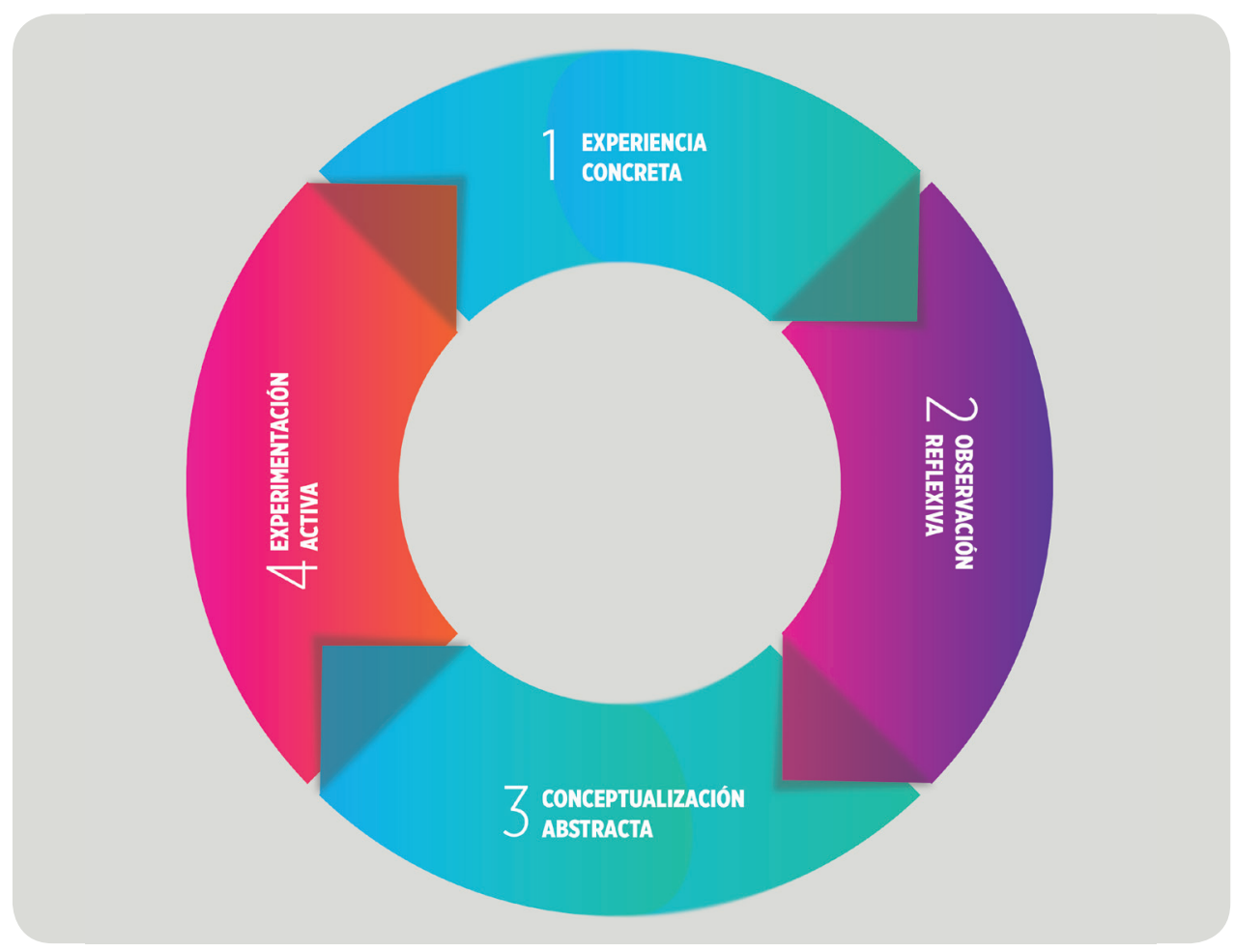

Figura 4. Ciclo de aprendizaje experiencial de Kolb (1984). Elaboración propia. 
Boud et al. (1985) realizan varias críticas al excesivo reduccionismo que planeta el modelo de Kolb. El modelo se basa principalmente en el examen del docente y obvia completamente al aprendiz y sus circunstancias. También olvida que la reflexión no solo se realiza respecto a los hechos, sino que también requiere examinar elementos personales como pueden ser las creencias del docente, sus intenciones, sus metas o la finalidad de su práctica docente. También se cuestiona que el aprendizaje experiencial considera al docente como sujeto reflexivo aislado mientras otros modelos postulan que la reflexión se enriquece si se realiza de modo grupal.

\subsection{El ciclo reflexivo de Gibbs.}

Graham Gibbs (1988) analizó el ciclo de Kolb y propuso un modelo que intentó superar algunas de las críticas dirigidas hacia Kolb.

Gibbs integra en su propuesta la parte del aprendizaje experiencial que entiende la reflexión como parte del proceso de aprendizaje que tiene por finalidad el desarrollo profesional y personal. Sin embargo, el núcleo de su ciclo reflexivo se basa en el aprendizaje mediante la acción o learning by doing. En el aprendizaje a través de la acción se trabaja la reflexión a partir de incidentes críticos. El término incidente crítico es descrito por Monereo (2010) y Bilbao y Monereo (2011) como "un suceso acotado en el tiempo y el espacio que, al superar un determinado umbral emocional del profesor pone en crisis o desestabiliza su propia identidad profesional” (p. 4). Esta técnica suele utilizarse con cierta frecuencia entre estudiantes de prácticas debido al impacto que conlleva el verse por primera vez ante la realidad del aula y de la escuela. La generación de incidentes suele suceder con relativa frecuencia y posibilita trabajar la reflexión a partir de la confusión y la inseguridad que se genera el choque entre teoría y práctica.

Gibbs describe seis etapas en su ciclo reflexivo: descripción, sentimientos, evaluación, análisis, conclusiones generales y específicas y plan de acción (en la Figura 5 se puede ver representadas las etapas del Ciclo Reflexivo de Gibbs). Cada una de las etapas tiene unos objetivos concretos y lleva asociadas unas cuestiones que el practicante reflexivo debe tratar de responder a modo de discurso interno. Las tres primeras etapas se refieren a la revisión y análisis de hechos pasados mientras que 
las tres siguientes se focalizan en dar sentido al incidente y en mejorar la actuación en futuras ocasiones.

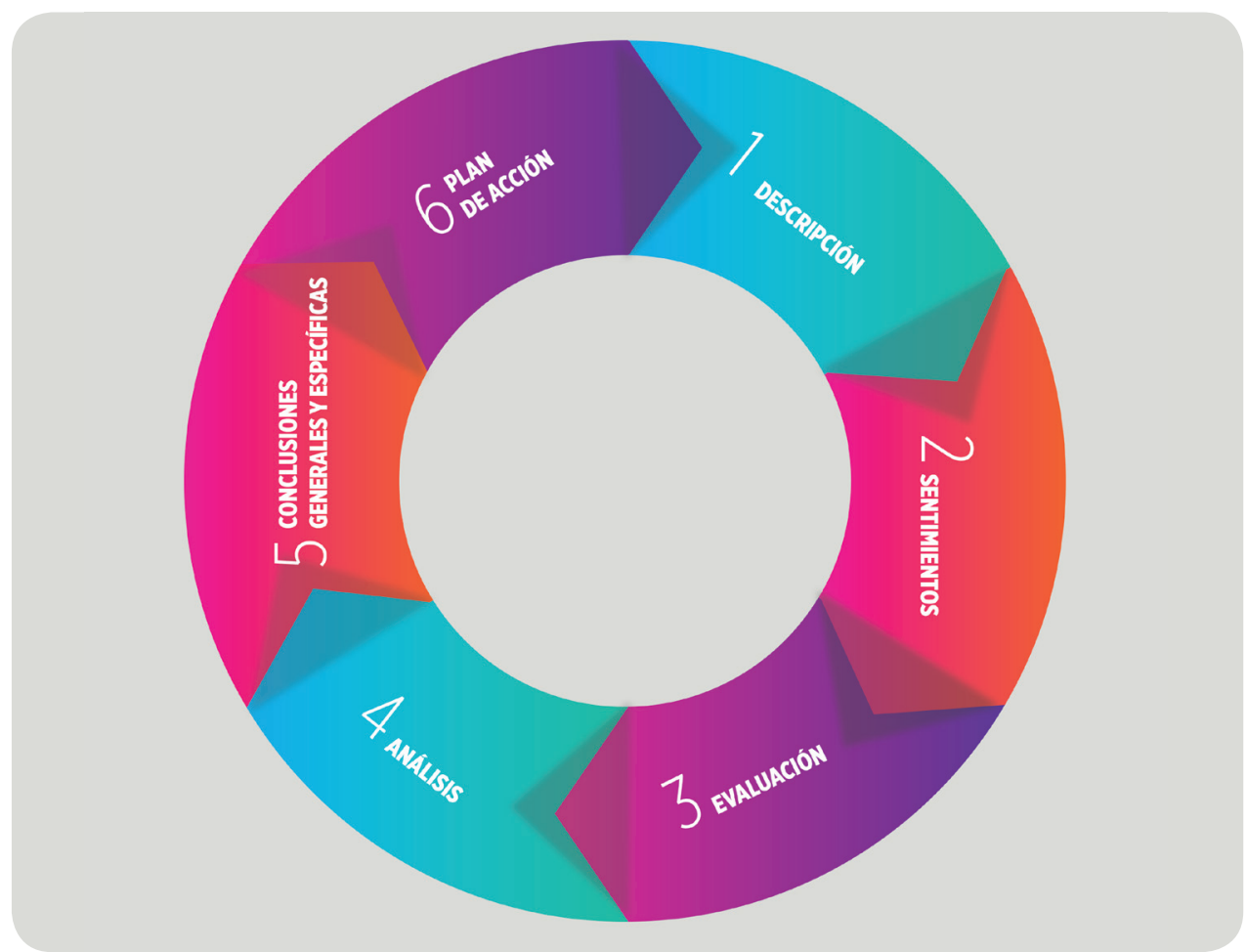

Figura 5. Ciclo reflexivo de Gibbs Adaptado de Gibbs, G. (1988). Learning by doing: A guide to teaching and learning methods. Birmingham: SCED.

El ciclo comienza con la descripción de la situación. El estudiante debe preguntarse ¿Qué ha pasado? A partir de esta cuestión, tratará de identificar el contexto de la acción mediante una breve descripción de los hechos. Se tratar de ser lo más objetivo posible y evitar hacer juicios de valor en la descripción de los hechos, mencionar detalles como quién participa de la situación, la propia implicación en el incidente, el resultado de lo ocurrido, etc.

La segunda etapa del ciclo responde a las cuestiones ¿Cómo he reaccionado?, ¿cuáles han sido mis sentimientos? y requiere identificar las emociones generadas a partir del incidente. Es la oportunidad de explorar sentimientos de forma aislada y sin juicios de 
valor. El estudiante debe detallar de qué forma observó que se manifestaban sus sentimientos. Por ejemplo, describir si identificó que estaba nervioso porque observó que le temblaban las manos y si ese estado emocional pudo influir en la decisión tomada.

En tercer lugar, se realizará la evaluación de la situación. En esta etapa se efectúan por primera vez juicios de valor revisando aspectos positivos y negativos del incidente. Se debe abordar no solo la propia actuación sino también la de las otras personas implicadas. En este punto el docente se preguntará ¿Qué ha ido mal?, ¿qué ha ido bien?, ¿por qué?

En la cuarta etapa se llevará a cabo un análisis de la situación. Algunas cuestiones a plantearse son ¿Qué sentido he dado a la experiencia?, ¿qué pasaba en realidad?, ¿qué ideas externas pueden ayudarme? Esta es la etapa más larga del ciclo de Gibbs, cada elemento debe ser considerado por separado y analizado a través de la literatura académica para comenzar a entrever posibles soluciones. No se trata tanto de indagar en la teoría para comprender los hechos como de buscar posibles soluciones para aplicar en la práctica.

En la penúltima fase se extraen conclusiones generales y conclusiones específicas. Las conclusiones generales identifican competencias que son necesarias para la práctica profesional y que se han adquirido o no. Las conclusiones específicas señalan fortalezas y debilidades personales que debe trabajar el docente de forma individual. Una vez identificadas las conclusiones se debe estar en disposición de establecer relaciones lógicas respecto a la actuación. El individuo se preguntará ¿Qué puedo concluir como profesional a partir de la experiencia y el análisis llevado a cabo?, ¿qué puedo concluir sobre mi situación personal en relación a mi desempeño?

Finalmente, el ciclo concluye trazando un plan de acción personal. Tomando en consideración todos los niveles examinados a lo largo del ciclo, se ha de proponer un plan de acción dirigido a futuros acontecimientos similares. Algunas preguntas serán ¿Actuaré de la misma forma o haré algo diferente?, ¿qué medidas o acciones voy a tomar respecto a lo aprendido?

Con este paso termina el ciclo reflexivo de Gibbs, considerando que, si en el fu- 
turo se produjera un incidente similar, el sujeto debería revisar de nuevo el ciclo y recordar las respuestas obtenidas a partir de la reflexión.

\subsection{EL modelo ALACT de Korthagen (2001).}

Korthagen (2001) critica en modelos anteriores que ninguno hace mención al conocimiento tácito del profesorado. El modelo reflexivo propuesto por Korthagen presta especial atención a ese componente irracional que, según los postulados de Schön, guía el comportamiento del profesorado en situaciones críticas. Por otro lado, a diferencia de los modelos de Kolb o Gibbs, este autor considera que la práctica reflexiva es también un proceso social y así lo detalla en su modelo.

El modelo de Korthagen se denomina ALACT2 a modo de acrónimo de las palabras que conforman las cinco fases del modelo. En castellano el modelo se ha traducido como acción, revisión de la acción, toma de conciencia de aspectos esenciales, creación de métodos de acción alternativos y ensayo. En la Figura 6 se detalla el ciclo reflexivo derivado del modelo de Korthagen.

El modelo ALACT se basa en tres principios fundamentales, la práctica en contextos reales como base del aprendizaje, la sistematización de la reflexión que consolida el hábito reflexivo y genera un aprendizaje autónomo y en tercer lugar la interacción social y la discusión grupal como fuentes necesarias en la reflexión que permiten transformar la información para poderla comunicar eficazmente.

En la primera fase del modelo se produce la acción o experiencia sobre la cual se va a reflexionar. Esta acción deviene de la práctica docente y requiere por parte del profesional tomar conciencia del contexto determinado en el que se genera el suceso.

Durante la segunda fase, el profesorado revisa la acción. No se limita a repasar descriptivamente los hechos, sino que examina los pensamientos que tuvieron lugar durante la acción, así como los sentimientos y emociones que emergieron y que le impulsaron hacia una determinada toma de decisiones. Este análisis no se limita al docente, sino que incluye la revisión de las emociones y deseos que esos mismos hechos generaron en el alumnado. 
En tercer lugar, llega la toma de conciencia sobre aspectos esenciales que han modulado o influido en la acción. La toma de conciencia requiere el examen de tres aspectos. El primero, la revisión de emociones o estados que pueden ocurrir de forma puntual como, por ejemplo, la irritación o el cansancio (del docente y/o del alumnado) y que pueden influir en un determinado comportamiento. En segundo lugar, se debe repasar la formación académica llevada a cabo durante los años en la facultad y que ofrece un mapa de actuación formal. Por último, el docente examinará las teorías implícitas asumidas, transmitidas de forma indirecta por el entorno sociocultural que le rodea y que afectan tanto a sí mismo como al alumnado.

Esta es la etapa más compleja del modelo para Korthagen (2010b). Cuando se reflexiona sobre la esencia de los comportamientos se comprenden cuáles son los mecanismos inconscientes que dirigen las acciones inmediatas del aula y por lo tanto se obtiene un conocimiento muy valioso profesionalmente. Lo difícil, según el autor, es hacer al docente salir de su zona de seguridad y vencer el miedo a descubrir una serie de mecanismos irracionales bajo los cuales actúa, ya que una vez desvelados, difícilmente podrán ser ignorados.

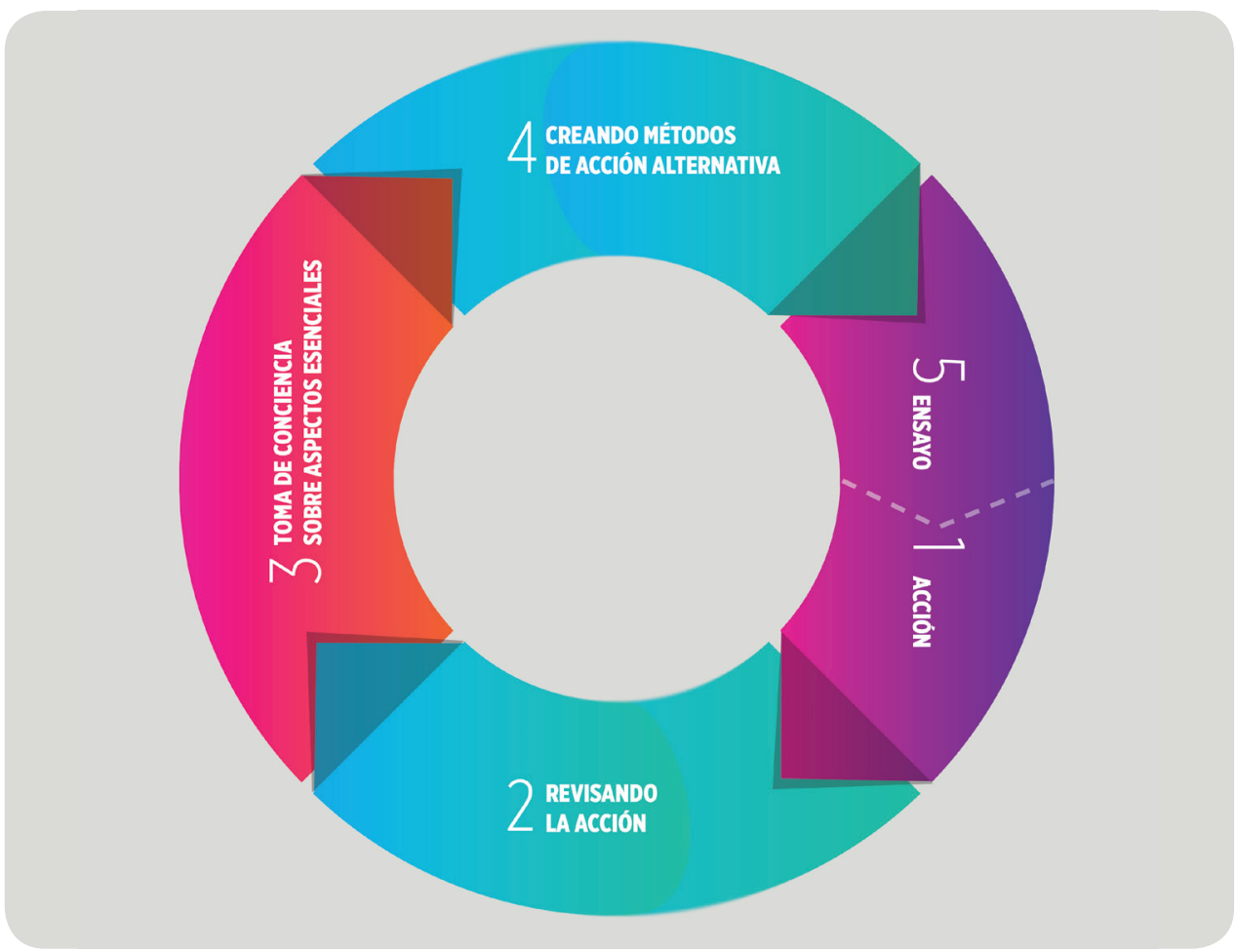

Figura 6. Modelo ALACT de reflexión. Adaptado de "The ALACT model”. Korthagen, F. (2001). Linking practice and theory: The pedagogy of realistic teacher education. Mahwah: Lawrence Erlbaum Associates. 
Tras reflexionar sobre los aspectos esenciales que modulan el comportamiento, el profesional reflexivo está en condiciones de crear métodos de acción alternativa que cambien la relación entre persona y fenómeno. Las reflexiones y nuevas ideas, antes de dar el paso de ponerlas en práctica, deben compartirse y compararse con las de otros docentes que hayan participado del mismo proceso reflexivo y que expongan del mismo modo sus experiencias y conclusiones. La reflexión grupal es un elemento clave para aumentar el efecto del cambio y responder mejor a los intereses formativos del profesorado.

Finalmente, se llegará al nivel sexto o de ensayo. En este punto se llevará a la práctica el plan establecido producto de las conclusiones obtenidas en los exámenes anteriores. Este momento supone el fin del proceso y el inicio de un nuevo ciclo reflexivo en el cual se volverán a considerar los nuevos hechos, los cambios introducidos y el resultado de la acción alternativa.

\subsection{El modelo de Wareing: Me, my, more, must.}

Finalmente, el modelo de Wareing (2017) merece la pena ser citado por dos razones. La primera de ellas es su actualidad, ya que a fecha de cerrar este trabajo es el último modelo reflexivo que se ha publicado en revistas de investigación. Y, en segundo lugar, porque el modelo rompe con varios de los esquemas anteriores en cuanto al contenido de las etapas reflexivas del ciclo. El modelo Me, my, more, must (ver Figura 7), se basa en la reflexión sobre los aspectos emocionales y valores personales que entran en juego durante la práctica profesional. Su objetivo es facilitar en el alumno un proceso de autodescubrimiento en relación a la profesión y descubrir aspectos de ésta que chocan frontalmente con los valores personales ante un determinado incidente.

En la primera etapa (Me) el profesional reflexivo inicia un diálogo interno en el cual se cuestiona aspectos básicos pero profundos sobre sí mismo. El docente debe descubrir sus valores, capacidades, personalidad y cómo estos aspectos encajan en su profesión. Algunas preguntas que se debe plantear el estudiante son ¿Quién soy?, ¿qué valores son importantes para mí?, ¿qué valores son importantes para mí como docente?, ¿qué necesito para sentirme seguro en el trabajo?, ¿qué 
aspectos personales me favorecen o perjudican en mi trabajo?

La segunda etapa (My), busca que el profesional diferencie lo que es como persona de lo que hace como profesional. Para ello debe reconocer lo que es propio de su personalidad, de su rol profesional y de la actividad que desempeña. Esta parte busca que se reconozca la presencia e impacto que pueden tener las emociones en el lugar de trabajo. El profesional se preguntará aspectos como ¿Cuáles son mis sentimientos y pensamientos respecto a esta experiencia?, ¿qué cosas me preocupan sobre mí y sobre las personas involucradas?, ¿quién me puede ayudar a dar sentido a la situación?

En la tercera etapa (More) el practicante reflexivo debe centrarse en el potencial aprendizaje que la situación puede ofrecer. Requiere tener curiosidad para profundizar en la comprensión de los hechos, dejar aparte los propios supuestos y prejuicios, escuchar y respetar las opiniones de los demás implicados. Las preguntas que pueden guiar al alumno son ¿Qué dudas se han generado a partir del incidente?, ¿qué ideas se han generado a partir de la situación?, ¿qué me ha sorprendido?, ¿qué más necesito averiguar respecto a esta experiencia?

La cuarta y última etapa (Must) es la que más evoca a los modelos anteriores de reflexión, en el sentido de instar al alumnado para que se involucre en la planificación de acciones de cara a situaciones similares. Aún así, el modelo insiste en la necesidad de que los valores personales formen parte de las acciones que se planifiquen, como medio para convertirse en el profesional al que se aspira ser. En esta etapa las cuestiones a plantearse son ¿Qué debo hacer para identificar mis necesidades de aprendizaje y mis objetivos de aprendizaje?, ¿con quién tengo que hablar para desarrollar mi plan de crecimiento profesional y qué debo incluir en ese plan?, ¿qué valores debo explorar para convertirme en el profesional que deseo? 


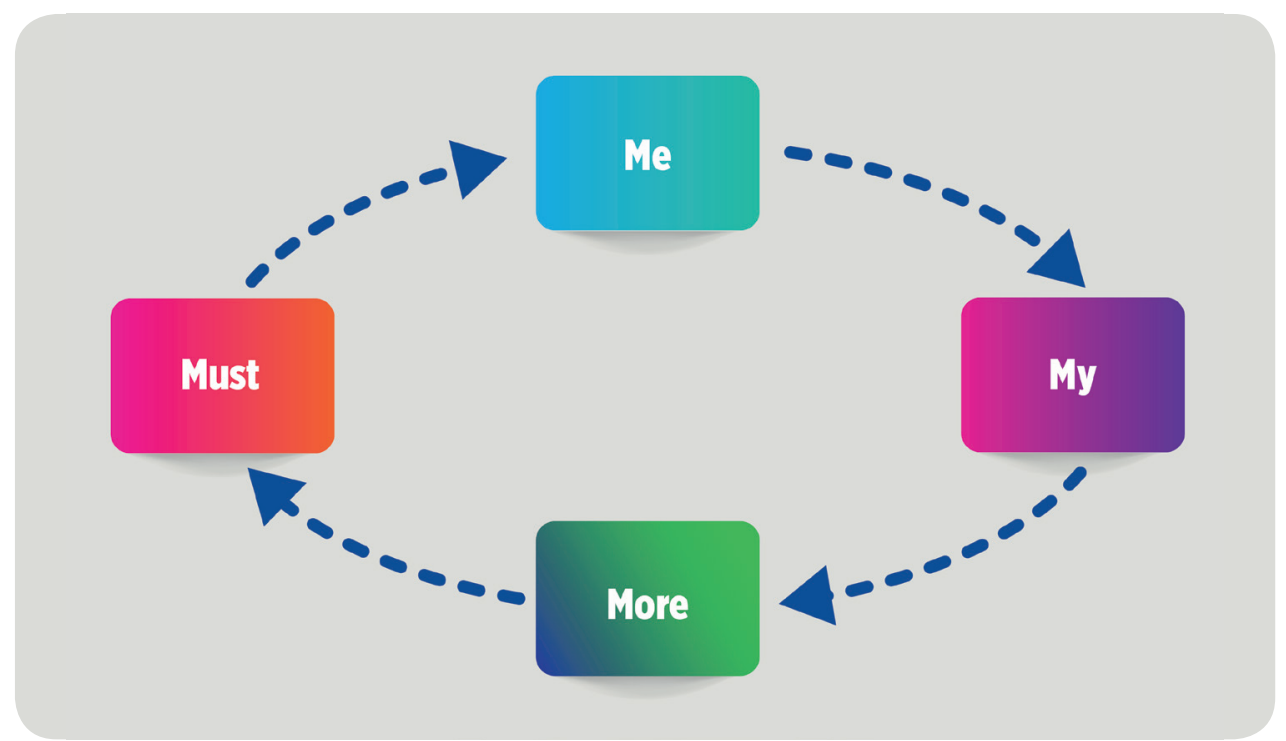

Figura 7. Modelo reflexivo Me, My, More, Must. Elaboración propia. 


\section{Niveles de reflexión docente}

En la literatura sobre práctica reflexiva hay referidas múltiples formas de clasificar los niveles de reflexión. La idea común de todas ellas es la existencia de un tipo de reflexión que requiere procesos cognitivos de bajo orden (recordar, reconocer, comprender, resolver, aplicar) y un tipo de reflexión que los requiere de alto orden (analizar, interpretar, crear, juzgar, evaluar) (Anderson y Krathwohl, 2001).

Entre los primeros acercamientos para diferenciar niveles de reflexión se encuentra la propuesta de Argyris y Schön (1974) y la de Habermas (1974 y 1990).

Argyris y Schön describen una clasificación en la que intervienen dos circuitos de aprendizaje. Un circuito de bucle único o "single-loop" y un circuito de bucle doble o "double-loop". En el ciclo de bucle único, el aprendizaje se produce bajo la aceptación de los valores dominantes en la educación. Este bucle es definido por la planificación, la enseñanza y la comprobación de resultados. En el ciclo de doble bucle, por el contrario, el aprendizaje se produce cuestionando los valores aceptados y es definido por el pensamiento, la práctica y el uso de niveles cognitivos elevados.

Habermas en su propuesta identifica tres dominios del conocimiento que denomina técnico-instrumental, práctico-comunicativo y emancipador. Los dos primeros serían categorías inferiores en cuanto a que utilizan el conocimiento y la información sin ningún tipo de conciencia crítica mientras que el nivel emancipador contiene esta conciencia y la orienta hacia el desarrollo de la autonomía personal del docente (Moreno y Siles, 2015). La clasificación de Habermas tuvo una gran acogida entre los investigadores de la práctica reflexiva y su influencia se evidencia al revisar propuestas posteriores de autores como Van Manen (1977) o Mezirow (1991) y más recientemente Jay y Johnson (2002) o Villalobos y Cabrera (2009).

Entre las categorizaciones más reconocidas además de las ya mencionadas, se encuentran los cuatro niveles reflexivos de Hatton y Smith (1995), los seis niveles propuestos por Valli (1997), los tres niveles de Strampel y Oliver (2007) o los cuatro niveles definidos por Kember, McKay, Sinclair y Wong (2008), quienes validaron un cuestionario que permitía medir el grado de pensamiento reflexivo de las producciones escritas del alumnado de magisterio en periodo de prácticas. 


\section{Tabla 6}

Niveles de reflexión categorizados por diversos autores.

\begin{tabular}{|c|c|}
\hline AUTOR & NIVELES DE REFLEXIÓN \\
\hline Argyris y Schön (1974) & $\begin{array}{l}\text { 1. Bucle único o "single-loop" } \\
\text { 2. Bucle doble o "double-loop" }\end{array}$ \\
\hline Habermas $(1974,1990)$ & $\begin{array}{l}\text { 1. Nivel técnico-instrumental } \\
\text { 2. Nivel práctico-comunicativo } \\
\text { 3. Nivel emancipador }\end{array}$ \\
\hline Van Manen (1977) & $\begin{array}{l}\text { 1. Reflexión técnica } \\
\text { 2. Reflexión práctica } \\
\text { 3. Reflexión crítica o conocimiento dialéctico. }\end{array}$ \\
\hline Mezirow $(1988,1991)$ & $\begin{array}{l}\text { 1. Reflexividad } \\
\text { 2. Reflexividad afectiva } \\
\text { 3. Reflexividad discriminatoria } \\
\text { 4. Reflexividad crítica } \\
\text { 5. Reflexividad conceptual } \\
\text { 6. Reflexividad psíquica } \\
\text { 7. Reflexividad teórica }\end{array}$ \\
\hline Hatton y Smith (1995) & $\begin{array}{l}\text { 1. Reflexión habitual } \\
\text { 2. Reflexión descriptiva } \\
\text { 3. Reflexión dialógica } \\
\text { 4. Reflexión crítica }\end{array}$ \\
\hline Valli (1997) & $\begin{array}{l}\text { 1. Reflexión técnica } \\
\text { 2. Reflexión en la acción } \\
\text { 3. Reflexión sobre la acción } \\
\text { 4. Reflexión deliberativa } \\
\text { 5. Reflexión personalística } \\
\text { 6. Reflexión crítica. }\end{array}$ \\
\hline Jay y Johnson (2002) & $\begin{array}{l}\text { 1. Reflexión descriptiva } \\
\text { 2. Reflexión comparativa } \\
\text { 3. Reflexión crítica }\end{array}$ \\
\hline Strampel y Oliver (2007) & $\begin{array}{l}\text { 1. Reflexión descriptiva y recuperación cognitiva. } \\
\text { 2. Reflexión dialógica y reconceptualización } \\
\text { 3. Reflexión crítica y dedicación }\end{array}$ \\
\hline Kember et al. (2008) & $\begin{array}{l}\text { 1. Acción habitual } \\
\text { 2. Comprensión } \\
\text { 3. Reflexión } \\
\text { 4. Reflexión crítica }\end{array}$ \\
\hline Larrivee y Cooper $(2005,2008)$ & $\begin{array}{l}\text { 1. Pre-reflexión } \\
\text { 2. Reflexión superficial } \\
\text { 3. Reflexión pedagógica } \\
\text { 4. Reflexión crítica }\end{array}$ \\
\hline
\end{tabular}

Nota: elaboración propia. 
En la Tabla 6 se recopilan las propuestas mencionadas hasta ahora sobre niveles de reflexión, sin embargo, la lista de autores que introducen sus propias clasificaciones es verdaderamente extensa (Handal y Lauvas, 1987; Day, 1993; Krol, 1996; Muradás y Porta, 2007; Hernández, Fonollosa y Chrisos, 1998; Zeichner y Liston,1996; Sparks-Langer, Simmons, Pasch, Colton y Starko, 1991; Surbeck, Park Han y Moyer, 1991; Brubacher, Case y Reagan, 2000; Ross, 1987; Ward y McCotter, 2004; Farrell, 2004; Lee, 2005; Ottesen, 2007; Mason y Klein, 2013).

La mayoría de investigadores añaden más categorías y subcategorías intentando afinar las particularidades bajo las que se define cada nivel, otros cambian la nomenclatura y definen de forma similar el contenido intentando ajustarlo a sus necesidades concretas. Lo cierto es que es habitual hallar en las categorizaciones mencionadas referencias a tres niveles reflexivos. Un nivel inicial que considera los hechos de forma aislada, centrado en el maestro como agente individual que reflexiona sobre sus actos y su habilidad profesional. Un segundo nivel donde el docente es capaz de realizar asociaciones entre hechos derivados de la práctica y la teoría educativa. Y, por último, un tercer nivel en el que el profesional examina profundamente las consecuencias éticas y sociopolíticas de la enseñanza y los propósitos de la educación.

En esta línea se encuentra la clasificación de la investigadora Barbara Larrivee $(2005,2008)$ que se va a desarrollar a continuación.

Larrivee (2000) en una de sus primeras aproximaciones al paradigma reflexivo revisa el concepto de pensamiento crítico aplicado a la práctica de aula. En su narrativa propone a los estudiantes la adopción de la reflexión crítica como forma de aumentar su aprendizaje durante el Practicum. Aunque cree que no existe una ruta predefinida para alcanzar la reflexión crítica, sí insta al compromiso con ésta a lo largo de toda la vida profesional.

Pocos años después (Larrivee, 2004), tras una exhaustiva revisión de la literatura relacionada con la práctica reflexiva y en particular con los niveles de reflexión, presenta una propuesta en la cual adopta su propia terminología para clasificar los niveles reflexivos. En este primer planteamiento describe cuatro ni- 
veles (reflexión superficial, reflexión pedagógica, reflexión crítica y auto-reflexión) que en una publicación posterior (Larrivee y Cooper, 2005) reformula ligeramente en la que será su propuesta definitiva (ver Figura 8) y en la que describe un primer nivel pre-reflexivo, un segundo nivel de reflexión superficial, un tercer nivel de reflexión pedagógica y un cuarto nivel denominado reflexión crítica. En este modelo, la auto-reflexión se considera una forma específica de reflexión crítica.

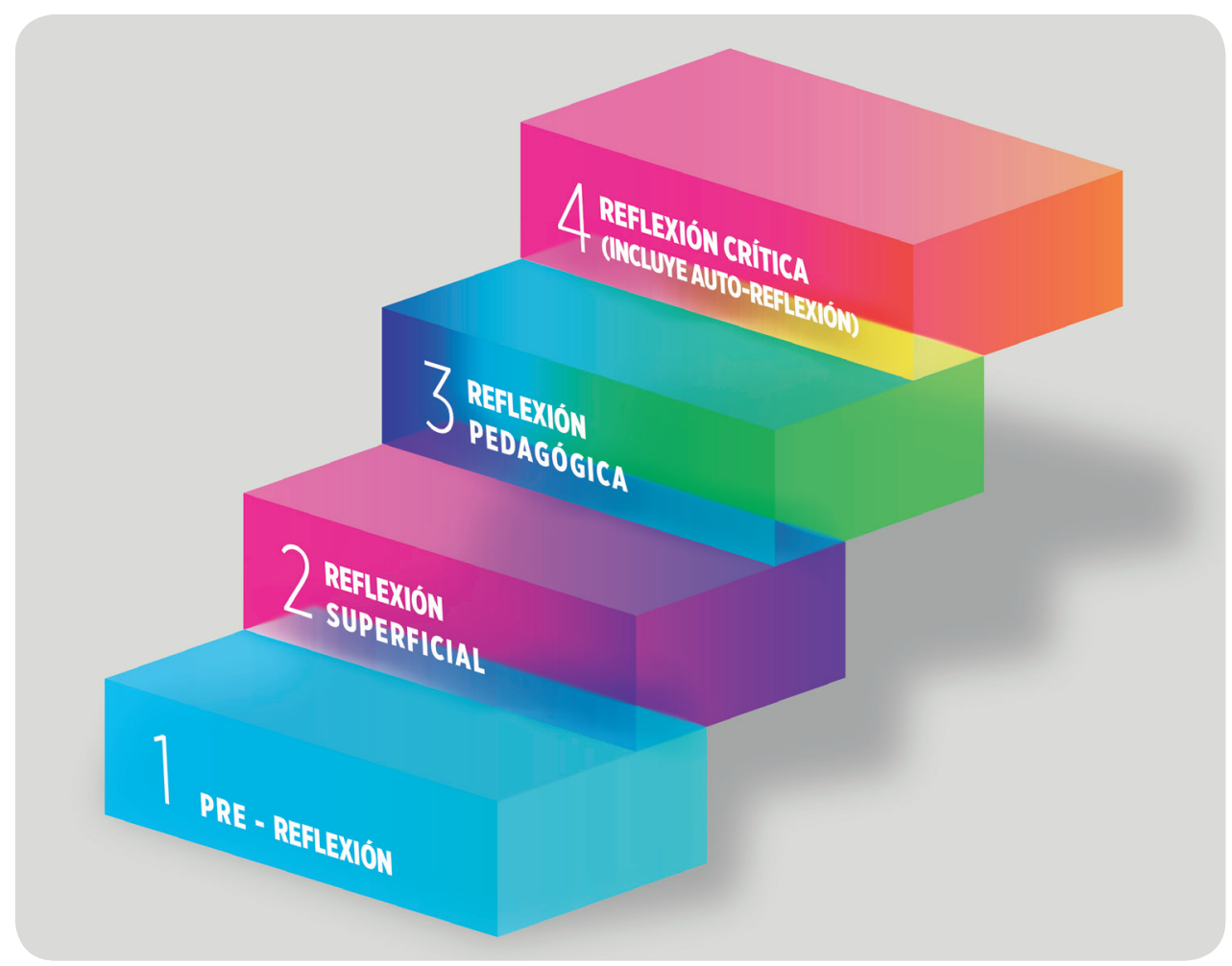

Figura 8. Niveles de reflexión sobre la práctica según Larrivee y Cooper (2005). Elaboración propia.

La jerarquía mostrada en la Figura 8 representa el nivel de complejidad cognitiva que requiere la reflexión, siendo la pre-reflexión la de menor exigencia cognitiva y la reflexión crítica la que requiere un mayor nivel de complejidad. En un mismo discurso se pueden hallar muestras de los cuatro niveles de reflexión, pero 
lo deseable para el practicante reflexivo es que primen las reflexiones del tercer y cuarto nivel.

El nivel de pre-reflexión, se caracteriza por la reacción automática que tiene el docente frente a los hechos. Sucede cuando los acontecimientos le superan y se percibe a sí mismo como víctima de las circunstancias. Atribuye las causas de su reacción a los estudiantes, al centro, al sistema educativo o a cualquier agente externo. Se ve incapaz de adaptar su docencia a las necesidades del alumnado y es ineficaz planteando respuestas alternativas ante un problema en el aula. Asume que la situación es como es, inamovible e incuestionable.

El término reflexión superficial es similar al concebido por Van Manen (1977) o Jay y Johnson (2002). Se trata de un nivel de reflexión de bajo orden, pero superior al nivel anterior. El docente es capaz de reflexionar sobre las estrategias y métodos que está utilizando para alcanzar los objetivos didácticos y está particularmente interesado en mantener el control y el orden en el aula. No se cuestiona en cambio si los objetivos que quiere conseguir se subordinan a unos intereses y motivos determinados que pueden no estar en sintonía con sus propios valores. A este nivel de reflexión, el maestro se pregunta: ¿Cómo puedo conseguir que el alumnado se centre en la tarea?, ¿he preparado suficientes actividades para hoy?, ¿̇hago demasiadas actividades de trabajo grupal?, ¿cómo puedo hacer para que los estudiantes atiendan más?

El nivel de reflexión pedagógica, según Larrivee (2005) es el que menor consenso obtiene en la literatura en cuanto explicar aquello que lo define. Otros términos para identificar este nivel son reflexión práctica, comparativa, conceptual, teórica, deliberativa, etc. La reflexión pedagógica busca la aplicación del conocimiento teórico a la enseñanza. El docente intenta comprender las bases teóricas y científicas que subyacen a la práctica de aula. Es capaz de reflexionar sobre lo que cree que hace (teoría expuesta) y lo que hace realmente (teoría en uso) y detectar disonancias entre ambas. Su fin es mejorar la práctica profesional y el aprendizaje, así que se cuestiona ¿Cómo puedo mejorar el aprendizaje de mis estudiantes?, ¿cómo puedo mejorar los resultados en las tareas cooperativas?, ¿favorezco la toma de decisiones?, ¿cómo puedo ayudarles a conectar con sus conocimientos previos? 
En cuarto lugar, se reflexiona críticamente cuando se consideran las implicaciones éticas y morales de las prácticas de aula. Este término es el que mayor consenso encuentra en la literatura sobre práctica reflexiva considerándose un tipo de "pensamiento de alto nivel” (p. 343). Bajo la reflexión crítica se entiende que el docente reflexivo no puede ser ajeno a la realidad sociopolítica. Requiere tomar conciencia sobre consecuencias de los propios actos y coherencia en la toma de decisiones en el aula ya que estas deben ser acordes a los valores e ideales democráticos de la sociedad. La reflexión crítica incluye la consideración de cuatro elementos fundamentales:
a. Cuestionamiento de prejuicios y valores personales que influyen en la enseñanza.
b. Consideración consciente de las consecuencias y de las implicaciones éticas de las propias prácticas en el aprendizaje del estudiantado.
c. Examen de la forma en que las propias prácticas contribuyen a la equidad y la justicia social.
d. Ejercicio de una práctica profesional acorde a los valores democráticos y socialmente res- ponsable.

Las consideraciones propias de un reflexivo crítico serían: ¿Tienen mis estudiantes oportunidades diarias de éxito?, ¿se está excluyendo a alguien durante la práctica diaria?, ¿influyen los agrupamientos en las oportunidades de éxito?, ¿promueve mi práctica la equidad?

Dentro de la reflexión crítica, se puede encontrar un tipo de reflexión con entidad propia, la auto-reflexión. Este nivel se caracteriza porque el docente mantiene un diálogo consigo mismo y es similar a la reflexión dialógica (Hatton y Smith, 1995) o reflexión interior (York-Barr et al. 2001). Para Larrivee (2005) la auto-reflexión es un proceso de introspección y descubrimiento de la relación entre lo personal y lo profesional. Se describe como el examen de creencias, valores, expectativas y asunciones del docente sobre el proceso enseñanza-aprendizaje y sobre la educación en general, sus principios, objetivos y fines. También requiere la revisión de cómo la huella familiar y el condicionamiento cultural impacta en la práctica e influye en el comportamiento de los estudiantes. Algunas preguntas auto-reflexivas serían: ¿Por qué soy tan intolerante con el comportamiento inapropiado de este alumno?, ¿mis actos inhiben la participación de los estudiantes?, ¿favorezco de algún modo la falta de respeto?, ¿mis prejuicios influyen en la respuesta que doy ante este comportamiento? 
En trabajos posteriores, Larrivee (2008) valida una herramienta para evaluar el nivel de práctica reflexiva del profesorado y en la cual refleja los niveles reflexivos descritos anteriormente a través de distintos ítems. Intenta además superar la dificultad terminológica que supone aunar distintas nomenclaturas de niveles reflexivos. Su objetivo es que el estudiante en prácticas pueda comprobar su propio avance como practicante reflexivo hacia los niveles más altos e introspectivos a partir de ciertos facilitadores y de la continuidad en el ejercicio de la reflexión. La escala de Larrivee (incluida en el Anexo 1) ha sido utilizada y adaptada en numerosas investigaciones sobre práctica reflexiva (Husu, Toom y Patrikainen, 2008; Parkes y Kajder, 2010; Mackay y Tymon, 2013; Murphy y Ermeling, 2016). 


\section{Métodos para fomentar la práctica reflexiva.}

Kori et al. (2014) indagaron sobre los métodos utilizados con mayor frecuencia para incentivar la práctica reflexiva y concluyeron que la práctica reflexiva se promueve principalmente mediante herramientas tecnológicas y que estas herramientas se suelen combinar con otros apoyos basados en la interacción humana. Las TIC más empleadas en la práctica reflexiva según estos autores fueron el blog, el portfolio, los diarios online y la vídeo-grabación, mientras que los apoyos basados en la interacción humana fueron principalmente el refuerzo y la retroalimentación del tutor, los grupos de discusión y el análisis de incidentes críticos.

Winchester y Winchester (2011) observaron a su vez que la reflexión se trabajaba fundamentalmente a través de tres medios: la escritura, la observación y el diálogo. La reflexión a través de la escritura utiliza como soporte portfolios o eportfolios, blogs, diarios reflexivos en papel o e-diarios y otras fórmulas similares en las que se emplea el texto escrito. La observación puede realizarse en diferentes direcciones, por ejemplo, del tutor hacia el alumno, del alumno hacia el tutor o entre pares. También puede llevarse a cabo de forma grupal mediante el visionado de vídeos. Finalmente, al utilizar técnicas dialógicas se suelen realizar grupos de discusión y entrevistas en las que se pide a los participantes que opinen y reflexionen sobre su práctica, dichas entrevistas también pueden registrarse a través de grabadoras y ser utilizadas posteriormente para la reflexión grupal.

Los estudios que revisan la efectividad de una herramienta reflexiva frente a otra parecen concluir que, si bien existe preferencia por el uso de métodos de reflexión basados en la escritura, no parecen existir diferencias significativas de unas herramientas frente a otras (Kori et al., 2014). Sin embargo, cuando el uso de las reflexiones tiene como fin la investigación se recomienda fehacientemente triangular diversas fuentes para la obtención de datos (Crawford, O’Reilly y Luttrell, 2012; Granberg, 2010; Kim y Hannafin, 2011).

Según concluye Yaffe (2010), la fiabilidad de las herramientas reflexivas depende de asegurar la ética en su uso y en particular de garantizar la privacidad y la responsabilidad en el uso de la información que se recoge. Cuando el alumnado 
reflexiona sobre su experiencia, debe tener libertad para realizar críticas y valoraciones negativas sobre lo observado, para ello necesita tener la seguridad de que esa información no se vuelve posteriormente en su contra.

\subsection{Métodos que se apoyan en la tecnología}

Las herramientas tecnológicas actúan como facilitadores de la reflexión (McVee, Bailey y Shanahan, 2008) a la vez que mejoran la competencia digital (Mishra y Koehler, 2006). Entre las tecnologías de la información y la comunicación (TIC, en adelante) más frecuentemente utilizadas para la práctica reflexiva se encuentran el vídeo, el blog, el portfolio digital y el diario reflexivo online.

La grabación en vídeo resulta útil para contextualizar el aprendizaje y tomar conciencia de los hechos con posterioridad. Permite pausar y repetir la visualización por lo que facilita el análisis detallado y la obtención de mayor número de elementos para la reflexión. Algunos trabajos que utilizan el vídeo como instrumento de reflexión se pueden encontrar en Stockero (2008), Yaffe, (2010), Calandra, Brantley-Dias, Lee y Fox (2009), Bannink y Van Dam, (2007) o Leijen, Admiraal, Wildschut y Simon (2008).

El uso del blog permite acompañar las entradas reflexivas con imágenes, vídeos y enlaces de apoyo. Promueve además la interacción entre iguales y entre alumno-tutor al tener la posibilidad de dejar comentarios o incluso de realizar un blog reflexivo grupal. Entre los autores que han utilizado el blog como medio para la reflexión se encuentran Paulus y Spence (2010), Fischer, Haley, Saarinen, y Chretien (2011) y Granberg (2010).

En cuanto a las ventajas del uso del portfolio digital como herramienta reflexiva es que, junto al e-diario, son las herramientas que mejor permiten establecer conexiones entre teoría y práctica, entre conocimientos previos y nuevos. Además, el e-portfolio permite valorar posibles mejoras en las habilidades reflexivas a lo largo del tiempo. Investigaciones que utilizan el e-portfolio reflexivo se pueden encontrar en Çimer (2011), Fox, White y Kidd (2011) o Sung, Chang, Yu y Chang (2009). 


\subsubsection{El diario reflexivo online}

Los e-diarios han sido utilizados para fomentar la práctica reflexiva en numerosos campos de la educación superior como por ejemplo trabajo social (Rutter, 2006), medicina (Boenink, Oderwald, De Jonge, Van Tilburg y Smal, (2004)), psicología (Jucks, Schulte-Löbbert y Bromme, 2007) o magisterio (Otienoh, 2009; Moon 2006, 2010). La mayoría de estudios que utilizan el diario reflexivo online, lo hacen con el objeto de desarrollar y promover la práctica reflexiva entre el estudiantado tal y como puede revisarse en King y Kitchener (1994), Ross (1990), Collier (1999), Dobbins (1996), Yost, (1997), Yost, Forlanza-Bailey y Shaw (1999), Kember et al. (2000) y Boenink et al. (2004).

El diario online puede llevarse a cabo de manera interactiva y dialógica o de manera autobiográfica (Keating, 1993). El uso del diario de forma dialógica se inicia con la escritura individual del alumno en prácticas que reflexiona sobre algún aspecto de su experiencia en el aula. La reflexión es compartida posteriormente con el tutor, el supervisor o un compañero crítico quien dará algún tipo de retroalimentación al redactor del diario en forma de preguntas o comentarios críticos.

En el diario de tipo autobiográfico el autor conoce previamente algún indicador (por ejemplo, se le facilita un modelo de ciclo reflexivo) que le ayude a dirigir la mirada hacia ciertos aspectos de la dinámica del aula y de la enseñanza. Posteriormente se redactan las entradas en el diario plasmando las experiencias y las reflexiones. El feedback en este caso suele venir de forma más espaciada y habitualmente corre a cargo del tutor de prácticas.

Entre los beneficios y ventajas del uso del diario reflexivo online, los autores coinciden en que este:

a. Ofrece la oportunidad de analizar en profundidad la propia experiencia y el propio aprendizaje (Henderson, Napan y Monteiro, 2004).

b. Permite establecer conexiones entre teoría y práctica (Loo y Thorpe, 2002).

c. Facilita la exploración de los propios valores, miedos y creencias respecto al trabajo como docente (Carson y Fisher, 2006) y ayuda a canalizar estas emociones (Palding y Wilson, 
2002; Bell (2001).

d. Estimula el pensamiento crítico y mejora la resolución de problemas (Kerka, 2002; Chitpin, 2006).

e. Proporcionan un medio para establecer y mantener contacto con tutores y supervisores (Palding y Wilson, 2002; Morgan, Rawlinson y Weaver, 2006; Wolf, 2008).

Larrivee y Cooper (2005) destacan la importancia del diario reflexivo para promover la reflexión por encima de otras herramientas debido a que permite observar de forma objetiva los comportamientos del aula, ayuda a esclarecer problemas conceptuales y dudas profesionales, facilita el registro de incidentes críticos así como la identificación de relaciones causa-efecto entre los acontecimientos, descubre pensamientos, comportamientos y hábitos que el profesional ignoraba por lo que abre la posibilidad de trabajar en los conflictos internos que puedan surgir. El diario reflexivo permite hacer un seguimiento temporal de la evolución del alumno en prácticas y por lo tanto pone en evidencia patrones de comportamiento y estrategias de actuación poco exitosas.

Sin embargo, el empleo del e-diario requiere tomar ciertas precauciones para que la práctica reflexiva sea verdaderamente efectiva. Por ejemplo conviene evitar que el alumnado se centre excesivamente en su persona cuando redacte en el diario. Debe guardar equilibro entre las observaciones que hace sobre sí mismo y las referidas al aula, a otros docentes y a otros elementos escolares (Pihlaja y Holst, 2011; Sutherland, Howard y Markauskaite, 2010) así mismo el tutor debe asegurarse que el alumnado no se limita a describir la rutina diaria del aula y del centro sin mayor aportación (Thompson y Pascal, 2012; Thorpe, 2004). Autores como Blaschke y Brindley (2011) proponen una introducción progresiva al uso del e-diario reflexivo comenzando por utilizarlo en otras materias distintas al Practicum para afianzar su uso. Otra de las propuestas de estos mismos autores es comenzar utilizando facilitadores (orientaciones, refuerzos, guías) e ir retirándolos paulatinamente conforme el alumno despeje dudas sobre lo que se demanda y coja soltura en la práctica reflexiva. 


\subsection{Métodos basados en la interacción humana}

La interacción humana es un elemento fundamental para mejorar el pensamiento crítico especialmente cuando se utiliza en combinación con otro tipo de herramientas tecnológicas.

Los métodos reflexivos basados en la interacción humana que se utilizan con mayor frecuencia son tres: el apoyo por parte del tutor y/o supervisor, la interacción con los iguales y los métodos mixtos donde se interacciona tanto con los iguales como con el tutor, en este último caso destaca la técnica del análisis de incidentes críticos.

\subsubsection{Apoyo del tutor y/o supervisor}

Según Power (2012), cuando se pide al estudiante que reflexione a través de diarios o portfolios se suele generar cierta inseguridad respecto a aquello que se ha de redactar. No es extraño, por lo tanto, que el tutor proporcione una serie de andamiajes o apoyos interactivos que contribuyan a reducir la ansiedad frente a este tipo de tarea.

Las ayudas que proporciona el tutor pueden tener un carácter más genérico o más dirigido (Davis, 2004). Si se prestan ayudas genéricas, estas no proporcionan ninguna pista sobre los asuntos a reflexionar, sino que se refieren al acto reflexivo en sí, reforzando el acto de parar y pensar ante los acontecimientos del aula. Las instrucciones dirigidas, por el contrario, sí que modulan la forma de pensar y enfocan la atención hacia aspectos concretos del comportamiento o de los hechos. Davis señala que las instrucciones genéricas son más coherentes con el propósito de la práctica reflexiva ya que estimulan la visión de conjunto y a medio plazo favorecen la autonomía.

Existen diversas formas bajo las cuales el tutor puede ayudar a mejorar la reflexión del alumnado. Por un lado, puede proporcionar materiales facilitadores como guías predefinidas y ejemplos de textos reflexivos. También puede establecer dinámicas de retroalimentación y refuerzo verbal, cuestionando y dirigiendo la atención del alumno sobre aspectos que se han pasado por alto. En tercer lugar, mediante 
entrevistas reflexivas individuales, el tutor puede guiar al alumnado explorando sus creencias y valores, indagando sobre el impacto de los acontecimientos e instándole a buscar respuestas alternativas.

a. Guías predefinidas y textos reflexivos:

El tutor proporciona al alumnado una serie de textos reflexivos que suelen consistir en experiencias prácticas reales o ficticias y en los que se muestran una serie de dificultades, dilemas, decisiones y consecuencias relacionadas con la intervención en el aula o con la educación en general. A partir de estos textos el alumnado debe reflexionar y extraer sus propias conclusiones de forma argumentada. Se pueden consultar ejemplos de trabajos con textos reflexivos en Fox et al., (2011); Jucks et al. (2007) o Kim y Hannafin (2008).

Existe la posibilidad de facilitar al estudiantado una guía predefinida en la que consten ciertas indicaciones y cuestiones que le ayuden a estructurar la reflexión. Esta guía tiene como fin principal centrar la reflexión en aspectos contextuales importantes y llevarla hacia niveles pedagógicos o críticos. A su vez también consigue reducir la incertidumbre del alumnado sobre qué se espera de él. Investigaciones que utilizan guías como medio reflexivo se pueden encontrar en Papadopoulos, Demetriadis, Stamelos y Tsoukalas (2011), Chen, Kinshuk Wei y Liu (2011), Yaffe (2010) o Crawford, et al. (2012).

\section{b. Refuerzo y retroalimentación del tutor}

A través del refuerzo y la retroalimentación el tutor se incentiva la reflexión y se modela el comportamiento del estudiante llevándole a asumir más y mejor sus responsabilidades en el aula (Hourani, 2013).

Según Hubbs y Brand (2005) dar retroalimentación durante el proceso de escritura del diario es esencial para el estudiantado ya que no solo permite al tutor llevar un seguimiento más cercano de la evolución de su alumnado sino que es altamente motivador para este último comprobar que sus aportaciones son leídas y valoradas. 
Para que el refuerzo del tutor sea eficaz según Power (2012), lo idóneo es combinar la retroalimentación oral con la escrita y que ambas tengan marcado carácter formativo, de lo contrario el alumnado se limita a reflexionar de forma superficial para cumplir y superar la evaluación.

Crawford et al. (2012) encuentran que la retroalimentación directa del tutor es el método preferido por el alumnado para apoyar la reflexión y llevar seguimiento de su evolución. Sin embargo, la idoneidad de la retroalimentación según Hubbs y Brand (2005) choca frontalmente con la realidad de la ratio en la universidad. La cantidad de alumnado de Practicum junto a la obligatoriedad de llevar a cabo otro tipo de tareas universitarias, hacen que el tutor frecuentemente no pueda dar más de tres o cuatro refuerzos en el periodo de prácticas, hecho que repercute directamente en la calidad habitual de las reflexiones.

\section{c. Entrevistas reflexivas individuales}

La entrevista reflexiva es una de las herramientas más utilizadas para triangular datos recogidos a través de otras fuentes y aumentar así la validez de las investigaciones (Winchester y Winchester, 2011; Reguant, 2007; Lee, 2005; Shaw, 2013).

Habitualmente la entrevista suele realizarse al concluir el periodo de prácticas y es el tutor quien la realiza por ser la persona responsable del seguimiento del alumnado en prácticas aunque lo idóneo es que el entrevistador tenga formación o experiencia en este tipo de método (Cohen, Manion y Morrison, 2011). Así, previamente se debe crear un ambiente relajado y un clima de confianza entre entrevistador y entrevistado que facilite el diálogo fluido entre ambos.

El tipo de entrevista que se suele emplear es semiestructurada ya que este formato permite explorar de forma natural anécdotas, hechos y opiniones evitando tanto respuestas monosílabas como la excesiva dispersión respecto al objeto de la entrevista, en este caso, la reflexión sobre la práctica.

Finalmente, destacar que las entrevistas pueden ser grabadas y revisadas posteriormente junto al alumno para obtener un análisis más profundo de sus reflexiones. 


\subsubsection{Apoyo del grupo de iguales}

El apoyo entre iguales se hace efectivo a través de los grupos de discusión y en menor medida mediante la tutorización entre iguales.

En ambos casos, la clave está en la libertad que otorga la libre expresión entre compañeros con los que no existe un condicionante jerárquico, los cuales además están viviendo situaciones similares en sus respectivos centros de prácticas. Las reflexiones que se generan en los grupos de discusión difieren sustancialmente -en fondo y en forma- de las obtenidas mediante diarios y portfolios (Chen et al., 2011).

El apoyo entre iguales es fundamental para reconocer que la misma anécdota es compartida por el resto y que el proceso de aprendizaje está sucediendo de forma paralela en todos ellos. Cada uno reflexiona sobre aquellas experiencias que más le han llamado la atención y entre sí establecen comparaciones o vuelven a recordar momentos que en su día pasaron por alto, así, se enriquece el análisis de la propia experiencia, se refuerzan algunas concepciones educativas, y se cambian otras, se comparan diferentes metodologías de enseñanza y distintas estrategias de resolución de problemas (Rodrigues, 2013), se contrasta la expectativa con la realidad, se analizan fortalezas y debilidades y en definitiva, se potencia el pensamiento crítico (Sung et al., 2009).

\subsubsection{Apoyo mixto}

El apoyo mixto en la práctica reflexiva se refiere al análisis de situaciones en las cuales participa tanto el tutor y/o el supervisor como el grupo de iguales. La metodología más utilizada para ello es el análisis de incidentes críticos.

Un incidente crítico es una situación espontánea, generalmente desagradable, que ha sido experimentada por un profesional en relación a su trabajo y que supone un punto de inflexión en la vida de esa persona (Tripp, 1993, 1994; Keatinge, 2002; Wolf y Zuzelo, 2006). En el contexto educativo los incidentes críticos pueden ser hechos cotidianos que ocurren en la escuela, pero depende del significado que cada individuo les otorgue el que puedan clasificarse o no como 
tales (Angelides, 2001).

Cuando se trabaja con incidentes críticos, el estudiantado en prácticas se esfuerza por identificar hechos que suceden en el aula o en la escuela y que chocan con sus valores, su ética, su modo de entender la educación, sus expectativas y sus conocimientos previos.

El siguiente paso, una vez identificado el incidente, es realizar un pequeño análisis personal sobre lo ocurrido. Tripp (1994) propone un modelo de cuatro etapas para profundizar en el significado de los acontecimientos. En este proceso, en primer lugar el sujeto describe y explica los hechos. El segundo paso es establecer qué significado tiene la situación para la persona implicada y para ello se recomienda categorizar la experiencia en base a adjetivos polarizados (divertido o molesto, típico o atípico). En tercer lugar el estudiantado debe adoptar una posición personal frente a los hechos y por último, debe establecer un plan de actuación para próximas ocasiones.

Tras realizar la primera reflexión de forma individual, el incidente y las conclusiones se pueden compartir con el tutor y los iguales de forma que todos escuchan y comparten sus opiniones respecto al mismo hecho. Esto favorece que el estudiantado revise por segunda vez la anécdota bajo el prisma de los demás y contemple otras consideraciones y propuestas de intervención.

La técnica del incidente crítico proporciona un nivel de reflexión profunda en el profesorado novel a través del examen exhaustivo y multifacético de un evento (Griffin, 2003), permite conectar la teoría con la práctica y facilita la toma de decisiones frente a dilemas profesionales (Nilsson, 2009). Al ser compartido con el grupo, propicia tomar conciencia de que las vivencias individuales comparten cualidades genéricas con las experiencias de los iguales y que estos comparten a su vez las mismas dudas, intereses, miedos y satisfacciones (Larrivee y Cooper, 2005) 


\section{Críticas al paradigma del pensamiento reflexivo}

El paradigma de la práctica reflexiva se ha sometido a numerosas revisiones y críticas. En general, las críticas recibidas pueden agruparse en cuatro bloques: críticas referidas al concepto y la teoría de práctica reflexiva, críticas hacia la metodología empleada para fomentar la reflexión, críticas sobre los beneficios pedagógicos o profesionales que se le atribuyen y críticas de carácter ético.

\subsection{Críticas teórico-conceptuales}

La crítica más habitual que se le plantea a la práctica reflexiva es la falta de consenso entre autores a la hora de unificar criterios terminológicos con los que referirse a los conceptos derivados de este paradigma.

Finlay (2003) y Fendler (2003) coinciden en la sensación de que el concepto de reflexión se puede definir de uno u otro modo en función de las necesidades del investigador, el objeto de la investigación, el paradigma teórico al que se acoge o la metodología que se quiere emplear. Así, la reflexión puede consistir en una muestra de la propia conciencia, en un método para mejorar el desempeño, en una aproximación intuitiva a la práctica o en una estrategia para revisar y reparar injusticias sociales.

En la misma línea Beauchamp (2015) critica que aquello que unos autores denominan práctica reflexiva otros lo identifican como reflexión, reflexividad, pensamiento reflexivo o análisis reflexivo y la mayoría de dichos autores obvian profundizar en el significado implícito del término que emplean. El temor de los investigadores (Collin, et al., 2013; Galea, 2012; Correa-Molina, Collin, Chaubet y Gervais, 2010; Kinsella, 2009) es que la práctica reflexiva se convierta en un concepto a la carta cuyo significado desvirtúe el peso de las investigaciones que se deriven en este campo.

A este respecto, Finlayson (2015) examinó los cambios conceptuales sucedidos en la práctica reflexiva a lo largo de las últimas décadas. Los resultados de su trabajo sugieren que el significado del término práctica reflexiva se mantuvo constante desde 1938, cuando Dewey dotó de estructura formal la teoría de la práctica reflexiva, 
hasta mediados de 1980, momento en el que el paradigma racional perdió peso en educación en favor de concepciones humanistas. A partir de este momento se han sucedido de forma cíclica múltiples interpretaciones que han ido resaltando uno $u$ otro aspecto de la reflexión. Según Finlayson, en la actualidad la práctica reflexiva se considera un proceso personal en el que cada cual construye el modelo reflexivo que más le acerca a sus objetivos y fines profesionales.

Dentro del marco teórico de la práctica reflexiva también se ha sometido a crítica la clasificación de la reflexión por niveles. Según Collin et al. (2013) estructurar la reflexión según niveles que van desde lo superficial hasta lo crítico supone que hay un tipo de reflexión buena y otra mala. Para Collin et al. (2013) cualquier reflexión es útil independientemente del nivel en el que se la sitúe ya que el nivel de la reflexión que se alcanza guarda más relación con el contexto y las circunstancias pedagógicas que con la capacidad del individuo para reflexionar. La práctica reflexiva no debe identificarse como una jerarquía de niveles en la cual se deja atrás uno para alcanzar el siguiente, más bien se concibe como una estructura en paralelo, donde suceden distintas reflexiones, algunas de menor y otras de mayor calado.

Otra observación respecto a los vacíos teorico-conceptuales es la falta de investigación sobre la práctica reflexiva grupal frente al habitual enfoque del individuo que reflexiona en privado. La literatura existente (Noffke y Brennan, 2005; Gelfuso y Dennis, 2014, Zeichner, 1993) muestra claros beneficios de la reflexión colectiva frente a la individual en lo referido a su eficacia para modificar el contexto en el que origina el problema. Si no se atiende al entorno social de enseñanza, el individuo termina creyendo en la exclusividad de sus problemas cuando la realidad muestra que estos problemas suelen ser compartidos por el resto del profesorado. Según Zeichner (1993) cuando se toma conciencia de que un problema es colectivo, se revela que dicho problema tiene un origen estructural y/o sistémico. Esta toma de conciencia es un paso necesario para el cambio y el progreso en educación.

Una cuarta crítica pone de relieve que la teoría de la práctica reflexiva obvia toda cuestión relacionada con el contexto social en el que se realiza la reflexión. Quinn $(1988,2000)$ por ejemplo, deposita la responsabilidad de fomentar la reflexión crítica en la propia institución educativa en la que el alumnado realiza las prácticas. 
La reflexión no ocurre en el vacío sino en un contexto donde conviven aspectos ideológicos y políticos, por lo tanto no se puede tratar la reflexión como una colección de hechos neutrales y aislados. Una práctica reflexiva estrictamente centrada en el individuo despoja a la organización de responsabilidad, por lo tanto, cuestionar la política institucional es parte ineludible de la reflexión y debe fomentarse desde el propio contexto institucional.

Finalmente, a la teoría de la reflexión se le critica ignorar los aspectos emocionales e identitarios y concebir la práctica reflexiva como un mero ejercicio intelectual. Para superar esta cuestión Shoffner (2009) propone elaborar un enfoque teórico de carácter holístico, que tenga en cuenta la influencia de las emociones del maestro en su actuación en el aula. Klein (2008) escribe sobre la necesidad de un enfoque integrador y de que "la formación del profesorado debe reconocer la vida interior de los profesores, sus esperanzas, creencias, emociones, sentimientos y valores" (p. 119). Asímismo, Finlay (2008) expone que la reflexión es un proceso multidimensional en el que una de sus facetas incluye el autodescubrimiento. En la práctica reflexiva debe haber un equilibrio entre lo emocional y lo racional.

\subsection{Críticas a la metodología}

La primera crítica sobre la metodología a tratar es planteada por Moon (1999a) y Korthagen (2001), quienes abordan en sus trabajos la necesidad de hacer operativa la reflexión. Reclaman ambos a la comunidad científica la adopción de una serie acuerdos que permitan establecer qué tipo de conocimientos, habilidades y destrezas se buscan mediante la práctica reflexiva. En base a estos referentes tal y como respalda Pollard (2002), se podrán desarrollar métodos más efectivos para promoverla e instrumentos eficaces para evaluarla.

Esta demanda encuentra firme oposición en autores como Hobbs (2007) o Edwards y Thomas (2010) que consideran que no se puede reducir la práctica reflexiva a un conjunto de técnicas, competencias y habilidades a evaluar. Para estos autores, reflexión y evaluación son incompatibles. Cuando el alumnado sabe que va a ser evaluado deja de intentar ser genuino en sus reflexiones y pasa a responder en base a lo que cree que el profesor espera de él. Collin et al. (2013) a este respecto su- 
gieren que el objeto de evaluación no debe ser el estudiantado y sus reflexiones sino la eficacia y pertinencia de los mecanismos de apoyo utilizados. Si no sabemos con certeza si dichos mecanismos son adecuados, no es posible realizar una evaluación honesta del estudiante.

En cuanto a carencias metodológicas también se reprueba la falta de preparación previa del estudiantado para ejercer la práctica reflexiva. Durante su aprendizaje teórico en la universidad no se enseña ni se fomenta el uso de la reflexión sistemática ni tampoco se explican los fundamentos básicos de este tipo de práctica (Meierdirk, 2016). Esta falta de habilidad da lugar en el momento del Practicum a lo que Baker (1990) denomina "una casa de espejos", es decir, el estudiante solo es capaz de centrarse en sus pensamientos y preocupaciones, en el aquí y el ahora, en la inmediatez. Considera los elementos que rodean su práctica de forma aislada y parcial, sin percibir su complejidad y su globalidad.

Otros autores (Collin et al., 2013; Sikka y Timoštšuk, 2008) abordan la deficiente preparación del tutor que pide a su alumnado que reflexione. El tutor que demanda reflexiones sobre la práctica tiene una serie de responsabilidades frente al alumnado. Estas van desde el mantenimiento y cuidado de las interacciones entre ambos hasta la habilidad para saber gestionar posibles emociones que surjan desde la reflexión.

Walkington (2005), por ejemplo, examina cómo influye la relación entre el supervisor del centro y el alumnado en la práctica reflexiva. Encuentra que la comunicación fluida y la confianza entre ambos influyen notablemente en las reflexiones del estudiante y lo hace aún más en lo referido al desarrollo de la identidad profesional de este.

Por otra parte Brookfield (1990) hace hincapié en la necesidad de contar con un tutor que sepa gestionar adecuadamente el impacto emocional profundo que puede causar en el estudiantado la reflexión crítica. En sus propias palabras:

Cuestionar los supuestos bajo los que actuamos y explorar ideas alternativas no sólo es difícil, sino también psicológicamente explosivo (...) Cuando 
estos supuestos explotan toda la estructura de nuestro mundo se desmorona. Por lo tanto, los educadores que fomentan el aprendizaje transformador son expertos en demolición psicológica y cultural (p. 178).

Así, la propuesta frente a la problemática de la preparación del docente pasa por suplir esta carencia mediante formación. Una formación en la que según Valli (1992) el tutor debe tomar consciencia sobre las consecuencias del tipo de práctica que está fomentando y aprender a reconocer y afrontar los posibles conflictos emocionales que el alumnado va a tener a lo largo de dichas prácticas.

Zeichner (1990) considera que el tutor debe ajustar sus expectativas sobre la práctica reflexiva a la realidad. Dicha realidad es que ni el periodo de prácticas dura el tiempo suficiente como para que la reflexión produzca cambios excepcionales en el estudiante ni el estudiante está siempre en condiciones de elegir entre un aprendizaje a medio plazo asentado en la reflexión o un conocimiento que responde a la demanda del aula de forma inmediata.

Las observaciones de Zeichner (1990) continúan abordando otro de los inconvenientes de la práctica reflexiva: se necesita tiempo y dedicación para desarrollar el hábito reflexivo y por lo tanto, se resta tiempo para la adquisición de otras destrezas igualmente importantes. Tampoco se puede sobrecargar al alumnado con un exceso de tareas, ya que este debe ajustarse a las demandas de sus prácticas y a las exigencias de la universidad. Se ha de encontrar un equilibrio entre el tiempo dedicado a la reflexión y el dedicado al resto de tareas del Practicum.

\subsection{Críticas a los fines de la reflexión}

El tercer tipo de crítica que recibe la práctica reflexiva se plantea de forma pionera por Gore y Zeichner (1991) y se relaciona con los fines emancipadores que se promueven a través de la reflexión.

Según estos autores y según recoge Zeichner (1993) conforme se avanza en el desarrollo de la práctica reflexiva se crea la ilusión de realizar prácticas emancipadoras, pero de forma sutil se sigue conservando la dependencia hacia el maestro. 
En este caso, el supervisor que tutoriza al alumno en su estancia de prácticas suele inconscientemente favorecer y sugerir un tipo de práctica acorde a sus propias experiencias y creencias. Esto convierte la reflexión en un acto de validación de situaciones dirigidas por otros.

Para Galea (2012) la práctica reflexiva se ha convertido en una serie de patrones rígidos que conducen al practicante hacia un ideal de profesorado que poco tiene de emancipador y rupturista. La práctica reflexiva se hace rutinaria y fomenta la homogeneidad y la estandarización de los resultados de aprendizaje.

Desde esta misma posición, Usher y Edwards (2007) consideran que cuanto más se intenta regular la reflexión más se cae bajo las imposiciones del sistema. La práctica reflexiva regulada en exceso deja de resultar empoderadora y fortalece de forma solapada la identidad docente predominante.

\subsection{Críticas éticas}

En este bloque dos son las críticas principales que se realizan. La primera de ellas cuestiona la ética de obligar al estudiantado a manifestar a través de la reflexión sus debilidades e inseguridades. La segunda crítica está relacionada con la garantía de confidencialidad de aquellos documentos o conversaciones en los que el estudiantado reflexiona sobre aspectos negativos de su experiencia.

Respecto a la primera crítica Fook (2010) manifiesta que revelar las propias debilidades y temores puede perjudicar emocionalmente al alumnado si el tutor no sabe gestionar adecuadamente estas inseguridades. El profesorado debería abstenerse de solicitar a su alumnado que reflexione si no está suficientemente capacitado para enfrentarse a emociones emergentes de la práctica, de lo contrario, según Yip (2006) las consecuencias pueden ser devastadoras, por ejemplo, un estudiante especialmente crítico con su desempeño podría socavar su autoestima y bloquear su aprendizaje.

En cuanto a la segunda crítica Ghaye (2007) señala que es cuestionable evaluar portfolios o diarios reflexivos y debería ser opcional para el alumnado reve- 
lar el producto de sus reflexiones. El derecho a la intimidad del alumnado debe primar desde el momento en que sus juicios pueden contener aspectos desagradables o emocionalmente negativos no solo para el alumnado sino también para el propio tutor que los valora.

Finlay (2008) apunta hacia otra dirección dentro del derecho a la intimidad del alumnado y es el uso y la divulgación que van a tener sus reflexiones dada la posibilidad mencionada anteriormente de que estas no sean complacientes con la institución (el centro educativo, la universidad) o con personas involucradas en su práctica (alumnado, familias, tutores y supervisores). Esta observación no se dirige solo al tratamiento de datos para la investigación sino también a la posibilidad de utilizar la información para realizar debates mediante grupos de discusión o evaluaciones interjuez entre otras posibilidades. El consentimiento informado en todos estos casos debería según Finlay (2008) ser un trámite de obligado cumplimiento. 


\section{Síntesis del marco teórico}

A lo largo de las páginas anteriores se han desarrollado de forma extensa los antecedentes que rodean al movimiento de la práctica reflexiva.

En primer lugar, se ha examinado la tendencia marcada por el Espacio Europeo de Educación Superior (EEES) en materia de educación a partir del Plan Bolonia, bajo el cual se determina la adquisición de competencias como elemento principal de capacitación en las titulaciones universitarias, hecho que afecta a la configuración de las titulaciones españolas. Entre las competencias a adqurir según el EEES se incluye la competencia reflexiva y en el caso de la titulación de Grado de Maestro en Educación Primaria (GMP) se señala la asignatura de Practicum como idónea para trabajar dicha competencia.

Seguidamente se ha abordado el origen y evolución del movimiento de la práctica reflexiva, reconociendo las aportaciones de John Dewey y Donald Schön como precursores en dotar de estructura formal al discurso reflexivo en educación. Tras estos autores se ha analizado la evolución del concepto de reflexión según distintas escuelas de pensamiento y se ha revisado los principales modelos de práctica reflexiva.

Se ha abordado seguidamente el debate en relación a los niveles de reflexión en términos de las funciones cognitivas empleadas y se ha reconocido que, al menos, existe un tipo de reflexión superficial, uno de carácter pedagógico y un tercer nivel de carácter crítico y que los tres niveles suceden de forma paralela en el individuo.

Se ha expuesto también los métodos e instrumentos utilizados con mayor frecuencia para fomentar la reflexión en función del uso o no de tecnología. Dentro del grupo que utiliza las TIC destaca el empleo de e-diarios o e-portfolios mientras que por el otro lado se suelen combinar técnicas como el incidente crítico, el feedback docente o los grupos de discusión.

El marco teórico ha concluido revisando algunas de las críticas más habituales que se le hacen al movimiento de la práctica reflexiva.

A continuación se presenta el bloque dedicado a describir el marco experimental en el que se pretende poner a prueba algunos de los postulados descritos en el marco teórico en relación al contexto particular del Practicum I del GMP de la UJI. 



\section{Parte III. Marco experimental}

\section{Contexto de la investigación}

En base a los datos expuestos en la Parte II del trabajo a continuación se detalla el contexto de la investigación y el planteamiento del problema a investigar.

La investigación se circunscribe al Practicum I de la titulación de Grado de Maestro en Educación Primaria en la Universitat Jaume I de Castellón y al alumnado que cursa esta materia.

Para el desarrollo de este punto de la tesis se ha tomado como referencia los artículos de García, Pérez, Ripollés, Salvador y Solsona (2007) y Sánchez-Tarazaga, Mateu, Ruiz y García, (2015) todos ellos docentes de la UJI implicados directamente en la adaptación del Practicum de Maestro a la estructura de los estudios de Grado. En el artículo de 2007 se recogen los cambios que durante ese periodo se estaban introduciendo en el Practicum modificando el plan anterior mientras que en el artículo de 2015 se plasman varias conclusiones basadas en el seguimiento y la evaluación del Practicum algunos años después de su implementación. Así mismo, para este apartado también se toma como referencia la Guía Docente del Practicum I para Grado en Maestro Primaria en el curso académico 2016-2017. La Guía Docente se puede consultar íntegramente en el Anexo 2.

Previamente al Plan Bolonia, el Practicum en la UJI se estructuraba en tres cursos en los que se iba aumentando progresivamente la cantidad de horas prácticas: Practicum I, de una semana de duración, Practicum II, de cuatro semanas y Practicum III, de siete semanas. Con el nuevo plan de estudios se amplían las horas dedicadas al Practicum y pasa a distribuirse íntegramente entre dos cursos (diez semanas para el Practicum I en tercer curso de Grado y quince semanas para el Practicum II durante el cuarto curso de Grado). En ambos casos el periodo de prácticas se realiza durante el segundo semestre del curso, entre enero y mayo. En particular durante el curso 2016-2017, el Practicum I se lleva a cabo desde el 1 de marzo de 2017 hasta el 24 de mayo de 2017. El horario lectivo a cumplir es el propio del centro al que se incorpore 
el alumnado, siendo el más habitual el de la jornada partida comprendida entre las 9-13 horas y entre las 15-17 horas.

La estructura organizativa del Practicum en la UJI se basa en el trabajo conjunto de tres entidades: la Comisión Mixta, la Oficina de Inserción Profesional y Estancias en Prácticas (OIPEP en adelante) y el equipo de Coordinación.

La Comisión Mixta está integrada por representantes de la Universidad, de la Conselleria d Educació y de los centros escolares. Esta Comisión tiene como funciones principales la validación tanto de los maestros supervisores como de los tutores, la coordinación de la demanda de plazas de estudiantes por parte de los centros educativos hacia la Universidad y el establecimiento de un documento de prácticas en el cual se identifican derechos y deberes del estudiantado, supervisores y tutores.

La OIPEP, por su parte, se encarga de gestionar la elaboración de los proyectos formativos, coordinar la oferta de plazas al alumnado, ofrecer apoyo al estudiantado y a los tutores y resolver posibles incidencias durante la estancia en prácticas. En particular, para organizar la selección de las plazas en los centros se utiliza una plataforma informática donde el alumnado elige el orden de preferencia de los centros donde desea realizar las prácticas. Las plazas son finalmente asignadas siguiendo el criterio de nota del expediente académico.

La tercera entidad de gestión es el Equipo de Coordinación de Practicum. Este equipo está constituido por un grupo de docentes que realizan funciones de coordinación y actúa de enlace entre la Universidad, los centros educativos y Conselleria. Corresponde al equipo coordinador realizar en cada curso reuniones informativas previas para alumnado, profesorado y escuelas. Estos equipos, a su vez, disponen de distintos medios para interactuar tanto con el alumnado como con el profesorado tutor: además de realizar tutorías presenciales, disponen de un correo electrónico específico para el Practicum, el Sistema de Información Académica (SIA) con la guía didáctica de las prácticas y un aula virtual, basada en la plataforma Moodle, en la que se exponen diversos materiales de consulta y se resuelven dudas e incidencias generales a través de foros habilitados para ello. 
Una vez realizado el proceso de asignación de centros y tutores corresponde a cada tutor establecer contacto con cada alumno asignado y comenzar así sus funciones de información, acompañamiento, seguimiento, supervisión, solución de incidencias y evaluación, todas ellas en coordinación con el alumnado de Practicum y el maestro supervisor del centro educativo al que se incorpora.

En cuanto al alumnado, cuando inicia el Practicum I tiene atribuidas de forma orientativa una serie de actividades con unos fines determinados que debe ir realizando conforme se desarrolla la estancia en prácticas. Estas actividades y sus objetivos se resumen en la Tabla 7 y suponen una inmersión progresiva en la vida del centro y en el aula hasta llegar a la planificación de unidades didácticas y de actividades pedagógicas diarias.

\section{Tabla 7}

Actividades y objetivos del Practicum I

\begin{tabular}{|l|l|}
\hline ACTIVIDADES & OBJETIVOS \\
a) Adaptación/preparación (1 semana) & Observar y analizar el centro y la clase. Durante los primeros de \\
esta primera semana, el alumnado estará bajo supervisión de \\
algún miembro del equipo directivo que le facilitará los docu- \\
mentos necesarios para entender las singularidades del centro. \\
Posteriormente se le asignará una clase donde comenzará la \\
observación y el análisis correspondiente. \\
b) Colaboración (2 semanas) \\
Participar, activamente o como simple observador en las reu- \\
niones o sesiones de trabajo de los equipos docentes, si estos lo \\
consideran conveniente. \\
Estudiar los programas y objetivos de diversas publicaciones re- \\
feridas a la etapa y niveles en los que desarrolalrá las prácticas \\
Planificar y desarrollar progresivamente unidades temáticas de \\
todas las áreas, bajo la supervisión del maestro. Será preceptivo \\
realizar esta tarea y entregar al tutor una programación de esta \\
fase.
\end{tabular}

Nota: Recuperado de Guía Docente del Practicum I de Grado de Maestro de Educación Primaria para el curso 20162017.

En cuanto al seguimiento por parte del tutor durante todo este periodo, si bien están establecidas con carácter obligatorio la realización de al menos tres reuniones con el centro que acoge al estudiantado y tres reuniones con el propio 
estudiante, se contempla, a criterio del profesorado, la posibilidad de utilizar cualquier otro instrumento que considere adecuado para llevar a cabo dicho seguimiento, como por ejemplo la realización de tutorías y seminarios individuales o grupales, la presentación de tareas de planificación o partes de la programación que se vayan realizando, la elaboración de diarios online o físicos, etc.

La evaluación final de Practicum se obtiene en base a diferentes elementos tales como la asistencia y participación en reuniones y seminarios con el tutor, la presentación de algún tipo tarea o actividad de seguimiento, la presentación de la memoria final y especialmente, la valoración emitida por el maestro supervisor del centro educativo. Se puede ver el desglose de pruebas y la ponderación de su valor en la evaluación en la Tabla 8.

\section{Tabla 8}

Evaluación del Practicum I y // según el tipo de prueba

\begin{tabular}{|l|l|}
\hline TIPO DE PRUEBA & PONDERACIÓN \\
Informe del maestro-supervisor & $50 \%$ \\
\hline & \\
Tutor UJl: & \\
Memorias e informes de prácticas & \\
Participación en Seminarios y/o tutorías que el profesorado organiza para su \\
estudiantado.
\end{tabular}

Nota: Recuperado de Guía Docente del Practicum I par el Grado en Maestro de Educación Primaria, curso 2016-2017.

El compromiso de la Universidad con la realización de unas prácticas reflexivas se establece a partir del Marco Español de Calificaciones para la Educación Superior (MECES) que establece como competencia específica para el Practicum I y II "Participar en la actividad docente y aprender a saber hacer, actuando y reflexionando desde la práctica (P04)". 
Para evaluar la adquisición de esta competencia el instrumento por excelencia es la memoria final de prácticas, descrita en la Guía Docente 2016-2017 de la siguiente forma:

La memoria no es solo un resumen de las actividades realizadas en el aula y en el centro a lo largo del periodo de prácticas. Ha de ser una autoevaluación, una reflexión y un análisis de los aspectos didácticos y metodológicos relacionados con el clima de clase, los problemas encontrados y las soluciones aportadas. Recogerá de forma técnica y reflexiva la realidad del aula y del periodo de actuación y evitará el carácter meramente descriptivo (p. 16).

Así, en la Guía de Prácticas se propone un esquema con distintos apartados para realizar la memoria (ver Anexo 2) y en cada uno de ellos se menciona de forma explícita la necesidad del alumnado de realizar una reflexión y una valoración crítica sobre ese momento concreto de la estancia, comenzando con la primera semana de adaptación y contextualización y concluyendo con la revisión global de toda la experiencia una vez finalizado el Practicum.

En el artículo de Sánchez-Tarazaga et al. (2015) también se menciona el compromiso desde el equipo de coordinación con la realización de un Practicum reflexivo, compromiso que se materializa a través de diversas acciones formativas dirigidas a tutores, supervisores y alumnado conjuntamente. En estas acciones se promueve para las tres partes implicadas la realización de diarios reflexivos que permiten llevar a cabo un seguimiento y ofrecer una retroalimentación con cierta periodicidad. Se promueve asimismo el empleo de seminarios y tutorías con el alumnado como espacio para el análisis reflexivo de incidentes, dudas y experiencias que surjan durante la estancia en prácticas. Sin embargo, todas estas iniciativas se establecen a modo de recomendación, dando libertad a cada tutor para acogerse o no a estas directrices. Así, no se puede afirmar de forma generalizada que todo el alumnado realiza un Practicum donde el eje del aprendizaje es la reflexión.

Por otro lado, la presente investigación se lleva a cabo seis años después de adaptar el plan de estudios del GMP al Plan Bolonia y de forma paralela a la evaluación externa de dicho plan. Como resultado de la mencionada evaluación se ha 
detectado en las distintas áreas del Departamento de Educación, la necesidad de mejorar varios aspectos estructurales del plan académico original para adaptarlo mejor a las demandas de la profesión docente. El nuevo diseño de la titulación, que se implementará en el curso 2018-2019, toma como referencia para las prácticas modelos formativos integradores como el de la Universitat de Lleida (Coiduras, Isus y Del Arco, 2015) e incorporará cambios que afectan a la estructura del Practicum de manera que los créditos destinados a la realización de prácticas en centros educativos se distribuirán de forma progresiva desde segundo a cuarto curso estableciendo un sistema dual que combinará teoría y práctica. Este hecho supone una oportunidad única para potenciar un estilo de prácticas de carácter reflexivo. 


\section{Planteamiento del problema}

El planteamiento del problema es el núcleo central de la investigación en torno al cual se encauza la toma de decisiones posterior con el fin de dar respuesta a dicho problema. Explica González (2007) que este primer acercamiento no debe resultar una camisa de fuerza, sino que debe permitir una aproximación abierta y flexible a la investigación (p. 119).

A través de la bibliografía revisada se pone de manifiesto que la práctica reflexiva sistematizada beneficia al docente en diferentes aspectos: contribuye a establecer nexos entre teoría y práctica, fomenta la toma de conciencia respecto a la realidad educativa, promueve la introspección y el mayor conocimiento sobre uno mismo, mejora la actuación ante la realidad del aula, contribuye a la formación permanente del profesorado y permite al individuo reflexivo participar en la construcción de una sociedad más igualitaria y crítica.

En numerosas universidades europeas los planes de estudio dirigidos a pregraduados en el área de educación incluyen asignaturas específicas para trabajar la práctica reflexiva vinculada a las prácticas externas. En España no existen materias concretas donde se trabaje esta competencia de forma exclusiva pero el modelo académico sí establece que la competencia reflexiva se fomente transversalmente en todas las asignaturas de forma que al realizar el Practicum, es decir, al tener contacto por primera vez con la realidad del aula, el alumnado debería estar en disposición tanto de aplicar sus conocimientos como de realizar reflexiones respecto a dicha realidad.

En la Universitat Jaume I, entre el profesorado encargado de coordinar y gestionar las prácticas externas, existe cierto compromiso con la promoción de un Practicum que incluya la reflexión como eje vertebrador de los aprendizajes y las experiencias adquiridas. De ese modo se persiguen dos objetivos, aumentar la calidad de las prácticas y proporcionar una formación integral que no se limite a desarrollar saberes referidos a conocimientos y habilidades -sin duda imprescindibles- sino también a perfilar otros saberes relacionados con la actitud crítica hacia la profesión. 
Con motivo de la próxima reestructuración en los planes de estudio del GMP en la UJI, el Practicum se va a ver afectado en toda su estructura. El nuevo modelo concibe la realización de prácticas y el contacto directo con el aula desde el segundo curso. Es esta la ocasión por lo tanto de reafirmar e impulsar el mencionado compromiso con la práctica reflexiva. Para ello es preciso contar con información preliminar que establezca un marco de actuación y fundamente las decisiones que se tomen al respecto de forma lo más objetiva posible.

Uno de los propósitos del presente trabajo es proporcionar evidencias sobre cómo se puede fomentar el pensamiento reflexivo del estudiantado de GMP durante la realización del Practicum I. 


\section{Objetivos}

El objetivo general de esta investigación es analizar el impacto que una intervención específica puede tener en la reflexión de los estudiantes de Practicum I del Grado de Maestro en Educación Primaria.

Este objetivo general se puede concretar a través de los siguientes objetivos específicos:

1. Indagar sobre los conceptos de reflexión, práctica reflexiva, niveles de reflexión y evaluación de la reflexión, en su devenir histórico hasta las aproximaciones conceptuales más recientes.

2. Identificar el nivel de reflexión del alumnado de Practicum I del GMP.

3. Introducir y valorar diferentes estrategias que fomenten la práctica reflexiva en diferentes momentos del Practicum I.

4. Aplicar diferentes metodologías para el registro y análisis de producciones de una muestra de alumnado seleccionada e indagar sobre su eficacia.

5. Examinar aquellos temas que preocupan al alumnado del GMP a la hora de enfrentarse por primera vez a las prácticas de carrera.

6. Proponer una serie de recomendaciones para promover un Practicum reflexivo. 


\section{Preguntas de investigación}

Debido al carácter interpretativo de la investigación cualitativa, las cuestiones de partida están formuladas como preguntas abiertas. Cada cuestión está relacionada con uno de los objetivos específicos mencionados en el punto anterior.

1. ¿Qué papel desempeña la práctica reflexiva en la formación de los maestros de educación primaria? (Objetivo 1)

2. ¿Cuál es el estado actual de la cuestión respecto a la práctica reflexiva? (Objetivo 1)

3. ¿Ha desarrollado el alumnado de tercer curso del Grado de Magisterio en Educación Primaria la competencia reflexiva cuando se enfrenta al Practicum I? (Objetivo 2)

4. ¿Se puede desarrollar el pensamiento reflexivo crítico a través de una intervención específica? (Objetivo 3)

5. ¿Qué metodología resulta de mayor utilidad para generar reflexiones críticas? (Objetivo 4)

6. ¿Cómo podemos utilizar las TIC para favorecer la reflexión durante el Practicum? (Objetivo 4)

7. ¿Qué tipo de cuestiones educativas pone de manifiesto el alumnado a través de la práctica reflexiva? (Objetivo 5)

8. ¿Cómo podemos promover un Practicum más reflexivo y crítico durante la formación previa en las aulas de la Universidad? (Objetivo 6) 


\section{Diseño de la investigación}

El término diseño en el marco de una investigación cualitativa se refiere al abordaje general que se utiliza en el proceso de investigación (Salgado-Lévano, 2007). El diseño, según esta autora, debe ser flexible, abierto y debe permitir su ajuste en función de las condiciones del escenario o ambiente.

Por su parte, Denzin y Lincoln (2011) definen el diseño de la investigación como "un conjunto flexible de directrices que conectan los paradigmas teóricos, en primer lugar, con las estrategias de investigación y, en segundo lugar, con los métodos para recopilar material empírico" (p. 14).

Por lo tanto, en el marco de esta tesis, el diseño de la investigación se concibe como el plan mediante el cual se va a disponer de las herramientas y los procedimientos más adecuados para conseguir los objetivos que se han determinado y para dar respuesta a las preguntas de investigación planteadas. El resumen del mencionado diseño se expone en la Tabla 9.

\section{Tabla 9}

Resumen de los elementos que determinan el diseño de la investigación

\begin{tabular}{|c|c|c|}
\hline OBJETO DE ESTUDIO & \multicolumn{2}{|c|}{$\begin{array}{l}\text { El pensamiento reflexivo del estudiantado de Grado de Magisterio en Educación Primaria } \\
\text { durante la realización del Practicum I. }\end{array}$} \\
\hline PROBLEMA DE INVESTIGACIÓN & \multicolumn{2}{|c|}{ Cómo se puede fomentar el pensamiento crítico del alumnado en el momento del Practicum I. } \\
\hline OBJETIVOS & General & $\begin{array}{l}\text { Analizar el impacto que una intervención específica puede tener en la } \\
\text { reflexión de los estudiantes de Practicum I del Grado de Maestro en } \\
\text { Educación Primaria. }\end{array}$ \\
\hline & Específicos & $\begin{array}{l}\text { 1. Indagar sobre los conceptos de reflexión, práctica reflexiva, niveles de } \\
\text { reflexión y evaluación de la reflexión, en su devenir histórico hasta las } \\
\text { aproximaciones conceptuales más recientes. } \\
\text { 2. Identificar el nivel de reflexión del alumnado de Practicum I del GMP. } \\
\text { 3. Introducir y valorar diferentes estrategias que fomenten la práctica } \\
\text { reflexiva en diferentes momentos del Practicum I. } \\
\text { 4. Aplicar diferentes metodologías para el registro y análisis de produccio- } \\
\text { nes de una muestra de alumnado seleccionada e indagar sobre su eficacia. } \\
\text { 5. Examinar aquellos temas que preocupan al alumnado del GMP a la hora } \\
\text { de enfrentarse por primera vez a las prácticas de carrera. } \\
\text { 6. Proponer una serie de recomendaciones para promover un Practicum } \\
\text { reflexivo. }\end{array}$ \\
\hline
\end{tabular}




\begin{tabular}{|c|c|c|}
\hline PARADIGMA & \multicolumn{2}{|l|}{ Socio-crítico } \\
\hline MÉTODO & \multicolumn{2}{|l|}{ Estudio de caso } \\
\hline \multirow[t]{4}{*}{$\begin{array}{l}\text { CRITERIOS DE CALIDAD } \\
(L I N C O L N \text { Y GUBA, 1985) }\end{array}$} & Credibilidad & $\begin{array}{l}\text { - Triangulación de instrumentos de recogida de información. } \\
\text { - Transcripción rigurosa de las entrevistas. } \\
\text { - Juicio interjueces para validar la entrevista. } \\
\text { - Grupo control. }\end{array}$ \\
\hline & Transferencia & $\begin{array}{l}\text { - Descripción detallada del diseño de investigación. } \\
\text { - Saturación de la información. }\end{array}$ \\
\hline & Dependencia & $\begin{array}{l}\text { - Pertinencia de la muestra. } \\
\text { - Identificación y descripción de las técnicas de análisis de datos. } \\
\text { - Generalización de resultados en la población de la que se extrae la } \\
\text { muestra. }\end{array}$ \\
\hline & Confirmabilidad & $\begin{array}{l}\text { Triangulación de datos. } \\
\text { Postura del investigador: supervisión, asesoramiento y guía. } \\
\text { Inexistencia de conflicto de interés. }\end{array}$ \\
\hline SELECCIÓN MUESTRAL & \multicolumn{2}{|c|}{$\begin{array}{l}\text { Muestreo no probabilístico, intencional y basado en criterios. } \\
\text { Muestra: Estudiantes de tercer curso matriculados en Practicum I del Grado de Maestro en } \\
\text { Educación Primaria de la UJl. }\end{array}$} \\
\hline $\begin{array}{l}\text { MÉTODOS DE RECOGIDA DE } \\
\text { INFORMACIÓN }\end{array}$ & \multicolumn{2}{|c|}{$\begin{array}{l}\text { Entrevista semiestructurada. } \\
\text { Diarios online (e-diarios). }\end{array}$} \\
\hline TÉCNICA DE INVESTIGACIÓN & \multicolumn{2}{|c|}{ Análisis de contenido. } \\
\hline INSTRUMENTOS DE ANÁLISIS & \multicolumn{2}{|c|}{ Software de análisis de datos cualitativos MaxQDA V.12 } \\
\hline PROCEDIMIENTO & \multicolumn{2}{|c|}{$\begin{array}{l}\text { 1. Definición de la investigación. } \\
\text { 1.1 Identificación del problema, contextualización. } \\
\text { 1.2 Objetivos. } \\
\text { 1.3 Preguntas de investigación. } \\
\text { 2. Búsqueda de fundamentación teórica. } \\
\text { 3. Desarrollo de la investigación. } \\
\text { 3.1 Selección de la muestra. } \\
\text { 3.2 Intervención y seguimiento. } \\
\text { 3.3 Aplicación de los instrumentos de recogida de información. } \\
\text { 4. Análisis de los datos obtenidos. } \\
\text { 5. Resultados y discusión. }\end{array}$} \\
\hline \multirow[t]{2}{*}{ CONCLUSIONES } & $\begin{array}{l}\text { Dificultades y } \\
\text { limitaciones }\end{array}$ & $\begin{array}{l}\text { En relación a la fundamentación teórica: falta de acuerdo terminológico. } \\
\text { En relación a la selección de la muestra: } \\
\text { mortandad experimental y generalización de resultados. }\end{array}$ \\
\hline & $\begin{array}{l}\text { Consideraciones } \\
\text { éticas }\end{array}$ & $\begin{array}{l}\text { Uso adecuado de fuentes documentales. } \\
\text { Consentimiento informado. } \\
\text { Transparencia en el tratamiento de datos y conclusiones. }\end{array}$ \\
\hline
\end{tabular}


A continuación, se desarrollan y justifican las variables del diseño.

\subsection{Paradigma y perspectiva teórica}

El concepto de paradigma propuesto por Kuhn en 1962 posibilitó en el mundo de la investigación establecer diferencias entre distintos enfoques teóricos y metodológicos (Contreras, 2004). Según este autor se entiende como paradigma las "realizaciones científicas universalmente reconocidas que, durante cierto tiempo, proporcionan modelos de problemas y soluciones a la comunidad científica" (p. 43).

Partiendo de esta conceptualización, en el ámbito pedagógico y educativo existe alto grado de consenso (Salgado-Lévano, 2007; Alvarado y García, 2008; Quesada y González, 2010) en distinguir como dominantes tres paradigmas, el paradigma positivista, el interpretativo y el socio-crítico.

El paradigma positivista, identificado también como cuantitativo, racionalista o empirista suele ser el más aceptado en investigación cuando se habla de Ciencias Naturales, pero cuando se trata de Ciencias de la Educación, tanto las condiciones del contexto como los elementos que se examinan y los fines que se persiguen hacen que este paradigma resulte insuficiente o inadecuado (Ricoy, 2006).

Respecto al paradigma interpretativo y el socio-crítico, ambos se suelen asociar a la investigación cualitativa.

El primero de ellos, también reconocido como naturalista, constructivista, interpretativo, fenomenológico, hermenéutico, humanista o etnográfico, incide en el análisis de las acciones humanas y de las relaciones sociales para describirlas y otorgarles un significado que acerque a su comprensión.

El paradigma socio-crítico, denominado a su vez transformativo, dialéctico o participativo, se asemeja notablemente al paradigma interpretativo en lo referido a aspectos metodológicos y conceptuales, pero incorpora además una llamada a la acción, una necesidad de modificar la estructura de dichas relaciones con un fin emancipador. 
En la Tabla 10 se muestran de forma esquematizada las dimensiones clave del paradigma socio-crítico.

\section{Tabla 10}

Dimensiones clave del paradigma socio-crítico

\begin{tabular}{l|l}
\hline DIMENSIONES & Sociocrítico- Transformativo \\
\hline FUNDAMENTOS & Teoría crítica \\
\hline FUNCIÓN & Transformar la realidad educativa con la participación consciente de los sujetos implicados. \\
\hline RECONOCIMIENTO DE LA & La práctica es teoría en acción. \\
REALIDAD EDUCATIVA & Integrados en la realidad educativa, comprometidos con la realidad y su cambio. \\
\hline SUJETOS & Concebido en el desarrollo, dinámico, participativo, consensuado \\
\hline DISEÑO DE LA INVESTIGACIÓN & Transformativo, participativo \\
\hline PROBLEMA DE INVESTIGACIÓN & Cobservación participante, etnográficos, tormenta de ideas, estudios de casos, modela- \\
\hline MÉTODOS Y TÉCNICAS & Decididas según intereses de los participantes \\
\hline MUESTRAS & Análisis grupal de los participantes, comparaciones, consenso \\
\hline PROCESAMIENTO DE DATOS & Contextualidad, transformación de la realidad, aceptación de los implicados. \\
\hline CRITERIOS DE VALIDEZ CIENTÍFICA & \\
\hline
\end{tabular}

Nota: Adaptado de "Cuadro resumen de los tres paradigmas de las investigaciones educativas y pedagógicas” por Quesada, C. y González, J. (2010). Los tres paradigmas científicos esenciales de las investigaciones educativas y pedagógicas. Monografías 2010. Cuba: Universidad de Matanzas Camilo Cienfuegos.

Tradicionalmente la adscripción a uno de los tres paradigmas conllevaba cierto ejercicio de oposición frente a los otros dos pero según Quesada y González (2010), las últimas tendencias epistemológicas en investigación pedagógica abogan o bien por el uso de diseños mixtos que permitan triangular paradigmas y utilicen de forma complementaria herramientas y métodos, o bien por la adopción de un paradigma en base a criterios de contingencia, esto es por resultar el más adecuado para afrontar el problema a tratar y no por suponer la supremacía del paradigma escogido frente a los otros.

En base a dichos criterios de contingencia, la presente investigación considera que paradigma socio-crítico el más adecuado para fundamentar y configurar el diseño de la investigación y por lo tanto la metodología y herramientas utilizadas 
para llevarla a cabo se ajustan a los presupuestos de dicho paradigma.

\subsection{Enfoque o método}

El método elegido para llevar adelante la investigación es el estudio de caso. Este enfoque se encuentra entre los métodos más utilizados dentro del diseño cualitativo junto a la investigación-acción o los métodos etnográficos (Expósito, Olmedo y Cano, 2004).

Entiende Stake (2005) por estudio de caso "el estudio de la particularidad y de la complejidad de un caso singular para llegar a comprender su actividad en circunstancias importantes" (p. 11).

Se espera a través de este método obtener una visión global del fenómeno estudiado centrando el interés de la investigación en un individuo, evento o institución sobre el cual se podrán generar hipótesis y en base a cuyos resultados se posibilita la toma de decisiones (Arnal, Del Rincón y Latorre, 1994). En este proceso, según Yin (2003) es un factor clave contextualizar el objeto de investigación, dado que es imposible separar las variables del estudio de su propio contexto.

Para Yin (2003) metodológicamente el estudio de caso responde a distintas características:

1. Facilita el análisis exhaustivo del contexto investigado. Se prioriza la calidad frente a la calidad y se analiza meticulosamente cada elemento, sujeto o documento, incorporando aspectos subjetivos e interpretativos a la comprensión del fenómeno.

2. Resulta adecuado en estudios donde el investigador no puede o no encuentra conveniente controlar exhaustivamente el contexto de investigación.

3. Las conclusiones que se obtienen pueden resultar una buena aproximación a la comprensión del contexto general en el que se sitúa el caso.

Entre las técnicas de recogida de información más habituales en el estudio de caso Cebreiro y Fernández (2004) mencionan las entrevistas, notas de campo, observaciones, grabaciones, documentos y textos. 
El estudio de caso responde a distintas clasificaciones. Por ejemplo, Stake (2005) propone tres tipos de estudio de caso en función de la finalidad a la que responden, el estudio de caso único o intrínseco, el instrumental o múltiple y el estudio de caso colectivo. El que concierne a esta tesis es el llamado estudio de caso colectivo ya que el interés de la investigación se centra en estudiar un fenómeno concreto en un determinado grupo poblacional. Para ello se seleccionan varios casos entre la población objetivo y se analiza en profundidad todo lo relativo a dicho fenómeno.

Yin (2003) distingue entre estudio de casos de enseñanza, en el que se plantean objetivos con carácter didáctico, y casos de investigación, orientados a la comprensión de contextos situacionales. En base a la disponibilidad de una teoría elaborada por parte del investigador, los casos también pueden considerarse como explicativos, exploratorios o descriptivos. La presente investigación se acogería a la segunda acepción del término, es decir, la metodología se corresponde con el estudio de caso de investigación de carácter exploratorio ya que se cuenta con un marco teórico previo que fundamenta la información obtenida al analizar los casos. Bajo esta consideración, el estudio de caso contribuye a la validación del marco teórico del que se parte.

\subsubsection{Criterios de calidad}

Los criterios de calidad a los que este trabajo doctoral se somete se basan en la propuesta de Lincoln y Guba (1985) y se refieren a la credibilidad, la transferencia, la dependencia y la confirmabilidad.

La credibilidad o valor de verdad se consigue cuando los resultados de la investigación reflejan una imagen representativa de la realidad. La credibilidad de este estudio vendría determinada por los siguientes aspectos:

- Realización de transcripciones textuales de las entrevistas.

- Uso de la triangulación en la recogida de datos con el objeto de determinar la congruencia de los resultados.

- Los hallazgos se consideran significantes y aplicables al contexto para el cual se dirige la investigación. 
- La entrevista reflexiva se sometió a validación inter-jueces. El trabajo completo ha sido sometido al juicio de otros profesionales y de expertos externos.

- Uso de grupo control para contrastar los resultados.

La transferencia o validez externa responde a la posibilidad de generalizar los resultados a otras poblaciones y/o contextos similares para conocer la representatividad del estudio. La posibilidad de transferencia de este trabajo se muestra en los siguientes aspectos:

- Se ha maximizado la información teórica recogida con el fin de documentar hechos y situaciones que permitan una comparación posterior de resultados con los hallazgos previos en este campo.

- Se ha descrito de manera exhaustiva el contexto en el que se lleva a cabo la investigación, de forma que permita realizar generalizaciones a otros entornos similares.

- Se han obtenido suficientes datos para llegar al punto de saturación de la información, esto es, hasta comprobar que no se añaden nuevos datos distintos a los ya registrados.

La dependencia o fiabilidad se refiere a la estabilidad de los datos, es decir, a la posibilidad de replicar el estudio y obtener hallazgos similares. La fiabilidad de este trabajo se garantiza en base a dos consideraciones:

- Se ha dejado constancia de todo el proceso seguido: selección de la muestra, recogida de información, identificación y descripción de las técnicas de análisis de datos, situación experimental y control, rol del investigador, etc.

- Triangulación de técnicas de recogida de información. Se han empleado tanto la grabación de las entrevistas como los textos escritos de los diarios online.

El criterio de confirmabilidad está relacionado con la objetividad, la ausencia de prejuicios en el investigador y de sesgos en la investigación. También se refiere a la forma en la que otros investigadores podrían replicar el estudio y llegar a conclusiones similares. Este criterio se observa en:

- $\quad$ Revisión del trabajo por agentes externos que pueden verificar si existe correspondencia entre los resultados obtenidos y las interpretaciones llevadas a cabo por el investigador. 
- Uso de registros lo más fieles posibles a la realidad. Las transcripciones de las entrevistas son textuales gracias a la grabación de éstas.

- Inexistencia de conflicto de interés por parte del investigador.

\subsection{Selección de la muestra}

La clasificación más habitual de los métodos de muestreo distingue entre muestreo probabilístico y muestreo no probabilístico. Alaminos y Castejón (2006) sostienen que ningún tipo de muestreo es superior al otro por sí mismo, sino que en función del problema investigado resultará más adecuado el empleo de uno u otro.

El muestreo probabilístico se utiliza habitualmente en investigación cuantitativa. Se caracteriza por seleccionar la muestra al azar y porque permite inferir los resultados a toda la población. Este muestreo se puede clasificar a su vez en muestreo aleatorio simple, muestreo aleatorio sistemático, muestreo estratificado y muestreo por conglomerados.

Por otro lado, el muestreo no probabilístico, propio, aunque no exclusivo, de la investigación cualitativa es aquel en el que la selección de los participantes no depende de la probabilidad sino de otro tipo de criterios y donde el aspecto clave es la representatividad de la muestra. Según Patton (2002) la potencia de este muestreo reside en conseguir que los casos seleccionados proporcionen la información de mayor riqueza posible para indagar sobre el objeto de estudio. Se busca la generalización de los resultados para el contexto específico en el que ocurre el fenómeno.

Alaminos y Castejón (2006) distinguen dentro del muestreo no probabilístico tres tipos de muestreo: el muestreo de conveniencia, el muestreo por cuotas y el muestreo intencional.

Dado que no es objeto de esta tesis realizar un estudio sobre los tipos de muestreo y con el fin de acotar la información, únicamente se va a desarrollar el muestreo al que se circunscribe este trabajo, es decir el muestreo intencional. Sin embargo, si se desea profundizar sobre el tema es posible remitirse a trabajos como los de Alaminos y Castejón (2006), Martínez-Salgado (2012) o Navarrete (2000) de entre los múltiples textos al respecto. 
El muestreo intencional según Alaminos y Castejón (2006) es el que desarrolla en mayor grado la potencialidad del muestreo no probabilístico. Constituye una estrategia de recolección de datos adecuada para muestras pequeñas y específicas. El muestreo intencional tiene a su vez diversas variantes entre las que el investigador elige en función del enfoque de su investigación.

La técnica utilizada en esta investigación es el muestreo intencional de criterio, cuya lógica reside en escoger aquellos casos que se ajustan a criterios predeterminados. De los sujetos seleccionados se espera que proporcionen información significativa y suficiente en relación al tema de interés. Se han establecido como necesarios los criterios de inclusión y exclusión que se exponen en la Tabla 11.

\section{Tabla 11}

Criterios de inclusión y exclusión de la muestra

\begin{tabular}{|c|c|}
\hline CRITERIOS DE INCLUSIÓN & CRITERIOS DE EXCLUSIÓN \\
\hline \multirow[t]{2}{*}{$\begin{array}{l}\text { Alumnado matriculado al menos del } 90 \% \text { de las asignatu- } \\
\text { ras de tercer curso de GMP. }\end{array}$} & $\begin{array}{l}\text { Alumnado que estuviera matriculado principalmente en } \\
4^{\circ} \text { curso de GMP con asignaturas de } 3^{\circ} \text {. }\end{array}$ \\
\hline & $\begin{array}{l}\text { Alumnado de } 3^{\circ} \text { con menos del } 90 \% \text { de asignaturas } \\
\text { matriculadas de este curso. }\end{array}$ \\
\hline $\begin{array}{l}\text { Alumnado matriculado en el Practicum I de GMP por } \\
\text { primera vez. }\end{array}$ & $\begin{array}{l}\text { Alumnado que hubiera cursado un Practicum educativo } \\
\text { anteriormente (por ejemplo, al haber cursado previa- } \\
\text { mente la titulación de Grado de Maestro/a en Educación } \\
\text { Infantll). }\end{array}$ \\
\hline $\begin{array}{l}\text { Alumnado con dedicación exclusiva a la carrera durante } \\
\text { el curso. }\end{array}$ & $\begin{array}{l}\text { Alumnado que durante el curso compagina la carrera con } \\
\text { trabajo u otros estudios. }\end{array}$ \\
\hline
\end{tabular}

El procedimiento de selección de la muestra se inicia durante el curso 2014-2015 estableciendo contacto mediante correo electrónico con el profesorado de la UJI que tiene asignado alumnado de Practicum I de GMP. Se solicita a estos docentes la posibilidad de que su alumnado colabore con el estudio y a aquellos que responden favorablemente se les proporciona la información necesaria para entender el objeto de estudio y el proceso de intervención que se Ilevaría a cabo con su alumnado. Además de los criterios de inclusión y exclusión, 
se pactan con los tutores dos condiciones respecto al reclutamiento de la muestra, por un lado, la voluntariedad y libertad del alumnado para participar o dejar la investigación sin repercusión alguna y por otro que dicha participación no fuera recompensada de forma directa a través de la nota final. El perfil deseable eran personas con motivación por el cambio y la transformación de la realidad. A aquellos sujetos que concluyeron la investigación se les emitió un certificado de participación que se adjunta en el Apéndice 1.

La muestra final estaba formada por 20 sujetos, 15 mujeres y 5 hombres de edades comprendidas entre los 20 y 21 años. Todos ellos fueron asignados al azar al grupo experimental ( 7 mujeres y 3 hombres) o al grupo control ( 8 mujeres y 2 hombres).

Conforme avanzó la intervención varios sujetos de la muestra abandonaron el estudio debido a incompatibilidades sobrevenidas, siendo destacable la mortalidad sufrida en el grupo experimental. Los datos que se analizaron al final del proceso fueron los correspondientes a cuatro sujetos experimentales ( 3 mujeres y 1 hombre) y siete sujetos control (5 mujeres y 2 hombres).

\subsection{Intervención y seguimiento}

Una vez seleccionada la muestra se explicó tanto a los sujetos del grupo control como a los del grupo experimental las características de la investigación más relevantes. Se comprobó que todos los individuos comprendían la intervención que se iba a llevar a cabo y cuál era su papel en dicho proceso. Finalmente se firmó el consentimiento informado con todos los participantes (en el Apéndice 2 se puede ver la plantilla de dicho documento). En la Tabla 12, se encuentra esquematizado el proceso seguido con cada uno de los grupos durante la intervención.

\section{Tabla 12}

Esquema de intervención durante la fase experimental.

\begin{tabular}{|c|c|c|c|}
\hline & ANTES DEL PRACTICUM & DURANTE EL PRACTICUM & DESPUÉS DEL PRACTICUM \\
\hline GRUPO CONTROL & $\begin{array}{l}\text { - Entrevista reflexiva pre- } \\
\text { Practicum. }\end{array}$ & $\begin{array}{l}\text { - Escritura del e-diario. } \\
\text { - Seguimiento mediante } \\
\text { feedbacks neutros. }\end{array}$ & $\begin{array}{l}\text { - Entrevista reflexiva post- } \\
\text { Practicum. }\end{array}$ \\
\hline $\begin{array}{l}\text { GRUPO } \\
\text { EXPERIMENTAL }\end{array}$ & $\begin{array}{l}\text { - Entrevista reflexiva pre- } \\
\text { Practicum. } \\
\text { - Seminario } 1 .\end{array}$ & $\begin{array}{l}\text { - Seminario } 2 . \\
\text { - Escritura del e-diario. } \\
\text { - Guía reflexiva. } \\
\text { - Seguimiento mediante } \\
\text { feedbacks reflexivos. }\end{array}$ & $\begin{array}{l}\text { - Entrevista reflexiva post- } \\
\text { Practicum. }\end{array}$ \\
\hline
\end{tabular}


Antes de comenzar el Practicum I se realiza tanto con el grupo control como con el grupo experimental una primera entrevista de carácter reflexivo orientada a conocer las opiniones particulares de los estudiantes sobre aspectos de la titulación, sobre la práctica reflexiva y sus expectativas respecto al Practicum.

Tras la entrevista, para el grupo experimental se concierta un primer seminario de dos horas de duración. Este seminario se estructura en dos partes, la primera orientada a familiarizarse con los conceptos clave de la práctica reflexiva, así como con la técnica del incidente crítico. La segunda es más dinámica y aplicada, en ella se trabaja mediante grupos de discusión y a través de juego de roles ejemplos de cómo puede llevarse a cabo la reflexión sobre determinados temas educativos. El contenido íntegro de este primer seminario se adjunta en el Apéndice 3.

Una semana después, coincidiendo con el inicio de periodo de prácticas se realiza un segundo seminario de dos horas de duración con el grupo experimental. En este segundo seminario cada uno de los sujetos debe aportar un incidente que ha considerado crítico y que ha sucedido a lo largo de la primera semana de prácticas. Se dedica la sesión a reflexionar sobre los incidentes reales aportados por el alumnado y el impacto que han causado mientras se dan verbalmente pautas relacionadas con la toma de conciencia del proceso reflexivo.

Durante el periodo de Practicum, al grupo control se le pide que reflexione sobre los temas y hechos que consideren oportunos en relación con su experiencia en prácticas y que a su vez elabore su entrada semanal en el diario online del aula virtual. Tras presentar cada entrada se les da una respuesta neutra, de agradecimiento, con el fin de alentarles a continuar con la investigación.

En el caso del grupo experimental, se proporciona una guía reflexiva -consultar Apéndice 4- que aborda los tres momentos clave del Practicum (adaptación, colaboración e intervención) y que sugiere algunos temas susceptibles de reflexión que podían emerger en cada uno de esos momentos.

Durante la redacción de las entradas del diario online se les responde por escrito una retroalimentación reflexiva a cada entrada, es decir, a partir de sus propias 
reflexiones se plantean otras distintas en relación a la misma anécdota o incidente.

El Practicum I se prolongó durante 11 semanas y durante este tiempo se realizaron entre 8 y 11 entradas del diario reflexivo en función del centro educativo donde se hiciera el Practicum y la coincidencia con fiestas locales.

Tras finalizar el periodo de prácticas se concertó una última reunión individual con todos los participantes y se realizó la entrevista reflexiva post Practicum.

\subsection{Métodos de recogida de información}

En este apartado se justifica el tipo de instrumentos que se han utilizado en la recogida de datos exponiendo brevemente los fundamentos teóricos y características de cada uno de ellos.

Se entiende por instrumento de investigación "un mecanismo para la medición de fenómenos que se utiliza para registrar la información, para evaluar, tomar decisiones y en última instancia para comprender." (Colton y Colbert, 2007, p. 5).

La investigación en ciencias humanas y sociales se abastece de múltiples instrumentos de recogida de información (encuestas, cuestionarios, escalas, entrevistas, grupos de discusión, observación, portfolios, etc.) cuya selección responde al propósito de la investigación. La mayoría de instrumentos suelen combinarse entre sí como forma de triangular datos cuantitativos y cualitativos en investigaciones mixtas o bien como forma de respaldar datos obtenidos en un tipo específico de investigación siendo este último caso el que se ajusta a este trabajo.

\subsubsection{Entrevista semiestructurada.}

La entrevista es el arte de realizar preguntas y escuchar respuestas (Denzin y Lincoln, 2011, p. 643). En concreto la entrevista cualitativa es definida por Fernández (2001) como: 
(...) un modelo de entrevista que propicia la integración dialéctica sujetoobjeto considerando las diversas interacciones entre la persona que investiga y lo investigado. Se busca comprender, mediante el análisis exhaustivo y profundo, el objeto de investigación dentro de un contexto único sin pretender generalizar los resultados. Constituye el fluir natural, espontáneo y profundo de las vivencias y recuerdos de una persona mediante la presencia y estímulo de otra que investiga, quien logra, a través de esa descripción, captar toda la riqueza de sus diversos significados (p. 15).

Mediante la entrevista se pretende por un lado obtener información en profundidad sobre un tema determinado y por otro comprender el significado que el entrevistado atribuye a dicho tema.

Díaz-Bravo, Torruco-García, Martínez-Hernández y Varela-Ruiz (2013) describen tres tipos de entrevista según la rigidez o flexibilidad en su aplicación y el tipo de datos que se obtienen. La entrevista puede ser estructurada, semiestructurada y no estructurada. Estos autores se posicionan en favor de la entrevista semiestructurada cuando la investigación es cualitativa puesto que guarda un mayor equilibro entre la flexibilidad en la respuesta y la uniformidad de las cuestiones que se plantean según el objeto de estudio.

En cuanto al número de entrevistas a realizar para que el estudio tenga validez, este viene dado por el llamado punto de saturación. Este es el punto en el que una nueva entrevista ya no ofrece nuevos datos respecto a las entrevistas anteriores y por lo tanto señala que la recogida de datos es completa (Flick, 2007).

Dada la anterior información, en lo que respecta a esta tesis, se ha empleado la entrevista semiestructurada por los motivos mencionados anteriormente por DíazBravo et al. (2013) referidos al equilibrio entre flexibilidad y rigurosidad. Así mismo, se ha tenido en consideración el punto de saturación para dejar de entrevistar participantes y finalmente, tanto entrevistas como transcripción y análisis de datos han sido realizados por la misma persona para favorecer la comprensión de la información desde lo particular a lo global. 
El procedimiento para la elaboración de la entrevista semiestructurada se basa en dos objetivos. El primero de ellos relacionado con la obtención de una línea base a comparar sobre los niveles de reflexión alcanzados por el alumnado antes del Practicum y en el caso del grupo experimental antes de la intervención. Para este objetivo se tomó como fuente la revisión bibliográfica y las rúbricas relacionadas con dichos elementos. El segundo objetivo está relacionado con la importancia de obtener información del alumnado respecto a la titulación del GMP de forma que al analizar sus respuestas se puedan extraer conclusiones aplicables a los nuevos planes de estudios del GMP.

Tras seleccionar una serie de elementos e ítems considerados relevantes para la investigación la entrevista quedó dividida en tres bloques diferenciados de información. El primer bloque orientado a conocer la opinión sobre los estudios y la profesión de maestro, el segundo bloque destinado a indagar sobre el concepto o idea de reflexión y el tercer bloque dirigido a conocer sus reflexiones respecto al Practicum.

Esta entrevista se remitió a cuatro profesionales de reconocido prestigio para someterse a validación. La validación se realizó en base a los tres criterios propuestos por Gairín (1993), univocidad o imposibilidad de interpretar el ítem de más de una manera, pertinencia o adecuación a las finalidades establecidas e importancia o grado de relevancia de dicho ítem.

Tras modificar la entrevista de acuerdo a las sugerencias recopiladas en la validación se realizó una segunda revisión a través de la aplicación de la entrevista de forma piloto a dos alumnos voluntarios que cumplían algunos criterios exigidos para la muestra pero cuyo perfil no se ajustaba a la totalidad de los requisitos para formar parte de esta. Tras la prueba piloto se volvió a modificar la escala acortando algunas cuestiones, eliminando otras y reformulando otras tantas.

Tras estas modificaciones se estableció finalmente la entrevista reflexiva utilizada en la intervención. Ejemplos de las preguntas definitivas de la entrevista final son: "Expresa lo que para ti significa ser un buen maestro", "tu idea sobre la educación y la enseñanza ¿̇se mantiene igual que cuando iniciaste la carrera?”, ¿cómo 
crees que se puede desarrollar la capacidad reflexiva?, ¿qué objetivos personales y/o profesionales te planteas conseguir con el Practicum? Se pueden revisar todas las preguntas de la entrevista en el Apéndice 5.

\subsubsection{Diarios online (e-diarios)}

Las nuevas tecnologías resultan extremadamente útiles en la investigación en ciencias sociales y en educación en particular. Los sistemas de recogida de información online a través de aplicaciones, plataformas o software ofrecen varias ventajas. Por un lado reducen los tiempos de recogida y transcripción de datos, por otro, no requieren presencialidad y además se adaptan al horario y ritmo de los usuarios. También en fases posteriores de la investigación tener la información centralizada facilita el tratamiento de datos reduciendo así tiempos y coste de investigación (Area y Adell, 2009).

Para este trabajo se ha utilizado la plataforma Moodle o Aula Virtual de la Universitat Jaume I. Además de resultar un recurso accesible y disponible con el cual están familiarizados todos los sujetos de la muestra por su uso habitual para el seguimiento de las asignaturas, el Aula Virtual proporciona un entorno controlado donde el intercambio de información se realiza de forma fluida, flexible y modulable. Esta plataforma facilita un espacio y un tiempo para realizar las tareas que se adapta a las necesidades de cada participante, también permite al investigador realizar un seguimiento óptimo de las entradas y a su vez le permite organizar y dirigir la información de múltiples formas según la demanda particular de cada momento.

Ortiz, Hernández y del Olmo (2013) encuentran como ventajas del uso de la plataforma Moodle como herramienta de recogida de datos que esta no requiere de conocimientos técnicos avanzados y que su uso repercute indiscutiblemente de manera positiva sobre las fases posteriores del estudio (p. 136).

Por otro lado, el uso del diario de investigación, tanto si es de carácter físico como online, es reconocido como uno de los instrumentos más adecuados para fomentar la emisión de opiniones y reflexionar sobre experiencias personales (Zabalza, 2004). Se puede revisar el punto 7.1 .2 de esta tesis para verificar las múltiples ventajas 
que ha supuesto el uso del diario reflexivo online en la investigación.

El diario permite mostrar la visión subjetiva del autor sobre la realidad. Permite describir e interpretar acontecimientos y situaciones que conducen a la comprensión de aspectos singulares de la realidad, observaciones, sentimientos, reacciones, interpretaciones, reflexiones, presentimientos, hipótesis y explicaciones (Kemmis y Mactaggart, 1988, p. 186).

A nivel metodológico en este trabajo se han seguido las consideraciones de Zabalza (1991) para que el uso del e-diario no suscite reactividad en los sujetos que lo van a utilizar:

En primer lugar, se ha definido con claridad la finalidad del diario y el lugar que este ocupa en la investigación, reforzando la importancia de las contribuciones de cada individuo en particular.

En segundo lugar, el investigador se ha mostrado durante todo el proceso como un lector neutral de los textos que se presentan, sin hacer juicios ni valoraciones de las opiniones y reflexiones de los autores.

En tercer lugar, se ha remarcado que las entradas del diario son absolutamente confidenciales entre investigador e investigado, desvinculadas de cualquier valoración académica o social, remarcando que el interés reside en la comprensión fenomenológica del contenido escrito.

Por último, se ha remarcado la necesidad e importancia de mantener la redacción de entradas de forma constante durante un tiempo prolongado, en este caso, durante todo el periodo del Practicum I, dado que la continuidad asegura la calidad de la información recogida y la obtención de una visión global del proceso más allá de la recolección puntual de datos.

Un aspecto especialmente cuidado ha sido el referido a la ética del uso del diario. Siguiendo una vez más a Zabalza (2004) la cuestión más importante al respecto es la transformación de un documento privado e íntimo en un documento 
público. Para ello, mediante el documento del consentimiento informado se garantizó que los nombres de los usuarios se utilizaran bajo acrónimo o pseudónimo de forma que sus reflexiones, en el caso de salir a la luz, difícilmente fueran asociadas a sus autores. Se garantizó además que en el momento de salir los resultados a la luz estos ya no estuvieran en condiciones de afectar académicamente al informante de ningún modo.

\subsection{Técnicas de investigación e instrumentos de análisis}

\subsubsection{Análisis de contenido}

La técnica de investigación utilizada en esta tesis es el análisis de contenido. En concreto se ha realizado un análisis del contenido de las transcripciones de las entrevistas grabadas que se formularon a los estudiantes y de los textos obtenidos mediante los diarios reflexivos online.

El análisis de contenido según describe Fernández (2002) tiene como objetivo la identificación de determinadas contribuciones de los participantes y su clasificación en forma de categorías. Los resultados que se obtienen pueden expresarse en indicadores y transformarse en términos numéricos por lo que permite la replicabilidad del estudio por parte de otros investigadores.

Esta investigación además se enmarca dentro del denominado Análisis de Contenido Clásico (Leech y Onwuegbuzle, 2007; Saldaña, 2009) en el cual se complementan dos momentos de análisis, uno de tipo deductivo y otro de tipo inductivo. En primer lugar, con la información recopilada, de forma deductiva se generan una serie de códigos o temas que conforman un primer sistema de categorías y se procede a realizar el primer análisis de los fragmentos. Tras este primer examen emergen de forma inductiva nuevos temas y códigos que no han sido previstos originalmente y se redefinen y/o eliminan otros. Una segunda lectura y codificación permite afinar el análisis y extraer el máximo partido a la información recogida.

En la preparación de la información para el tratamiento de los datos mediante la técnica de Análisis de Contenido se ha seguido el esquema definido por Bustos 
(2011) basado en tres fases: definición de la unidad de análisis, construcción de un sistema de categorías y definición del protocolo de análisis.

En la primera fase se ha establecido el fragmento como unidad de registro, entendiendo como fragmento una parte de una contribución interpretable y codificable en una de las categorías del sistema de análisis establecido.

En la segunda fase se ha elaborado un sistema de categorías. Este sistema categórico inicial se ha construido de forma deductiva a partir del marco teórico revisado y por lo tanto acorde con los niveles de reflexión establecidos por Larrivee (2008). Las categorías cumplen a su vez con los criterios citados por Fernández (2002), es decir, resultan pertinentes y adecuadas a los objetivos de la investigación, son exhaustivas, homogéneas y mutuamente excluyentes.

Finalmente, en la tercera etapa, se ha establecido un protocolo de análisis en el que se distinguen tres pasos:

1. Recopilación de los textos susceptibles de análisis y preparación de estos para su codificación. Se han reunido todos los datos en bruto, tanto las entrevistas registradas en archivos de audio como las entradas de los diarios online. Se ha procedido a pasar a texto escrito los archivos de audio de las entrevistas reflexivas.

2. Reestructuración y transformación de la información. Por razones de concordancia con el lenguaje utilizado en la tesis se han traducido algunos textos redactados en valenciano a castellano. Por otro lado, se ha revisado el material recopilado y corregido faltas ortográficas, gramaticales y sintácticas. Se han reagrupado párrafos de forma que las ideas expresadas en ellos tengan sentido y unidad.

3. Aplicación de las técnicas de análisis cualitativo. Con los códigos y las categorías creados se ha procedido a realizar el análisis de contenido propiamente dicho con la ayuda del software MAXQDA en su versión 12.

\subsubsection{Software de análisis de datos cualitativos MAXQDA v.12}

El software de análisis de datos cualitativos ha ido mejorando y ganando prestaciones en los últimos años hasta el día de hoy. Entre las ventajas de utilizar este 
tipo de programas se encuentran las mencionadas por Davidson y di Gregorio (2011). Estos autores consideran que este tipo de software ofrece un espacio digital para reunir y organizar los materiales de estudio. Proporcionan una serie de herramientas que permiten extraer fragmentos, yuxtaponer, interpretar y recomponer los datos y finalmente, facilitan el acceso a la información mejorando así la transparencia de la investigación (p. 627).

El procedimiento de análisis de datos realizado en esta tesis se basa en las directrices propuestas por Saldaña (2009) ya mencionadas previamente en el apartado referido al análisis de contenido. Este procedimiento se basa en dos ciclos de codificación y análisis, uno inicial de carácter deductivo, exploratorio y descodificador y otro posterior con la información reorganizada, de carácter inductivo, más refinado y con objetivo codificador.

La codificación temática se entiende en este trabajo como la asignación de códigos a distintos fragmentos de la información que se han organizado según temáticas o categorías. La finalidad de este primer análisis es obtener una aproximación general al tipo de reflexión que predominaba en el discurso de los participantes (superficial, pedagógico o crítico) y al tipo de temas, intereses y preocupaciones que prevalecen en dicho discurso. Paralelamente, este análisis conlleva la obtención de información dirigida a perfilar las categorizaciones y a establecer otras nuevas para el segundo ciclo del análisis.

Para obtener un primer acercamiento al nivel de reflexión se utilizó tanto para los diarios online como para las entrevistas pre y post Practicum una codificación basada en la propuesta original de Larrivee (2008). En el segundo ciclo de análisis, se mantuvieron los códigos para el análisis de los diarios, pero en el caso de las entrevistas se generó un nuevo elemento que se denominó meta-reflexión, dirigido a identificar fragmentos donde se reflexionara sobre el propio acto reflexivo. Dado que las habilidades metacognitivas son procesos de orden superior, se entiende que la capacidad de reflexionar sobre la propia reflexión requiere igualmente habilidades de pensamiento de orden superior. 


\section{Tabla 13}

Códigos utilizados para el análisis de los niveles de reflexión

\begin{tabular}{|c|c|c|}
\hline NIVELES DE REFLEXIÓN & CÓDIGO & DESCRIPCIÓN \\
\hline Pre-reflexión & PR & $\begin{array}{l}\text { Reacción automática, rutinaria, reactiva y carece de análisis previo. } \\
\text { Se excluye de toda responsabilidad sobre la situación. } \\
\text { Sus creencias y concepciones sobre la enseñanza son generalizadas } \\
\text { y no se fundamentan en la evidencia, la teoría o la investigación. }\end{array}$ \\
\hline Reflexión superficial & $\mathrm{RS}$ & $\begin{array}{l}\text { Utiliza retórica vacía y frases tópicas, } \\
\text { Narra el plan de actuación sin motivarlo. } \\
\text { Describe los hechos de forma aséptica. } \\
\text { Comenta emociones no vinculadas a procesos cognitivos. }\end{array}$ \\
\hline Reflexión pedagógica & $\mathrm{RP}$ & $\begin{array}{l}\text { Establece relación entre conocimiento pedagógico previo (teórico, o } \\
\text { experiencial) con el nuevo conocimiento. } \\
\text { Analiza el impacto de la tarea en el propio aprendizaje. } \\
\text { Revisa su ejecución: reconoce y analiza sus limitaciones, identifica } \\
\text { causalidades, propone mejora futuras. } \\
\text { Explica y justifica formas originales, creativas y arriesgadas de } \\
\text { desarrollar la actividad. }\end{array}$ \\
\hline Reflexión crítica & $\mathrm{RC}$ & $\begin{array}{l}\text { Identifica consecuencias o implicaciones del aprendizaje en diferentes } \\
\text { contextos: social, cultural, histórico, económico, político, éticos, etc. } \\
\text { Revisa y compara la nueva información respecto a sus propias asun- } \\
\text { ciones, creencias, señala cambios realizados en éstas. } \\
\text { Realiza planteamientos que desafían o cuestionan el estatus quo } \\
\text { establecido, adopta un rol de investigador activo. }\end{array}$ \\
\hline Auto reflexión & AR & Existe autoobservación y metapensamiento. \\
\hline Meta reflexión & MR & $\begin{array}{l}\text { Es capaz de referirse hacia su propia capacidad reflexiva. } \\
\text { Expresa su opinión sobre el acto reflexivo. }\end{array}$ \\
\hline
\end{tabular}

En la Tabla 13 se describe la codificación temática basada a los niveles de reflexión de Larrivee (2008) junto al concepto de meta reflexión, incorporado en el segundo ciclo de análisis de las entrevistas. 


\section{Tabla 14}

Categorías generales y códigos de los temas emergentes

\begin{tabular}{|c|c|c|}
\hline TEMAS DE REFLEXIÓN & CÓDIGO & DESCRIPCIÓN \\
\hline Características del alumnado & CA & $\begin{array}{l}\text { Características y cualidades del alumnado que llaman la atención en } \\
\text { el aula o en el centro. (Ver subcategorías) }\end{array}$ \\
\hline Características del profesorado & $\mathrm{CP}$ & $\begin{array}{l}\text { Atributos y particularidades en relación a la acción docente del tutor } \\
\text { o de otros maestros del centro. }\end{array}$ \\
\hline $\begin{array}{l}\text { Didáctica y Organización } \\
\text { Escolar }\end{array}$ & DOE & $\begin{array}{l}\text { Temas pedagógicos que pertenecen a materias vinculadas al área. } \\
\text { (Ver subcategorías) }\end{array}$ \\
\hline Didácticas específicas & DE & $\begin{array}{l}\text { Contenidos y actividades didácticas relacionados con materias } \\
\text { específicas. (Ver subcategorías) }\end{array}$ \\
\hline Características de las familias & CF & $\begin{array}{l}\text { Particularidades que presentan las familias al interactuar con el } \\
\text { resto de comunidad educativa en relación a sus hijos e hijas. }\end{array}$ \\
\hline Características socio-críticas & CSC & $\begin{array}{l}\text { Aspectos de la sociedad y del entorno que guardan relación con la } \\
\text { educación. (Ver subcategorías). }\end{array}$ \\
\hline Grado de Magisterio Primaria & GMP & Referencias a la titulación de GMP en general en relación al Practicum. \\
\hline
\end{tabular}

Respecto a los temas de reflexión, se realizó una codificación inicial con los temas generales que se esperaban encontrar y tras el primer análisis se establecieron nuevas categorías y distintas subcategorías incluidas dentro de algunas de las categorías generales bajo las cuales se realizó el segundo análisis. En la Tabla 14 se puede ver la codificación final de las categorías generales y su descripción mientras que en la Tabla 15 se desglosan las subcategorías.

Paralelamente a la codificación temática también se realizó la codificación de los participantes a la investigación con el fin de preservar su anonimato, utilizando la numeración del 1 al 11. Los miembros pertenecientes al grupo experimental se corresponden con los números 1, 6, 7 y 9. Mientras que forman parte del grupo control los participantes número 2, 3, 4, 5, 8, 10 y 11. 


\section{Tabla 15}

Subcategorías en relación a las categorías generales

\begin{tabular}{|c|c|}
\hline CÓDIGOS GENERALES & SUBCÓDIGOS \\
\hline \multirow[t]{3}{*}{$\mathrm{CSC}$} & Sociedad \\
\hline & Política \\
\hline & Sistema Educativo \\
\hline \multirow{6}{*}{ DOE } & Didáctica y metodología \\
\hline & Diversidad y NEE \\
\hline & Convivencia \\
\hline & Organización Escolar \\
\hline & Evaluación \\
\hline & TIC \\
\hline \multirow[t]{4}{*}{$C A$} & Comportamiento \\
\hline & Motivación \\
\hline & Aspectos cognitivos \\
\hline & Personalidad \\
\hline \multirow[t]{5}{*}{ DE } & Conocimiento del medio \\
\hline & Lengua \\
\hline & Matemáticas \\
\hline & Artes plásticas \\
\hline & Educación Física \\
\hline
\end{tabular}




\section{Procedimiento}

Para no repetir la información dada en los apartados anteriores, en este punto se va a realizar un esquema (Figura 9) que refleje de forma rápida y visual el procedimiento seguido en la globalidad del proceso.

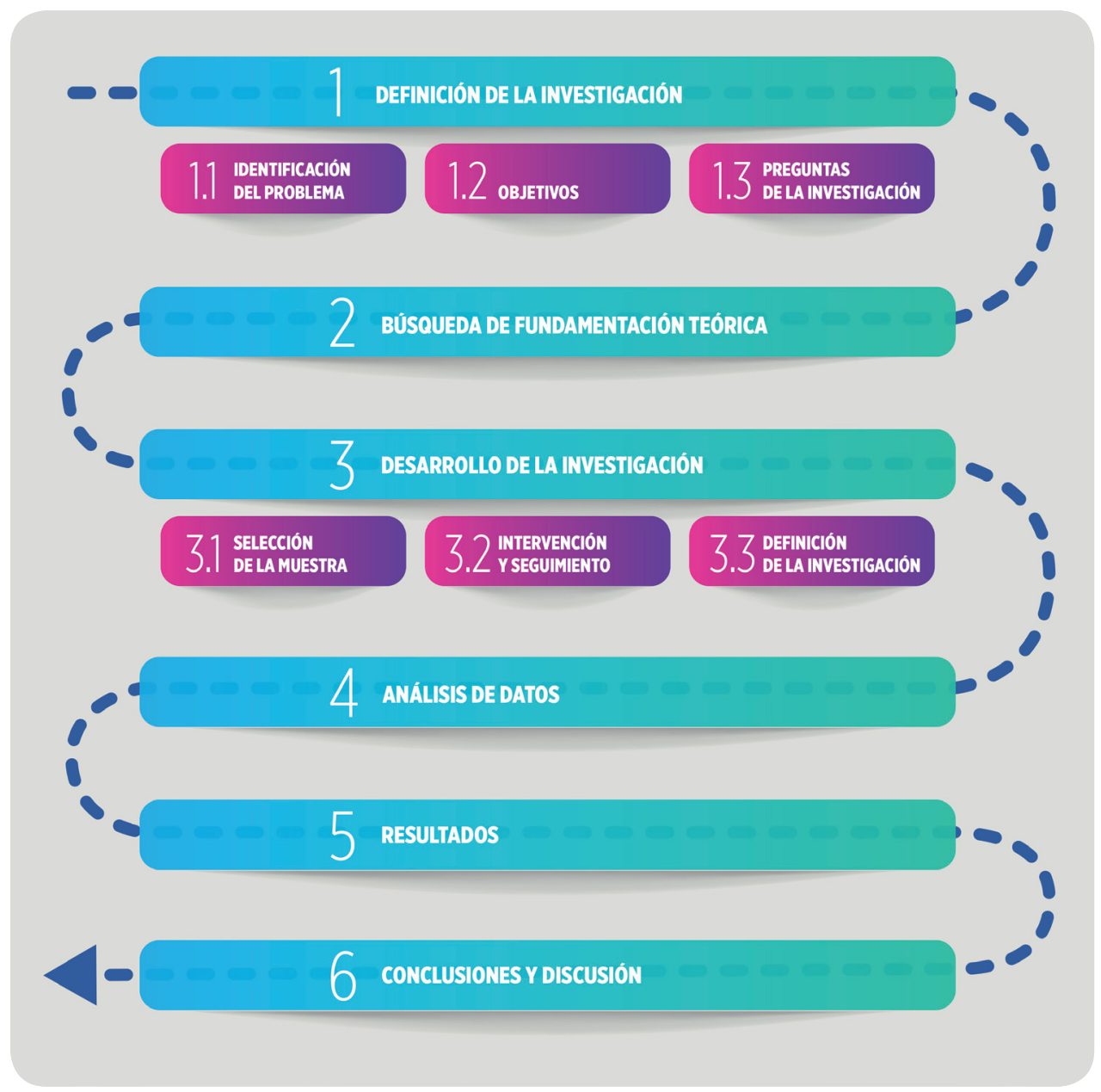

Figura 9. Procedimiento seguido en la investigación. 


\section{Resultados}

En esta sección se exponen los resultados obtenidos tras el análisis de los datos extraídos a partir de los instrumentos de recogida de información mediante la técnica de análisis de contenido. El conjunto completo de transcripciones de las entrevistas y de entradas en los diarios se incluye en un CD que se adjuntará al propio trabajo para su consulta y/o revisión. Para respetar el anonimato de las personas que han participado en la investigación los nombres propios se han sustituido por números que van desde el alumno número 1 hasta el número 11.

\subsection{Análisis de las entrevistas pre y post Practicum}

Mediante este primer análisis se espera averiguar si existen diferencias en las reflexiones realizadas por el grupo experimental y por el grupo control respecto a las respuestas proporcionadas en las entrevistas realizadas antes y después del Practicum.

\subsubsection{Resultados de las entrevistas para el grupo experimental}

En la Tabla 16 se muestran los resultados de dichas entrevistas para los alumnos pertenecientes al grupo experimental. Cabe recordar que este grupo está formado por los participantes 1, 6, 7 y 9 . En la primera columna figuran todos los participantes numerados y se especifica si los resultados se corresponden a la entrevista pre Practicum (EPRE) o post Practicum (EPOST). En el resto de columnas se reflejan numéricamente la cantidad de reflexiones realizadas para cada una de las categorías reflexivas tanto antes como después del Practicum.

\section{Tabla 16}

Resultados entrevista pre y post Practicum en el grupo experimental

\begin{tabular}{|c|c|c|c|c|c|c|}
\hline PARTICIPANTES & CRÍTICA & $\begin{array}{l}\text { AUTO- } \\
\text { REFLEXIÓN }\end{array}$ & PEDAGÓGICA & SUPERFICIAL & $\begin{array}{l}\text { PRE- } \\
\text { REFLEXIÓN }\end{array}$ & $\begin{array}{l}\text { META- } \\
\text { REFLEXIÓN }\end{array}$ \\
\hline № 1 EPRE & 2 & 0 & 8 & 8 & 2 & 2 \\
\hline №1 EPOST & 1 & 2 & 7 & 10 & 0 & 2 \\
\hline № 6 EPRE & 1 & 0 & 14 & 7 & 0 & 3 \\
\hline № 6 EPOST & 0 & 4 & 11 & 5 & 0 & 3 \\
\hline № 7 EPRE & 1 & 3 & 7 & 6 & 2 & 3 \\
\hline № 7 EPOST & 5 & 5 & 4 & 6 & 0 & 4 \\
\hline № 9 EPRE & 1 & 0 & 8 & 9 & 1 & 2 \\
\hline № 9 EPOST & 2 & 3 & 9 & 3 & 0 & 4 \\
\hline
\end{tabular}


Examinando los resultados de la reflexión crítica y la autorreflexión, considerada esta última como una forma de reflexión crítica, se encuentra que en todos los casos aumentaron las reflexiones en la entrevista posterior al Practicum respecto a la entrevista previa. Los casos más notables son los del participante 7, que pasa de realizar 4 reflexiones críticas a 10 y el participante 9 , que pasa de realizar 1 a realizar 5 en la entrevista final. A continuación, se exponen varios ejemplos de reflexión crítica y auto-reflexión extraídos de las entrevistas del grupo experimental:

Yo creo que [la crisis] afecta muy notablemente por el tema de los recortes, tanto a todo el profesorado que se ven ahogados o también el tema de las clases, que quieren innovar metodologías, pero a veces cuando tienes clases de treinta alumnos con el ratio tan grande es imposible, pero si no hay dinero suficiente pues está claro que las clases cada vez se aglomeran más. Luego quieres introducir nuevos recursos, pero si el colegio no tiene suficiente dinero para introducirlos o comprar nuevas cosas tampoco es un factor a favor, pero también soy de las que pienso que aunque hayan recortes, y está claro que en el sistema educativo hay grandes recortes, hay que ser un poco positivo e intentar salir de esa adversidad porque a lo mejor en el colegio materiales no se pueden comprar pero ¿por qué no empezar a hacer cosas más creativas con los niños? (A6, EPRE)

Una vez vino un papá y explicó su trabajo, que era químico y aprendieron un montón. Y pensé que cualquier persona con un poco de gracia, con labia para los niños y que se sepa el temario puede explicarlo y puede ser buen profesor. Ese día me quedé pensando "te tiraste estudiando cuatro años". Pero para detectar algún problema sí que necesitas la carrera. Cuando me he puesto a hacer la programación y he pensado actividades que no solo te tienen que divertir, sino que también tienes que enseñarles algo, tienen que aprender algo. Yo he sabido hacer cosas distintas y que aprendieran a la vez, no sólo divertidas y eso síque ha sido gracias a la carrera. (A7, EPOST)

En el caso de la reflexión pedagógica los resultados muestran que esta no ha aumentado tras el Practicum excepto en el caso del alumno 9. En el resto de individuos disminuye la cantidad de reflexiones pedagógicas proporcionadas en la entrevista final respecto a la inicial, sin embargo, aún con este resultado se realizan entre 4 y 11 reflexiones de este nivel. Un ejemplo de reflexión pedagógica en la entrevista del grupo experimental es la que proporciona este participante: 
Pues lo que no me gustaría es prepararles para un examen con un objetivo final, por ejemplo ahora lo de las reválidas. No me gustaría que las escuelas se convirtiesen en un Bachiller que son dos años preparatorios para un examen, sino que me gustaría, aunque suene muy utópico, enseñarles la vida, es decir, el día a día, las situaciones problemáticas y cómo enfrentarse a ellas. (A9, EPRE)

En cuanto a la reflexión superficial, dos de los participantes ( 9 y 6 ) reducen las reflexiones en esta categoría en la entrevista final mientras que en el caso del alumno 7 el resultado queda igual y en el caso 1 aumenta el número de reflexiones superficiales. Un ejemplo de reflexión superficial lo proporciona el alumno 9:

La carrera [Magisterio] no te hace ser un maestro hasta que no llegas a la práctica porque en realidad ahi es donde aprendes. Y entonces llegas a ser un maestro siguiendo las pautas de mi tutor, de mi profesor de prácticas y ya está. (A9, EPRE)

Cabe desatacar que tras realizar el Practicum y pasar por la situación experimental todos los participantes dejaron de realizar pre-reflexiones, la única categoría que no es considerada propiamente un nivel de reflexión, por este motivo no es posible ofrecer un ejemplo de esta en el grupo experimental.

Respecto a la capacidad de realizar meta-reflexiones, se observa que en dos de los casos ( 1 y 6 ) se obtiene el mismo resultado antes que después del Practicum y en otros dos (7 y 9) aumenta el número de meta-reflexiones tras el Practicum. A continuación, se incluye un extracto de las entrevistas con un ejemplo de meta-reflexión:

Quizá reflexión es simplemente hacer la conclusión de todo lo que has vivido, qué te ha aportado, dentro de la objetividad, como más imparcial y reflexión crítica es quizá lo mismo, pero añadiendo qué mejorarías tú, menos imparcial, añadiendo qué ideas darías tú, si has puesto algún aspecto negativo qué harías para mejorarlo, no simplemente decir esto no me ha parecido bien y esto sí sino proponer alguna opción de mejora. (A7, EPRE)

Si se atiende a la evolución de los alumnos sobre sí mismos, en los participantes 7 y 9 se observa una clara evolución en las respuestas dadas antes y después 
del Practicum. En ambos, anteriormente a las prácticas y a la intervención, la mayoría de reflexiones se ubican en los niveles pedagógico y superficial mientras que tras ese periodo se reducen las de tipo superficial y aumentan las de tipo crítico y autoreflexivo. Este mismo efecto se puede observar, aunque de forma menos notable en el alumno 6 . En cuanto al alumno 1, aunque la mayoría de sus reflexiones se ubican tanto antes como después de la intervención en los niveles pedagógico y superficial, sí se observa un aumento de la reflexión crítica y la auto-reflexión junto a la eliminación de pre-reflexiones en la entrevista post Practicum.

\subsubsection{Resultados de las entrevistas para el grupo control}

A continuación, se procede a examinar detenidamente los resultados de las entrevistas para el grupo control. Se pueden consultar los datos obtenidos en la Tabla 18. Al igual que en la Tabla 17, la primera columna refleja a los participantes numerados para las dos entrevistas, pre y post Practicum, mientras que en el resto de columnas figuran numéricamente las reflexiones realizadas para cada categoría reflexiva.

\section{Tabla 17}

Resultados entrevista pre y post Practicum para el grupo control

\begin{tabular}{|c|c|c|c|c|c|c|}
\hline PARTICIPANTES & CRÍTICA & $\begin{array}{l}\text { AUTO- } \\
\text { REFLEXIÓN }\end{array}$ & PEDAGÓGICA & SUPERFICIAL & $\begin{array}{l}\text { PRE- } \\
\text { REFLEXIÓN }\end{array}$ & $\begin{array}{l}\text { META } \\
\text { REFLEXIÓN }\end{array}$ \\
\hline № 2 PRE & 0 & 0 & 1 & 8 & 6 & 1 \\
\hline № 2 POST & 0 & 0 & 1 & 12 & 5 & 0 \\
\hline № 3 PRE & 1 & 1 & 9 & 10 & 0 & 3 \\
\hline № 3 POST & 1 & 1 & 9 & 4 & 0 & 3 \\
\hline № 4 PRE & 2 & 1 & 1 & 7 & 6 & 2 \\
\hline № 4 POST & 2 & 1 & 5 & 7 & 2 & 2 \\
\hline № 5 PRE & 0 & 0 & 3 & 6 & 6 & 1 \\
\hline № 5 POST & 1 & 0 & 6 & 7 & 2 & 0 \\
\hline № 8 PRE & 1 & 2 & 2 & 10 & 1 & 2 \\
\hline № 8 POST & 2 & 1 & 4 & 11 & 1 & 2 \\
\hline № 10 PRE & 1 & 3 & 6 & 6 & 2 & 3 \\
\hline № 10 POST & 2 & 4 & 4 & 8 & 1 & 0 \\
\hline № 11 PRE & 0 & 2 & 2 & 7 & 4 & 3 \\
\hline № 11 POST & 1 & 0 & 2 & 11 & 3 & 3 \\
\hline
\end{tabular}


Los resultados del grupo control para las categorías de reflexión crítica y auto-reflexión indican que con excepción de los alumnos 5, 10 y 11 no suceden cambios en la cantidad de reflexiones críticas antes y después del Practicum. En el caso de los alumnos 5 y 11 se reducen las reflexiones críticas en la entrevista posterior y en el caso del 10 aumentan. Destaca el participante 2, el cual no logra realizar una reflexión que pueda categorizarse en este ámbito ni antes ni después de las prácticas. Ejemplos de reflexión crítica y auto-reflexión hallados en las entrevistas del grupo control pueden ser respectivamente:

Creo que [economía y educación] están relacionadas estrechamente ya que los recursos que se invierten en la educación son esenciales. No quiero decir que a mayores recursos económicos mejor educación, sino que sí que ayuda. Si el gobierno destina dinero a un colegio, podrá tener mejores infraestructuras, mejor material, los maestros se verán gratificados, se transforma en becas de comedor, de autobuses, etc. y es proporcional, supongo que habrá casos que tendrán mucho menos dinero y aun así seguirán saliendo adelante. (A10, EPOST)

Pienso que tengo mucho autocontrol. Había un profesor que le costaba poco perder los nervios y soltaba cosas que no debía soltar. Yo creo que soy muy tranquilo y tengo mucha paciencia. Creo que ser joven hace que tengas más ganas de innovar y hacer cosas nuevas. Soy también afectivo y emocional. Por otra parte, a veces me falta nervio o sangre para cuando veo alguna cosa que está mal, decir "stop" ahí, sacar el brío. (A10, EPOST)

Para la reflexión pedagógica se observa que tras el Practicum tres participantes aumentan las reflexiones de este nivel (números 4, 5 y 8) mientras otros tres las mantienen igual (números 2, 3 y 11) y solo en uno de los casos se reduce este tipo de reflexión tras finalizar las prácticas (número 10). Un ejemplo de reflexión pedagógica podría ser:

El recurso didáctico más importante es el preparárselo el día de antes o días antes y llevar a clase algo hecho por ti, no el libro de texto. Me parece que los libros de texto a veces ponen actividades que no tienen ningún sentido o explican cosas que realmente si tú reflexionas dices "esto no me sirve ni a mí ni a ellos", y a veces [los libros] se 
equivocan. Si tú previamente no lo miras y no analizas lo que hay, ¿cómo vas a transmitir eso a tus alumnos? La verdad es que me encantaría llegar a un colegio y que no hubiese libro de texto y todo me lo tuviese que preparar yo. (A4, EPOST)

Siguiendo con los resultados para la reflexión superficial, esta aumenta en todos los individuos excepto en dos, el número 4, que queda igual antes y después del Practicum y el 3 cuyas reflexiones superficiales disminuyen tras el Practicum. Un ejemplo de reflexión superficial extraído de las entrevistas sería:

Creo que hay gente que subestima la profesión, hay muchísima gente que se burla de magisterio y no entiendo por qué, porque no estamos todo el día pintando ni pasándolo bien con los niños sino todo lo que hay detrás y no se ve. (A2, EPOST)

En cuanto a la pre-reflexión solo el participante 3 no realiza ninguna ni antes ni después del Practicum. El resto de individuos reducen este tipo de reflexión en la entrevista final si bien todos mantienen al menos una pre-reflexión. Un ejemplo de pre-reflexión en las entrevistas del grupo control sería:

Con la asignatura de Música no me sentía a gusto y no tenía claro que eso fuera lo que yo quería hacer con los niños y de hecho no voy a ser profesora de música. (A11, EPOST)

En cuanto a la capacidad meta-reflexiva, ninguno de los participantes logró aumentar la cantidad de meta-reflexiones en la entrevista final. Cuatro de ellos realizaron la misma cantidad de meta-reflexiones antes y después del Practicum (números 3, 4, 8 y 11) y tres de ellos (números 2,5 y 10) habiendo realizado meta-reflexiones en la entrevista previa no las realizaron en la entrevista final. Se puede considerar el siguiente párrafo un ejemplo de meta-reflexión en el grupo control:

Reflexión es la comparación entre lo que tú tienes adquirido con lo que te enfrentas después y reflexión crítica es cuando tú das tu opinión. Cuando tú das tu opinión una vez ya has reflexionado sobre lo que piensas respecto a esa reflexión. Hacia un enfoque algo más subjetivo. (A8, EPRE) 
En cuanto a la evolución de los participantes respecto a sí mismos, el alumno 2 mejora el número de reflexiones superficiales, pero no evoluciona en el resto de categorías. El alumno 3 no realiza una mejora sustancial de reflexiones entre la primera entrevista y la última. El número 4 mejora únicamente en la reflexión superficial y mantiene iguales o reduce las reflexiones en el resto de ámbitos. El número 5 sí que logra realizar más reflexiones en todas las categorías reflexivas excepto para la meta-reflexión y consigue disminuir la pre-reflexión tras el Practicum. El número 8 mejora la reflexión superficial y pedagógica y el resto se mantienen idénticas. El participante número 10 mejora a nivel crítico y superficial y reduce tanto las reflexiones pedagógicas como las pre-reflexiones en la entrevista post Practicum. Finalmente, el participante 11 aumenta las reflexiones de tipo superficial y disminuye la pre-reflexión mientras que el resto de niveles reflexivos quedan igual o ligeramente reducidos.

Para concluir esta parte del análisis, se comparan entre sí los resultados obtenidos por ambos grupos (experimental y control) en las entrevistas pre y post Practicum y tal y como puede verse en las Tablas 18 y 19. En este caso cambia la distribución de columnas y filas de ambas tablas encontrándose en la primera columna las filas correspondientes a los niveles de reflexión y en las columnas posteriores el número de participante, identificados a su vez como pertenecientes al grupo referencia a la cantidad de reflexiones que cada individuo realiza asociadas a un determinado nivel reflexivo. Nótese que el sumatorio de los resultados del grupo control es en ocasiones mayor que el del expermiental debido a que este primer grupo está compuesto por un mayor número de participantes, así es importante realizar una lectura individual de cada dato y no limitarse a mirar el conjunto de estos.

\section{Tabla 18}

Resultados comparados de la entrevista inicial en el grupo experimental y control.

\begin{tabular}{|l|c|c|c|c|c|c|c|c|c|c|c|c|c|}
\hline NIVEL REFLEXIÓN & GRUPO EXPERIMENTAL & \multicolumn{10}{|c|}{ GRUPO CONTROL } \\
\hline Participantes & 1 & 6 & 7 & 9 & $\Sigma$ & 2 & 3 & 4 & 5 & 8 & 10 & 11 & $\Sigma$ \\
\hline Crítica/Auto-reflexión & 2 & 1 & 4 & 1 & 8 & 0 & 2 & 3 & 0 & 3 & 4 & 2 & 14 \\
\hline Pedagógica & 8 & 14 & 7 & 8 & 37 & 1 & 9 & 1 & 3 & 2 & 6 & 2 & 24 \\
\hline Superficial & 8 & 7 & 6 & 9 & 30 & 8 & 10 & 7 & 6 & 10 & 6 & 7 & 54 \\
\hline Pre-reflexión & 2 & 0 & 2 & 1 & 5 & 6 & 0 & 6 & 6 & 1 & 2 & 4 & 25 \\
\hline Meta-reflexión & 2 & 3 & 3 & 2 & 10 & 1 & 3 & 2 & 1 & 2 & 3 & 3 & 15 \\
\hline
\end{tabular}




\section{Tabla 19}

Resultados comparado de la entrevista final en el grupo experimental y en el control.

\begin{tabular}{|c|c|c|c|c|c|c|c|c|c|c|c|c|c|}
\hline NIVEL REFLEXIÓN & GRL & & RIME & TAL & & GRL & & & & & & & \\
\hline Participantes & 1 & 6 & 7 & 9 & $\Sigma$ & 2 & 3 & 4 & 5 & 8 & 10 & 11 & $\Sigma$ \\
\hline Crítica/Auto-reflexión & 3 & 4 & 10 & 5 & 22 & 0 & 2 & 3 & 1 & 3 & 6 & 1 & 16 \\
\hline Pedagógica & 7 & 11 & 4 & 9 & 31 & 1 & 9 & 5 & 6 & 4 & 4 & 2 & 31 \\
\hline Superficial & 10 & 5 & 6 & 3 & 24 & 12 & 4 & 7 & I & 11 & 8 & 11 & 60 \\
\hline Pre-reflexión & 0 & 0 & 0 & 0 & 0 & 5 & 0 & 2 & & & 1 & 3 & 14 \\
\hline Meta-reflexión & 2 & 3 & 4 & 4 & 13 & 0 & 3 & 2 & 0 & 2 & 0 & 3 & 10 \\
\hline
\end{tabular}

Se observa en las tablas expuestas que antes del Practicum ambos grupos obtienen resultados similares en la reflexión crítica/auto-reflexión, ningún alumno llega a realizar más de cuatro reflexiones de este tipo y en el caso del grupo control hay dos participantes ( 2 y 5) que no realizan ninguna. Sin embargo, en la entrevista postPracticum en el grupo experimental todos los individuos logran mejorar la cantidad de reflexiones críticas, dos de ellos sobrepasan las 4 reflexiones de la entrevista inicial (10 y 5 reflexiones hechas por los alumnos 7 y 9 respectivamente) mientras que en el grupo control uno de los alumnos (el número 10) aumenta hasta 6 reflexiones y el número 5 que antes del Practicum no realiza ninguna, en esta ocasión incluye una reflexión crítica. El resto de participantes mantiene la misma cantidad de reflexiones críticas excepto el número 11 que las reduce tras el Practicum.

Al observar los resultados comparativos en el caso de la reflexión pedagógica, se halla que si bien antes del Practicum los miembros del grupo experimental realizan algunas reflexiones más que los miembros del grupo control, en la segunda entrevista dos ellos (número 1 y 6 ) disminuyen este tipo de reflexiones, el número 7 mantiene la misma cantidad y el 9 la incrementa ligeramente. Los miembros del grupo control, por otro lado o bien aumentan las reflexiones pedagógicas tras el Practicum (alumnos $4,5,8$ ) o bien las mantienen (alumnos $2,3,11$ ) y solo en un caso se reducen (alumno 10).

En cuanto a la reflexión superficial, los resultados para ambos grupos antes del Practicum son similares (entre 6 y 9 reflexiones realiza el grupo experimental y 
entre 6 y 10 reflexiones el grupo control). Sin embargo, tras las prácticas, el grupo experimental obtiene resultados irregulares en cuanto que en uno de los casos aumenta (alumno 1), en otro queda igual (alumnos 7) y los otros dos participantes reducen este tipo de reflexión ( 6 y 9). En el grupo control en cambio la reflexión superficial aumenta en casi todos los casos (2, 5, 8, 10 y 11) excepto en el caso 3 que disminuye $y$ en el 4 que se mantiene igual.

Para la pre-reflexión, el grupo experimental antes del Practicum realiza un número menor de pre-reflexiones por alumno que el grupo control. Después del Practicum el grupo experimental ya no realiza pre-reflexiones y el grupo control logra reducirlas en todos sus miembros, aunque solo el alumno 3 no realiza ninguna.

Finalmente, en cuanto a la meta-reflexión ambos grupos comienzan con cantidades similares de meta-reflexiones pero tras su paso por el periodo de prácticas, el grupo experimental las mantiene o aumenta y el grupo control las mantiene o reduce.

\subsubsection{Sintesis de resultados en ambos grupos para la entrevista reflexiva}

Haciendo una breve recopilación de los resultados obtenidos en este punto se puede observar cómo en general tras el Practicum todos los participantes aumentan el número de reflexiones en la entrevista final sin embargo el grupo experimental las aumenta especialmente a nivel crítico y el grupo control lo hace a nivel superficial y en menor medida a nivel pedagógico. Tras el Practicum los participantes de ambos grupos reducen las pre-reflexiones, pero el grupo experimental lo hace de forma más contundente. En cuanto a la meta-reflexión, para el grupo control no se observa ningún aumento en ésta tras el Practicum mientras que varios miembros del grupo experimental sí la aumentan.

\subsection{Análisis del diario reflexivo online.}

A través del análisis del diario reflexivo se pretenden conocer dos aspectos. En primer lugar, al igual que con las entrevistas, se espera comprobar cuál ha sido la evolución de las reflexiones a lo largo del Practicum para el grupo experimental y para 
el grupo control. En segundo lugar, se examinan también las temáticas y preocupaciones principales sobre las que han reflexionado los participantes de ambos grupos a lo largo de su estancia en prácticas.

\subsubsection{Análisis de los niveles de reflexión de los e-diarios.}

En este apartado se exponen los resultados relacionados con los niveles de reflexión recogidos en los e-diarios reflexivos a lo largo del Practicum I.

\subsubsection{Resultados de los diarios online para el grupo experimental}

Comenzando por el grupo experimental, en la Tabla 20 se pueden observar los resultados obtenidos en cada una de las entradas del diario en orden cronológico. En la primera columna se detalla el número que corresponde a cada participante y a su vez el número de la entrada del diario. En el resto de columnas se refleja numéricamente la cantidad de reflexiones de un determinado nivel para cada entrada del e-diario.

\section{Tabla 20}

Resultado niveles de reflexión en diarios online del grupo experimental

\begin{tabular}{|c|c|c|c|c|c|}
\hline PARTICIPANTES & CRÍTICA & AUTO-REFLEXIÓN & PEDAGÓGICA & SUPERFICIAL & PRE- REFLEXIÓN \\
\hline № 1 Entrada 1 & 0 & 0 & 0 & 3 & 0 \\
\hline № 1 Entrada 2 & 0 & 0 & 0 & 1 & 0 \\
\hline № 1 Entrada 3 & 0 & 0 & 1 & 0 & 0 \\
\hline № 1 Entrada 4 & 0 & 0 & 1 & 0 & 0 \\
\hline № 1 Entrada 5 & 1 & 0 & 1 & 0 & 0 \\
\hline № 1 Entrada 6 & 0 & 0 & 1 & 1 & 0 \\
\hline № 1 Entrada 7 & 0 & 0 & 2 & 1 & 0 \\
\hline №1 Entrada 8 & 1 & 1 & 0 & 2 & 0 \\
\hline № 6 Entrada 1 & 0 & 0 & 2 & 0 & 0 \\
\hline № 6 Entrada 2 & 0 & 0 & 1 & 1 & 0 \\
\hline № 6 Entrada 3 & 0 & 1 & 1 & 1 & 0 \\
\hline i № 6 Entrada 4 & 0 & 1 & 0 & 0 & 0 \\
\hline
\end{tabular}




\begin{tabular}{|c|c|c|c|c|c|}
\hline № 6 Entrada 5 & 0 & 0 & 3 & 0 & 1 \\
\hline № 6 Entrada 6 & 0 & 0 & 0 & 1 & 0 \\
\hline № 6 Entrada 7 & 1 & 0 & 1 & 0 & 1 \\
\hline № 6 Entrada 8 & 2 & 0 & 0 & 0 & 0 \\
\hline № 7 Entrada 1 & 0 & 0 & 0 & 1 & 0 \\
\hline № 7 Entrada 2 & 1 & 0 & 0 & 1 & 0 \\
\hline № 7 Entrada 3 & 1 & 0 & 1 & 1 & 0 \\
\hline № 7 Entrada 4 & 0 & 0 & 1 & 0 & 0 \\
\hline № 7 Entrada 5 & 0 & 0 & 1 & 0 & 0 \\
\hline № 7 Entrada 6 & 0 & 0 & 1 & 0 & 0 \\
\hline № 7 Entrada 7 & 1 & 0 & 0 & 0 & 0 \\
\hline № 7 Entrada 8 & 0 & 0 & 1 & 0 & 0 \\
\hline № 7 Entrada 9 & 0 & 0 & 2 & 0 & 0 \\
\hline № 7 Entrada 10 & 0 & 0 & 1 & 0 & 0 \\
\hline № 7 Entrada 11 & 0 & 0 & 0 & 1 & 0 \\
\hline № 9 Entrada 1 & 1 & 0 & 1 & 0 & 0 \\
\hline № 9 Entrada 2 & 1 & 0 & 0 & 2 & 0 \\
\hline № 9 Entrada 3 & 1 & 0 & 2 & 0 & 0 \\
\hline № 9 Entrada 4 & 0 & 1 & 3 & 1 & 0 \\
\hline № 9 Entrada 5 & 2 & 0 & 1 & 0 & 0 \\
\hline № 9 Entrada 6 & 1 & 0 & 3 & 0 & 0 \\
\hline № 9 Entrada 7 & 2 & 1 & 1 & 0 & 0 \\
\hline № 9 Entrada 8 & 1 & 0 & 2 & 0 & 0 \\
\hline № 9 Entrada 9 & 1 & 0 & 2 & 0 & 0 \\
\hline № 9 Entrada 10 & 0 & 2 & 4 & 2 & 0 \\
\hline
\end{tabular}

En primer lugar, el seguimiento de los diarios reflexivos del grupo experimental para la reflexión crítica y la auto-reflexión evidencia que en tres de los cuatro miembros del grupo (números 1, 6 y 9) se obtiene una evolución positiva en la cantidad de reflexiones realizadas en las últimas entradas del diario respecto a las primeras. El número 7 en cambio conforme avanza en sus entradas reduce hasta eliminar por completo las reflexiones de este nivel. 
Algunos ejemplos de reflexiones críticas y auto-reflexiones halladas en los diarios del grupo experimental serían respectivamente:

Trabajando la educación en valores se consiguen despertar los sentimientos de los alumnos. Enseñarles que es bueno expresar las emociones aunque parece que en la sociedad que vivimos hoy en día nos enseñan a reprimirlas. Bajo mi punto de vista en la sociedad existe gran cantidad de gente analfabeta emocionalmente. No saben cómo responder antes sus emociones. Trabajando esto desde la educación primaria fortalecería mucho más a las personas. (A6, entrada 8)

Es importante como futuro docente saber cómo funciona el centro en el que va a trabajar. Por eso, como alumnos en prácticas, ha sido importante la asistencia a las reuniones que se celebraban (claustros, reuniones de ciclo, cocopes, etc.) El maestro o la maestra además de enseñar tiene que hacer otras tareas que se asocian a su trabajo y es aqui donde me he dado cuenta de que todos estos aspectos son igual de importantes que los otros puesto que sin coordinación no habría los mismos resultados. Es importantísimo que se sepa trabajar entre personas y que se sepa trabajar en grupo y desde mi punto de vista la Universidad sí que ha sabido enseñarnos esta realidad desde nuestros estudios. (A9, entrada 10)

En el caso de la reflexión pedagógica, conforme avanzan las entradas en los diarios los participantes 1, 7 y 9 las aumentan mientras que el número 6 no realiza un avance claro a lo largo de sus entradas ya que realiza las mimas reflexiones en las primeras que en las últimas. Un ejemplo de reflexión pedagógica en los diarios del grupo experimental sería:

Esta semana quiero destacar el tema de las pruebas diagnósticas emitidas por Conselleria a nivel estatal ya que se acercan y han dado mucho de qué hablar. Pues bien, me encuentro con la presión que sufre la tutora de 4ํpor estas pruebas, que bajo mi punto de vista generan un estrés y una mala calidad de la transmisión de conceptos teóricos, porque de prácticos ni hablar. El tiempo aquí se convierte en el peor aliado. Estas pruebas se han de realizar la segunda semana de mayo, es decir, a un mes de finalizar el curso escolar y eso significa que no se han dado todos los temas, como es lógico. Esto genera una presión al docente porque debe terminar de darlo todo para 
que sus alumnos estén capacitados en responder a dichas pruebas. Pienso que de esta manera los alumnos no retienen lo aprendido ya que se da con prisa, no les da tiempo de adquirir y retener los conceptos y tampoco disponen del tiempo necesario para ponerlo en práctica. (Alumno 1, entrada 5)

Respecto a la reflexión superficial, en los participantes 1, 6 y 9 no se observan cambios notables conforme avanzan las entradas de los diarios, sino que en general se mantienen de forma similar a lo largo de todo el periodo de prácticas. En el caso del participante 7 en cambio sí se observa que conforme avanzan sus entradas reduce las reflexiones de tipo superficial. Una muestra de este tipo de reflexión recogida de los diarios se expone a continuación:

Desde la universidad nos han hecho entender y comprender que la educación artística y visual es igual que las matemáticas o la lengua. La universidad le ha dado un peso muy importante a esta asignatura, pero desgraciadamente esta importancia no se ve reflejada en la realidad actual de la escuela. (A9, entrada 2)

Por último, respecto a las pre-reflexiones, tres de los participantes (1, 7 y 9) no realizan ninguna entrada considerada como tal a lo largo del Practicum. El participante número 6 en cambio, comienza las primeras entradas sin ninguna pre-reflexión, pero hacia la segunda mitad del Practicum introduce un par de pre-reflexiones. Un ejemplo de pre-reflexión realizada por este alumno sería:

En la universidad se centran más en materias troncales y estaría bien que nos enseñaran técnicas, dinámicas, etc. de cómo poder trabajar especialmente la resolución de conflictos. (A6, entrada 7)

15.2.1.2 Resultados de los diarios online para el grupo control

Los resultados de los e-diarios reflexivos del grupo control se exponen en la Tabla 21. 
Tabla 21

Resultados de los niveles de reflexión en diarios online del grupo control

\begin{tabular}{|c|c|c|c|c|c|}
\hline PARTICIPANTES & CRÍTICA & AUTO REFLEXIÓN & PEDAGÓGICA & SUPERFICIAL & PRE REFLEXIÓN \\
\hline № 2 Entrada 1 & 0 & 0 & 0 & 2 & 0 \\
\hline № 2 Entrada 2 & 0 & 0 & 0 & 1 & 0 \\
\hline № 2 Entrada 3 & 0 & 0 & 0 & 0 & 1 \\
\hline № 2 Entrada 4 & 0 & 0 & 0 & 1 & 0 \\
\hline № 2 Entrada 5 & 0 & 1 & 0 & 0 & 0 \\
\hline № 2 Entrada 6 & 0 & 0 & 0 & 1 & 0 \\
\hline № 2 Entrada 7 & 1 & 0 & 0 & 0 & 0 \\
\hline № 2 Entrada 8 & 0 & 0 & 1 & 0 & 0 \\
\hline № 3 Entrada 1 & 0 & 0 & 1 & 0 & 0 \\
\hline № 3 Entrada 2 & 0 & 0 & 0 & 2 & 0 \\
\hline № 3 Entrada 3 & 0 & 0 & 1 & 0 & 0 \\
\hline № 3 Entrada 4 & 0 & 0 & 0 & 1 & 1 \\
\hline № 3 Entrada 5 & 0 & 0 & 0 & 0 & 2 \\
\hline № 3 Entrada 6 & 0 & 0 & 0 & 2 & 1 \\
\hline № 3 Entrada 7 & 0 & 0 & 1 & 0 & 0 \\
\hline № 3 Entrada 8 & 0 & 0 & 1 & 0 & 3 \\
\hline № 3 Entrada 9 & 0 & 0 & 0 & 1 & 0 \\
\hline № 3 Entrada 10 & 0 & 0 & 1 & 1 & 1 \\
\hline № 4 Entrada 1 & 0 & 0 & 0 & 0 & 0 \\
\hline № 4 Entrada 2 & 0 & 0 & 0 & 1 & 0 \\
\hline № 4 Entrada 3 & 0 & 0 & 1 & 0 & 0 \\
\hline № 4 Entrada 4 & 0 & 0 & 1 & 0 & 0 \\
\hline № 4 Entrada 5 & 0 & 0 & 1 & 0 & 0 \\
\hline № 4 Entrada 6 & 0 & 0 & 0 & 1 & 0 \\
\hline № 4 Entrada 7 & 0 & 0 & 0 & 0 & 0 \\
\hline № 4 Entrada 8 & 0 & 0 & 0 & 1 & 0 \\
\hline № 4 Entrada 9 & 0 & 0 & 0 & 0 & 1 \\
\hline № 4 Entrada 10 & 0 & 0 & 0 & 0 & 1 \\
\hline № 4 Entrada 11 & 0 & 0 & 2 & 2 & 0 \\
\hline
\end{tabular}




\begin{tabular}{|c|c|c|c|c|c|}
\hline № 5 Entrada 1 & 0 & 0 & 0 & 1 & 0 \\
\hline № 5 Entrada 2 & 0 & 0 & 1 & 1 & 0 \\
\hline № 5 Entrada 3 & 0 & 1 & 0 & 0 & 0 \\
\hline № 5 Entrada 4 & 0 & 0 & 0 & 1 & 0 \\
\hline № 5 Entrada 5 & 0 & 0 & 1 & 1 & 0 \\
\hline № 5 Entrada 6 & 0 & 1 & 0 & 0 & 0 \\
\hline № 5 Entrada 7 & 0 & 0 & 0 & 0 & 2 \\
\hline № 5 Entrada 8 & 0 & 0 & 0 & 1 & 0 \\
\hline № 5 Entrada 9 & 0 & 0 & 0 & 0 & 1 \\
\hline № 8 Entrada 1 & 0 & 0 & 0 & 1 & 0 \\
\hline № 8 Entrada 2 & 0 & 0 & 0 & 0 & 1 \\
\hline № 8 Entrada 3 & 0 & 1 & 0 & 0 & 0 \\
\hline № 8 Entrada 4 & 0 & 1 & 0 & 0 & 0 \\
\hline № 8 Entrada 5 & 0 & 0 & 1 & 0 & 0 \\
\hline № 8 Entrada 6 & 0 & 0 & 0 & 1 & 0 \\
\hline № 8 Entrada 7 & 0 & 0 & 0 & 0 & 1 \\
\hline № 8 Entrada 8 & 0 & 0 & 0 & 1 & 0 \\
\hline № 8 Entrada 9 & 0 & 0 & 0 & 0 & 1 \\
\hline № 8 Entrada 10 & 1 & 0 & 0 & 0 & 0 \\
\hline № 10 Entrada 1 & 0 & 0 & 0 & 0 & 0 \\
\hline № 10 Entrada 2 & 0 & 0 & 0 & 1 & 0 \\
\hline № 10 Entrada 3 & 0 & 1 & 0 & 0 & 0 \\
\hline № 10 Entrada 4 & 0 & 0 & 0 & 1 & 0 \\
\hline № 10 Entrada 5 & 0 & 0 & 0 & 0 & 1 \\
\hline № 10 Entrada 6 & 0 & 0 & 0 & 0 & 0 \\
\hline № 10 Entrada 7 & 0 & 0 & 1 & 0 & 0 \\
\hline № 10 Entrada 8 & 0 & 0 & 0 & 1 & 0 \\
\hline № 10 Entrada 9 & 0 & 0 & 1 & 0 & 0 \\
\hline № 10 Entrada 10 & 0 & 0 & 1 & 1 & 0 \\
\hline № 10 Entrada 11 & 0 & 0 & 0 & 1 & 2 \\
\hline № 11 Entrada 1 & 0 & 0 & 0 & 0 & 0 \\
\hline
\end{tabular}




\begin{tabular}{|c|c|c|c|c|c|}
\hline № 11 Entrada 2 & 0 & 0 & 0 & 0 & 1 \\
\hline № 11 Entrada 3 & 0 & 0 & 1 & 0 & 0 \\
\hline № 11 Entrada 4 & 0 & 0 & 0 & 1 & 0 \\
\hline № 11 Entrada 5 & 0 & 0 & 0 & 0 & 1 \\
\hline № 11 Entrada 6 & 0 & 0 & 0 & 0 & 0 \\
\hline № 11 Entrada 7 & 0 & 0 & 0 & 0 & 2 \\
\hline № 11 Entrada 8 & 0 & 0 & 0 & 0 & 1 \\
\hline № 11 Entrada 9 & 0 & 0 & 0 & 0 & 0 \\
\hline № 11 Entrada 10 & 0 & 0 & 0 & 1 & 0 \\
\hline № 11 Entrada 11 & 0 & 0 & 0 & 1 & 2 \\
\hline
\end{tabular}

Continuando ahora con el análisis de los e-diarios reflexivos del grupo control se observa que en lo que respecta a la reflexión crítica y auto-reflexión, hay tres participantes (3, 4 y 11) que no realizan reflexión alguna atribuible a este criterio. Otros tres participantes ( 5,8 y 10) sí realizan alguna reflexión crítica pero no se observa evolución a lo largo de los diarios. Por último, el alumno número 2 es el único que evoluciona a nivel reflexivo crítico, pasando de no hacer reflexiones críticas en sus primeras entradas a incluir alguna en las últimas.

Mucha gente, ignorante a mi parecer, siempre habla de la profesión de maestro como si fuésemos unos vagos que no hacemos nada, que cobran bien y tienen muchas vacaciones. Lo que esa gente desconoce, es la gran labor que hay detrás de cada uno de esos alumnos. Los niños no aprenden ni a leer, ni a sumar, ni a restar por amor al arte, detrás hay mucha paciencia, esfuerzo y constancia que solo alguien que tenga alguna vinculación con la educación sabe. Esos maestros "vagos" son los que cada día están con sus hijos, enseñándoles, no sólo a nivel académico, sino también modales y valores, haciendo de maestros y de padres. Esos niños después llegan a su casa con sus padres (que hacen este tipo de afirmaciones sobre los maestros) y no tienen ni rutina, ni constancia, ni esfuerzo. Primero que cada uno mire lo que tiene en su casa. (A8, entrada 10)

Esta semana lo que más me ha llamado la atención ha venido de una falta de respeto por parte de una niña. Le di mucha confianza, quizá demasiada. Finalmente, un día 
se puso muy pesada, no me hacía caso y le amenacé diciéndole que le iba a poner un cero. Como seguía sin tomarme en serio, le dije que se lo había puesto. Su respuesta fue que me odiaba, que nunca más sería mi amiga y que la relación entre nosotras había acabado. Me quedé sorprendida porque lo que me dijo me llegó a doler, me molestó mucho porque he llegado a cogerle cariño, entonces le dije que si se portaba bien se lo quitaría, reculando.

Pensando bastante en el tema me di cuenta de que si no cambiaba mi actitud con ella siempre se iba a aprovechar de mi y haría lo que quisiera conmigo. Así que decidi echarle la bronca cuando se lo mereciera y hacer lo que tuviera que hacer.

Así que los días de después hice lo planeado y sí, se enfadó conmigo y me decía muchas cosas hirientes, pero finalmente su comportamiento ha empezado a cambiar. (A5, entrada 6)

En cuanto a la reflexión pedagógica, en la mayoría de los participantes del grupo control no se da una evolución a lo largo de las entradas de los diarios. Los participantes número 2, 4, 5, 8 y 11 realizan similar cantidad de reflexiones pedagógicas al principio del Practicum que al final de este. Los participantes número 3 y 10 en cambio sí mejoran a lo largo de sus entradas la cantidad de reflexiones pedagógicas. Un ejemplo de reflexión pedagógica en el grupo control sería el que se expone a continuación:

Esta semana reflexioné sobre la importancia de enseñar a trabajar en grupo desde bien pequeños. Desde que entré al colegio los niños están sentados por grupos de 5 personas, al principio puede parecer que de esta manera no trabajan porque hablan con el que tienen al lado o se entretienen mirando qué hace el de enfrente, pero la verdad es que estoy sorprendiéndome con los resultados. Cada miembro del equipo tiene una función que debe cumplir si quiere que su equipo funcione bien. Cada alumno se va dando cuenta que su aportación es importante y que, si uno falla, repercute a su equipo.

Pienso que se debería aplicar en todas las aulas ya que en un futuro ya sea para los estudios o para el trabajo vas a convivir con personas, aunque algunas de ellas 
no sean de tu agrado y hay que empezar desde pequeños a saber coexistir con los compañeros. (A2, entrada 8)

Continuando con la reflexión superficial, la mayoría de miembros del grupo control realizan más reflexiones superficiales en las últimas entradas del diario que en las primeras (3, 4, 8, 10 y 11) y dos de ellos realizan menos reflexiones superficiales conforme avanzan sus entradas ( 2 y 5 ). Un ejemplo de reflexión superficial recogido en los diarios del grupo control sería:

A lo largo de esta semana no se ha hecho ninguna actividad extra por lo que la monotonía del horario ha ocupado todo el tiempo. Esto hace que los niños y niñas se sientan más incómodos porque se aburren y no encuentran algo que les motive lo suficiente como para prestar la atención necesaria. (A3, entrada 9)

Finamente, al examinar las pre-reflexiones, todos los individuos excepto el número 2 realizan más pre-reflexiones en las entradas finales del diario que en las iniciales. Destacar el caso del alumno 2 quien realiza una única pre-reflexión en todo el proceso. Como ejemplo de pre-reflexión en el grupo control se expone la siguiente:

Desde el principio sabía que esta semana iba a ser dura o pesada ya que me perdía las fiestas de la Magdalena. Jamás me he perdido ni un solo día de ellas en mi vida y este año sabía que tenía que afrontarlo al estar fuera de Castellón. Mi sorpresa ha sido ver cómo cada mañana me levantaba sin esfuerzo, con ganas de ir a clase, sin pensar lo que me estaba perdiendo sino lo que iba a ganar ese día. (A2, entrada 3)

Para concluir este apartado, finalmente se va a comparar la cantidad de reflexiones de cada categoría que realizan los miembros del grupo experimental frente a las del grupo control (ver Tabla 22). En la primera columna de la tabla figuran los niveles mencionados y en las otras columnas los participantes numerados, agrupados según su pertenencia al grupo experimental o al grupo control. Los datos numéricos de la tabla se corresponden con la cantidad total de reflexiones que cada participante ha realizado en su diario reflexivo. 


\section{Tabla 22}

Reflexiones en los e-diarios del grupo experimental vs grupo control

\begin{tabular}{|c|c|c|c|c|c|c|c|c|c|c|c|c|c|}
\hline NIVEL REFLEXIÓN & GRL & EX & & & & GRU & CO & ROL & & & & & \\
\hline Participantes & 1 & 6 & 7 & 9 & $\Sigma$ & 2 & 3 & 4 & 5 & 8 & 10 & 11 & \\
\hline Crítica/Auto-reflexión & 3 & 5 & 3 & 14 & 25 & 2 & 0 & 0 & 2 & 3 & 1 & 0 & 8 \\
\hline Pedagógica & 6 & 8 & 8 & 19 & 41 & 1 & 5 & 3 & 2 & 1 & 3 & 1 & \\
\hline Superficial & 8 & 3 & 4 & 5 & 20 & 5 & 7 & 5 & 5 & 3 & 5 & 3 & \\
\hline Pre-reflexión & 0 & 2 & 0 & 0 & 2 & 1 & 8 & 2 & 3 & 3 & 3 & 7 & 27 \\
\hline
\end{tabular}

Tal y como se puede observar, todos los participantes que pasaron por la situación experimental han realizado comparativamente mayor número de reflexiones críticas y pedagógicas que los que participaron como grupo control. Se identifica de igual modo que los miembros de ambos grupos han realizado similar cantidad de reflexiones de tipo superficial. En el caso de la pre-reflexión, los alumnos del grupo control han realizado mayor número de estas que los del grupo experimental ya en este último ningún participante -excepto el número 6las realizó mientras que todos los miembros del grupo control las realizaron en mayor o menor medida.

\subsubsection{Síntesis de resultados en ambos grupos para los e-diarios reflexivos}

Recapitulando la información sobre los resultados obtenidos en el análisis de los niveles reflexivos de los diarios online, se puede determinar que en general los miembros que han pasado por la situación experimental han reducido notablemente las pre-reflexiones, hecho que no ha sucedido en el grupo control. Por otro lado, el grupo experimental ha evolucionado y mantenido a lo largo de los diarios un mayor número de reflexiones críticas y auto-reflexiones que el grupo control. Esta tendencia también se observa, aunque de forma algo más moderada en el caso de la reflexión pedagógica. Finalmente, a nivel de reflexión superficial no se observan diferencias en el número de reflexiones realizadas por el grupo experimental frente al control. 


\subsubsection{Análisis de los temas emergentes.}

El último de los aspectos a analizar es el referido a los temas que emergen en los diarios reflexivos online del alumnado. Se trata de recapitular las temáticas sobre las cuales más reflexiona el alumnado durante el Practicum con independencia del nivel reflexivo al que puedan pertenecer dichas reflexiones.

En la Tabla 23 se pueden ver los temas sobre los cuales han reflexionado los participantes. En la primera columna figuran todas las categorías temáticas y subcategorías. En las otras columnas figuran los participantes agrupados según su pertenencia al grupo experimental o control. Las cifras que aparecen incluidas en la tabla muestran las veces que un determinado alumno ha reflexionado sobre un tema. La codificación y descripción de las categorías generales figuran en la Tabla 14.

El resultado más destacable de la tabla de temáticas del grupo experimental frente al grupo control es la parte relacionada a la reflexión sobre aspectos socio-críticos (ASC) que han surgido a partir de la experiencia práctica. Así, se evidencia que únicamente los miembros del grupo experimental -excepto el número 1- se plantean este tipo de cuestiones en sus diarios reflexivos mientras que los miembros del grupo control no lo hacen en ningún caso.

Otra diferencia intergrupal se da en las reflexiones sobre didáctica de la lengua, sobre la cual solo reflexionan participantes del grupo experimental y ninguno del grupo control.

Sobre el resto de elementos emergentes en las reflexiones no se encuentra una pauta concreta que diferencie entre los temas que preocupan al grupo experimental y los del grupo control, por el contrario, se observan temáticas similares entre ambos grupos y las diferencias que existen son más bien de carácter interindividual. 


\section{Tabla 23}

Temas de reflexión del grupo experimental y del grupo control

\begin{tabular}{|c|c|c|c|c|c|c|c|c|c|c|c|c|}
\hline \multirow{2}{*}{\multicolumn{2}{|c|}{$\begin{array}{l}\text { Temas de reflexión } \\
\text { Participantes }\end{array}$}} & \multicolumn{4}{|c|}{ Grupo experimental } & \multicolumn{7}{|c|}{ Grupo control } \\
\hline & & 1 & 6 & 7 & 9 & 2 & 3 & 4 & 5 & 8 & 10 & 11 \\
\hline \multicolumn{2}{|l|}{ EPP } & 1 & 0 & 1 & 4 & 1 & 2 & 0 & 1 & 1 & 3 & 2 \\
\hline \multicolumn{2}{|l|}{ GMP } & 2 & 5 & 1 & 4 & 2 & 0 & 0 & 1 & 2 & 5 & 1 \\
\hline \multicolumn{2}{|l|}{ RF } & 0 & 0 & 2 & 3 & 0 & 0 & 1 & 1 & 1 & 1 & 3 \\
\hline \multicolumn{2}{|l|}{\begin{tabular}{l}
$\mathrm{CP}$ \\
\hdashline
\end{tabular}} & 0 & 1 & 1 & 3 & 1 & 1 & 2 & 1 & 1 & 1 & 0 \\
\hline \multirow{3}{*}{ ASC } & Sociedad & 0 & 1 & 0 & 8 & 0 & 0 & 0 & 0 & 0 & 0 & 0 \\
\hline & Política & 0 & 0 & 2 & 2 & 0 & 0 & 0 & 0 & 0 & 0 & 0 \\
\hline & Sistema Educativo & 0 & 0 & 2 & 1 & 0 & 0 & 0 & 0 & 0 & 0 & 0 \\
\hline \multirow{6}{*}{ DOE } & Metodología & 1 & 3 & 2 & 4 & 1 & 1 & 3 & 0 & 1 & 4 & 1 \\
\hline & Diversidad y NEE & 7 & 1 & 1 & 3 & 0 & 2 & 1 & 3 & 2 & 2 & 2 \\
\hline & Convivencia & 1 & 3 & 0 & 3 & 1 & 1 & 0 & 2 & 3 & 0 & 3 \\
\hline & Organización & 1 & 1 & 1 & 3 & 0 & 2 & 1 & 0 & 0 & 2 & 3 \\
\hline & Evaluación & 1 & 2 & 0 & 0 & 0 & 1 & 1 & 0 & 1 & 0 & 2 \\
\hline & $\mathrm{TIC}$ & 0 & 0 & 1 & 0 & 0 & 0 & 2 & 0 & 0 & 3 & 2 \\
\hline \multirow[t]{5}{*}{ DE } & Conocimiento del Medio & 0 & 0 & 0 & 0 & 0 & 0 & 2 & 0 & 0 & 2 & 0 \\
\hline & Lengua & 0 & 2 & 1 & 1 & 0 & 0 & 0 & 0 & 0 & 0 & 0 \\
\hline & Matemáticas & 0 & 1 & 0 & 1 & 0 & 0 & 1 & 0 & 0 & 0 & 0 \\
\hline & Artes Plásticas & 0 & 0 & 0 & 1 & 0 & 0 & 0 & 0 & 0 & 1 & 1 \\
\hline & Educación Física & 0 & 0 & 0 & 0 & 0 & 1 & 0 & 0 & 0 & 0 & 0 \\
\hline \multirow[t]{4}{*}{ CA } & Comportamiento & 0 & 0 & 0 & 1 & 0 & 3 & 0 & 2 & 3 & 0 & 0 \\
\hline & Motivación & 0 & 2 & 0 & 0 & 0 & 0 & 0 & 0 & 0 & 0 & 0 \\
\hline & Cognitivas & 0 & 0 & 0 & 1 & 0 & 0 & 1 & 0 & 0 & 0 & 1 \\
\hline & Personalidad & 1 & 0 & 0 & 0 & 0 & 0 & 1 & 1 & 0 & 0 & 0 \\
\hline
\end{tabular}

El análisis de las temáticas emergentes por lo tanto se va a realizar sin distinguir entre condición experimental o control, agrupando todas las aportaciones respecto a un mismo tema, ya que el objetivo es determinar qué aspectos educativos preocupan más al alumnado de Practicum y qué temas escolares producen mayor número de reflexiones (ver Tabla 24). La tabla se ha organizado situando en la primera 
columna los temas generales de reflexión que se han ido recopilando en la lectura de los diarios y los subtemas que se han derivado de algunas de las categorías generales.

Los cuatro primeros códigos obedecen a categorías generales que carecen de subcategorías y los cuatro siguientes se desglosan en varias subcategorías. En la segunda columna se establece un recuento que se corresponde con las veces en que un determinado tema surge en los diarios como foco de reflexión.

\section{Tabla 24}

Temas de reflexión agrupados

\begin{tabular}{|l|l|l|}
\hline Temas de reflexión & Total temas \\
\hline EPP & & 16 \\
\hline GMP & & 23 \\
\hline RF & & 12 \\
\hline CP & & 12 \\
\hline ASC & Sociedad & 9 \\
\hline$(16)$ & Política & 4 \\
\hline & Sistema Educativo & 3 \\
\hline DOE & Metodología & 21 \\
\hline$(92)$ & Diversidad y NEE & 24 \\
\hline & Convivencia & 17 \\
\hline & Organización & 14 \\
\hline & Evaluación & 8 \\
\hline DE & TIC & 8 \\
\hline (15) & Conocimiento del Medio & 4 \\
\hline & Lengua & 4 \\
\hline & Matemáticas & 3 \\
\hline & Artes Plásticas & 3 \\
\hline CA & Educación Física & 1 \\
\hline (17) & Comportamiento & 9 \\
\hline & Motivación & 2 \\
\hline & Cognitivas & 3 \\
\hline & Personalidad & 3 \\
\hline
\end{tabular}


Se puede observar que los temas sobre los que más han reflexionado los participantes son los codificados como DOE (didáctica y organización escolar) con un total de 92 reflexiones al respecto. En segundo lugar, con 23 reflexiones se sitúan las reflexiones referidas al Grado de Maestro en Educación Primaria (GMP). Sobre las características de los alumnos de primaria (CA) se reflexiona hasta en 17 ocasiones. Las categorías relacionadas con la evolución personal del estudiante durante el Practicum (EPP) y sobre aspectos socio-críticos (ASC) obtienen 16 reflexiones respectivamente. Por otro lado, se encuentran 15 reflexiones relativas a didácticas específicas (DE) y finalmente se recopilan 12 reflexiones que tratan la relación con las familias (RF) y 12 sobre las características del profesorado (CP).

Seguidamente se procede a desglosar cada una de las áreas temáticas utilizando ejemplos que contribuyan a ilustrar el tipo de reflexión correspondiente a cada categoría. En primer lugar, se detallan las categorías generales para las cuales no hay subcategorías y posteriormente se especificarán las que sí tienen.

Comenzando por la evolución personal del alumno durante Practicum (EPP) los participantes hacen referencia a cómo va siendo su inmersión en la vida del centro y cómo evoluciona su propio aprendizaje.

He tenido la oportunidad de dar varias clases durante estas semanas, pienso que empiezo a desenvolverme con soltura y he perdido la vergüenza, también considero que los alumnos y alumnas tienen confianza en mí y me ven como una maestra más. (A11, entrada 4)

Durante todo este tiempo he visto funcionar la escuela a diferentes niveles. Como un docente más he aprendido a coordinarme con el centro como conjunto $y$ he intentado aprovechar esta experiencia participando en todas las posibilidades que había a mi alcance para poder sacar el máximo beneficio y el máximo aprendizaje de este Pràcticum I. Me he intentado involucrar con el centro de varias formas, gracias a las cuales he podido obtener un aprendizaje más significativo del que hubiera obtenido si sólo hubiera cumplido con el mínimo exigible. (A9, entrada 10) 
En general cuando reflexionan sobre del Grado en Maestro de Educación Primaria suele ser para echar en falta más prácticas dentro de la titulación y menos teoría o para resaltar la deficiente preparación que percibe el alumno respecto a recursos didácticos útiles para afrontar situaciones del aula:

Concluir diciendo que considero que he aprendido más en estas semanas de prácticas en la escuela que en los dos años de universidad. Y veo un problema en que no se hagan prácticas en el 1er y $2^{\circ}$ año de carrera, puesto que por ejemplo, de muchas teorías y/o actividades que he visto en $1^{\circ}$ ya casi ni me recordaba. (A10, entrada 11)

Decir que las prácticas además de enseñarme la realidad de esta profesión también me han hecho pensar en lo que me ha servido durante los tres años de carrera y lo que no ha sido útil a la hora de poner en práctica mis conocimientos. Bajo mi punto de vista y resumiendo, creo que durante la carrera en ciertas asignaturas deberían hacer más prácticas y menos teoría. (A1, entrada 8)

En cuanto a las relaciones con las familias (RF) las reflexiones inciden en la falta de objetividad y confianza con los tutores y la falta de implicación real con el centro:

Por lo que estoy observando la mayoría de los padres y madres que se quieren involucrar más en la educación de sus hijos lo único que hacen es quejarse del profesorado: se quedan a espiar desde las vallas, quieren acompañar a sus hijos hasta la clase porque no se fían (¿De qué? ¿De quién?), exigen que su hijo vuelva a hacer una división delante suya porque en casa síque le salen..., y asi mil reclamaciones más. (A10, entrada 5)

Durante esta semana ha ocurrido un conflicto con un alumno de mi clase y su madre. La tutora se ha reunido con ella para aclarar la situación, al parecer la madre estaba descontenta con el trato que estábamos teniendo con su hijo (nosotras y el resto de profesores del centro). Nuestro trato hacia este alumno es igual al que tenemos con el resto de la clase. Hemos intentado apaciguar la situación y tranquilizar a la madre, pero sin dejar de reñir al alumno cuando se comporta mal en clase. (A11, entrada 7) 
Respecto a las características del profesorado (CP), el alumnado suele reflexionar sobre la actuación de su propio tutor y sobre a aspectos formativos del profesorado:

Quizá el problema está en que los profesores deberían estar actualizados en estos temas [educación emocional] mediante cursos o charlas por parte del Ministerio de Educación al igual como reciben otros tipos de cursos menos importantes como por ejemplo, yoga. ¿Por qué no se priorizan unas cosas sobre otras? ¿Es preciso utilizar los recursos con estos tipos de cursos que, en mi opinión, no afectan ni positiva ni negativamente a los alumnos? (A9, entrada 3 )

La labor de la tutora en este caso no es la adecuada. En mi humilde opinión y nunca quitándole mérito a una mujer que está día tras día con ellos y no sé hasta qué punto ha intentado evitar estos comentarios, pienso que esto se debería haber parado desde la primera falta de respeto y el primer comentario fuera de lugar. (A5, entrada 2)

A continuación, se van a detallar y ejemplificar los resultados relacionados con las subcategorías correspondientes a las categorías generales de aspectos sociocríticos (ASC), didáctica y organización escolar (DOE), didácticas específicas (DE) y características del alumnado (CA).

En primer lugar, para el código ASC (aspectos socio-críticos), se observa que los participantes reflexionan en primer lugar sobre la sociedad en general ( 9 reflexiones), en segundo lugar, sobre política educativa (4 reflexiones) y en tercer lugar se mencionan aspectos relacionados con el sistema educativo en general (3 reflexiones). Algunos ejemplos de las tres subcategorías respectivamente serían:

Quizá en estos tiempos de crisis sí que hemos podido ver a una sociedad más competitiva que la de años atrás y esto ha hecho que todos en mayor o menor medida nos hayamos vuelto más competitivos a la hora de alcanzar o de llegar a alguna meta. Todo esto ha arrastrado a que se castigue más lo negativo que a que se premie lo positivo, por lo tanto aquí estará el papel de la institución educativa que tendrá el objetivo de educar a seres humanos que intenten cambiar esta conducta que se está creando. (A9, entrada 5) 
(...) Cuando la directora preguntó en el ayuntamiento por qué no se podían aplazar las obras hasta verano, ya que no eran de necesidad inmediata, estos les dijeron que no podía ser y dejaron caer que las obras tenían que estar acabadas antes de las elecciones para que de esta manera dejaran con buena imagen al partido de gobierno actual. Lo que a mi me asombra, es que sea más importante la imagen de un partido y los méritos que van a hacer en la cuenta atrás que el bienestar y la educación de los niños. (A7, entrada 7)

Yo creo que el problema está en que quien marca los contenidos, los objetivos, qué dar en el aula, no tiene ninguna idea de cómo enseñar a un niño, ni qué le gusta a un niño, ni sabe nada sobre sus necesidades. Lo único que saben es que cuando el niño tenga 18 años y tenga que ir a la universidad tendrá que saber infinidad de cosas que después realmente no le van a servir. (A7, entrada 9)

Para el código DOE (didáctica y organización escolar), las reflexiones del alumnado han ido dirigidas en primer lugar a la atención a la diversidad y a las necesidades educativas especiales (24 reflexiones). En segundo lugar, se reflexiona sobre la metodología que se emplea en la escuela (21 reflexiones). También es objeto de reflexión el tema de la convivencia en el aula y en el centro (17 reflexiones) así como algunos aspectos propios de la organización escolar (14 reflexiones) y en último lugar, los alumnos reflexionan sobre la evaluación del alumnado (8 reflexiones) y sobre el uso de las tecnologías de la información y la comunicación en la escuela (8 reflexiones).

Algunos ejemplos de reflexiones sobre diversidad y necesidades educativas especiales se exponen a continuación, considerando que en general los participantes constatan la gran diversidad que existe dentro de las aulas y los pocos recursos que tienen los centros para hacerles frente.

Para terminar esta reflexión, decir que hace falta más personal del campo de la psicología ya que el proceso para diagnosticar a los alumnos que muestran cierta dificultad en seguir el ritmo de la clase, estos son diagnosticados con tardanza. (A1, entrada 1)

Mi planteamiento o reflexión viene cuando me doy cuenta que los cuatro niños que 
necesitan ayuda, solo la tienen una vez a la semana y en el aula la profesora no se la puede prestar porque exceptuando los dos días que viene la educadora, tiene que estar todo el tiempo pendiente del niño que tiene Asperger. (...) Desde mi punto de vista, y sé que parece un poco general, el problema es que no hay suficientes profesionales, ya sea una educadora más días a la semana, o que los otros cuatro alumnos pudieran salir más horas a refuerzo para mejorar en lo que más lo necesitan. (A7, entrada 1)

En cuanto a ejemplos de reflexiones sobre metodología, los alumnos comentan sobre la metodología empleada en el aula en la que realizan las prácticas, pero también sobre la metodología que predomina en la educación actual así como de aquellas propuestas que ponen en práctica por sí mismos y los resultados que obtienen.

Cada vez que empiezo un tema nuevo en alguna asignatura, veo de qué manera puedo innovar o hacerlo diferente de cómo pone en el libro y se me vienen mil ideas a la cabeza, pero siempre tengo algún impedimento. En cuanto quiero hacer alguna actividad un poco más extensa o elaborada, me faltan días, no tengo materiales o necesito demasiado espacio; una vez consigo hacer algo innovador y quiero que tenga peso sobre la nota, me veo súper limitada, ya que la mayoría de la nota recae sobre los exámenes y deberes. (A7, entrada 4)

En ésta semana lo que más me ha podido llamar la atención es el tipo de actividades que se han llevado a cabo. Bajo mi punto de vista, un poco desfasadas y con poca preparación. Se han hecho manualidades, pero pienso que antes la maestra debe saber cómo se hacen y llevar alguna muestra, algo que no ha sido asi. Después se han hechos los típicos crucigramas, etc. Creo que en pleno siglo XXI y con toda la tecnología que tenemos a nuestro alcance, se podían haber realizado actividades mucho más modernas, lúdicas e igual de enriquecedoras que las antiguas o más. (A8, entrada 5)

Respecto a la subcategoría de convivencia, el alumnado hace referencia principalmente a la forma en que se lleva a cabo la resolución de conflictos y las situaciones conflictivas que surgen en el aula. Algunos ejemplos serían: 
En esta cuarta semana dos niños tuvieron un pequeño enfrentamiento entre ellos, típicas discusiones de niños de 8 años. Durante estas semanas he ido viendo cómo mi tutora iba solucionando los problemas que surgían durante las clases, los conflictos dentro y fuera del aula, las charlas con ellos sobre cualquier tema... Y la verdad, me sorprenden los recursos que tiene para todo y que siempre da la respuesta correcta. Sabe lo que hace en cada momento y cómo lo hace. (A2, entrada 4)

Lo que más me ha llamado la atención de esta semana y que además, me llama la atención desde la primera semana que entré en esa clase, son las faltas de respeto continuas que se tienen los niños entre ellos. Como salen de su boca barbaridades y palabras que sorprende escucharlas en niños y niñas de 8 años.

Creo recordar que yo a esa edad no se me ocurría faltarle al respeto a mis compañeros de esa manera. Pero como estoy pudiendo comprobar, los tiempos cambian y los niños/as hoy en día están mucho más espabilados que antes. Las razones no sé muy bien cuáles podrían ser. (A5, entrada 2)

Las reflexiones sobre la subcategoría de organización escolar hacen referencia a las reuniones de coordinación, los horarios lectivos y aspectos organizativos del centro y del aula. Tal y como se puede ver en los ejemplos expuestos a continuación:

El aula también es un elemento clave en el acto de enseñanza-aprendizaje puesto que, si esta no está dotada de aquello que sus alumnos requieren, no está acondicionada para el nivel al que va dirigida ni sus espacios están bien dispuestos, puede repercutir de forma negativa en la adquisición de conocimientos de sus alumnos. Durante mis prácticas he visto la importancia que tiene el distribuir bien a los escolares y viendo si había relación verdadera entre lo que decía la teoría y los resultados que mostraba la práctica. (A9, entrada 10)

Algo que no sabíamos ninguno de nosotros era el mecanismo de elección de directores y directoras: tras cumplir los dos primeros años en el cargo, si el director o directora quiere volver a presentarse el puesto es para él o ella, aunque haya otra persona que también quiera serlo. En el caso de que la directora o el director no quiera volver a ejercer el cargo, si no hay nadie que quiera ocupar su lugar, está obligado u obligada a continuar uno o dos años más. (A11, entrada 9) 
Para la subcategoría de evaluación, se encuentran diversas reflexiones sobre las pruebas que ha implantado la LOMCE y sobre los momentos clave de evaluación en el aula y en el centro. Por ejemplo:

En esta entrada de mi diario de prácticas voy a hablar sobre las famosas pruebas diagnósticas. (...) En los modelos que he podido ver sobre pruebas de años anteriores he observado que son realmente difíciles. Al parecer ha llegado a oídos de la dirección del centro que en otras escuelas los maestros y maestras ayudan a sus alumnos y alumnas. Lo cual no me parece mal ya que se trata de una competición totalmente innecesaria y que pone a los alumnos nerviosos. (A11, entrada 10)

Es bueno hacer una evaluación previa para ver quién necesita refuerzo en según qué partes. El haber sacado a la pizarra a niños que no habían sabido hacer el problema me sirvió para asegurarme de que lo entendían. Iba interactuando con todos los alumnos y no solo con el que había sacado a la pizarra. Además, intentaba hacer preguntas a aquellos que podía ver que no estaban entendiendo el problema. (A6, entrada 5)

Finalmente, para concluir la categoría DOE se revisan las reflexiones relacionadas con las nuevas tecnologías de la información y la comunicación (TIC). En este caso, suelen reflexionar sobre las posibilidades que ofrecen las TIC en el aula y las tecnologías que se usan en el centro de forma habitual.

Las TIC se encargan de mejorar y dar un nuevo rumbo a la educación, para ello editoriales como "Blinklearning" y "SM" que antes realizaban exclusivamente libros de texto, ahora también emplean una metodología aplicada a las TIC. (...) El objetivo de estas editoriales es realizar un cambio en el ámbito académico. ¿Pero sucede esto de verdad? Yo creo que todos estos recursos los saben vender muy bien, pero que después en el aula lo único que utilizamos es el libro digital proyectado en la pantalla, pero como el libro normal, no les damos ningún uso más. En mi aula hay una pizarra digital y tenemos CD's con programas de visión del cuerpo humano en 3D o realidad aumentada pero nunca se han usado. La mayoría de los profesores se excusan que no saben cómo van o no tienen tiempo. (A7, entrada 6 ) 
Nos han enseñado cómo se gestiona todo desde el programa Ítaca de la Generalitat, pese a que algunos días este programa se encuentra inaccesible por problemas internos del servidor. También hemos hablado sobre el problema existente con el correo electrónico del centro ya que los padres y las madres utilizan este medio para asuntos que deben tratarse en persona, como por ejemplo quejas sobre la escuela, sobre otros alumnos y alumnas o sobre otros padres y madres. (A11, entrada 9)

Continuando con los códigos que contienen subcategorías, se van a describir los resultados relativos a las didácticas específicas (DE). Para esta categoría las materias que se han mencionado con mayor frecuencia son las de Conocimiento del Medio (4 reflexiones) y la de Lengua (4 reflexiones), en segundo lugar, Matemáticas (3 reflexiones) y Artes Plásticas (3 reflexiones) y por último se ha realizado una reflexión relacionada con la materia de Educación Física. En general las didácticas específicas que se mencionan en los diarios suscitan reflexiones dirigidas a los resultados -positivos o negativos- de la puesta en práctica de la metodología estudiada durante la carrera respecto a esas áreas en concreto.

Un ejemplo de reflexión que involucra la materia de Conocimiento del Medio sería:

Lo que más me ha llamado la atención esta semana y más me ha gustado es que hemos cambiado el rumbo de las clases de Ciencias Naturales y hemos dejado el libro la semana pasada para experimentar con los niños. El experimento en sí era bastante sencillo. Consistió coger cajas de plástico vacías y llenarlas de agua. Posteriormente ir introduciendo diferentes objetos de hechos con diferentes materiales, es decir, un trozo de madera, un tapón de corcho, una moneda de metal etc. Con ello lo que practicamos y descubrieron los niños fue en qué consistía la densidad, la relación entre la masa y el volumen de un objeto. (A10, entrada 4)

Un ejemplo de reflexión sobre la materia de Lengua sería el expuesto a continuación:

El hecho de que la profesora haya usado las asignaturas de Lengua Castellana y Valenciana para tratar el mismo tema me ha parecido genial puesto que la lengua 
oral y escrita se puede trabajar desde muchos aspectos. Se puede decir que a lo largo de esta semana se ha llevado a cabo un trabajo interdisciplinar entre ambas asignaturas. ( $A 6$, entrada 2$)$

La siguiente es una reflexión relacionada con la materia de Matemáticas:

Vi a los niños y a las niñas con ganas a de aprender y con ganas de jugar con las matemáticas. Lo que síque es cierto es que cuando los niños se ven en un contexto diferente de trabajo (en este caso dentro del gimnasio haciendo matemáticas), no toman la misma seriedad a este tipo de actividades que a las que se hacen en una clase convencional. No están acostumbrados a las nuevas metodologías de la educación y ellos piensan que si jugamos no estamos aprendiendo: es absolutamente falso.

A partir de aquí, y gracias a la concienciación que les hice antes de realizar esta actividad, se dieron cuenta de que estábamos aprendiendo matemáticas en un gimnasio y con el material que utilizaban para hacer Educación Física: estaban aprendiendo con juegos. Para ellos era increíble. (A9, entrada 6)

Para ilustrar las reflexiones sobre Artes Plásticas se podría considerar el siguiente ejemplo:

Como hecho destacable puedo contar que la Educación Artística en este centro no está organizada como normalmente lo está en otros centros escolares. Se encuentra dividida en ciclos de una sesión a la semana y se mezclan los alumnos que forman todas las clases del ciclo en cuestión y se forman grupos que trabajan cosas distintas, los talleres son: orientación, teatro, taller de recortar, cocina, dibujo, taller de ceras, pintura e informática. Durante estas semanas cada maestro o maestra tiene un taller asignado por el que van pasando todos los grupos de alumnos. (A11, entrada 3)

Y finalmente la única reflexión recogida respecto al área de Educación Física:

A principios de la semana se hizo una salida al Pabellón "Ciutat de Castelló" para participar con un equipo de fútbol sala que enseñó a los niños la importancia del trabajo grupal, que todos son igual de importantes dentro de un equipo. Esto se hizo 
con varias escuelas y sus diferentes alumnos. Me pareció un hecho a destacar de esa salida que en la clase magistral de fútbol sala participaron todos los niños de todos los colegios no solamente unos pocos, además, si alguno iba en silla de ruedas, también lo sacaban a la cancha y un futbolista se encargaba de estar con él y hacía que el resto de niños también jugaran con él y le pasaran la pelota, no dejándolo a un lado por esta característica. Esta salida del centro resulta destacable por ser una jornada de educación, deporte, integración y valores. (A3, entrada 2)

Para concluir la exposición de resultados respecto a los temas de reflexión se van a desarrollar los resultados pertenecientes al código CA (características del alumnado). Para este código se encuentra en primer lugar la categoría de comportamiento (9 reflexiones), seguido de las categorías de personalidad y aspectos cognitivos (3 reflexiones respectivamente) y finalmente la motivación (2 reflexiones).

Siguiendo el orden mencionado, la categoría de comportamiento son las observaciones de los participantes respecto a la conducta que suelen presentar los alumnos en el aula. A este respecto sería un ejemplo de este ítem:

Me sorprendió muchísimo que cuando les dices que corrijan las actividades que tienen mal, que se callen porque si no los vas a tirar o cuando les intentas decir que no tienen por qué meterse en los asuntos de los demás, para ellos es como si no les dijeras nada. Asientan con la cabeza en un primer momento, pero acto seguido hacen lo que quieren. Es una guerra constante que tienen con la tutora. Se pasan horas y horas de patio castigados haciendo la tarea y aun asi pasan de todo. En este caso, ¿qué debemos hacer? (A8, entrada 1)

Un ejemplo de reflexión sobre la personalidad de los alumnos podría ser el aquí descrito:

No es de las niñas que viene a darte un abrazo todas las mañanas, ni de las que te dice que no quiere que te vayas. Más bien es bastante distante y seria conmigo en muchas ocasiones, aunque ya le pille el truquillo. Es una niña bastante dura por fuera, pero todo lo contrario por dentro. Y si a eso le sumas lo que me dijo su hermana mayor ya te lo puedes imaginar. (A5, entrada 6 ) 
Sobre aspectos cognitivos se puede identificar el siguiente ejemplo:

Tenemos que tener en cuenta que la edad en la que se encuentran estos alumnos pertenece al estadio de las operaciones concretas. Es decir, para desarrollar su personalidad parten de la toma de consciencia de ellos mismos y de los otros, por lo tanto, este alumno tendrá muy en cuenta lo que piensan y lo que opinan el resto de sus compañeros. Es en este estadio cuando consolidan y amplían su proceso de socialización relacionándose con el resto de individuos. Es muy importante para su desarrollo afectivo el depender especialmente de referentes más significativos, como, por ejemplo en este caso, nuestra figura como docentes. (A9, entrada 8)

Y finalmente, un ejemplo de reflexión sobre la motivación del alumnado sería:

Los niños necesitan dinámicas nuevas para sentirse motivados. Salir de la rutina y monotonía de siempre. Solo asi de esta forma se consigue su total participación. (A6, entrada 4)

\subsubsection{Sintesis de resultados para los temas emergentes.}

Para recapitular brevemente los resultados obtenidos en en este apartado se destaca que, con la excepción de la alusión exclusiva por parte del grupo expermiental a temas sociocríticos y a temas sobre didáctica de la lengua, el resto de cuestiones se tratan de forma similar por ambos grupos.

En cuanto a las temáticas en concreto sobre las que se reflexionan, en orden desdendente -de mayor cantidad de referencias a menos- se tratan temas relacionados con la didáctica y la organización escolar, con el Grado de Maestro en Educación Primaria, sobre características del alumnado de primaria, sobre la evolución del estudiante durante el Practicum, sobre aspectos socio-críticos, sobre didácticas específicas y finalmente se reflexiona sobre la relación con las familias y las características del profesorado. 


\subsection{Triangulación de instrumentos y resultados}

Tras la exposición de resultados en función del instrumento de recogida de información a continuación se va proceder a triangular dichos resultados como una forma de aumentar la validez de la investigación. En particular se van a integrar de forma comparativa los resultados obtenidos respecto a los niveles de reflexión conseguidos mediante los diarios y los obtenidos mediante las entrevistas pre y post Practicum. El objetivo es encontrar similitudes que confirmen y apuntalen los datos recabados por ambos medios.

En la Tabla 25, se expone la comparación entre resultados para el grupo experimental en función de las diferentes herramientas de recogida de información. En la primera columna figuran los participantes del grupo experimental, el tipo de herramienta de recogida de información y el momento en el que se recoge dicha información. En el caso de la entrevista este momento puede ser antes o después del Practicum mientras que en el caso del diario online las entradas se organizan en dos grupos, las primeras entradas del diario (realizadas al inicio del Practicum) y las entradas finales del diario (realizadas las últimas semanas de Practicum). En el resto de columnas se detallan numéricamente los datos correspondientes a cada nivel reflexivo.

\section{Tabla 25}

Triangulación de resultados según el método de recogida de información en el grupo experimental

\begin{tabular}{|c|c|c|c|c|}
\hline $\begin{array}{l}\text { PARTICIPANTES } \\
\text { GR. EXPERIMENTAL }\end{array}$ & $\begin{array}{l}\text { CRÍTICA / } \\
\text { AUTO-REFLEXIÓN }\end{array}$ & PEDAGÓGICA & SUPERFICIAL & PRE- REFLEXIÓN \\
\hline № 1 Entrevista PRE & 2 & 8 & 8 & 2 \\
\hline № 1 Entradas 1-4 & 0 & 2 & 4 & 0 \\
\hline №1 1 Total inicio & 2 & 10 & 12 & 2 \\
\hline № 1 Entrevista POST & 3 & 7 & 10 & 0 \\
\hline № 1 Entradas 5-8 & 3 & 4 & 4 & 0 \\
\hline № 1 Total final & 3 & 11 & 14 & 0 \\
\hline № 6 Entrevista PRE & 1 & 14 & 7 & 0 \\
\hline № 6 Entradas 1-4 & 2 & 4 & 2 & 0 \\
\hline № 6 Total inicio & 3 & 18 & 9 & 0 \\
\hline
\end{tabular}




\begin{tabular}{|c|c|c|c|c|}
\hline № 6 Entrevista POST & 4 & 11 & 5 & 0 \\
\hline № 6 Entradas 5-8 & 3 & 4 & 1 & 2 \\
\hline № 6 Total final & 7 & 15 & 6 & 2 \\
\hline № 7 Entrevista PRE & 4 & 7 & 6 & 2 \\
\hline № 7 Entradas 1-5 & 2 & 3 & 3 & 0 \\
\hline № 7 Total inicio & 6 & 10 & 9 & 2 \\
\hline № 7 Entrevista POST & 10 & 4 & 6 & 0 \\
\hline № 7 Entradas 6-11 & 1 & 5 & 1 & 0 \\
\hline № 7 Total final & 11 & 9 & 7 & 0 \\
\hline № 9 Entrevista PRE & 1 & 8 & 9 & 1 \\
\hline № 9 Entradas 1-5 & 6 & 7 & 3 & 0 \\
\hline № 9 Total inicio & 7 & 15 & 12 & 1 \\
\hline № 9 Entrevista POST & 5 & 9 & 3 & 0 \\
\hline № 9 Entradas 6-10 & 8 & 12 & 2 & 0 \\
\hline № 9 Total final & 13 & 21 & 5 & 0 \\
\hline
\end{tabular}

Las entrevistas anteriores y posteriores al Practicum en general han conseguido suscitar mayor cantidad de reflexiones que los diarios. En el caso de la entrevista inicial comparada con las primeras entradas del diario, se cumple esta premisa en todos los participantes tanto para la reflexión pedagógica como para la reflexión superficial, mientras que en el caso de la reflexión crítica los alumnos 6 y 9 suponen una excepción al hacer más reflexiones críticas en sus primeras entradas del diario que en las últimas. Mencionar asimismo que en el caso de la pre-reflexión esta sucede en tres ocasiones (1, 7 y 9) en la entrevista anterior al Practicum, pero no en las primeras entradas de los diarios.

Respecto a la cantidad de reflexiones de la entrevista post Practicum y las últimas entradas del diario, en general mediante la entrevista también se consigue un mayor número de reflexiones que mediante el diario en el nivel superficial. En el caso de la reflexión pedagógica los participantes 7 y 9 tienen ligeramente mayor cantidad de reflexiones en las entradas finales del diario que en las entrevistas. En el caso de la reflexión crítica solo el alumno 9 realiza más reflexiones en el diario que en la entrevista. 
En cuanto a la pre-reflexión, solo un alumno (6) realiza pre-reflexiones en las últimas entradas del diario, el resto no las realiza ni en las entradas ni en la entrevista final.

En cuanto a la coherencia de los datos obtenidos mediante ambos instrumentos los resultados son moderados pero positivos e indican que sí existe concordancia entre unos medios de recogida de información y otros. Destaca especialmente el caso de la reflexión crítica en la cual sí se ve una progresión tanto en las entrevistas como en los diarios. Conforme avanza el Practicum en el grupo experimental se afianza la aparición de reflexiones críticas en los e-diarios. El otro caso especialmente reseñable es el de las pre-reflexiones, salvo el alumno 6 que realiza pre-reflexiones en las últimas entradas del diario, el resto de miembros tras comenzar la intervención dejan drásticamente de realizarlas tanto en el diario como en las entrevistas.

Para la reflexión pedagógica, en los diarios se constata un aumento de reflexiones en las entradas finales mientras que en las entrevistas solo uno de los participantes (alumno 9) mejora las reflexiones pedagógicas en la entrevista final mientras que el resto reducen este tipo de reflexión. Al final de la intervención, dos participantes realizan más reflexiones pedagógicas mediante la entrevista (1 y 6) y dos mediante los diarios (7 y 9). Este tipo de reflexión es el que menos coherencia obtiene al comparar entre instrumentos de recogida de información ya que en los diarios se observa progresión y en las entrevistas en cambio reducción de las reflexiones pedagógicas.

En cuanto a la reflexión superficial ambos instrumentos recogen resultados análogos según los cuales conforme transcurre el Practicum todos reducen las reflexiones superficiales, hecho que se mantiene en la entrevista final. Únicamente el alumno 1 aumenta las reflexiones superficiales en la entrevista final, aunque en el diario sigue una progresión similar a sus compañeros.

Para triangular los resultados del grupo control se ha realizado una tabla con los elementos organizados de forma idéntica que la descrita anteriormente para el grupo experimental (ver Tabla 26). 
En general al igual que sucede para el grupo experimental, el grupo control también realiza un mayor número de reflexiones mediante la entrevista (independientemente de si se trata de la inicial o la final) que mediante el diario.

\section{Tabla 26}

Triangulación de resultados según el método de recogida de información en el grupo control

\begin{tabular}{|c|c|c|c|c|}
\hline $\begin{array}{l}\text { PARTICIPANTES } \\
\text { GR. CONTROL }\end{array}$ & $\begin{array}{l}\text { CRÍTICA/ } \\
\text { AUTO-REFLEXIÓN }\end{array}$ & PEDAGÓGICA & SUPERFICIAL & PRE- REFLEXIÓN \\
\hline № 2 Entrevista PRE & 0 & 1 & 8 & 6 \\
\hline № 2 Entradas 1-4 & 0 & 0 & 4 & 1 \\
\hline № 2 Total inicio & 0 & 1 & 12 & 7 \\
\hline № 2 Entrevista POST & 0 & 1 & 12 & 5 \\
\hline № 2 Entradas 5-8 & 2 & 1 & 1 & 0 \\
\hline № 2 Total final & 2 & 2 & 13 & 5 \\
\hline № 3 Entrevista PRE & 2 & 9 & 10 & 0 \\
\hline № 3 Entradas 1-5 & 0 & 2 & 3 & 3 \\
\hline № 3 Total inicio & 2 & 11 & 13 & 3 \\
\hline № 3 Entrevista POST & 2 & 9 & 4 & 0 \\
\hline № 3 Entradas 6-10 & 0 & 3 & 4 & 5 \\
\hline № 3 Total final & 2 & 12 & 8 & 5 \\
\hline № 4 Entrevista PRE & 3 & 1 & 7 & 6 \\
\hline № 4 Entradas 1-5 & 0 & 3 & 1 & 0 \\
\hline № 4 Total inicio & 3 & 4 & 8 & 6 \\
\hline № 4 Entrevista POST & 3 & 5 & 7 & 2 \\
\hline № 4 Entradas 6-11 & 0 & 2 & 4 & 2 \\
\hline № 4 Total final & 3 & 7 & 11 & 4 \\
\hline № 5 Entrevista PRE & 0 & 3 & 6 & 6 \\
\hline № 5 Entradas 1-4 & 1 & 1 & 3 & 0 \\
\hline № 5 Total inicio & 1 & 4 & 9 & 6 \\
\hline № 5 Entrevista POST & 1 & 6 & 7 & 2 \\
\hline № 5 Entradas 5-9 & 1 & 1 & 2 & 3 \\
\hline № 5 Total final & 2 & 7 & 9 & 5 \\
\hline № 8 Entrevista PRE & 3 & 2 & 10 & 1 \\
\hline
\end{tabular}




\begin{tabular}{|c|c|c|c|c|}
\hline № 8 Entradas 1-5 & 2 & 1 & 1 & 1 \\
\hline № 8 Total inicio & 5 & 3 & 11 & 1 \\
\hline № 8 Entrevista POST & 3 & 4 & 11 & 1 \\
\hline № 8 Entradas 6-10 & 1 & 0 & 2 & 2 \\
\hline № 8 Total final & 4 & 4 & 13 & 3 \\
\hline № 10 Entrevista PRE & 4 & 6 & 6 & 2 \\
\hline № 10 Entradas 1-5 & 1 & 0 & 2 & 1 \\
\hline № 10 Total inicio & 5 & 6 & 8 & 3 \\
\hline № 10 Entrevista POST & 6 & 4 & 8 & 1 \\
\hline № 10 Entradas 6-11 & 0 & 3 & 3 & 2 \\
\hline № 10 Total final & 6 & 7 & 11 & 3 \\
\hline № 11 Entrevista PRE & 2 & 2 & 7 & 4 \\
\hline № 11 Entradas 1-5 & 0 & 1 & 1 & 2 \\
\hline № 11 Total inicio & 2 & 3 & 8 & 6 \\
\hline № 11 Entrevista POST & 1 & 2 & 11 & 3 \\
\hline № 11 Entradas 6-11 & 0 & 0 & 2 & 5 \\
\hline № 11 Total final & 1 & 2 & 13 & 8 \\
\hline
\end{tabular}

En cuanto a coherencia de resultados obtenidos mediante ambos instrumentos, para la reflexión crítica y la auto-reflexión se manifiesta una alta coherencia entre instrumentos. Los datos recogidos por ambos medios tienden a mostrar que en el grupo control la reflexión crítica se reduce a lo largo del Practicum o se mantiene igual que al inicio de este. Únicamente los participantes 5 y 10 muestran algunas diferencias en esta tendencia. El alumno 5 consigue mejorar ligeramente la reflexión crítica en la entrevista final pero no en el diario. En cuanto al número 10, aumenta notablemente las reflexiones críticas en la entrevista final mientras que en las últimas entradas del diario no realiza este tipo de reflexión.

La reflexión pedagógica, al igual que sucede con el grupo experimental, es la que menos coherencia inter-instrumental presenta. Por un lado, los participantes 2 y 3 tienen comportamientos similares en ambos instrumentos, en la entrevista final no consiguen cambios frente a la inicial y en el diario en cambio sí elevan la 
cantidad de reflexiones pedagógicas progresivamente. Otros dos participantes (4 y 8) mejoran la reflexión pedagógica en la entrevista final, pero en cambio las reducen en las últimas entradas del diario. Y, por último, los alumnos 5, 10 y 11 obtienen resultados distintos en función de cada instrumento, así, el número 5 consigue progresión en la entrevista, el 10 lo hace en el diario y el 11 no obtiene progreso con ningún instrumento.

En lo que respecta a la reflexión superficial se da una coherencia aceptable entre instrumentos. Los alumnos 4, 8, 10 y 11 mantienen en mayor o menor medida progresión en las reflexiones superficiales desde la entrevista inicial y las primeras entradas del diario hasta la entrevista final y las últimas entradas. Los participantes 2 y 5 aumentan la reflexión en la entrevista post Practicum frente a la entrevista inicial mientras que en los diarios se reducen y finalmente el alumno 3 reduce reflexiones superficiales en la entrevista final y las aumenta en el diario.

Para concluir, en el caso de la pre-reflexión, a diferencia de lo que sucede con el grupo experimental, donde se mantiene la coherencia entre instrumentos, en el grupo control en cambio dicha coherencia es moderada. Mediante la entrevista, se ve una clara progresión descendente entre la entrevista inicial y la final, en cambio mediante los diarios, la progresión que se observa es ascendente, es decir, los participantes hacen mayor número de pre-reflexiones en las últimas entradas de los diarios que en las primeras.

\subsubsection{Síntesis de la triangulación de instrumentos y resultados}

En resumen, de la triangulación de instrumentos de recogida de información se obtiene la siguiente información: en general la entrevista reflexiva consigue generar mayor cantidad de reflexiones de cualquier nivel que el diario online a la vez que consigue reducir las pre-reflexiones. En el grupo experimental la información resulta coherente entre instrumentos para la reflexión crítica, la superficial y la pre-reflexión mientras que no se evidencia del mismo modo en la reflexión pedagógica. Para el grupo control, los instrumentos generan consonancia en los resultados cuando se trata de reflexión crítica y reflexión superficial, en cambio esta consonancia no se refleja de forma clara en las reflexiones pedagógicas y pre-reflexiones. Los 
instrumentos de recogida de información -diarios online y entrevistas- presentan su mayor coherencia para ambos grupos participantes en los datos correspondientes a las reflexiones crítica y superficial. 


\section{Síntesis del marco experimental}

A lo largo de este capítulo se han expuesto los aspectos fundamentales que justifican el diseño de la investigación, desde su contexto y el planteamiento del problema hasta los objetivos y preguntas de investigación a las que se espera dar respuesta, el paradigma de investigación al que se adscribe la tesis, la selección de la muestra, los métodos de recogida de información, la intervención llevada a cabo con los participantes y el proceso de análisis de datos.

Tras el planteamiento de todo lo anteriormente mencionado se ha procedido a explicar los resultados obtenidos para el grupo experimental y para el grupo control de forma individual y de forma comparada. Los datos que se han analizado son los recogidos a través de las dos entrevistas realizadas (antes del Practicum y después del Practicum) y de los diarios reflexivos elaborados durante todo el Practicum.

En particular se ha analizado información referida a los niveles reflexivos de los participantes y sobre los temas educativos que más les han preocupado durante el periodo de prácticas.

Finalmente se ha llevado a cabo la triangulación de instrumentos de recogida de información y de resultados con el fin de comprobar la coherencia entre ambos y de dotar de mayor validez a la investigación.

A continuación, en el siguiente bloque se expondrán las conclusiones extraidas a partir de todo el proceso de investigación y en las que se pretende relacionar y contrastar las aportaciones recogidas en el marco teórico con las obtenidas en el marco experimental. 


\section{Conclusiones y discusión}

En este capítulo se debaten las aportaciones más significativas de esta tesis. En primer lugar, en relación a los objetivos propuestos se responderán las preguntas de investigación. En segundo lugar, se realizará una reflexión a modo de conclusión final. En tercer lugar, se presentarán algunas limitaciones y condicionantes del trabajo que deben tenerse en cuenta para una mejor contextualización de los resultados. Seguidamente se tratarán los aspectos éticos que garantizan el rigor científico de la tesis y finalmente se señalarán algunas líneas futuras que pueden dar continuidad a la investigación en el campo de la práctica reflexiva.

\subsection{Discusión sobre los objetivos y las preguntas de investigación}

Objetivo 1: Indagar sobre los conceptos de reflexión, práctica reflexiva, niveles de reflexión y evaluación de la reflexión, en su devenir histórico hasta las aproximaciones conceptuales más recientes.

Este objetivo y las preguntas que lo acompañan están vinculados principalmente al apartado de la tesis dedicado a la fundamentación teórica y es a partir de ahí donde se extraen respuestas a esta cuestión. Las conclusiones a este objetivo son por tanto aportaciones de carácter conceptual, producto del estudio y la revisión de la literatura en este campo y no tanto resultados empíricos.

Las preguntas de investigación vinculadas a este objetivo son:

\section{¿Qué papel desempeña la práctica reflexiva en la formación de los maestros de educación primaria?}

La práctica reflexiva desempeña un papel muy relevante en relación a la profesión de maestro de Educación Primaria y en particular al Practicum. El motivo de que la reflexión crítica sea un tema emergente en el ámbito académico sin duda se encuentra en el paradigma educativo promovido desde el EEES y su más inmediata consecuencia, el Plan Bolonia. Desde las políticas educativas europeas 
se señala la necesidad de fomentar el aprendizaje de competencias entre las que se encuentra la competencia reflexiva. Para ello se subraya la importancia de la realización de prácticas externas como fuente necesaria para establecer vínculos con la teoría y completar así el conocimiento. El Practicum supone por sí mismo un potente generador de reflexiones en el alumnado de Grado de Maestro al proporcionar por primera vez un espacio donde confrontar el mundo académico y teórico, las expectativas e ideas previas y la realidad de las aulas.

En la UJI tras unos años de puesta en marcha de las titulaciones adaptadas a los planes de Bolonia y tras las primeras promociones de estudiantes graduados, se comienzan a obtener impresiones fundamentadas sobre el desarrollo de la formación impartida en los grados. Este es el caso del GMP que tras someterse a evaluación ha suscitado entre la comunidad docente una serie de reflexiones a partir de las cuales se han planteado propuestas de mejora. Así, para el curso académico 2018-2019 se iniciará en esta universidad una modificación del plan académico, con cambios estructurales que afectarán especialmente a la configuración del Practicum. Es por lo tanto este un momento clave para establecer nuevos enfoques de aprendizaje que favorezcan la formación basada en la competencia reflexiva.

\section{¿Cuál es el estado actual de la cuestión respecto a la práctica reflexiva?}

\section{a) En cuanto al término y sus características definitorias:}

Existen numerosos estudios que abordan la reflexión y la práctica reflexiva desde múltiples perspectivas, sin embargo, no se ha logrado alcanzar una definición consensuada que pueda considerarse universal sobre estos términos sino que cada autor suele poner énfasis en uno u otro aspecto en función del enfoque pedagógico en uso (Calderhead, 1989).

Para superar los desacuerdos terminológicos suele hacerse referencia a una serie de características definitorias que posibilitan que la investigación en este campo pueda ser operativa. Weber (2013) propone una serie de condiciones recopiladas a partir de la revisión de artículos publicados y define la práctica reflexiva 
como un proceso que requiere ser enseñado, que implica la toma de decisiones y que afecta positivamente al rendimiento académico.

Producto del análisis de la literatura (véase el marco teórico), en el presente trabajo se ha propuesto una definición de la práctica reflexiva que añade a las características citadas los siguientes rasgos:

1. La práctica reflexiva requiere intencionalidad, es decir, el individuo debe tener el propósito de pensar sobre sus actos, sobre los acontecimientos y el contexto en el que tiene lugar la acción docente. El profesional reflexivo mantiene una actitud de compromiso con la docencia y esto conlleva un cuestionamiento deliberado de todo lo relativo a la profesión docente.

2. La segunda característica relevante sobre la práctica reflexiva es que requiere utilizar procesos metacognitivos de alto nivel tales como examinar y analizar situaciones complejas, establecer relaciones entre distintos elementos, utilizar estrategias de resolución de problemas, tomar decisiones y evaluar previamente las posibles consecuencias de dichas decisiones. LoS problemas de la educación no son simples y su resolución requiere, por lo tanto, estrategias complejas de pensamiento.

3. Una tercera condición implica que los docentes deben ser investigadores activos de su propia actividad y del ambiente que la rodea. Tener curiosidad por averiguar los motivos de un determinado comportamiento propio o ajeno y no quedarse con lo superficial. También conlleva ser capaz de poner en cuestión las propias convicciones y certezas, en busca de un mayor conocimiento sobre la realidad.

4. Y finalmente, la práctica reflexiva toma como base para la reflexión tanto la experiencia vivida en primera persona como la experiencia vicaria de los hechos. Son los acontecimientos significativos y críticos los que originan reflexiones de forma natural, sin embargo, también es posible reflexionar y extraer conclusiones a partir de las experiencias vividas por otros mediante la observación de sus actos y las consecuencias que de tales actos se derivan.

Estos cuatro puntos descritos junto a los identificados por Weber (2013) ofrecen una visión más amplia y comprensiva de la práctica reflexiva que contribuye a incrementar las líneas de investigación y de intervención didáctica dirigidas a la adquisición de esta competencia. 
Formar a los futuros docentes como prácticos reflexivos implica enseñarles a observar cuidadosamente la realidad. Educar su mirada para percibir aspectos que no resultan obvios a simple vista y ayudarles a otorgar nuevos significados a las situaciones educativas.

Conlleva asumir que las ideas no son fijas e inamovibles y aceptar como parte del proceso formativo del alumnado el cuestionamiento del discurso del docente para ir creando un relato pedagógico propio.

Enseñar a reflexionar supone desmitificar la idea que muchos estudiantes llevan al iniciar los estudios de magisterio, de que tras su paso por el Grado habrán obtenido una serie de recetas que aplicarán con éxito en el aula. El estudiante reflexivo entiende que los problemas educativos son complejos y de ahí la dificultad para encontrar soluciones universalmente satisfactorias.

Por último, y vinculado a la intencionalidad, la práctica reflexiva requiere tiempo para ser enseñada, para adquirirse y para ponerse en práctica. No es razonable esperar que tras una breve formación o periodo práctico el estudiantado esté preparado para conducirse como práctico reflexivo en el futuro.

\section{b) En cuanto a los niveles de reflexión:}

Otra idea sometida a debate es la referida a los niveles de reflexión docente. Existe cada vez más acuerdo (Collin et al., 2013) en respaldar que los niveles reflexivos (superficial, pedagógico y crítico) no suceden de forma secuencial sino en paralelo. Esto sugiere que, dado que es posible en un mismo discurso encontrar distintos niveles reflexivos, no se puede afirmar que exista un tipo de reflexión mejor que otro sino que reflexionar guarda más relación con el contexto pedagógico que con la capacidad de reflexionar en sí (Quinn, 2000).

Esta tendencia sitúa en el punto de mira el contexto en el que el alumno se forma. No solo cuestiona el ámbito de formación teórica (la Universidad) sino también el de formación práctica (los centros educativos). La labor de los entornos formativos y de los profesionales que actúan en dichos espacios debería resultar 
intelectualmente estimulante y favorecedora del pensamiento crítico. El alumno cuyas reflexiones son superficiales o cuyo discurso no llega a considerarse reflexivo (pre-reflexiones) es probable que esté inmerso en un contexto que no incita o incluso que castiga el pensamiento crítico. Es difícil desarrollar la competencia reflexiva en entornos donde aprender es sinónimo de asimilar fielmente el material de estudio o de mostrar acuerdo con el profesorado (Finlay, 2008; Quinn, 2000).

\section{c) En cuanto a los modelos reflexivos:}

En este tema se observa una línea de progreso definida desde los planteamientos racionales y técnicos (Dewey, 1933; Argyris y Schön, 1978; Kolb, 1984), donde prima la observación objetiva de los hechos y un cierto distanciamiento en el análisis, hasta otras tendencias que incorporan la reflexión sobre aspectos sociales y contextuales (Korthagen, 2011). Finalmente, las propuestas más actuales que consideran las emociones y los sentimientos que se generan en relación a los hechos como elementos de interés a analizar (Gibbs, 1988; Wareing, 2017). Diversos autores (Finlay, 2008; Shoffner, 2009) ponen sobre la mesa esta cuestión y reclaman nuevas competencias por parte de tutores y supervisores relacionadas con la capacidad de manejar adecuadamente las emociones y los sentimientos del alumno. Supervisor y tutor no son meros espectadores, sino que tienen un papel fundamental derivado de su función de acompañamiento. El Practicum es también un momento de autodescubrimiento para el alumno y saber gestionar las emociones emergentes, en ocasiones contradictorias o directamente relacionadas con la frustración ante la realidad, debe ser un requisito esencial de quienes ejercen la labor de tutoría.

\section{Objetivo 2: Identificar el nivel de reflexión del alumnado de Practicum I del Grado de Maestro en Educación Primaria en la Universitat Jaume I.}

Este objetivo se responde en el apartado dedicado al marco experimental y, en concreto, en el punto dedicado al análisis de los resultados de la entrevista reflexiva realizada antes del Practicum. 
Pregunta de investigación:

\section{1. ¿Ha desarrollado el alumnado de tercer curso del Grado de Magisterio en Educación Primaria la competencia reflexiva cuando se enfrenta al Practicum I?}

En base a los resultados obtenidos puede responderse que el alumnado en el momento de iniciar el Practicum realiza principalmente el tipo de reflexión considerado superficial, es decir, en general cuando reflexiona no establece conexiones entre teoría y práctica y no profundiza en sus creencias u opiniones, sino que utiliza lo que se podría calificar como "retórica vacía". Trata los temas de forma tópica o trivial y expresa emociones no vinculadas a procesos cognitivos de alto orden. Se dan, sin embargo, excepciones en varios participantes en lo que se refiere a la reflexión de tipo pedagógico y esto posiblemente se deba a su formación teórica previa. La formación académica les permite estar familiarizados con múltiples conceptos e ideas pedagógicas a partir de las cuales pueden realizar un mejor análisis de la profesión, sus características y ajustar sus expectativas sobre aquello que pueden encontrar en aula.

Sin embargo, en lo que concierne a la reflexión crítica no se puede decir, a partir de los resultados obtenidos, que sea habitual encontrar este tipo de reflexión en el momento previo al Practicum. Muy pocos alumnos manifiestan en la entrevista pensamientos y afirmaciones que puedan considerarse como críticos, pocas veces se contemplan repercusiones o causas socio-políticas y consecuencias de los acontecimientos y pocos planteamientos se dirigen a cuestionar la realidad establecida.

Por lo tanto, se puede afirmar que el alumnado que se enfrenta al Practicum, en general no profundiza en su relato sobre los acontecimientos ni va más allá de lo cercano o inmediato en sus reflexiones. Todo apunta a que la competencia crítica no se ha desarrollado en los cursos previos o al menos no se ha creado un hábito a este respecto.

Objetivo 3: Introducir y valorar diferentes estrategias que fomenten la práctica reflexiva en diferentes momentos del Practicum I. 
Este objetivo encuentra respuesta en el apartado del marco teórico que justifica las estrategias que mejor resultado obtienen para fomentar la práctica reflexiva, así como en el apartado experimental dedicado a describir la intervención realizada con el grupo experimental y por último el conjunto de los resultados obtenidos para ambos grupos. Las estrategias de intervención aplicadas son la formación teóricopráctica en materia de práctica reflexiva previa al Practicum, la técnica del incidente crítico antes y durante el Practicum y la retroalimentación sostenida durante el periodo de prácticas a partir de las entradas del diario online.

La pregunta de investigación formulada a partir de este objetivo es:

\section{1. ¿Se puede desarrollar el pensamiento reflexivo crítico a través de una intervención específica?}

La respuesta es que efectivamente sí se puede mejorar o desarrollar el pensamiento reflexivo crítico a partir de una serie de intervenciones.

Según la clasificación de Davis (2004) del tipo de apoyos para fomentar la reflexión, se hallan dos tipos generales de intervención. Por un lado, aquellas que están pensadas para estimular la reflexión de forma directa y que, por lo tanto ayudan al alumno a situar la mirada sobre los acontecimientos. Y, por el otro, aquellas que, por su neutralidad, resultan inocuas y confían en la capacidad del estudiante para generar sus propias reflexiones sin ser influidos de forma directa por agentes externos. El primer tipo de apoyo sería el recibido por el grupo experimental y el segundo, sería más bien un "no apoyo", y sería el caso del grupo control.

En líneas generales y en base a los resultados obtenidos, se puede afirmar que el hecho de no dar facilitadores y limitarse a proporcionar comentarios neutros de ánimo a los participantes no ha tenido efecto en la mejora progresiva de la reflexión crítica. Sin embargo, los participantes que sí han recibido de forma sostenida dichos apoyos han mejorado sensiblemente la toma de conciencia crítica sobre los acontecimientos. 
En general los resultados recogidos en las entrevistas y en los diarios al finalizar el Practicum muestran que ambos grupos mejoran o al menos aumentan las reflexiones independientemente del grupo al que pertenezcan, por lo tanto, se puede afirmar que el hecho de realizar el Practicum es, per sé, generador de reflexiones. Sin embargo mientras que el grupo experimental mejora progresivamente el tipo de reflexión más crítica y disminuye la pre-reflexión, el grupo control aumenta principalmente las reflexiones superficiales y las pedagógicas, sin cambios en las pre-reflexiones.

Analizando brevemente los efectos que cada apoyo ha tenido en los resultados se puede decir que, en primer lugar, la formación previa de carácter teóricopráctico ha tenido como resultado inmediato la toma de conciencia sobre lo que se considera reflexión y lo que no, y eso se ha evidenciado al comprobar desde las primeras entradas en los diarios la eliminación de comentarios pre-reflexivos. También se ha manifestado en la toma de conciencia respecto a múltiples perspectivas de enfocar un mismo acontecimiento en educación y en especial en lo que se refiere a observar causas y consecuencias más allá de la inmediatez del aula, cuestionando aspectos sociales, económicos, políticos, etc.

Respecto a la técnica del incidente crítico (Flanagan, 1954), ha resultado un excelente facilitador a la hora de ayudar a identificar hechos que chocan con los valores, expectativas y formas particulares de entender la educación. El grupo control, no instruido al respecto, supo identificar por sí mismo acontecimientos de la vida del centro y del aula definibles como incidentes críticos como así se observa en sus diarios. Sin embargo, el grupo experimental no solo identifica y describe incidentes sino que es capaz de examinarlos con mayor detenimiento y dotarles de un significado más profundo, es decir, el impacto en su aprendizaje y reflexión sobre la profesión ha sido mayor.

Finalmente, la retroalimentación dada a los participantes, tanto si esta ha sido neutra como si ha sido reflexiva, ha supuesto en ambos grupos un apoyo emocional al sentir su esfuerzo compartido y reconocido. En el caso del grupo experimental cuya retroalimentación consistía en sugerencias, observaciones y opiniones referidas a sus propias reflexiones, estas observaciones se han utilizado como 
modelos y ejemplos en base a los cuales ampliar su mirada. Esta apertura de la perspectiva ante los hechos se traduce en un aumento de reflexiones críticas según avanzan las entradas del diario y en la entrevista final.

Respecto al efecto de la intervención es necesario reconocer que es positivo pero moderado. Esto se debe, posiblemente, al corto periodo de tiempo dedicado a la intervención. Es posible aventurar que, si estas estrategias reflexivas u otras similares se incorporaran en algunas materias de la titulación con anterioridad al Practicum de forma que el hábito reflexivo estuviera creado y asentado, el efecto de la intervención durante el Practicum habría sido más notable. También es posible pensar que dar continuidad y seguimiento a la investigación durante el curso siguiente en el Practicum II hubiera proporcionado mayor firmeza a los resultados. En este caso no solo se podría haber observado la evolución de los participantes, sino que se podría haber indagado a su vez el efecto de la retirada progresiva de apoyos en el grupo experimental.

\section{Objetivo 4: Aplicar diferentes metodologías para el registro y análisis de producciones de una muestra de alumnado seleccionada e indagar sobre su eficacia.}

La respuesta para este objetivo se encuentra por un lado en la parte del marco teórico que hace referencia a formas de registrar la información reflexiva entre las cuales existe una clasificación en función del uso o no uso de las TIC (Kori et al., 2014) y en el apartado del marco experimental dirigido a examinar los resultados obtenidos mediante las dos metodologías principales que se han utilizado en la investigación esto es la entrevista pre y post Practicum y al diario reflexivo online.

Las preguntas de investigación en este caso son:

\section{1. ¿Qué metodología resulta de mayor utilidad para generar reflexiones críticas?}

La literatura publicada al respecto no parece justificar especialmente el uso de una herramienta frente a otras (Kori et al., 2014). En cambio, sí es determinante 
asegurar a las personas implicadas la privacidad de sus reflexiones para garantizar la libertad de opinión sin que conlleve repercusiones (Yaffe, 2010).

Una vez garantizados estos aspectos a los participantes de la investigación, tras comparar los dos instrumentos utilizados (entrevistas y e-diarios) los resultados obtenidos señalan inequívocamente a la entrevista reflexiva como el instrumento que mayor cantidad de reflexiones ha generado para ambos grupos (control y experimental). Para explicar este hecho existen dos cuestiones clave. La primera es que la entrevista ha sido diseñada y validada específicamente para esta función y cada pregunta formulada exige del entrevistado una mínima reflexión en la respuesta. En la escritura del diario en cambio no se exigía para ninguno de los dos grupos un mínimo de reflexiones ni existía un límite de espacio para ello. Cada participante redactaba sus entradas con libertad absoluta para hablar de los temas que deseara en la forma y extensión que considerara oportuna. Esto ha supuesto que un mismo participante realice entradas largas o cortas, con mayor o menor cantidad reflexiones y con mayor o menor profundidad de estas en función de su propio criterio y de los factores que le hayan sido determinantes en ese momento.

La segunda explicación se refiere a la sostenibilidad en el tiempo del diario reflexivo y a lo que se podría denominar "efecto cansancio". Las reflexiones vertidas en los diarios son aportaciones realizadas durante meses, desde el comienzo hasta el final del Practicum, mientras que las entrevistas se han realizado de forma puntual, en un lapso temporal corto. La exigencia de esfuerzo y constancia de los diarios online es muy superior a la de las entrevistas. Reflexionar de forma sostenida en el tiempo es costoso tanto en el esfuerzo cognitivo requerido como en la disponibilidad misma del tiempo del alumnado. Así, conforme se reduce el tiempo disponible (por proximidad de exámenes o entrega de memorias y trabajos) y conforme aumenta el cansancio frente a la actividad reflexiva, ésta se realiza de forma menos concienzuda.

Este denominado "efecto cansancio" está en consonancia con varios resultados hallados tanto para el grupo control como el experimental. En el caso del grupo experimental, las reflexiones pedagógicas superan en las primeras entradas del diario a las del grupo control y, sin embargo, conforme avanza el tiempo comienzan a reducirse. Aun estando igualmente por encima del grupo control, el grupo expe- 
rimental parece estancarse y no progresar mientras que el grupo control, que parte de una cantidad mucho menor, las aumenta.

Siguiendo con el grupo experimental, en este caso respecto a las reflexiones críticas, todos parecen progresar excepto el participante 7 , que conforme avanzan sus entradas semanales va reduciendo las reflexiones críticas hasta que en sus últimas entradas deja de hacerlas. Este efecto no se observa sin embargo en su entrevista final, donde hace reflexiones a un nivel similar al de sus compañeros del grupo experimental.

En el grupo control, la fatiga ante la tarea reflexiva se observaría principalmente en el aumento de las pre-reflexiones en las últimas entradas del diario en detrimento de otro tipo de reflexiones más elaboradas.

A pesar de que en el diario online parece acusar más la fatiga de los participantes que la entrevista, lo cierto es que al realizar la triangulación entre ambos se obtiene una alta coherencia entre los resultados obtenidos en lo que respecta a la reflexión crítica, a la reflexión superficial y a la pre-reflexión, siendo la reflexión pedagógica la que menor coherencia entre instrumentos ha obtenido.

\section{2. ¿Cómo podemos utilizar las TIC para favorecer la reflexión durante el Practicum?}

En esta investigación se han utilizado los diarios online a través de plataformas virtuales (Moodle) y en segundo lugar, como parte facilitadora en las entrevistas, la grabación de las respuestas a través de un dispositivo móvil.

Al utilizar la grabación como un facilitador durante la entrevista se consigue agilizar y dar naturalidad a la conversación a la vez que permite fluir el pensamiento sin la limitación que supondría que el entrevistador tomara notas a mano. Este medio además permite recoger fielmente la conversación y no perder matices que de otro modo serían prácticamente imposibles de captar. 
Respecto al uso de diarios online mediante Moodle o el uso de otros instrumentos como portfolios digitales o vídeo grabaciones, la investigación reconoce ampliamente su utilidad para impulsar la práctica reflexiva (McVee et al., 2008; Mishra y Koehler, 2006). El diario online utilizado en esta investigación ha resultado efectivo en ambos grupos para establecer conexiones entre teoría y práctica (Henderson et al., 2004) así como para explorar los propios valores, temores, expectativas y creencias respecto a la profesión docente (Carson y Fisher, 2006) y en el caso del grupo experimental ha conseguido estimular el pensamiento crítico (Chitpin, 2006).

Sin embargo, en base a la experiencia que ha proporcionado la investigación, para potenciar el pensamiento crítico mediante las TIC deben darse preferiblemente dos condiciones. La primera condición es poseer un conocimiento previo de las herramientas tecnológicas que se van a emplear para la reflexión. El alumnado debe estar familiarizado con anterioridad con el instrumento elegido: aula virtual, blog, aplicaciones para gestionar e-portfolios o e-diarios, etc. para que el aprendizaje sobre el uso de estas herramientas no interfiera en su efectividad para la reflexión.

Y, en segundo lugar, el efecto que pueda tener la herramienta TIC empleada debe combinarse preferiblemente con el refuerzo y las orientaciones del tutor, supervisor o incluso el grupo de iguales (Morgan et al. 2006; Wolf, 2008). En el caso que nos ocupa se ha evidenciado que el refuerzo activo y no neutro sobre las reflexiones de los diarios online es el que ha conseguido mejorar el pensamiento crítico a lo largo del proceso mientras que el grupo sin este refuerzo no ha conseguido progresión.

En cuanto a las posibilidades que ofrecen las TIC para potenciar la práctica reflexiva, no solo se debe poner el foco de atención en el alumnado. Los supervisores que tutelan gran número de alumnos de Practicum con frecuencia se quejan de que ello dificulta enormemente las tareas de seguimiento y directamente imposibilita la regularidad en el intercambio de opiniones. En este caso las TIC se convierten en un potente aliado al posibilitar la comunicación sin necesidad de coincidir ambas partes en un mismo espacio físico o temporal. El poder utilizar el correo electrónico, dejar comentarios en blogs o en foros e incluso utilizar servicios de vídeo conferencia como Skype o Google Hangouts para, por ejemplo, realizar seminarios grupales, resultarían de gran utilidad para ahorrar tiempo y facilitar el seguimiento del alumnado pero 
especialmente serían determinantes para, a través de ese contacto más asiduo, establecer un clima de confianza tutor-alumno donde el segundo perciba que está siendo escuchado, que sus preocupaciones se tienen en cuenta y que las orientaciones se ajustan a sus vivencias cuando todavía se tiene capacidad de maniobra sobre estas y no cuando se revisan las memorias una vez ha concluido el periodo de prácticas, momento en el cual ya no es posible introducir cambios en la acción.

\section{Objetivo 5: Examinar aquellos temas que preocupan al alumnado del GMP a la hora de enfrentarse por primera vez a las prácticas de carrera.}

Este objetivo se consigue al revisar la parte experimental de la tesis dedicada a los resultados y en particular al punto que trata sobre el análisis de los temas emergentes en los e-diarios. La pregunta de investigación relacionada es:

\section{¿Qué tipo de cuestiones educativas pone de manifiesto el alumnado a través de la práctica reflexiva?}

A la luz de los resultados obtenidos, los temas que más preocupan a los alumnos de Practicum son los que afectan al área de didáctica y organización escolar (DOE) seguido de aspectos relativos al Grado de Maestro. Reflexionan también sobre el alumnado del aula y del centro en el que están y efectúan observaciones sobre su propia evolución durante el periodo de prácticas.

Los temas que se mencionan con menor frecuencia son en orden descendente, aspectos socio-culturales que influyen en la educación (solo el grupo experimental), didácticas específicas, aspectos relativos a las familias del alumnado y en último lugar se hacen alusiones a la labor del profesorado del centro.

Dentro de los temas relativos al área DOE, destacan las reflexiones sobre la atención a la diversidad, sobre la metodología empleada en las sesiones docentes y la convivencia tanto en el centro como en el aula. Temas relacionados con la organización escolar o con las TIC también son objetos de reflexión, aunque en menor medida. 
A partir de estos resultados se pueden establecer varias conclusiones vinculadas a varios supuestos del marco teórico.

En primer lugar, según diversos autores (Hatton y Smith, 1995; Jay y Johnson, 2002; Larrivee, 2008) al describir la reflexión superficial se señala que la preocupación principal está relacionada con el control del aula y el comportamiento del alumnado mientras que en la crítica los temas tratados son los relativos a aspectos sociales, culturales, políticos y/o económicos que inciden en la educación. Los resultados muestran que ambos grupos manifiestan preocupación por temas relacionados con el comportamiento y el control del aula, lo cual es comprensible dado que es la primera vez que se enfrentan a este tipo de cuestiones, pero por otro lado solo el grupo experimental reflexiona sobre la sociedad, la política educativa y el sistema educativo, confirmando que estas preocupaciones surgen a través de la reflexión que exige más alto nivel de recursos cognitivos, esto es, la reflexión crítica.

Se ha mencionado a lo largo de la tesis la importancia del Practicum como el momento en el que se establecen relaciones entre la teoría recibida, la práctica y las propias creencias y expectativas. En los temas emergentes se ha evidenciado que sí se cumple esta premisa cuando se muestra como el segundo tema que más ha preocupado al alumnado es el propio Grado de Maestro. Las reflexiones al respecto están relacionadas con la aplicabilidad en el aula de sus conocimientos previos a nivel conceptual y procedimental, sobre los cuales extraen conclusiones en relación al cumplimiento de los supuestos teóricos y metodológicos que se han estudiado y en relación a las expectativas que se han cumplido y las que no. Una de las consecuencias de esta comparación entre mundo académico y profesional, tal y como se refleja en algunos diarios y en algunas respuestas de la entrevista final, es la existencia del "efecto lavado" (Hobson et al., 2009; Egido y López, 2013), es decir, el alumno se convence de que la formación teórica no le está resultando útil para enfrentarse a la práctica y que la profesión se aprende realmente en el aula, por observación e imitación su tutor y por ensayo-error.

Objetivo 6: Proponer una serie de recomendaciones para promover un Practicum reflexivo. 
La pretensión de este trabajo también es participar en el cambio de la realidad y con ese fin se da respuesta a este objetivo estableciendo una serie de sugerencias dirigidas a los agentes directamente involucrados en el Practicum. La respuesta a este objetivo es el resultado de integrar marco teórico y el marco experimental pero también de compendiar varias de las respuestas descritas en las anteriores preguntas de investigación. La pregunta de investigación en este caso es:

\section{¿Cómo podemos promover un Practicum más reflexivo y crítico en la Universidad?}

Para responder a la pregunta formulada a continuación se van a listar una serie de propuestas.

Propuesta 1: Fomentar activamente entre el profesorado supervisor de la universidad y el tutor del centro educativo la conciencia de la importancia de que el alumnado desarrolle la competencia reflexiva.

Esta propuesta implica una serie de acciones:

- Toma de conciencia respecto a la adquisición del pensamiento crítico como un derecho fundamental del alumnado en su desarrollo profesional. Adquirir esta competencia repercutirá directamente en el modo de ejercer la profesión docente pero también afectará a su actuación como ciudadano.

- Acciones formativas para supervisor y tutor dirigidas a la adquisición de conocimientos básicos que les ayuden a comprender en qué consiste la práctica reflexiva y qué metodologías son más adecuadas para fomentarla.

- Clarificación terminológica con el alumnado. Preparar al alumno para ejercer la reflexión crítica durante el Practicum partiendo del acuerdo terminológico entre las tres partes implicadas. Esta acción es importante para que el alumno entienda lo que se espera de él, dado que el concepto de reflexión es difuso incluso entre los propios profesionales.

Propuesta 2: Reflexionar sobre las competencias que debe tener el supervisor que promueve la práctica reflexiva. 
Para llevar a cabo esta propuesta, algunas directrices serían:

- Revisar el estilo relacional del supervisor con el alumno. El docente que promueve la práctica reflexiva debe intentar suavizar su posición jerárquica para establecer un clima de confianza que permita al alumno mostrar sus reflexiones reales y no las que responden a la deseabilidad social frente al evaluador. En este sentido se requiere en el supervisor cierta apertura mental para aceptar opiniones distintas a las propias.

- Valorar habilidades de dinamización y coordinación. El tutor que promueve la reflexión debe ser también buen dinamizador, tener contacto fluido con su alumnado, proponer tareas acordes a la disponibilidad de este y gestionar reuniones y seminarios provechosos donde se compartan aspectos relativos al Practicum.

- Importancia de las habilidades de gestión emocional. Las emociones y sentimientos que surgen durante la práctica reflexiva pueden generar un alto malestar en el alumnado. El supervisor debe tratar dichas emociones con respeto, favorecer su análisis y ayudar al alumno a gestionarlas de forma eficaz.

\section{Propuesta 3: Introducir de forma combinada estrategias, herramientas y apoyos que conduzcan a la adquisición del pensamiento crítico.}

- Utilizar de forma combinada estrategias metodológicas para fomentar la reflexión, tales como role playing, estudio de casos, tutorización entre iguales, uso de guías y modelos reflexivos, etc. Trabajar especialmente mediante técnicas de apoyo mixto como por ejemplo la técnica del incidente crítico para favorecer momentos y espacios donde se compartan opiniones y se extraigan conclusiones a partir de la propia experiencia.

- Aprovechar los seminarios y los grupos de discusión como parte de la función tutorial. El seminario supone una fórmula excelente para aprender de la experiencia de los iguales, reconocerse entre sí como personas que comparten realidades similares y reinterpretar la realidad desde posiciones diferentes a su rol habitual.

- Trabajar sobre los temas que se han revelado de interés durante el Practicum. Abordar aquellas preocupaciones que ya han sido planteadas a partir de los diarios o durante las tutorías. Se trata de reflexionar a partir de preocupaciones reales para que las conclusiones puedan ser verificadas o aplicadas en el aula con cierta inmediatez generando así nuevas ideas. Muchos de los problemas cotidianos que surgen en el aula son consecuencia directa de políticas educativas y aspectos socioeconómicos que afectan a los centros. Este tipo 
de reflexión no siempre es evidente para el estudiante por lo que se sugiere el abordaje explícito de estas cuestiones por parte del supervisor.

- $\quad$ Asegurarse de que el alumno no utiliza los instrumentos para la reflexión de forma meramente testimonial, es decir, limitándose a describir la rutina cotidiana sin mayor profundidad. La reflexión requiere ir más allá de la simple recopilación de hechos, exige actividad analítica, crítica y establecer relaciones entre elementos.

- Una memoria final de prácticas estandarizada no puede constituir el único instrumento reflexivo. Pese a su utilidad para valorar la trayectoria del alumno y constatar su trabajo a lo largo del Practicum, no permite, tras su revisión y con la calificación como único feedback, generar cambios a corto o medio plazo.

- Uso de las TIC en el intercambio de ideas y opiniones. Uso de e-portfolios o e-diarios, como instrumentos para recoger las reflexiones del alumnado. Aprovechar aquellas herramientas con las que el alumno se siente más familiarizado o que están más disponibles para agilizar y facilitar la comunicación y la coordinación.

\section{Propuesta 4: Establecer en el Practicum modelos de relación dialógica en-} tre tutor, supervisor y alumno.

- $\quad$ Ejercer el Modelo Reflexivo de Supervisión (Pérez, 2001). Bajo este modelo el tutor y el supervisor ayudan al alumno a analizar críticamente su práctica así como a integrar aspectos teórico-prácticos de su formación. Ambos profesionales deben enseñar al estudiante a cuestionarse sus propias creencias, explorar sus prejuicios, analizar sus ideas previas y establecer conclusiones donde se aprecien cambios respecto a las ideas iniciales.

- Trabajo coordinado entre supervisor y tutor. Establecer alianzas entre ambos en beneficio del alumno. Deben mostrar de forma complementaria cómo encaja el mundo teórico y el práctico fortaleciendo la relación entre universidad y escuela para que los estudiantes no perciban distancia entre ambas.

- El tutor del centro como mentor. La labor del docente que trabaja junto al alumno de prácticas debe entenderse como una relación de acompañamiento y supervisión durante todo el proceso de tutorización. Ser un mentor supone trabajar conjuntamente durante un periodo prolongado de tiempo y generar cierta complicidad con el alumno. Este hecho le permitirá ir más allá de la transmisión de habilidades para desenvolverse en el aula. Considerar el tutor como un mentor supone constituirse en un modelo para el alumno y a la vez ser receptivo ante lo que éste le pueda aportar. 


\subsection{Conclusión final}

Llegados a este punto es el momento de recapitular y hacer un breve corolario respecto a varias conclusiones que se desprenden de esta tesis doctoral.

Es preciso comenzar haciendo mención al contexto y al momento en el cual se ha realizado este estudio. En la actualidad, la Universitat Jaume I está en pleno proceso de reforma de los estudios del Grado de Maestro o Maestra en Educación Primaria. A partir de los próximos dos cursos tendrán lugar profundos cambios estructurales y ello supone una oportunidad para reforzar la presencia de la competencia reflexiva en la titulación. Se debe para ello abordar dos aspectos fundamentales de la gestión institucional.

El primer aspecto se refiere a la inclusión de la competencia reflexiva en el plan de estudios desde primer curso y en todas las materias que configuran la titulación, con el necesario cambio metodológico que ello conllevaría. A este respecto, el profesorado debe ser consciente de que fomentar la práctica reflexiva no puede limitarse a introducir una serie de modificaciones formales en las guías docentes cuya apariencia sea impecable pero cuya puesta en práctica sea inexistente. Afirman Imbernón y Colén (2014) que este tipo de modificaciones vacías solo lastran la posibilidad real de cambio. Por lo tanto, la acción formal debe acompañarse de acción real y conllevar una revisión de la metodología docente. Se requiere introducir innovaciones en el aula universitaria aprendiendo de la experiencia de otras universidades, como la propuesta por Colén, Jarauta y Castro (2016) en la Universidad de Barcelona, donde trabajan la competencia reflexiva en el aula universitaria mediante el uso de la metodología de Rincones de Trabajo integrando a su vez el modelo reflexivo de Kolb. O como la iniciativa llevada a cabo por Piqué, Comas y Lorenzo (2010) que promueven un intercambio de conocimiento entre maestros de los centros educativos y alumnos universitarios en el cual, los primeros se acercan a la universidad para compartir su experiencia en el aula y los segundos acuden de forma puntual a las escuelas para observar y aprender las dinámicas que allí se llevan a cabo.

El segundo aspecto se basa en la integración del Practicum en el plan de estudios como eje vertebrador del currículum y no como una asignatura más. Llevar 
adelante esta iniciativa implica la distribución de los créditos de Practicum desde primer curso hasta cuarto, compatibilizando las clases teóricas con la experiencia práctica, tal y como muestran experiencias previas como la de la Universidad de Lleida (Coiduras et al., 2015). Un modelo de formación dual debe fortalecer la relación entre universidad-escuela, superar por fin, la limitación que ya esgrimía Zeichner en 1990 respecto a la corta duración del periodo de prácticas para que la acción reflexiva produzca cambios sensibles en el estudiantado. Por último, este modelo también podría contribuir a desmitificar la idea de que el verdadero aprendizaje sobre la profesión reside únicamente en la práctica (Hobson et al., 2009; Egido y López, 2013), despreciando así la teoría. A este respecto, desde primer curso el alumnado podría identificar la influencia y el efecto de la una sobre la otra, mejorar la transferencia de conocimientos académicos e iniciar así una espiral de reflexiones en torno a la educación que con el plan de estudios actual comienza en el penúltimo curso.

Los docentes que forman a futuros maestros precisan adquirir un compromiso personal con el desarrollo del pensamiento crítico de su alumnado. Deben ser conscientes de su privilegiada posición a la hora de influir en la percepción del estudiante respecto a la realidad educativa y no es poca la responsabilidad que tienen en esta cuestión. Se requiere hacer un acto de introspección sobre la propia práctica donde la pregunta clave sea qué tipo de maestro se está formando en la universidad y qué parte de esa realidad corresponde a cada uno. Una respuesta honesta reconocerá que no es suficiente formar docentes para que sean buenos transmisores de conocimiento. Esa es solo una de las competencias -importante sin duda- que le definirán como profesional. Ser maestro también consiste en adoptar una visión socio-crítica de la educación y del entorno en el que se vive, esta posición permite cuestionar la realidad y no conformarse, permite el cambio educativo y permite en definitiva ejercer una ciudadanía responsable.

\subsubsection{Limitaciones de la investigación}

A continuación se van a comentar una serie de limitaciones que han surgido durante del proceso investigador. 
A nivel teórico la limitación más evidente ha sido la falta de acuerdo terminológico respecto al concepto de reflexión y de práctica reflexiva tras revisar la investigación publicada al respecto. Trabajar con conceptos teóricos tan permeables dificulta el entendimiento y la comunicación entre autores al exponer resultados. Por ello, para salvar esta dificultad, se ha precisado en todo momento el modelo, perspectiva y concepto teórico al que se adscribía o al que hacía referencia el autor del trabajo, de forma que se espera que todo el relato resulte coherente.

A nivel experimental, dos han sido las limitaciones principales encontradas. La referida al tamaño muestral y la mortandad experimental y la relacionada con la generalización de la investigación.

En cuanto al tamaño de la muestra y la mortalidad experimental, hay que reconocer que encontrar la muestra original no resultó en absoluto difícil gracias a la colaboración de los supervisores de Practicum y al deseo inicial de los participantes de contribuir a un estudio cuyo fin implicaba introducir algunas mejoras en la titulación. Así, se consiguió superar el número de participantes planteado como óptimo para llevar adelante el estudio.

Sin embargo, el aumento de las demandas para el grupo experimental, conforme avanzaba la investigación, tuvo como consecuencia el abandono de algunos de sus miembros. Este hecho es indicativo de la dificultad y esfuerzo que supone reflexionar de forma consciente durante un periodo sostenido en el tiempo y está relacionado con el "efecto cansancio" comentado en el apartado de la discusión sobre la efectividad de las herramientas utilizadas.

Otra explicación posible está relacionada con la no existencia explícita de recompensa material o académica para los participantes. El estudio requería estudiantes que se esforzaran movidos por la motivación intrínseca hacia el cambio, pero la realidad ha mostrado que esta motivación se sostiene cuando la demanda es pequeña, como ha sido el caso del grupo control, mientras que si la exigencia aumenta, el compromiso con la investigación se reduce.

A pesar de la mortalidad sufrida en el grupo experimental, el tamaño final 
de la muestra permite igualmente cumplir los criterios mínimos de saturación, de forma que los datos obtenidos por ambos grupos completan perfectamente el espectro de respuestas posibles.

La segunda limitación se refiere a la generalización de la investigación. La pretensión de este estudio desde el primer momento ha sido modesta. Todo el trabajo se ha realizado principalmente para abordar una realidad muy particular que se corresponde al Grado de Maestro o Maestra en Educación Primaria de la Universitat Jaume I. Ello tiene como consecuencia una buena generalización interna de los resultados hacia el grupo y el contexto al que pertenece la muestra, pero una limitada $x$ generalizabilidad externa hacia otros contextos distintos al estudiado. Sin embargo, no por ello se puede negar la posibilidad de que algunos hallazgos sean perfectamente compatibles con los que se podrían encontrar si se analizaran otras titulaciones y otras universidades y, por lo tanto, las conclusiones también pudieran serles de utilidad ajustando algunos elementos a esas otras realidades.

\subsubsection{Consideraciones éticas}

Las investigaciones de carácter cualitativo deben respetar la ética en el proceso investigador y en su proceder científico si se pretende que el conocimiento verdaderamente avance. Según la taxonomía de Russell y Purcell (2009) esta investigación se considera de riesgo mínimo puesto que cuida el anonimato de los participantes y no expresa los resultados de forma personalizada sino bajo seudónimo y garantizando la privacidad. Así mismo, los efectos experimentales derivados de la intervención no suponen para los participantes ningún tipo de riesgo. Los tres puntos clave que confirman la ética de la investigación son:

1. Uso correcto y objetivo de las fuentes documentales: todas las fuentes empleadas en este trabajo, tanto si provienen de la revisión de la literatura como si son producto de la información obtenida en entrevistas, revisiones, recomendaciones o informes de mejora, lo han sido de forma transparente, objetiva y adecuadamente referenciadas. Las opiniones vertidas por el investigador se distinguen de forma clara de las opiniones de otros autores consultados, así mismo se ha evitado de forma contundente el plagio. En lo que respecta a citas y referencias se han adoptado las 
medidas recomendadas por la American Psychological Association en su última versión (APA, 2010).

2. Requerimiento del consentimiento informado en los participantes previamente al inicio en la investigación. En este documento, cuyo modelo puede verse en el Apéndice 2, se detalla el propósito de la investigación, la función de cada participante y las condiciones del proceso, se informa de sus derechos y compromisos respecto a esta y se les garantiza la confidencialidad en el tratamiento de datos y en la divulgación de los mismos.

3. Transparencia en el tratamiento de datos y en la presentación de conclusiones. El tratamiento y análisis de los datos han sido sometidos a técnicas analísticas aplicadas con máximo rigor científico. La transparencia del proceso ha primado en todo momento y cada detalle se encuentra ampliamente especificado tanto en la descripción del procedimiento seguido como en la exposición de resultados y conclusiones.

\subsubsection{Líneas futuras de investigación}

De forma paralela al desarrollo de la tesis se han encontrado cuestiones que bien por no formar parte del foco inicial de interés, bien por haber surgido de forma fortuita durante el proceso o bien por necesidad pragmática de profundizar en unos temas en detrimento de otros, no han podido ser abordados con la exhaustividad que hubieran requerido. Esos temas pasan a formar parte de futuras líneas de investigación.

La primera línea que puede dar continuidad a este estudio es la posibilidad de examinar a medio y largo plazo, en una investigación de carácter longitudinal, la evolución de la práctica reflexiva. Si se realizara un estudio a este nivel se podría llevar a cabo una intervención y seguimiento sostenido en el tiempo, conforme van transcurriendo los cursos y las prácticas de la titulación. En este caso se podrían obtener datos relativos al mantenimiento de los cambios en el tiempo y a la generalización de la práctica reflexiva a otras materias o prácticas. 
Una segunda propuesta es profundizar en la meta-reflexión, entendida como la capacidad de pensar sobre la propia habilidad reflexiva y sobre la reflexión en sí misma. No existen demasiados estudios en este campo y en este trabajo, aunque se ha incluido como elemento del análisis no se ha llegado a profundizar debidamente en ella ante a la imperiosa necesidad de acotar la información para ajustarla a unos plazos determinados. Esto no excluye que en un futuro próximo puedan utilizarse dichos datos y de ello derivarse otra serie de estudios al respecto.

Finalmente, otra línea interesante -pero delicada- de investigación que se podría abordar es el análisis de la competencia reflexiva de los docentes universitarios y/o de los tutores de los centros. Prácticamente todos los estudios sobre práctica reflexiva sitúan el foco de atención en el alumnado mientras que el resto de profesionales implicados (supervisores, tutores y otros docentes) nunca son el núcleo principal de la investigación. Respecto a los profesionales, se suele analizar su metodología, su vínculo con el alumno, su acompañamiento durante las prácticas y otras funciones colaterales, pero nunca se pone en cuestión su propia capacidad para pensar reflexivamente o para servir de modelos en unas prácticas pedagógicas reflexivas. Evaluar la capacidad de reflexión de los compañeros es, evidentemente, un tema incómodo y por ello esta es una línea futura escasamente explorada en la literatura 



\section{Parte IV. Referencias}

A

Alaminos, A., y Castejón, J.L. (2006). Elaboración, análisis e interpretación de encuestas, cuestionarios y escalas de opinión. Alicante: Marfil.

Alsina, A., y Esteve, O. (2009). ¿Cómo aprender competencias profesionales durante la formación inicial de maestros? Algunas aportaciones desde el aprendizaje realista, en II Congreso Internacional Claves para la implicación de los estudiantes en la universidad. A 'Taula A: Planificació de la docència centrada en l'estudiant. Girona: Universitat de Girona. Recuperado de http://dugi-doc. udg.edu:8080/handle/10256/1952

Alvarado, L., y García, M. (2008). Características más relevantes del paradigma sociocrítico. Revista Universitaria de Investigación, 9(2), 187-202.

Anderson, L., y Krathwohl, D. (Eds.) (2001). A Taxonomy for Learning, Teaching, and Assessing: A Revision of Bloom's Taxonomy of Educational Objectives. New York: Longman.

ANECA (2005). Libro blanco para el título de grado en Magisterio. Vol. I. Madrid: ANECA. Recuperado de http://www.aneca.es/var/media/150404/ libroblanco jun05 magisterio1.pdf

ANECA (2006). El programa de convergencia europea de ANECA (2003-2006). Madrid: ANECA. Recuperado de http://www.aneca.es/Documentos-ypublicaciones/Otros-documentos-de-interes/Convergencia-Europea

Angelides, P. (2001). The development of an efficient technique for collecting and analyzing qualitative data: The analysis of critical incidents. International Journal of Qualitative Studies in Education, 14(3), 429-442. doi: 10.1080/09518390110029058

APA (2010). Publication Manual of the American Psychological Association. Washington, DC: American Psychological Association. 
Archer, M. (2010). Introduction: The reflexive re-turn. En M. Archer (Ed.), Conversations about reflexivity (pp. 1-14). London: Routledge.

Area, M., y Adell, J. (2009). ELearning: Enseñar y Aprender en Espacios Virtuales. En J. de Pablos (Coord.), La tecnología educativa en el siglo XXI (pp. 391-424). Málaga: Editorial Aljibe.

Argyris, C., y Schön, D. (1974). Theory in practice: Increasing professional effectiveness. Washington, DC: Jossey-Bass.

Argyris, C., y Schön, D. (1978). Organizational learning: A theory of action perspective (Vol. 173). Reading, MA: Addison-Wesley.

Arnal, J., Del Rincón, D., y Latorre, A. (1994). Investigación educativa. Fundamentos y metodología. Barcelona: Labor.

B

Baker, S. (1990). Reflection, doubt, and the place of rhetoric in postmodern social theory. Sociological Theory, 8(2), 232-245. doi: 10.2307/202208

Bannink, A., y Van Dam, J. (2007). Premature closure and guided reinvention: A case study in a Web-based learning environment. Teachers and Teaching: Theory and Practice, 13(6), 565-586. Recuperado de http://www.tandfonline.com/ doi/abs/10.1080/13540600701683499

Barnett, R. (1992). Improving Higher Education. Buckingham: SRHE/Open University Press.

Bates, A. J., Ramirez, L., y Drits, D. (2009). Connecting university supervision and critical reflection: Mentoring and modeling. The Teacher Educator, 44(2), 90112. doi: $\underline{10.1080 / 08878730902751993}$

Beauchamp, C. (2006). Understanding reflection in teaching: A framework for analysing the literature (Tesis doctoral) Université McGill, Canada.

Beauchamp, C. (2015). Reflection in teacher education: issues emerging from a review of current literature. Reflective Practice: International and Multidisciplinary Perspectives, 16(1), 123-141. doi: 10.1080/14623943.2014.982525 
Bell, G.L. (2001, Marzo). Reflective Journal writing in an Inquiry-Based Science Course for Elementary Pre-service teachers. Artículo presentado en el Annual International Meeting of the National Association for Research in Science Teaching St. Louis. Recuperado de https://eric.ed.gov/?id=ED457128

Bengtsson, J. (2003). Possibilities and limits of self-reflection in the teaching profession. Studies in Philosophy and Education, 22, 295-316. doi:10.1023/A:1022813119743

Béres, L. (2017). Maintaining the ability to be unsettled and learn afresh: what philosophy contributes to our understanding of 'reflection'and 'experience'. Reflective Practice, 280-290. doi: 10.1080/14623943.2016.1269003

Bilbao, G., y Monereo, C. (2011). Identificación de incidentes críticos en maestros en ejercicio: Propuestas para la formación permanente. Revista Electrónica de Investigación Educativa, 13 (1), 135-151. Recuperado de http://www.scielo. org.mx/scielo.php?script=sci_arttext\&pid=S1607-40412011000100009\&Ing =es\&tIng=es

Blaschke, L. M., y Brindley, J. E. (2011). Establishing a foundation for reflective practice: A case study of learning journal use. European Journal of Open, Distance and E-learning, 14(2). Recuperado de http://www.eurodl.org/index.php?p=speci al\&sp=articles\&inum $=3 \&$ article $=446 \&$ article $=438$

Bleakley, A. (1999). From reflective practice to holistic reflexivity. Studies in higher education, 24(3), 315-330.

Boenink, A. D., Oderwald, A. K., De Jonge, P., Van Tilburg, W., y Smal, J. A. (2004). Assessing student reflection in medical practice. The development of an observer-rated instrument: Reliability, validity and initial experiences. Medical Education, 38(4), 368-377. doi: 10.1046/j.1365-2923.2004.01787.x

Bolhuis, S. M., y Simons, P. R. J. (1999). Leren en werken [Learning and working]. Deventer: Kluwer.

Bolívar, A. (2011). Enseñar competencias en educación para la ciudadanía. Aula de innovación educativa, 19(199), 38-41.

Boud, D., Keogh, R. y Walker, D. (1985). Reflection: Turning experience into learning. London: Kogan Page. 
Boyd, E. M. y Fales, A. W. (1983). Reflective learning: key to learning from experience, Journal of Humanistic Psychology, 23, 99-117.

Boyd, P. C., Boll, M., Brawner, L., y Villaume, S. K. (1998). Becoming reflective professionals: An exploration of preservice teacher's struggles as they translate language and literacy theory into practice. Action in Teacher Education, 19(4), 61-75. doi: 10.1080/01626620.1998.10462892

Bretonés, A. (2013). El Prácticum de Magisterio en Educación Primaria: una mirada retrospectiva. Revista Complutense de Educación, 24(2), 443-471. Recuperado de http://search.proquest.com/openview/a81e70af70fa7203e9 a6f5321d3f6ac7/1?pq-origsite $=$ gscholar $\& \mathrm{cbl}=54848$

Bright, B. (1996). Reflecting on "reflective practice". Studies in the Education of Adults, 28(2), 162-184. doi: $10.1080 / 02660830.1996 .11730638$

Brockbank, A. y McGill I. (2002). Aprendizaje reflexivo en la educación superior. Madrid: Morata.

Brookfield, S. (1990). Using critical incidents to explore learners' assumptions, en J. Mezirow (ed.) Fostering critical reflection in adulthood (pp. 177-193). San Francisco: Jossey-Bass.

Brubacher, J., Case, C. y Reagan, T. (2000). Cómo ser un docente reflexivo. La construcción de una cultura de la indagación en las escuelas. Barcelona: Gedisa.

Buchberger, F. (2000). Teacher Education Policies in the European Union: Critical Analysis and Identification of main Issues. En VV. AA.: Teacher Education Policies in the European Union. Lisbon: European Network on Teacher Education Policies (ENTEP) (pp. 9-49). Portuguese Presidency of the Council of the European Union.

Bustos, A. (2011). Presencia docente distribuida. (Tesis doctoral). Universitat de Barcelona, Barcelona. Recuperado de http://www.psyed.edu.es/prodGrintie/ tesis/Tesis A_Bustos_PresenciaDocenteDistribuida_V_web_2011.pdf 
Calandra, B., Brantley-Dias, L., Lee, J. K., y Fox, D. L. (2009). Using video editing to cultivate novice teachers' practice. Journal of Research on Technology in Education, 42(1), 73-94. doi: 10.1080/15391523.2009.10782542

Calderhead, J. (1989). Reflective teaching and teacher education. Teaching and Teacher Education, 15(1), 43-51. doi: 10.1016/0742-051X(89)90018-8

Carson, L. y Fisher, K. (2006). Raising the bar on criticality: Students' critical reflection in an internship program. Journal of Management Education, 30(5), 700-723.

Cebreiro, B. y Fernández M. (2004). Estudio de casos. En F. Salvador, J. L. Rodríguez y A. Bolívar, Diccionario enciclopédico de didáctica. Volumen I (pp. 665-668). Málaga: Aljibe.

Çimer, S. O. (2011). The effect of portfolios on students' learning: Student teachers' views. European Journal of Teacher Education, 34(2), 161-176. doi: 10.1080/02619768.2011.552183

Cohen, L., Manion, L., y Morrison, K. (2011). Research methods in education (7th ed.). Abingdon: Routledge.

Coiduras, J. L., Isus, S., y Del Arco, I. (2015). Formación inicial de docentes en alternancia. Análisis desde las percepciones de los actores en una experiencia de integración de aprendizajes. Educar 51(2), 277-299. doi: 10.5565/rev/ educar.670

Cole, A. L. y Knowles, J. G. (2000). Researching teaching: Exploring teacher development through reflective inquiry. Boston, MA: Allyn and Bacon.

Colén, M. T., Jarauta, B. y Castro, L. C. (2016). El aprendizaje reflexivo en la formación inicial de maestros/as: de la experiencia a la integración y síntesis de los contenidos. Revista Complutense de Educación, 27(1), 179-198. Recuperado de http://revistas.ucm.es/index.php/RCED/article/view/45679

Colton, D., y Colbert, R. W. (2007). Designing and constructing instruments for social research and evaluation. San Francisco: John Wiley \& Sons, Inc. 
Collier, S. T. (1999). Characteristics of reflective thought during the student teaching experience. Journal of Teacher Education, 50(3), 173-181. Recuperado de http://journals.sagepub.com/doi/pdf/10.1177/002248719905000303

Collin,S.Karsenti, T.yKomis, V.(2013).Reflectivepracticeininitialteachertraining:critiques and perspectives. Reflective Practice: International and Multidisciplinary Perspectives, 14(1), 104-117. doi: 10.1080/14623943.2012.732935

Comas, M.A. (2013). El EEES, identidad y competitividad Europea: Principios fundamentales e interpretación de las principales autoridades. Revista de Docencia Universitaria, 11(1), 243-263. Recuperado de http://red-u.net/redu/ files/journals/1/articles/380/public/380-2008-1-PB.pdf

Contreras, R. (2004). El paradigma científico según Kuhn. Desarrollo de las ciencias: Del conocimiento artesanal hasta la ciencia normal. Revista VI Escuela Venezolana para la Enseñanza de la Química, 43-51. Recuperado de http:// www.webdelprofesor.ula.ve/ciencias/ricardo/PDF/Paradigma_Cientifico segun Kuhn.pdf

Correa-Molina, E., Collin, S., Chaubet, P., y Gervais, C. (2010). Concept de réflexion: un regard critique. Éducation et francophonie, XXXVIII, 135-155.

Crawford, S., O'Reilly, R., y Luttrell, S. (2012). Assessing the effects of integrating the reflective framework for teaching in physical education (RFTPE) on the teaching and learning of undergraduate sport studies and physical education students. Reflective Practice, 13(1), 115-128. doi: $\underline{10.1080 / 14623943.2011 .626025}$

Cruickshank, D. y Applegate, J. (1981). Reflective teaching as a strategy for teacher growth. Educational Leadership, 38(7), 553-554.

Chen, N. S., Kinshuk Wei, C. W., y Liu, C. C. (2011). Effects of matching teaching strategy to thinking style on learner's quality of reflection in an online learning environment. Computers y Education, 56, 53-64.

Chitpin, S. (2006). The use of reflective journal keeping in a teacher education program: a Popperian analysis. Reflective Practice: International and Multidisciplinary Perspectives, 7(1), 73-86. Recuperado de http://www.tandfonline.com/doi/ abs/10.1080/14623940500489757 


\section{D}

Darling-Hammond, L. (1999). Educating teachers for the next century: Rethinking practice and policy. En G. Griffin (Ed.), The education of teachers: 98th NSSE Yearbook, Part I (pp. 221-256). Chicago: NSSE.

Davidson, J., y Di Gregorio, S. (2011). Qualitative research, technology, and global change. En N. K. Denzin y M. D. Giardina (Eds.), Qualitative inquiry and global crises (pp. 79-96). Walnut Creek, CA: Left Coast Press.

Davis, E. A. (2004). Creating critique projects. En M. C. Linn, E. A. Davis, y P. Bell (Eds.), Internet environments for science education (pp. 215-229). Cambridge, UK: Cambridge University Press.

Day, C. (1993). Reflection: a necessary but not sufficient condition for professional development. British Educational Research Journal, 19, 83-93. doi: $\underline{10.1080 / 0141192930190107}$

Declaración De Bolonia. (1999). Declaración conjunta de los Ministros Europeos de Educación. Recuperado de http://www.educacion.gob.es/ boloniaensecundaria/img/Declaracion_Bolonia.pdf

De Dea Roglio, K., y Light, G. (2009). Executive MBA programs: The development of the reflective executive. Academy of Management Learning y Education, 8(2), 156-173. doi: 10.5465/AMLE.2009.41788840

Delors, J. (1996). La Educación encierra un tesoro. UNESCO. Madrid: Santillana.

Denton, D. (2011). Reflection and learning: Characteristics, obstacles, and implications. Educational Philosophy and Theory, 43(8), 839-852.

Denzin, N. K., y Lincoln, Y. S. (2011). The Sage handbook of qualitative research. London: Sage.

Dewey, J. (1916). Democracy and Education: An Introduction to Philisophy of Education. New York: Macmillan.

Dewey, J. (1933). How we think: A restament of the relations of reflective thinking to the educative process. Boston: D: C Heath. 
Díaz-Bravo, L., Torruco-García, U., Martínez-Hernández, M., y Varela-Ruiz, M. (2013). La entrevista, recurso flexible y dinámico. Investigación en educación médica, 2(7), 162-167. doi: 10.1016/\$2007-5057(13)72706-6

Dobbins, R., (1996). The challenge of developing a 'reflective practicum.' Asia-Pacific Journal of Teacher Education, 24(3), 269-280.

Domingo, A. (2013). Práctica reflexiva para docentes. De la reflexión ocasional a la reflexión metodológica. Saarbrücken, Alemania: Publicia.

Dupuis, A. M. (1985). Philosophy of education in historical perspective. Lanham, MD: University Press of America, Inc.

E

Edwards, G., y Thomas, G. (2010). Can reflective practice be taught? Educational Studies, 36, 403-414. doi: 10.1080/03055690903424790

Egido, I. y López, E. (2013). Análisis del prácticum en los estudios de magisterio en españa a partir de los datos de TEDS-M. En TEDS-M: Estudio Internacional sobre la formación inicial en matemáticas de los maestros. Informe Español. Volumen I/ (pp. 108-135). Madrid: MECD.

Eraut, M. (1995). Schön shock: A case for reframing reflection-in-action? Teachers and Teaching: Theory and Practice, 1(1), 9-22.

Ewart, G. y Straw, B. S. (2005). A seven-month practicum: Collaborating teachers' responses. Canadian Journal of Education, 28(1), 185-202. doi: $10.2307 / 1602160$

Expósito, J., Olmedo, E., y Cano, A. F. (2004). Patrones metodológicos en la investigación española sobre evaluación de programas educativos. Revista Electrónica de Investigación y Evaluación Educativa, 10(2), 185-209. Recuperado de http:// www.uv.es/relieve/v10n2/RELIEVEv10n2_2.pdf 
Farrell, T. S. (2004). Reflective practice in action: 80 reflective breaks for busy teachers. Thousand Oaks, CA: Corwin Press.

Farrell, T. S. (2012). Reflecting on reflective practice: (re)visiting Dewey and Schön. TESOL Journal, 3(1), 7-16. doi:10.1002/tesj.10

Fendler, L. (2003). Teacher reflection in a hall of mirrors: Historical influences and political reverberations. Educational Researcher, 32(3), 16-25.

Fernández, F. (2002). El análisis de contenido como ayuda metodológica para la investigación. Revista de Ciencias Sociales, Universidad de Costa Rica, 11, 3553. Recuperado de http://www.redalyc.org/pdf/153/15309604.pdf

Fernández, R. (2001). La entrevista en la Investigación cualitativa. Revista Pensamiento Actual, 2(3), 14-21.

Finlay, L. (2003). The reflexive journey: mapping multiple routes. En L. Finlay y B. Gough (eds.) Reflexivity: a practical guide for researchers in health and social sciences (pp. 3-20). Oxford: Blackwell Publishing.

Finlay, L. (2008). Reflecting on 'Reflective practice'. Practice-Based Professional Learning Center, 52, 1-27. Recuperado de http://www.open.ac.uk/opencetl/ resources/pbpl-resources/finlay-l-2008-reflecting-reflective-practice-pbplpaper-52

Finlayson, A. (2015). Reflective practice: has it really changed over time? Reflective Practice, 16(6), 717-730, doi: 10.1080/14623943.2015.1095723

Fischer, M. A., Haley, H. L., Saarinen, C. L., y Chretien, K. C. (2011). Comparison of blogged and written reflections in two medicine clerkships. Medical Education, 45, 166-175.

Flanagan, J. (1954). The critical incident technique. Psychological Bulletin, 51, 327-358.

Flick, U. (2007). Introducción a la investigación cualitativa. Madrid: Morata Paideia. 
Fook, J. (2010). Beyond reflective practice: reworking the 'critical' in critical reflection. En H. Bradbury, N. Frost, S. Kilminster, y M. Zukas (Eds.), Beyond reflective practice approaches to professional lifelong learning (pp. 37-51). London: Routledge.

Fook, J., y Askeland, G.A. (2006). The 'critical' in critical reflection. En S. White, J. Fook, y F. Gardner (Eds.), Critical reflection in health and social care (pp. 228240). Maidenhead: Open University Press/McGraw-Hill Education.

Fox, R. K., White, C. S., y Kidd, J. K. (2011). Program portfolios: Documenting teachers' growth in reflection-based inquiry. Teachers and teaching: Theory and practice, 17(1), 149-167. Recuperado de http://www.tandfonline.com/doi/ab s/10.1080/13540602.2011.538506

Francis, A., Tyson, L., y Wilder, M. S. (1999). An analysis of the efficacy of a reflective thinking instructional module of the reflective thinking demonstrated in the field experience logs of early elementary preservice teachers. Action in Teacher Education, 21(3), 38-44.

G

Gairín, J. (1993). Evaluación de programas y cursos. En A. Ferrández, J. Peiro y J. Puente (Coords). La evaluación en la educación de personas adultas (pp. 77109). Madrid: Diagrama.

Galea, S. (2012). Reflecting Reflective Practice. Educational Philosophy and Theory, 44(3). doi: 10.1111/j.1469-5812.2010.00652.x

García, R., Pérez, I., Ripollés, A., Salvador, M. y Solsona F. J. (2007, Junio). El practicum en la titulación de Maestro de la Universitat Jaume I de Castellón: una propuesta para el futuro grado en el marco del EEES. Comunicación presentada en el IX Symposium Internacional sobre Practicum. Practicum y Prácticas en empresas en la formación universitaria, Pontevedra.

Gelfuso, A., y Dennis, D. V. (2014). Getting reflection off the page: The challenges of developing support structures for pre-service teacher reflection. Teaching and Teacher Education, 38, 1-11. doi: 10.1016/j.tate.2013.10.012 
Ghaye, T. (2007). Is reflective practice ethical? (The case of the reflective portfolio). Reflective Practice: International and Multidisciplinary Perspectives, 8(2), 151-162. doi: 10.1080/14623940701288859

Ghaye, T. (2010). Teaching and learning through reflective practice: a practical guide for positive action. London: Routledge.

Gibbs, G. (1988). Learning by doing: A guide to teaching and learning methods. Birmingham: Sced.

Gimeno-Sacristán, J. (comp.) (2008). Educar por competencias, ¿qué hay de nuevo? Madrid: Morata.

Giovannelli, M. (2003). Relationship between reflective disposition toward teaching and effective teaching. The Journal of Educational Research, 96(5), 293-309.

Gómez, M. V. (2011). Desarrollo profesional del maestro. La competencia reflexiva Evaluación de un programa formativo en el contexto panameño. (Tesis doctoral). Universitat de Lleida, Lleida. Recuperado de http://www.tdx.cat/ handle/10803/77742

González, F. L. (2007). Investigación cualitativa y subjetividad: los procesos de construcción de la información. México: McGraw-Hill.

González, J. y Wagenaar, R. (eds.) (2006). Tuning Educational Structures in Europe II. La contribución de las universidades al Proceso de Bolonia. Bilbao: Publicaciones de la Universidad de Deusto. Recuperado de http://www. deusto-publicaciones.es/deusto/pdfs/tuning/tuning04.pdf

González, M. (2001). ¿Qué se aprende en el Prácticum? En L. Iglesias, M. Zabalza, A. Cid y M. Raposo (coords). Desarrollo de competencias personales y profesionales en el Prácticum. VI Simposium Internacional sobre el Prácticum. Lugo: Unicopia.

Gore, J. y Zeichner, K. (1991) Action Research and Reflective Teaching in Pre-service Teacher Education, Teaching and Teacher Education, 7(2), 119-136. 
Granberg, C. (2010). Social software for reflective dialogue: Questions about reflection and dialogue in student teachers' blogs. Technology, Pedagogy and Education, 19(3), 345-360. doi: 10.1080/1475939X.2010.513766

Griffin, M. (2003). Using Critical Incidents to Promote and Assess Reflective Thinking in Preservice Teachers. Reflective Practice, 4(2).

Gutek, G. L. (2005). Historical and philosophical foundations of education: A biographical introduction. Upper Saddle River, NJ: Pearson Education, Inc.

Gutiérrez, L., Gorospe, J. M., De Aberasturi, E. J. y Etxeberria, A. I. (2009). El modelo reflexivo en la formación de maestros y el pensamiento narrativo: estudio de un caso de innovación educativa en el Practicum de Magisterio. Revista de educación, 350, 493-505. Recuperado de http://www.revistaeducacion.mec. es/re350/re350 22.pdf

$\mathrm{H}$

Habermas J. (1990). El discurso filosófico de la modernidad. Madrid: Taurus.

Habermas, J. (1974). Theory and practice, trans. J. Viertel. London: Heinemann.

Handal, G., y Lauvas, P. (1987). Promoting reflective teaching. Milton Keynes, UK: Open University Press.

Hatton, N., y Smith, D. (1995). Reflection in teacher education: towards a definition and implementation. Teaching and Teacher Education, 11(1), 33-49.

Hébert, C. (2015). Knowing and/or experiencing: a critical examination of the reflective models of John Dewey and Donald Schön. Reflective Practice, 16(3), 361-371. doi: 10.1080/14623943.2015.1023281

Henderson, K., Napan, K., y Monteiro, S. (2004, diciembre). Encouraging reflective learning: An online challenge. Conferencia presentada en Beyond the comfort zone: Proceedings of the 21st ASCILITE Conference, Perth. Recuperado de http://www.ascilite.org/conferences/perth04/procs/henderson.html 
Hernández, F., Fonollosa, M., y Chrysos, A. (1998). Niveles de reflexión en la práctica docente en un curso de formación inicial del profesorado utilizando el correo electrónico como sistema tutorial. Píxel-Bit. Revista de Medios y Educación, (10), 111-121. Recuperado de http://acdc.sav.us.es/ojs/index.php/pixelbit/ article/view/579

Hickson, H. (2011). Critical reflection: Reflecting on learning to be reflective. Reflective Practice: International Multidisciplinary Perspectives, 12(6), 829-839. doi: 10.1080/14623943.2011.616687

Hilton, G. L. S. (2010). Teacher Education in England. En K. G. Karras y C. C. Wolhuter (Eds.). International Handbook on Teacher Education Worldwide (Vol. 1) (pp. 585-599). Athens: Atrapos Editions.

Hobbs, V. (2007). Faking it or hating it: can reflective practice be forced? Reflective Practice, 8(3), 405-417. doi: 10.1080/14623940701425063

Hobson, A. J., Ashby, P., Malderez, A. y Tomlinson, P. D. (2009). Mentoring beginning teachers: What we know and what we don't. Teaching and Teacher Education, 25, 207-216. doi: 10.1016/i.tate.2008.09.001

Hourani, R. B. (2013). Pre-service teachers' reflection: Perception, preparedness and challenges. Reflective Practice: International and Multidisciplinary Perspectives, 14(1), 12-30. doi: 10.1080/14623943.2012.732947

Hubbs, D. L., y Brand, C. F. (2005). The paper mirror: Understanding reflective journaling. Journal of Experiential Education, 28(1), 60-71.

Husu, J., Toom, A., y Patrikainen, S. (2008). Guided reflection as a means to demonstrate and develop student teachers' reflective competencies. Reflective Practice, 9(1), 37-51. doi: 10.1080/14623940701816642

Imbernón, F. y Colén, M. T. (2014). Los vaivenes de la formación inicial del profesorado. Una reforma siempre inacabada. Tendencias pedagógicas, 24, 265-284. 
Ixer, G. (2000). Assumptions about reflective practice. Reclaiming Social Work. The Southport Papers, 1. En J. Harris, L. Froggett y I. Paylor (eds.) Reclaiming Social Work: The Southport paper (pp. 79-92). Birmingham: Venture Press.

J

Jarvis, P. (1992). Reflective practice and nursing. Nurse Education Today, 12(3), 174-181.

Jay, J. K. y Johnson, K. L. (2002). Capturing complexity: a typology ofreflective practice for teacher education. Teaching and Teacher Education, 18, 73-85.

Johns, C. (1995). Framing learning through reflection within Carper's Fundamental Ways of Knowing in nursing. Journal of Advanced Nursing, 22(2), 226-234. doi: 10.1046/j.1365-2648.1995.22020226.x

Johnston, M. (2000). Cambiar la enseñanza, cambiar la formación. Cuadernos de Pedagogía, 290, 42-45.

Jové, G., Agulló, M. J., Coiduras, J. L., Marsellés, M. A., Rives, R., Valls, M. J. y Cano, S. (2007). La formación práctica como bisagra en los procesos de innovación y de cambio en la titulación de maestro. Investigación en la Escuela, 62, 97114. Recuperado de http://www.investigacionenlaescuela.es/articulos/62/ R62_8.pdf

Jucks, R., Schulte-Löbbert, P., y Bromme, R. (2007). Supporting experts' written knowledge communication through reflective prompts on the use of specialist concepts. Journal of Psychology, 215(4), 237-247.

K

Keatinge, D. (2002). Versatility and flexibility: attributes of critical incident technique in nursing research. Nursing and Health Sciences, 4, 33-39.

Kember, D., Leung, D. Y., Jones, A., Loke, A. Y., McKay, J., Sinclair, K. y Yeung, E. (2000). Development of a questionnaire to measure the level of reflective thinking. Assessment y evaluation in higher education, 25(4), 381-395. doi: 10.1080/713611442 
Kember, D., McKay, J., Sinclair, K., y Wong, F. K. Y. (2008). A four-category scheme for coding and assessing the level of reflection in written work. Assessment y Evaluation in Higher Education, 33(4), 369-379. doi: $\underline{10.1080 / 02602930701293355}$

Kemmis, S. (1985). Action research and the politics of reflection. En D. Boud, R. Keogh, y D. Walker (Eds), Reflection: Turning experience into learning (pp. 139-163). New York: Nichols.

Kemmis, S. y McTaggart, R. (1988). The action research planner. Victoria: Deakin University.

Kerka, S. (2002). Journal writing as an adult learning tool. Practice Application Brief, 22. Recuperado de https://eric.ed.gov/?id=ED470782

Killion, J., y Todnem, G. (1991). A process of personal theory building. Educational Leadership, 48(6), 14-17. Recuperado de http://ascd.com/ASCD/pdf/ journals/ed_lead/el_199103 killion.pdf

Kim, M., y Hannafin, M. (2008). Grounded design of Web-enhanced case-based activity. Education Technology Research and Development, 56, 161-179. doi: 10.1007/s11423-006-9010-9

Kim, M., y Hannafin, M. (2011). Scaffolding 6th graders' problem solving in technologyenhanced science classrooms: A qualitative case study. Instructional Science, 39, 255-282.

King, P. M., y Kitchener, K. S. (1994). Developing reflective judgment: Understanding and promoting intellectual growth and critical thinking in adolescents and adults. San Francisco: Jossey-Bass.

Kinsella, E. A. (2009). Professional knowledge and the epistemology of professional practice. Nursing Philosophy, 11, 3-14.

Klein, S. (2008). Holistic reflection in teacher education: Issues and strategies. Reflective Practice, 9, 111-121. doi: 10.1080/14623940802005384 
Koerner, M. y Abdul-Tawwab, N. (2006). Using community as a resource for teacher education: a case study. Equity and Excellence in Education, 39, 37-46. doi: 10.1080/10665680500478767

Kolb, D. (1984). Experiential learning: Experience as the source of learning and development. London: Prentice Hall.

Kori, K., Pedaste, M., Leijen, Ä., y Mäeots, M. (2014). Supporting reflection in technologyenhanced learning. Educational Research Review, 11, 45-55.

Korthagen, F. A. (2001). Linking practice and theory: The pedagogy of realistic teacher education. Mahwah: Lawrence Erlbaum Associates.

Korthagen, F. A. (2010). La práctica, la teoría y la persona en la formación del profesorado. Revista Interuniversitaria de Formación del Profesorado, 68 (24.2), 83-101. Recuperado de https://dialnet.unirioja.es/servlet/ articulo?codigo $=3276048$

Korthagen, F. A. (2011). Principios para una formación eficaz. Cuadernos de pedagogía, 417, 56-59.

Korthagen, F. A. y Lagerwerf, B. (2001). Teachers' professional learnig: how does it work? En F. A. Korthagen, J. Kessels, B. Koster, B. Lagerwerf y T. Wubbels: Linking practice and theory: The pedagogy of realistic teacher education ( $\mathrm{pp}$. 175-206). Mahwah: Lawrence Erlbaum Associates.

Krol, C. (1996, febrero). Preservice teacher education students' dialogue journals: what characterizes students' reflective writing and a teacher's comments. Comunicación presentada en The Annual Meeting of the Association of Teacher Educators, St. Louis, MO. Recuperado de https://eric. ed.gov/?id=ED395911

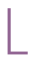

Larrivee, B. (2000). Transforming Teaching Practice: Becoming the critically reflective teacher, Reflective Practice: International and Multidisciplinary Perspectives, 1(3), 293-307. doi: 10.1080/713693162 
Larrivee, B. (2004, junio). Assessing teachers' level of reflective practice as a tool for change. Conferencia presentada en Third International Conference on Reflective Practice, Gloucester, UK.

Larrivee, B. (2005). Authentic classroom management: Creating a learning community and building reflective practice. Boston, MA: Allyn y Bacon.

Larrivee, B. (2008). Meeting the Challenge of Preparing Reflective Practitioners. The New Educator, 4(2), 87-106. doi: 10.1080/15476880802014132

Larrivee, B., y Cooper, J. M. (2005). An educator's guide to teacher reflection. Stamford, CT: Cengage Learning.

Lasley, T. J. (1992). Inquiry and reflection: Promoting teacher reflection. Journal of Staff Development, 13(1), 24-29.

Latorre, M. J. y Blanco, F. J. (2011). El prácticum como espacio de aprendizaje profesional para docentes en formación. REDU Revista de Docencia Universitaria, 9(2), 35-54. doi: 10.4995/redu.2011.6157

Lee, H-L. (2005). Understanding and assessing preservice teachers' reflective thinking. Teaching and Teacher Education, 21, 699-715.

Lee, I. (2008). Fostering preservice reflection through response journals. Teacher Education Quarterly, 35(1), 117-139.

Leech, N. L., y Onwuegbuzie, A., J. (2007). An Array of Qualitative Data Analysis Tools: A Call for Data Analysis Triangulation. School Psychology Quarterly, 22 (4), 557-584.

Leijen, Ä., Admiraal, W. F., Wildschut, L., y Simon, P. R. J. (2008). Pedagogy before technology: What should an ICT intervention facilitate in practical dance classes? Teaching in Higher Education, 13(2), 219-231. doi: 10.1080/13562510801923351

Lincoln, Y. y Guba, E. (1985). Naturalistic inquiry. Newbury Park, CA: Sage. 
Liston, D. y Zeichner, K. (1993). Formación del profesorado y condiciones sociales de la escolarización. Madrid: Morata.

Loo, R. y Thorpe, K. (2002). Using reflective learning journals to improve individual and team performance. Team Performance Management: An International Journal, 8(5/6), 134-139.

Lorenzo, J. A. (2010). La formación práctica del magisterio: perspectivas. CEE Participación Educativa, 15, 26-39. Recuperado de http://www.mecd.gob.es/ revista-cee/pdf/n15-lorenzo-vicente.pdf

Louden, W. (1991). Understanding teaching. London: Cassell.

Lunnenberg, M., Korthagen, F. y Swennem, A. (2007). The teacher educator as a role model. Teaching and Teacher Education, 23, 586-601.

M

Mackay, M., y Tymon, A. (2013). Working with uncertainty to support the teaching of critical reflection. Teaching in higher education, 18(6), 643-655. doi: 10.1080/13562517.2013.774355

Mahlios, M., Engstrom, D., Soroka, G., y Shaw, D. M. (2008). A study of student teachers' reflections on their beliefs, thoughts, and practices. Action in Teacher Education, 30(1), 64-80. doi: 10.1080/01626620.2008.10463482

Maldonado, A. (2004). La adecuación de las Titulaciones de Maestro al Espacio Europeo de Educación Superior. Madrid: ANECA.

Marcos, J. M., Sanchez, E., y Tillema, H. (2011). Promoting teacher reflection: What is said to be done. Journal of Education for Teaching: International Research and Pedagogy, 37(1), 21-36. Recuperado de http://www.tandfonline.com/ doi/abs/10.1080/02607476.2011.538269

Marhuenda, F. (2001). Las prácticas en empresas: con qué propósitos y bajo qué condiciones. En L. Iglesias, M. Zabalza, A. Cid y M. Raposo, (coords). Desarrollo de competencias personales y profesionales en el Prácticum. VI Simposium Internacional sobre el Prácticum. Lugo: Unicopia. 
Martinet, M.; Raymond, D. y Gauthier C. (2004). Formación de docentes: Orientaciones, competencias profesionales. Québec: Ministerio de Educación de Québec.

Martínez-Bonafé, J. (2005). La formación del profesorado y el discurso de las competencias. Revista Interuniversitaria de Formación del Profesorado, 18(3), 127-144. Recuperado de http://www.rinace.net/rlei/numeros/vol4num1/Revista_educacion_inclusiva_V.4_N\%C3\%82\%C2\%B01.pdf\#page=127

Martínez-Clares, P., Martínez-Juárez, M., y Muñoz-Cantero, J. M. (2008). Formación basada en competencias en educación sanitaria: aproximaciones a enfoques y modelos de competencia. Relieve, 14(2), 1-23. Recuperado de http://www. uv.es/RELIEVE/v14n2/RELIEVEV14n2_1.pdf

Martínez-Salgado, C. (2012). El muestreo en investigación cualitativa. Principios básicos y algunas controversias. Ciênc. saúde coletiva, 17(3), 613-619. Recuperado de http://www.scielosp.org/pdf/csc/v17n3/v17n3a06

Mason, K. O. y Klein, S. R. (2013). Land, sea and sky: mapmaking as reflection in pre-service teacher education, Reflective Practice: International and Multidisciplinary Perspectives, 14(2), 209-22. doi: 10.1080/14623943.2012.749228

McLaughlin, T. (1999). Beyond the reflective teacher. Educational Philosophy and Theory, 31, 9-25.

McVee, M. B., Bailey, N. M., y Shanahan, L. E. (2008). Teachers and teacher educators learning from new literacies and new technologies. Teaching Education, 19(3), 197-210. doi: 10.1080/10476210802250216

Meierdirk, C. E. (2016). Is reflective practice an essential component of becoming a professional teacher? Reflective Practice: International and Multidisciplinary Perspectives, 17(3), 369-378. doi: 10.1080/14623943.2016.1169169

Mérida, R., Farré, A. F., Morcillo, M. V. S., Sequeiros, C., Egea, O. M. T., Molina, A. T., y Peña, A. O. (2003). El prácticum en la Facultad de Ciencias de la Educación de la Universidad de Córdoba. En El Prácticum en la Formación Inicial del Profesorado de Magisterio y Educación Secundaria: Avances de investigación, fundamentos y programas de formación (pp. 255-262). Granada: Editorial Universidad de Granada. 
Mezirow, J. (1981). A critical theory of adult learning and education. Adult education quarterly, 32(1), 3-24.

Mezirow, J. (1988). On critical reflection. Adult Education Quarterly, 48(3), 185-198.

Mezirow, J. (1991). Transformative dimensions of adult learning. San Francisco: JosseyBass.

Ministerio de Educación y Ciencia. (2006). Borrador de propuesta Directrices para la Elaboración de Titulos Universitarios de Grado y Máster. Madrid: MEC.

Minor, L. C., Onwuegbuzie, A. J., Witcher, A. E. y James, T. L. (2002). Preservice teachers' educational beliefs and their perceptions of characteristics of effective teachers. The Journal of Educational Research, 96(2), 116-127.

Mishra, P., y Koehler, M. J. (2006). Technological pedagogical content knowledge: A framework for teacher knowledge. Teachers College Record, 108(6), 10171054. Recuperado de http://citeseerx.ist.psu.edu/viewdoc/download?doi=1 0.1.1.523.3855\&rep=rep1\&type=pdf

Monereo, C. (2010). La formación del profesorado: Una pauta para el análisis e intervención a través de incidentes críticos. Revista Iberoamericana de Educación, 52, 149-178. Recuperado de http://eva.universidad.edu. uy/pluginfile.php/363661/mod_resource/content/O/Formacion_del profesorado a traves IC.pdf

Montero, L. (2001). La construcción del conocimiento profesional docente. Rosario: Homo Sapiens Ediciones.

Moon, J. (1999a). Learning journals: A handbook for academics, students and profesional development. London: Kogan Page.

Moon, J. (1999b). Reflection in Learning and Professional Development Theory and Practice. London: Kogan Page.

Moon, J. (1999c). A handbook of reflective and experiential learning: Theory and practice. London, Routledge. 
Moon, J. (2006). Learning journals: A handbook for reflective practice and professional development. London/New York: Routledge.

Moon, J. (2010). Learning journals and logs, reflective diaries. Good practices in teaching and learning. Dublin: University College Dublin. Recuperado de http://ar.cetl.hku.hk/pdf/ucdtla0035.pdf

Moreno, I. M., y Siles, J. (2015). Pensamiento crítico en enfermería: de la racionalidad técnica a la práctica reflexiva. Aquichan, 14(4), 594-604. doi: 10.5294/2734

Morgan, J., Rawlinson, M. y Weaver, M. (2006). Facilitating online reflective learning for health and social care professionals. Open Learning, 21(2), 167-176. Recuperado de http://www.tandfonline.com/doi/abs/10.1080/02680510600715594

Mulder, M., Weigel, T., y Collings, K. (2011). El concepto de competencia en el desarrollo de la educación y formación profesional en algunos Estados miembros de la UE: un análisis crítico. Revista de currículum y formación del profesorado, 12(3), 1-26. Recuperado de http://www.ugr.es/ recfpro/rev123ART6.pdf

Mulnix, J. W. (2012). Thinking critically about critical thinking. Educational Philosophy and Theory, 44(5), 464-479.

Muradás, M., Porta, M. (2007). Las memorias del Practicum I de maestros de Educación Infantil: sobre qué reflexionan los alumnos. En A. Cid, M. Muradás, M. Zabalza, M. González, M. Raposo y L. Iglesias (Coord.), Buenas prácticas en el Practicum (pp. 977-990). Santiago de Compostela: Imprenta universitaria.

Murphy, D. L., y Ermeling, B. A. (2016). Feedback on reflection: comparing rating-scale and forced-choice formats for measuring and facilitating teacher team reflective practice. Reflective Practice, 17(3), 317-333. doi: $\underline{10.1080 / 14623943.2016 .1164681}$

Murray, J. y Wishar, J. (Eds.) (2011). Teacher Education in Transition: the Changing Landscape across the UK. Bristol: ESCalate. 
Nagle, J. (2008). Becoming a reflective practitioner in the age of accountability. The Educational Forum, 73(1), 76-86. doi: 10.1080/00131720802539697

Navarrete, J. M. (2000). El muestreo en la investigación cualitativa. Investigaciones sociales, 4(5), 165-180. Recuperado de http://revistasinvestigacion.unmsm. edu.pe/index.php/sociales/article/viewFile/6851/6062

Ng, P. T., Lan, L. K. Y., y Thye, J. T. E. (2004). Developing reflective teachers: The experience of two modules in the teacher training programme at the National Institute of Education, Singapore. Asia Pacific Education Review, 5(2), 200-206.

Nilsen, P., Nordström, G., y Ellström, P. (2012). Integrating research-based and practicebased knowledge through workplace reflection. Journal of Workplace Learning, 24(6), 403-415.

Noffke, S., y Brennan, M. (2005). The dimensions of reflection. A conceptual and contextual analysis. International Journal of Progressive Education, 1(3), 5878. Recuperado de https://eric.ed.gov/?id=ED296968

Nilsson, P. (2009). From lesson plan to new comprehension: exploring pupils teachers' pedagogical reasoning in learning about teaching. European Journal of Teacher Education, 32(3), 239-258. doi: 10.1080/02619760802553048

0

ORDEN ECl/3854/2007, de 27 de diciembre, por la que se establecen los requisitos para la verificación de los títulos universitarios oficiales que habiliten para el ejercicio de la profesión de Maestro en Educación Infantil. Boletín Oficial del Estado (29 de diciembre 2007), 53735-53738.

ORDEN ECl/3857/2007, de 27 de diciembre, por la que se establecen los requisitos para la verificación de los títulos universitarios oficiales que habiliten para el ejercicio de la profesión de Maestro en Educación Primaria. Boletín Oficial del Estado (29 de diciembre 2007), 53747-53750. 
Ortiz, A. M., Hernández, C. P., y del Olmo, E. (2013). Utilización de Moodle como plataforma para la investigación educativa: aplicación a los córpora de aprendices de lenguas. Pixel-Bit. Revista de Medios y Educación, 43, 125138. Recuperado de http://acdc.sav.us.es/ojs/index.php/pixelbit/article/ view/383

Osterman, K. F., \& Kottkamp, R. B. (1993). ReflectivePractice for Educators: Improving Schooling through Professional Development. Newbury Park, CA.: CorwinPress.

Osterman, K. P. y Kottkamp, R. B. (2004). Reflective practice for educators: Improving schooling through profesional development. Thousand Oaks, CA: Corwin Press.

Ostorga, A. N. y Estrada, V. L. (2009). Impact of an action research instructional model: Student teachers as reflective thinkers. Action in Teacher Education, 30(4), 18- 27.

Otienoh, R. O. (2009). Reflective practice: The challenge of journal writing. Reflective Practice, 10(4), 477-489. doi: 10.1080/14623940903138332

Ottesen, E. (2007). Reflection in teacher education. Reflective practice, 8(1), 31-46. doi: 10.1080/14623940601138899

$\mathrm{P}$

Palding, E. y Wilson, A. (2002). Demystifying Reflection: A Study of Pedagogical Strategies That Encourage Reflective Journal Writing. Teachers College Record, 104, (7), 1393-1421. Recuperado de https://www.researchgate. net/profile/Elizabeth_Spalding/publication/249400288 Demystifying Reflection_A Study_of_Pedagogical_Strategies That_Encourage Reflective_Journal_Writing/links/5773b45608aeb9427e23f20f.pdf

Papadopoulos, P. M., Demetriadis, S. N., Stamelos, I. G., \& Tsoukalas, I. A. (2011). The value of writing-to-learn when using question prompts to support webbased learning in ill-structured domains. Educational Technology Research and Development, 59(1), 71-90. 
Parkes, K. A., y Kajder, S. (2010). Eliciting and Assessing Reflective Practice: A Case Study in Web 2.0 Technologies. International Journal of Teaching and Learning in Higher Education, 22(2), 218-228. Recuperado de https://eric. ed.gov/?id=EJ930156

Parmigiani, D. (2001). Hacer pensar saber: hipótesis para el prácticum en la formación de los maestros italianos. En L. Iglesias, M. Zabalza, A. Cid y M. Raposo (coords.): Desarrollo de competencias personales y profesionales en el Prácticum. VI Simposium Internacional sobre el Prácticum. Lugo: Unicopia.

Patton, M. (2002). Qualitative research and evaluation methods. Thousand Oaks: Sage Publications.

Paulus, T., y Spence, M. (2010). Using blogs to identify misconceptions in a large undergraduate nutrition course. TechTrends, 54(5), 62-68.

Pavié, A. (2011). Formación docente: hacia una definición del concepto de competencia profesional docente. Revista electrónica interuniversitaria de formación del profesorado, 14(1), 67-80. Recuperado de https://dialnet.unirioja.es/ descarga/articulo/3678767.pdf

Pérez, M. P. (2001). La tarea supervisora en la formación del profesorado de las etapas de educación infantil y primaria: un modelo reflexivo de supervisión (Tesis Doctoral), Universidad de Granada, Granada. Recuperado de http://hdl. handle.net/10481/28585

Pérez, M. P. (2008). Competencias adquiridas por los futuros docentes desde la formación inicial. Revista de Educación, 347, 343-367. Recuperado de http:// www.revistaeducacion.mec.es/re347/re347 16.pdf

Pérez, M. P., Benarroch, A., Jiménez, M. A., Smith, G. y Rojas, G. (2006). ¿Se puede estimular la reflexión en el supervisor y en el alumno universitario durante el periodo de Practicum? Enseñanza, (24), 33-51. Recuperado de http://espacio.uned.es/fez/eserv/bibliuned:20165/se_puede.pdf

Perrenoud, P. (2004). Diez nuevas competencias para enseñar. Barcelona: Graó.

Perrenoud, P. (2007). Desarrollar la práctica reflexiva en el oficio de enseñar. Profesionalización y razón pedagógica. Barcelona: Graó. 
Perrenoud, P. (2012). Cuando la escuela pretende preparar para la vida. Barcelona: Graó.

Pierson, W. (1998) Reflection and nursing education. Journal of Advanced Nursing, 27, 165-170.

Pihlaja, P. M. y Holst, T. K. (2011). How reflective are teachers? A study of kindergarten teachers' and special teachers' level of reflection in day care. Scandinavian Journal of Education, 1(17). doi:10.1080/00313831.2011.628691.

Pinto, V. (2005). La adecuación de las titulaciones de maestro al Espacio Europeo de Educacion Superior. En M.A Fortea y L. Lapeña (Eds.). El camí cap a la convergència educativa a Europa (Vol. 3). Actes de la IV Jornada de Millora Educativa i III Jornada d harmonització europea de la Universitat Jaume I. Castellón: Universitat Jaume I.

Piqué, B.; Comas, A. y Lorenzo, N. (2010). Estratègies de pràctica reflexiva en la formació inicial de mestres d'educació infantil. Barcelona: Graó.

Pollard, A. (2002). Reflective teaching: Effective and evidence-informed professional practice. London: Continuum.

Power, J. B. (2012) Towards a greater understanding of the effectiveness of reflective journals in a university language program, Reflective Practice: International and Multidisciplinary Perspectives, 13(5) 637-649. doi: 10.1080/14623943.2012.697889

Procee, H. (2006). Reflection in education: A kantian epistemology. Educational Theory, 56(3), 237-253.

Q

Quesada, C. y González, J. (2010). Los tres paradigmas científicos esenciales de las investigaciones educativas y pedagógicas. Monografías 2010. Cuba: Universidad de Matanzas Camilo Cienfuegos.

Quinn, F. M. (1998). Reflection and reflective practice. En F.M. Quinn (ed). Continuing professional development in nursing (pp. 121-145). Cheltenham: Stanley Thornes. 
Quinn, F. M. (2000). The principles and practice of nurse education. London: Stanley Thornes.

$\mathrm{R}$

Real Decreto 1393/2007, de 29 de octubre, por el que se establece la ordenación de las enseñanzas universitarias oficiales (pp. 58454-58468). Madrid: Boletín Oficial del Estado.

Real Decreto 1440/1991, de 30 de agosto, por el que se establece el título universitario, oficial de Maestro, en sus diversas especialidades y las directrices generales propias de los planes de estudios conducentes a su obtención (pp. 3300333018). Madrid: Boletín Oficial del Estado.

Reguant, M. (2007). Contribución del "e-Diario compartido", como experiencia pedagógica, para el desarrollo de las competencias transversales de pensamiento crítico-reflexivo y aprendizaje autónomo en el Prácticum de la especialidad de maestros de Educación Física (Tesis doctoral), Universitat de Barcelona, Barcelona. Recuperado de http://hdl.handle.net/2445/11465

Reid, B. (1993). But we are doing it already. Nurse Education Today, 13, 305-309.

Ricoy, C. (2006). Contribución sobre los paradigmas de investigación. Revista Educaçao, 31(1). Recuperado de https://periodicos.ufsm.br/reveducacao/ article/view/1486

Riesco, M. (2008). El enfoque por competencias en el EEES y sus implicaciones en la enseñanza y el aprendizaje. Tendencias pedagógicas, 13, 79-106. Recuperado de http://www.industriales.upct.es/pdfs/competencias riesco.pdf

Rodrigues, R. (2013). El desarrollo de la práctica reflexiva sobre el quehacer docente, apoyada en el uso de un portafolio digital, en el marco de un programa de formación para académicos de la Universidad Centroamericana de Nicaragua. (Tesis Doctoral), Universidad Autónoma de Barcelona, Barcelona. Recuperado de http://www.tdx.cat/bitstream/handle/10803/108035/ RRODRIGUES TESIS.pdf?sequence=1 
Roma, J. (2007). La reflexión como eje central del desarrollo profesional. Educación médica, 10(1), 30-36. Recuperado de http://scielo.isciii.es/pdf/edu/v10n1/ formacion.pdf

Rose, E. (2016). Reflection in asynchronous online postsecondary courses: a reflective review of the literature. Reflective Practice, 17(6), 779-791. doi: $\underline{10.1080 / 14623943.2016 .1220936}$

Rosen, D. (2008). Impact of case-based instruction on student teachers' reflection on facilitating children's learning. Action in Teacher Education, 30(1), 28-36.

Ross, D. (1987, octubre). Reflective teaching: meaning and implications form preservice teacher educators. Comunicación presentada en Reflective Inquiry Conference, Houston.

Ross, D. (1990). Programmatic structures for the preparation of reflective teachers. En R. T. Clift, W. R. Houston y M. C. Pugach (Eds.), Encouraging reflective practice in education: An analysis of issues and programs (pp. 97-118). New York, NY: Teachers College Press.

Russell, B. y Purcell, J. (2009). Online Research Essentials. Designing and Implementing Research Studies. San Francisco: Jossey-Bass Publishing.

Russell, T. (2005). Can reflective practice be taught? Reflective Practice, 6(2), 199204. doi: $10.1080 / 14623940500105833$

Rutter, L. (2006). Supporting reflective, practice-based learning and assessment for postqualifying social work. Reflective Practice, 7(4), 469-82. doi: $\underline{10.1080 / 14623940600987072}$

Ryan, M. (ed.) (2015). Teaching Reflective Learning in Higher Education. A Systematic Approach Using Pedagogic Patterns. London: Springer.

Ryan, T. (2005). When you reflect are you also being reflexive. The Ontario Action Researcher, 8(1), 2. 
Saldaña, J. (2009). The coding manual for qualitative researchers. Los Angeles, CA: SAGE.

Salgado-Lévano, A. C. (2007). Investigación cualitativa: diseños, evaluación del rigor metodológico y retos. Liberabit, 13(13), 71-78. Recuperado de http://www. scielo.org.pe/scielo.php?pid=S1729-48272007000100009\&script $=$ sci arttext

Salinas, D. (2007, junio). EEES y Practicum: ¿Cómo encajar el practicum en el nuevo marco?. Comunicación presentada en IX Symposium Internacional sobre Practicum. Practicum y prácticas en empresas en la formación universitaria, Pontevedra.

Sánchez-Tarazaga, L., Mateu, R., Ruiz, M. P., García, R. (2015, junio). Avances y retos en la calidad del prácticum de maestros en la Unversitat Jaume l: una mirada reflexiva. Comunicación presentada en XIII Symposium Internacional sobre el Practicum y las Prácticas Externas, Pontevedra.

Sanjurjo, L. O. (2002). La formación práctica de los docentes. Reflexión y acción en el aula. Rosario: Homo Sapiens.

Schön, D. (1983). The reflective practitioner: how professionals think in action. London: Temple Smith.

Schön, D. (1987). La formación de profesionales reflexivos. Hacia un nuevo diseño de la enseñanza y el aprendizaje de las profesiones. Barcelona: Paidós.

Schön, D. A. (1995). Knowing-in-action: The new scholarship requires a new epistemology. Change: The Magazine of Higher Learning, 27(6), 27-34.

Shaw, R. (2013). A model of the transformative journey into reflexivity: an exploration into students' experiences of critical reflection, Reflective Practice: International and Multidisciplinary Perspectives, 14(3), 319-335. doi: $\underline{10.1080 / 14623943.2013 .767229}$ 
Shoffner, M. (2009). The place of the personal: Exploring the affective domain through reflection in teacher preparation. Teaching and Teacher Education, 25, 783-789.

Sikka, H., y Timoštšuk, I. (2008). The role of reflection in understanding teaching practice. Problems of Education in the 21st Century, 7, 147-152.

Smyth, J. (1988). Deliberating upon reflection in action as a critical form of profesional education. Studies in Continuing Education, 10(2), 164-171.

Sparks-Langer, G. M., Simmons, G. M., Pasch, J. M., Colton, A. y Starko, A. (1991). Reflective pedagogical thinking: how can we promote it and measure it? Journal of Teacher Education, 41, 23-32.

Stake, R. (2005). Investigación con estudio de casos. Madrid, Morata.

Stanley, C. (1998). A framework for teacher reflectivity. TESOL Quarterly, 32(3), 584591.

Stockero, S. L. (2008). Using a video-based curriculum to develop a reflective stance in prospective mathematics teachers. Journal of Mathematics Teacher Education, 11, 373-394. doi: 10.1007/s10857-008-9079-7

Strampel, K., y Oliver, R. (2007). Using technology to foster reflection in higher education. En R. J. Atkinson, C. McBeath, S. K. A. Soong, y C. Cheers (Eds.), ICT: Providing choices for learners and learning (pp. 972-982). Proceedings of the 24th Annual Conference of the Australasian Society for Computers in Learning in Tertiary Education, Singapore.

Sung, Y. T., Chang, K. E., Yu, W. C., y Chang, T. H. (2009). Supporting teachers' reflection and learning through structured digital teaching portfolios. Journal of Computer Assisted Learning, 25, 375-385.

Surbeck, E.; Park Han, E. y Moyer, J .E. (1991). Assessing reflective responses in journals. Educational Leadership, 48(6), 25-27. Recuperado de http://www.ascd.com/ ASCD/pdf/journals/ed_lead/el_199103 surbeck.pdf 
Sutherland, L., Howard, S., y Markauskaite, L. (2010). Professional identity creation: Examining the development of beginning preservice teachers' understanding of their work as teachers. Teaching and Teacher Education, 26, 455-465. doi: 10.1016/i.tate.2009.06.006

T

Tate, S., y Mills, M. (2004). The development of critical reflection in the health professions. London: Higher Education Authority.

Thompson, N. y Pascal, J. (2012). Developing critically reflective practice. Reflective Practice: International and Multidisciplinary Perspectives, 13(2), 311-325. doi: $\underline{10.1080 / 14623943.2012 .657795}$

Thompson, S., y Thompson, N. (2008). The critically reflective practitioner. Basingstoke: Palgrave Macmillan.

Thorpe, K. (2004). Reflective learning journals: From concept to practice. Reflective Practice: International and Multidisciplinary Perspectives, 5(3), 327-343.

Thorsen, C. A. y DeVore, S. (2013). Analyzing reflection on/for action: A new approach. Reflective Practice: International and Multidisciplinary Perspectives, 14(1), 88-103. doi: $10.1080 / 14623943.2012 .732948$

Tigchelaar, A. y Korthagen, F. (2004). Deepening the exchange of student teaching experiences: implications for the pedagogy of teacher education of recent insights into teacher behaviour. Teaching and Teacher Education, 20, 665679.

Tripp, D. (1993). Critical incidents in teaching: Developing professional judgement. London: Routledge Falmer.

Tripp, D. (1994). Teachers' lives, critical incidents, and professional practice. Qualitative Studies in education, 7(1), 65-76. doi: 10.1080/0951839940070105

U

Usher, R. y Edwards, R. (2007). Lifelong Learning. Signs, discourses and practices. Dordrecht: Springer. 
Valli, L. (1992). Reflective teacher education." Cases and critiques. Albany: State University of New York Press.

Valli, L. (1997). Listening to other voices: A description of teacher reflection in the United States. Peabody Journal of Education, 72(1), 67-88.

Van Manen, M. (1977). Linking ways of knowing with ways of being practical. Curriculum Inquiry, 6(3), 205-228.

Van Manen, M. (1991). The tact of teaching. London, ON: The Althouse Press.

Villalobos, J. y Cabrera, C. M. (2009). Los docentes y su necesidad de ejercer una práctica reflexiva. Revista de Teoría y Didáctica de las Ciencias Sociales, 14, 139-166. Recuperado de http://www.saber.ula.ve/ handle/123456789/29671

W

Walkington, J. (2005). Becoming a teacher: Encouraging development of teacher identity through reflective practice. Asia Pacific Journal of Teacher Education, 33, 53-64. doi: 10.1080/1359866052000341124

Wallace, M. (2002). Training foreign language teachers: A reflective approach. Cambridge: Cambridge University Press.

Ward, J. R., y McCotter, S. S. (2004). Reflection as a visible outcome for pre-service teachers. Teacher and Teacher Education, 20, 243-257.

Wareing, M. (2017). Me, my, more, must: a values-based model of reflection. Reflective Practice, 18, 1-12. doi: 10.1080/14623943.2016.1269002

Weber, S. (2013). Can preservice teachers be taught to become reflective thinkers during their first internship experience? (Tesis doctoral), Liberty University, Lynchburg, VA. Recuperado de http://digitalcommons.liberty.edu/cgi/ viewcontent.cgi?article $=1740 \&$ context $=$ doctoral 
Winchester, T. M., y Winchester, M. (2011). Exploring the impact of faculty reflection on weekly student evaluations of teaching. International Journal for Academic Development, 16(2), 119-131. doi: 10.1080/1360144X.2011.568679

Wolf, K. (2008, octubre). A blogging good time-the use of blogs as a reflective learning and feedback tool for final year public relations students. Conferencia en WACE Asia Pacific Conference, Sydney. Recuperado de https://www.researchgate. net/profile/Eddo Coiacetto/publication/29469473 Academic standards for_work_integrated_learning_a_case_study_from_urban_and_regional_ planning/links/00b49519441b741a85000000.pdf\#page=649

Wolf, Z. R., y Zuzelo, P. R. (2006). "Never again" stories of nurses: dilemmas in nursing practice. Qualitative Health Research, 16(9), 1191-1206.

Y

Yaffe, E. (2010). The reflective beginner: Using theory and practice to facilitate reflection among newly qualified teachers. Reflective Practice, 11(3), 381-391. doi: $\underline{10.1080 / 14623943.2010 .490070}$

Yin, R. K. (2003). Case study research: Design and methods. Thousand Oaks, CA: Sage.

Yip, K. S. (2006). Self-reflection in reflective practice: A note of caution. British Journal of Social Work, 36, 777-788.

York-Barr, J., Sommers, W. A., Ghere, G. S., y Montie, J. (2001). Reflective practice to improve schools. Thousand Oaks, CA: Corwin Press.

Yost, D. S. (1997). The moral dimensions of teaching and preservice teachers: Can moral dispositions be influenced? Journal of Teacher Education, 48, 281-292.

Yost, D. S., Forlenza-Bailey, A., y Shaw, S. F. (1999). The teachers who embrace diversity: The role of reflection, discourse, and field experience in education. The Professional Educator, 21(2), 1-14 
Zabalza, M. (1991). Los diarios de clase. Barcelona: PPU.

Zabalza, M. A. (2004). Diarios de clase. Un instrumento de investigación y desarrollo profesional. Madrid. Narcea.

Zabalza, M. A. (2009). Prácticum y formación: ¿En qué puede formar el prácticum? En M. Raposo et alt. (Coords.), El prácticum más allá del empleo. Formación vs. Training (pp. 45-65), Pontevedra: Imprenta Universitaria.

Zeichner, K. (1990). Changing directions in the practicum: Looking ahead to the 1990's. Journal of Education for Teaching, 16(2), 105-131. doi: $10.1080 / 0260747900160201$

Zeichner, K. (1993). El maestro como profesional reflexivo. Cuadernos de Pedagogía, 220, 44-49.

Zeichner, K. (2010). Nueva epistemología en la formación del profesorado en la universidad. Revista Interuniversitaria de Formación del Profesorado, 68 (24.2), 123-149. Recuperado de https://dialnet.unirioja.es/descarga/ articulo/3276054.pdf

Zeichner, K. y Liston, D. (1999). Enseñar a reflexionar a los futuros docentes. En: F. Angulo, J. Barquín y A. I. Pérez (Coords.) Desarrollo profesional del docente: política, investigación y práctica (pp. 506-532). Madrid: AKAL.

Zeichner, K., y Liston, D. P. (1996). Reflective teaching: An introduction. Mahwah, New Jersey: Lawrence Erlbaum Associates. 



\section{Anexo 1}

\section{Survey of Reflective Practice: A Tool for Assessing Development as a Reflective Practitioner}

\section{Self Assessment}

\begin{tabular}{|c|c|c|c|}
\hline \multirow{2}{*}{$\begin{array}{l}\text { Practice Indicators } \\
\text { For each indicator, select the rating you think best represents your current practice. } \\
\text { I am a teacher/teacher candidate who: } \\
\text { LEVEL 1 : PRE-REFLECTION }\end{array}$} & \multicolumn{3}{|c|}{ Assessment Criteria } \\
\hline & Frequently & Sometimes & Infrequently \\
\hline \multicolumn{4}{|l|}{ Operates in survival mode, reacting automatically without consideration of alternative responses } \\
\hline \multicolumn{4}{|l|}{ Enforces preset standards of operation without adapting or restructuring based on students' responses } \\
\hline \multicolumn{4}{|l|}{ Does not support beliefs and assertions with evidence from experience, theory or research } \\
\hline \multicolumn{4}{|l|}{ Is willing to take things for granted without questioning } \\
\hline \multicolumn{4}{|l|}{ Is preoccupied with management, control and student compliance } \\
\hline \multicolumn{4}{|l|}{ Fails to recognize the interdependence between teacher and student actions } \\
\hline \multicolumn{4}{|l|}{ Views student and classroom circumstances as beyond the teacherís control } \\
\hline \multicolumn{4}{|l|}{ Attributes ownership of problems to students or others } \\
\hline \multicolumn{4}{|l|}{ Fails to consider differing needs of learners } \\
\hline \multicolumn{4}{|l|}{ Sees oneself as a victim of circumstances } \\
\hline \multicolumn{4}{|l|}{ Dismisses students' perspectives without due consideration } \\
\hline \multicolumn{4}{|l|}{ Does not thoughtfully connect teaching actions with student learning or behavior } \\
\hline \multicolumn{4}{|l|}{ Describes problems simplistically or unidimensionally } \\
\hline Does not see beyond immediate demands of a teaching episode & & & \\
\hline
\end{tabular}

\begin{tabular}{|c|c|c|c|}
\hline LEVEL 2 : SURFACE REFLECTION & Frequently & Sometimes & Infrequently \\
\hline \multicolumn{4}{|c|}{ Limits analysis of teaching practices to technical questions about teaching techniques } \\
\hline \multicolumn{4}{|c|}{ Modifies teaching strategies without challenging underlying assumptions about teaching and learning } \\
\hline \multicolumn{4}{|c|}{ Fails to connect specific methods to underlying theory } \\
\hline \multicolumn{4}{|l|}{ Supports beliefs only with evidence from experience } \\
\hline \multicolumn{4}{|l|}{ Provides limited accommodations for students' different learning styles } \\
\hline \multicolumn{4}{|l|}{ Reacts to student responses differentially but fails to recognize patterns } \\
\hline \multicolumn{4}{|l|}{ Implements solutions to problems that focus only on short-term results } \\
\hline \multicolumn{4}{|l|}{ Makes adjustments based on past experience } \\
\hline \multicolumn{4}{|l|}{ Questions the utility of specific teaching practices but not general policies or practices } \\
\hline Provides some differentiated instruction to address students' individual differences & & & \\
\hline
\end{tabular}




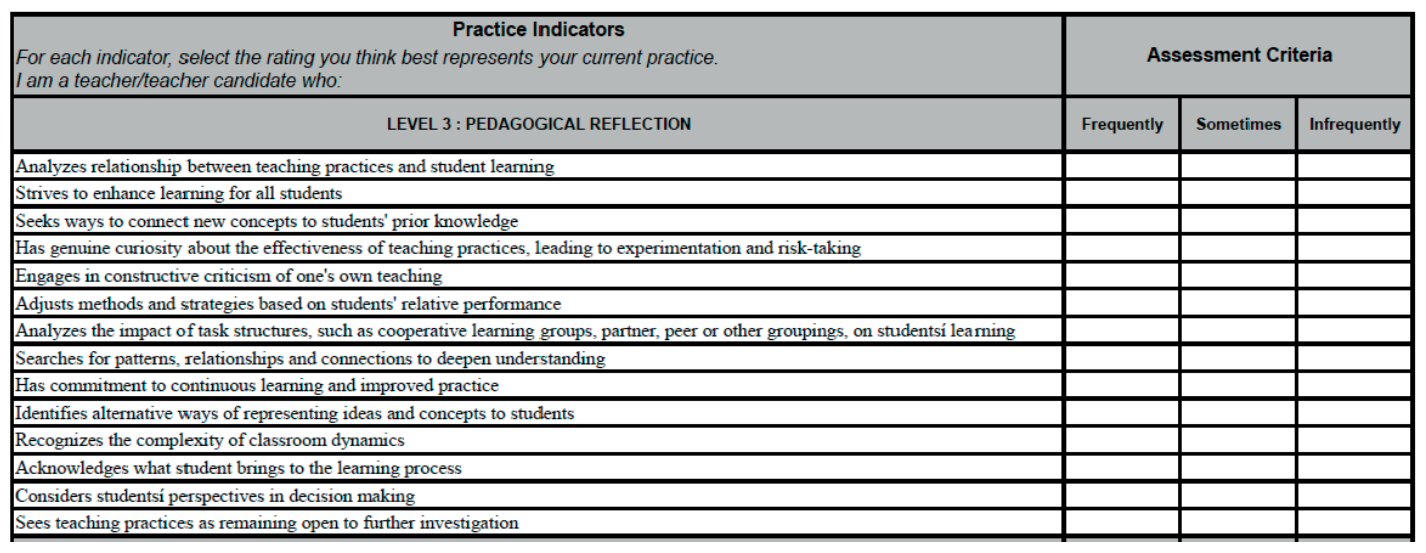

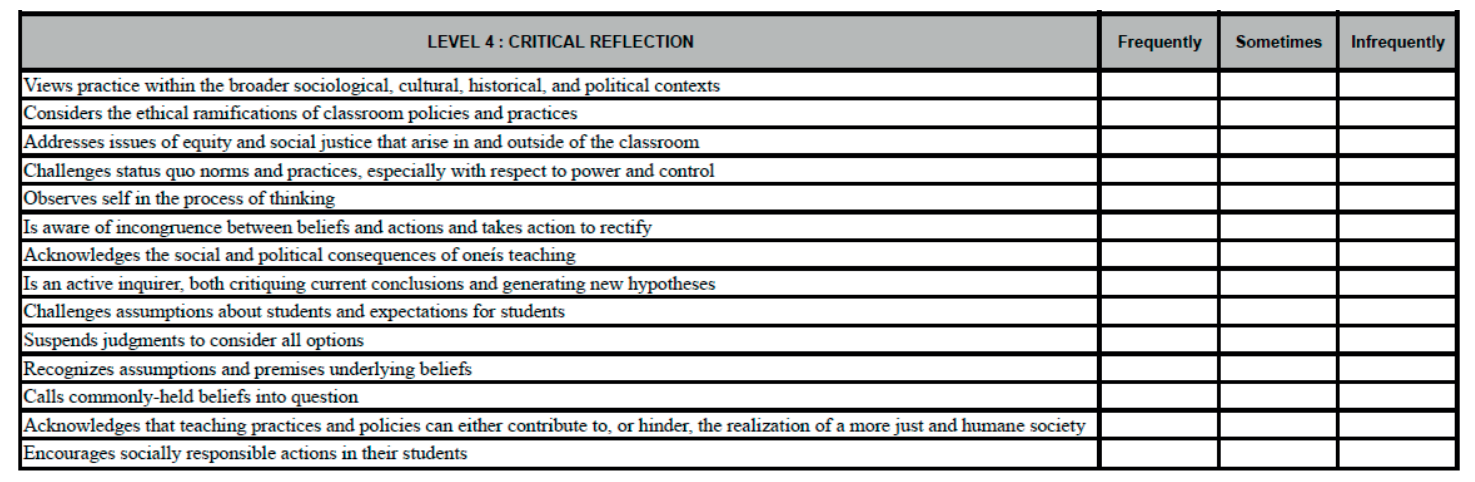


Anexo 2

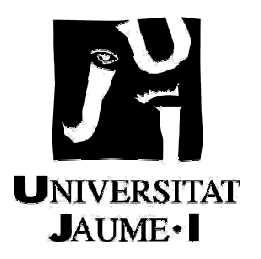

Document de

\section{PRÀCTIQUES EXTERNES}

de les Titulacions de

\section{MESTRE o MESTRA D'EDUCACIÓ}

\section{INFANTIL I PRIMÀRIA}

[MI1025, MI1039, MP1026, MP1039]

FACULTAT DE CIÈNCIES HUMANES I SOCIALS

practicum_mestre@uji.es

Curs acadèmic

2016/2017 


\section{ÍNDEX}

1. INTRODUCCIÓ: PRACTICUM DE LA TITULACIÓ DE MESTRE. FACULTAT DE CIÈNCIES HUMANES I SOCIALS. CURS ACADÈMIC 2016-2017 ….....................................4

2. COMPETÈNCIES GENÈRIQUES I ESPECÍFIQUES .........................................................

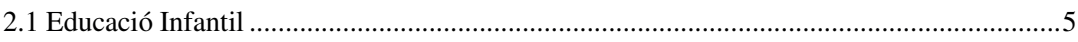

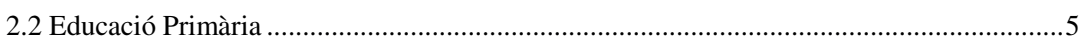

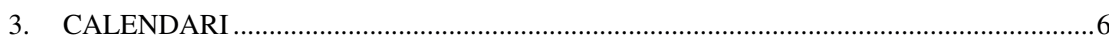

3.1. Període de realització de les pràctiques als centres ...........................................................6

3.2. Entrega de la memòria..........................................................................................

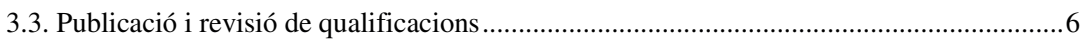

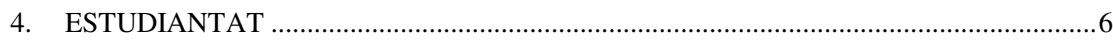

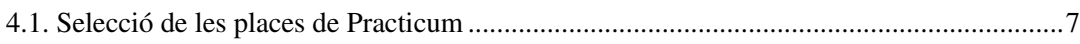

4.2. Incidències: Places nominatives ...............................................................................

4.2.1. Modificació de l'horari places nominatives ........................................................... 8

4.2.2. Documentació per sol-licitar una plaça nominativa ................................................. 8

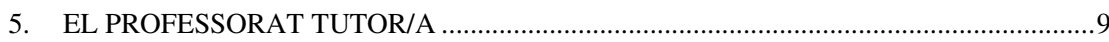

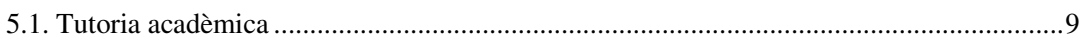

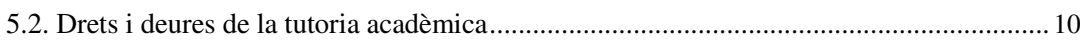

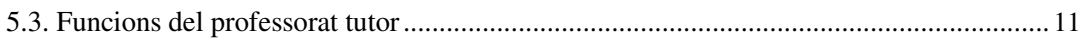

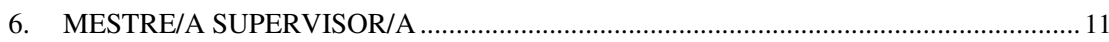

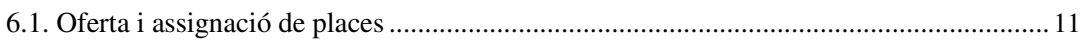

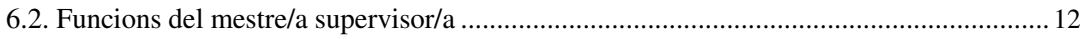

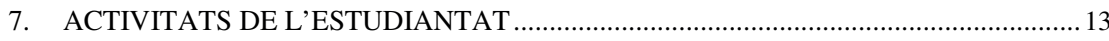

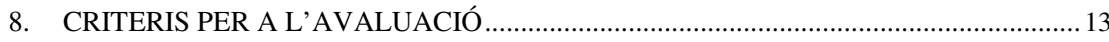

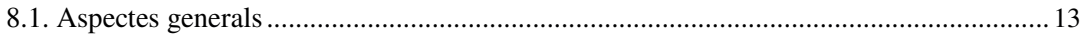

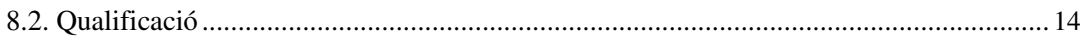

9. DIRECTRIUS PER A UN ADEQUAT FUNCIONAMENT DINS DEL CENTRE DE

PRÀCTIQUES 14 


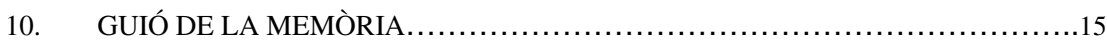

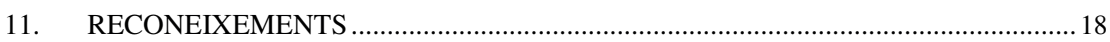

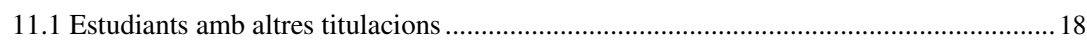

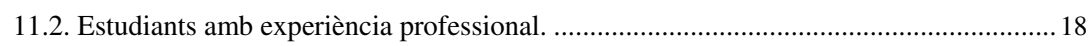

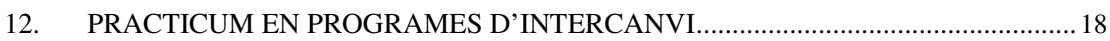

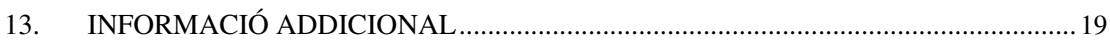

13.1. Protocols d'actuació davant incidències i dubtes durant el període de practicum. ......... 19

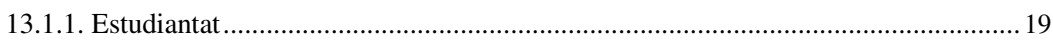

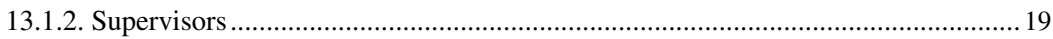

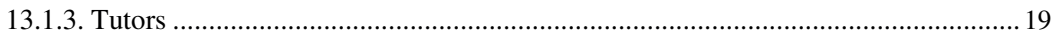

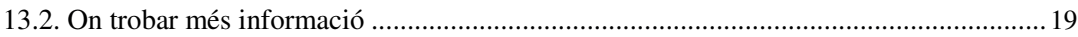

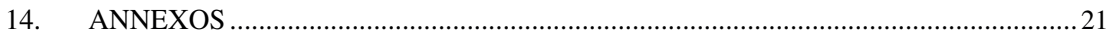

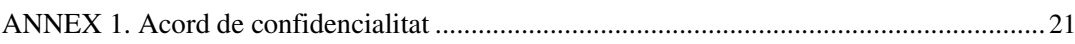

ANNEX 2. Full per a sol-licitar plaça nominativa (a reomplir per l'estudiantat)............22

ANNEX 3. Proposta de calendari per a desenvolupar les pràctiques (plaça nominativa).......24

ANNEX 4. Document places nominatives - Projecte d'investigació o innovació acadèmica-.

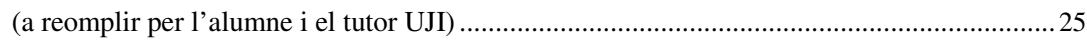

ANNEX 5. Full d'avaluació del Practicum.......................................................................... 26

ANNEX 6. Orientacions per al tutor/a a l'hora de fer les visites als centres educatius ..........27

ANNEX 7. Tutorial per a realitzar el Projecte Formatiu (PF) .......................................... 28

ANNEX 8. Addenda al projecte formatiu de les pràctiques externes curriculars..................31

ANNEX 9. Full d'avaluació de la memòria de pràctiques .................................................. 32 


\section{INTRODUCCIÓ: PRACTICUM DE LA TITULACIÓ DE MESTRE. FACULTAT DE CIÈNCIES HUMANES I SOCIALS. CURS ACADÈMIC 2016-2017}

Elaborada per la Subcomissió de Pràctiques de la Comissió Mixta, formada per la inspectora M. José Arnau, en representació de la Direcció Territorial d'Educació de Castelló, per directors de centres d'Educació Infantil i Primària i per la Coordinació d'estades en pràctiques de les titulacions de Mestre/a d'Educació Infantil i Mestre/a d'Educació Primària (MI1025, MI1039, MP1026, MP1039), en representació de la Universitat Jaume I.

\section{ANTECEDENTS}

L'ORDRE ECI/3854/2007, de 27 de desembre, per la qual s'estableixen els requisits per a la verificació del títols universitaris oficials que habiliten per a l'exercici de la professió de Mestre en Educació Infantil, en el seu apartat 5è, diu: El Practicum es desenvoluparà en centres d'educació infantil reconeguts com a centres de formació en pràctiques mitjançant convenis entre les Administracions Educatives i les Universitats. Tindrà caràcter presencial $i$ estarà tutelat per professors universitaris $i$ mestres d'educació infantil acreditats com a tutors de pràctiques. El Practicum es realitzarà en els un o en els dos cicles dels ensenyaments d'educació infantil.

L'ORDRE ECI/3857/2007, de 27 de desembre, per la qual s'estableixen els requisits per a la verificació del títols universitaris oficials que habiliten per a l'exercici de la professió de Mestre en Educació Primària, en el seu apartat 5è diu: El Practicum es desenvoluparà en centres d'educació primària reconeguts com a centres de formació en pràctiques mitjançant convenis entre les Administracions Educatives i les Universitats. Tindrà caràcter presencial $i$ estarà tutelat per professors universitaris $i$ mestres d'educació primària acreditats com a tutors de pràctiques. El Practicum es realitzarà en els tres cicles dels ensenyaments d'educació primària.

Per tant, les pràctiques de Mestre/a d'Educació Infantil i Primària són professionalitzadores. La normativa de Pràctiques Externes de la UJI reconeix que les titulacions amb professions regulades tenen directrius pròpies pel que fa al desenvolupament de les mateixes.

Aquest document està emmarcat dins de les directrius establertes per la Normativa de pràctiques acadèmiques externes de la Universitat Jaume I.

El vigent Conveni de Cooperació educativa entre la Universitat Jaume I i la Generalitat Valenciana, en matèria d'estades en pràctiques, estableix en la seua clàusula cinquena:

"La Conselleria d'Educació i Ciència es compromet a acceptar estudiants de la titulació de mestre per a la realització de pràctiques en règim d'estades en pràctiques”.

La Direcció Territorial d'Educació de Castelló és la que du a terme, a efectes d'àmbit d'aplicació administrativa i jurídica, l'esmentat conveni. Per tant, les pràctiques 
externes dels Graus en Mestre/a d'Educació Infantil i Mestre/a d'Educació Primària, $\underline{\text { sols es podran realitzar en la província de Castelló. }}$

\section{COMPETÈNCIES GENÈRIQUES I ESPECÍFIQUES}

Les competències genèriques i específiques que haurà d'assolir l'estudiantat durant el seu període de pràctiques són les citades a continuació.

\subsection{Educació Infantil}

P01 - Adquirir un coneixement pràctic de l'aula i de la gestió de la mateixa.

P02 - Conèixer i aplicar els processos d'interacció i comunicació en l'aula, així com dominar les destreses i habilitats socials necessàries per a fomentar un clima que facilite l'aprenentatge i la convivència.

P03 - Controlar i fer el seguiment del procés educatiu i, en particular, d'ensenyament i aprenentatge mitjançant el domini de tècniques i estratègies necessàries.

P04 - Relacionar teoria i pràctica amb la realitat de l'aula i del centre.

P05 - Participar en l'activitat docent i aprendre a saber fer, actuant i reflexionant des de la pràctica.

P06 - Participar en les propostes de millora en els diferents àmbits d'actuació que es puguen establir en un centre.

P07 - Regular els processos d'interacció i comunicació en grups d'estudiants de 0-3 anys i de 3-6 anys.

P08 - Conèixer formes de col-laboració amb els diferents sectors de la comunitat educativa i de l'entorn social.

\subsection{Educació Primària}

DDUJI59 - Adquirir un coneixement pràctic de l'aula i de la seua gestió.

P01 - Conèixer formes de col-laboració amb els distints sectors de la comunitat educativa i de l'entorn social.

P02 - Conèixer i aplicar els processos d'interacció i comunicació en l'aula, així com dominar les destreses i habilitats socials necessàries per a fomentar un clima que facilite l'aprenentatge i la convivència.

P03 - Controlar i fer el seguiment del procés educatiu i, en particular, d'ensenyament i aprenentatge per mitjà del domini de tècniques i estratègies necessàries.

P04 - Participar en l'activitat docent i aprendre a saber fer, actuant i reflexionant des de la pràctica.

P05 - Participar en l'activitat docent i aprendre a saber fer, actuant i reflexionant des de la pràctica en anglès. 
P06 - Participar en les propostes de millora en els distints àmbits d'actuació que es puguen establir en un centre.

P07 - Regular els processos d'interacció i comunicació en grups d'estudiants de 6-12 anys.

P08 - Relacionar teoria i pràctica amb la realitat de l'aula i del centre.

\section{CALENDARI}

\subsection{Període de realització de les pràctiques als centres}

PRACTICUM I: De l'1 de març fins al 24 de maig de 2017 en l'horari lectiu del docent.

PRACTICUM II: Del 23 de gener fins al 24 de maig de 2017 en l'horari lectiu del docent.

L'horari pot dependre de la ubicació i tipologia del centre. En cap cas les pràctiques podran començar abans de l'1 de desembre ni realitzar-se més enllà del 31 de maig de 2017.

La Comissió Mixta aprova el calendari, establint que les pràctiques dels Graus de Mestre/a d'Educació Infantil i Primària de la UJI, han de realitzar-se en el segon semestre. A més a més, en el primer semestre s'ha de remetre el llistat de centres i places assignades.

\subsection{Entrega de la memòria}

La memòria s'ha d'entregar al professorat tutor de la Universitat degudament redactada abans del 2 de juny de 2017.

\subsection{Publicació i revisió de qualificacions}

El tutor de la Universitat publicarà les qualificacions, així com les dates de revisió abans del dia 16 de juny, d'acord amb el procediment establert per la Normativa d'Exàmens. Una volta realitzada la revisió, el tutor enviarà les qualificacions a la Comissió de Coordinació de Practicum abans del 23 de juny de 2017.

\section{ESTUDIANTAT}

Per tal de poder matricular-se de l'assignatura de Practicum I l'estudiant haurà d'haver superat el $60 \%$ dels crèdits d'assignatures de formació bàsica i obligatòries (107 crèdits). En el cas del Practicum II, a més, l'estudiant haurà d'haver aprovat el

Practicum I.

Els requisits per a cursar el Practicum els podeu consultar al següent enllaç:

http://ujiapps.uji.es/serveis/oipep/base/programes/pe/normativa-asseguraces/ 
En el cas de l'alumnat amb necessitats específiques de suport educatiu, es seguirà el protocol de la USE per a l'atenció a la diversitat (PAD).

\subsection{Selecció de les places de Practicum}

Durant el mes de novembre de 2016, l'estudiantat disposarà de dos dies per triar un col·legi del llistat ofertat pels centres mitjançant l'IGLU, seguint el criteri de rendiment acadèmic.

La distribució i assignació de les places s'atendrà a criteris objectius i principis d'inclusió, transparència, publicitat, accessibilitat universal i igualtat d'oportunitats, a més de considerar els condicionants derivats de situacions de discapacitat, si escau.

S'ha de tindre en compte que hi ha centres que ofereixen la seua docència en altres llengües, pel qual seran els propis centres els que determinen els requisits lingüístics.

Finalment, durant la segona quinzena de novembre la Comissió resoldrà les assignacions d'estudiants $\mathrm{i}$ de centres. Una volta assignada la plaça definitiva, no es permetran canvis per a la millora del centre.

\subsection{Incidències: Places nominatives}

L'alumnat podrà sol-licitar una plaça nominativa si presenta qualsevol incompatibilitat sobre el calendari de pràctiques, motivada per alguna de les següents causes:

a) Laborals. El treball ha d'estar reglat per un contracte legalitzat. A aquesta modalitat també poden optar aquelles persones que realitzen un voluntariat oficial.

b) Acadèmiques. Es consideren causes acadèmiques la realització d'altres estudis universitaris; avançar el Practicum per tancar l'expedient acadèmic (tenint en compte la normativa de la UJI, en relació al màxim de crèdits a realitzar per curs); participació en projectes d'investigació i/o d'innovació educativa; i demora de la data d'inici del Practicum per la realització d'una estada dins del programa Erasmus durant el primer semestre.

c) Familiars. Qualsevol causa de conciliació familiar degudament justificada.

La sol-licitud d'una plaça nominativa s'ha de realitzar mitjançant la presentació d'una instància (Annex 2) abans del 30 de setembre de 2016 pel Registre General de l'UJI dirigida a la Comissió de Coordinació de Pràctiques de Mestre/a d'Educació Primària $i$ Mestre/a d'Educació Infantil. L'alumnat haurà de presentar un escrit exposant la causa de la sol-licitud on cal especificar la preferència de zona o localitat per a realitzar les pràctiques i la proposta de calendari. Les mateixes dades s'han d'introduir al següent enllaç:

https://docs.google.com/a/uji.es/forms/d/1rCeuvUX75CJ3FB3qoYlGTmQEM5yif66O1 y5jQz_giYw/viewform?c=0yw=1

En cap cas l'estudiant anirà a parlar directament amb un centre concret. Serà la

Comissió de Coordinació de Practicum qui decidirà en última instància el centre de pràctiques i qui contactarà amb els centres seleccionats basant-se en la proposta de l'alumne/a. 


\subsubsection{Modificació de l'horari places nominatives}

L'horari que realitza l'alumne al centre s'ha d'ajustar a l'horari lectiu del docent, es a dir, 6 hores diàries en jornada partida o continua, depenent del centre. És important realitzar les pràctiques en tots els moments d'aquesta franja horària per donar continuïtat a les programacions de les diferents assignatures. Les opcions per a realitzar un Practicum amb plaça nominativa adaptat a casuístiques de compatibilitat horària deuen ajustar-se a una de les següents propostes:

a) L'estudiant no pot assistir a una de les hores del extrems de la franja horària (primera o última del matí o primera o última de la vesprada). En aquest cas:

a. Haurà de recuperar les hores allargant $\mathrm{o}$ avançant l'estada de pràctiques, $\mathrm{i}$

b. Realitzarà les tres últimes setmanes de forma ininterrompuda en horari complet.

b) L'estudiant no pot assistir en horari de vesprada. En aquest cas: farà les pràctiques a un centre amb jornada continua.

c) Altres. Es pot realitzar altra proposta personalitzada, però la Comissió de Coordinació valorarà la seua viabilitat.

La Comissió de Coordinació de Practicum, una vegada valorada i acceptada la proposta de modificació horària presentada per l'estudiant, li assignarà un centre en la zona que haja sol-licitat.

\subsubsection{Documentació per sol-licitar una plaça nominativa}

La documentació que cal adjuntar amb la instància és:

a) Còpia del full de matrícula del curs 2016-2017, on conste l'assignatura de Practicum (MI1025, MI1039, MP1026, MP1039).

b) Proposta de calendari per a desenvolupar les pràctiques (Annex 3). Aquesta proposta haurà de garantir el compliment d'un mínim de tres setmanes d'intervenció consecutiva en horari complet en la part final del Practicum.

Per tal de visualitzar d'una manera més clara els horaris, l'alumnat omplirà el calendari que es facilita marcant els dies d'assistència al centre, l'horari que farà i les hores a realitzar cada dia. A més a més, aportarà el còmput d'hores de cadascuna de les setmanes. L'alumnat del Practicum I haurà de realitzar 300 hores de permanència en el centre en horari lectiu (respectant l'horari de cada centre, que normalment és de 9 a $13.30 \mathrm{~h}$ i de 15.30 a $17.00 \mathrm{~h}$ ). L'alumnat de Practicum II haurà de realitzar 450 hores, també en horari lectiu.

Laborals:

c) Contracte laboral o justificant oficial corresponent (també s'ha d'entregar el contracte en el cas de voluntariat).

d) Horari laboral. En el cas que al contracte laboral no aparega l'horari, serà necessari aportar un document signat per l'empresa amb els horaris de treball. 
e) En el cas de voluntariat (validat per l'Oficina de Cooperació al Desenvolupament i Solidaritat), s'ha de presentar un document amb les funcions que està realitzant el voluntari.

Acadèmiques:

f) Horari d'estudis. En cas d'assistir a altres estudis superiors s'ha d'aportar un document oficial en el que aparega l'horari.

g) Projectes d'investigació o innovació educativa amb professorat que impartisca docència als Graus en Mestre/a d'Educació Infantil i Mestre/a d'Educació

Primària i que es responsabilitze de la tutorització de les pràctiques (Annex 4).

h) Certificat de qualificacions (sols si es demana convocatòria extraordinària de fi de carrera).

i) Certificat d'estada Erasmus (en cas de tornar més tard de la data d'inici de les pràctiques).

Familiars:

j) S'ha de presentar la documentació pertinent segons el cas concret (llibre de família, certificat mèdic, etc.).

La Comissió de Coordinació de Pràcticum estudiarà cada cas i farà pública la resolució a finals d'octubre. Les resolucions es faran publiques a través de l'aula virtual.

En cap cas les pràctiques podran començar abans de gener (a excepció de tancament d'expedient i de casos que per motius de falta d'hores disponibles podran començar a partir de l'1 de desembre ) ni realitzar-se més enllà del 31 de maig de 2017.

\section{EL PROFESSORAT TUTOR/A}

\subsection{Tutoria acadèmica}

Segons la normativa de pràctiques acadèmiques externes de la Universitat Jaume I, és prescriptiu que els tutors d'aquestes assignatures compleixin una sèrie de requisits:

Article 13. Tutoria acadèmica

2. La designació del tutor acadèmic o tutora acadèmica de les pràctiques externes curriculars de grau es realitzarà a proposta del departament amb l'informe previ del coordinador o coordinadora de pràctiques externes, després de la consulta a la Vicedirecció o Vicedeganat del grau corresponent tenint en compte el seu grau de compliment en els cursos anteriors. S'assignaran crèdits de Pla d'Ordenació Docent (POD) als tutors i tutores prèviament a l'inici del curs.

El període de tutorització dels alumnes de pràctiques serà durant tot el curs acadèmic. Es a dir, els tutors podran tindre assignats alumnes de pràctiques de places nominatives en període extraordinari. 


\subsection{Drets i deures de la tutoria acadèmica}

\section{Article 14.}

1. Els drets dels tutors acadèmics i tutores acadèmiques són els següents:

a) Reconeixement de la seua activitat en els termes que estableix la Universitat.

b) Ser informats sobre la normativa que regula les pràctiques externes, així com del projecte formatiu i de les condicions en què es s'ha de desenvolupar l'estada de l'estudiantat que ha de tutelar.

c) Tenir accés a l'entitat cooperadora per al compliment dels fins propis de la seua funció.

d) Ser compensats segons la normativa d'indemnitzacions de comissió de serveis de les despeses ocasionades en els seus desplaçaments ${ }^{1}$.

e) Rebre la informació i formació necessàries per a tutoritzar estudiantat amb discapacitats.

2. Els deures dels tutors acadèmics i tutores acadèmiques són els següents:

a) Seguir les indicacions del coordinador o coordinadora de pràctiques externes i les establertes en la guia docent.

b) Formar-se en la seua labor a través de la formació permanent del professorat.

c) Vetllar pel normal compliment del desenvolupament del programa de pràctiques externes, i garantir la compatibilitat de l'horari de realització de les pràctiques amb les obligacions acadèmiques, formatives i de representació i participació de l'estudiantat.

d) Coordinar-se amb el supervisor o supervisora de l'entitat cooperadora tenint en compte, si escau, els informes de seguiment.

e) Informar al supervisor del document de pràctiques.

f) Elaborar el projecte formatiu amb el supervisor o supervisora i l'estudiantat, autoritzar-ne les modificacions, custodiar-lo i publicitar-lo segons el procediment establert (Annex 7).

g) Dur a terme el procés avaluador de les pràctiques externes de l'estudiantat d'acord amb el que estableix aquesta normativa i les guies docents corresponents, si escau.

h) Guardar confidencialitat pel que fa a qualsevol informació que conega com a conseqüència de la seua activitat de tutoria.

i) Informar a la coordinació de les possibles incidències sorgides.

j) Respectar la propietat intel·lectual en els termes establerts per la legislació reguladora de la matèria.

\footnotetext{
${ }^{1}$ Aquest document el trobareu en Dietes Practicum a: http://www.uji.es/CA/departaments/edu/docs/
} 
k) Disposició addicional de la normativa de pràctiques: en les assignatures de Pràctiques Externes dels Graus en Mestre/a d'Educació Infantil i Mestre/a d'Educació Primària (MI1025, MI1039, MP1026 i MP1039) als tutors i tutores se'ls podrà assignar estudiantat d'ambdues titulacions (independentment del que figure al seu POD).

\subsection{Funcions del professorat tutor}

Fer-se càrrec del grup d'estudiants que se li assigne, explicar-los el pla de pràctiques i establir les estratègies pròpies per a executar-lo. Per a desenvolupar aquesta tasca el tutor/a mantindrà amb l'estudiantat tutoritzat almenys tres reunions: una abans de començar les pràctiques, un altra durant el seu període de realització i una darrera a l'acabament d'aquestes.

Mantenir un contacte estret amb els mestres supervisors a fi d'intercanviar opinions que permeten una millor supervisió-tutorització de l'estudiantat. Per a això el tutor/a haurà de realitzar almenys tres contactes amb el centre, el primer i l'últim han de ser presencials, un al llarg de la primera setmana de permanència de l'estudiantat a l'escola, el segon durant el període de realització i l'altre durant la darrera setmana (Annex 6).

Complimentar i signar el document acreditatiu del Projecte Formatiu a cada estudiant. Les instruccions per tal d'omplir aquest document es troben a l'Annex 7 d'aquest document. El Projecte Formatiu ha d'estar signat per totes les parts interessades (tutor/a UJI, supervisor/a i estudiantat), s'ha de pujar a l'IGLU i la còpia en paper s'ha d'enviar per correu intern a l'OIPEP, durant la primera setmana de pràctiques.

Valorar l'informe final del supervisor/a i avaluar els documents (memòria) presentats per l'estudiantat. Realitzar la revisió de la nota amb els estudiants. Per últim, omplir el formulari facilitat per la Comissió de coordinació de pràctiques, amb la qualificació definitiva de l'estudiantat.

\section{MESTRE/A SUPERVISOR/A}

\subsection{Oferta i assignació de places}

L'equip directiu ha de vetllar perquè les places ofertades complisquen en els següents requisits:

- Els mestres que s'oferisquen per supervisar l'alumnat en pràctiques hauran de complir un $80 \%$ de docència en un mateix grup. Per tant, no podran ser supervisors de pràctiques aquells mestres de suport i els especialistes. Excepte en el cas dels supervisors per als estudiants de la Menció d'Educació Física i de Música.

*Per tal de disminuir les possibles incidències, preguem assegurar-se de que les places introduïdes són les correctes. 
L'equip directiu del centre serà el responsable d'assignar un supervisor a cada estudiant de pràctiques. Es prioritzaran els següents criteris per a la selecció dels mestres supervisors:

- Haver-se format com a supervisor de pràctiques externes als cursos proposats pel CEFIRE.

- Realitzar qualsevol activitat d'innovació a l'aula (per exemple, us de TICs o altres elements dinamitzadors de l'aprenentatge).

- Que l'any anterior no hagen tingut cap alumne de pràctiques.

- Quan es troben en igualtat de condicions, l'assignació es realitzarà per sorteig.

En cas que es produïsca la baixa d'un mestre-supervisor, l'equip directiu s'encarregarà d'assignar a l'alumne un altre mestre del centre com a supervisor. La baixa s'ha de comunicar al tutor-UJI, qui completarà, juntament amb les parts afectades, l'Annex 8 d'aquest document. En aquest cas, és necessari signar novament el Projecte Formatiu amb les dades del nou supervisor.

\subsection{Funcions del mestre/a supervisor/a}

a) Mantenir amb el tutor o tutora els contactes necessaris per a planificar, supervisar i avaluar les pràctiques de l'estudiantat.

b) Orientar l'estudiantat en la pràctica diària.

c) Orientar l'estudiantat en pràctiques tutoritzades sobre les característiques del grup o unitat escolar en els quals les realitzarà.

d) Analitzar el treball amb aquest i guiar-lo en la preparació i desenvolupament de programacions, activitats, materials didàctics, etc.

e) Supervisar el conjunt de l'activitat de l'estudiantat, valorar-lo per emetre un informe global sobre aquesta i avaluar-lo amb el tutor o tutora (Annex 5).

f) Signar l'acord de confidencialitat amb l'alumne/a (Annex 1).

En la relació personal del supervisor amb l'estudiantat, s'aplicarà la normativa relativa a abstenció i recusació establerta en el procediment administratiu comú. L'estudiantat no pot tindre relació familiar, ni d'amistat, ni de servei amb el supervisor.

Els mestres de l'escola podran sol-licitar el certificat acreditatiu de supervisió de les pràctiques a través del següent enllaç:

https://docs.google.com/a/uji.es/forms/d/1ijDPjaJXbBMAzOOsDON4fPD4zt7zYifIpaWVcymF 


\section{ACTIVITATS DE L'ESTUDIANTAT}

L'estudiantat cal que planifique la tasca que fa amb el professorat tutor i el mestre supervisor, que el rep a l'aula, en funció dels objectius que s'han assenyalat per a cada curs, així com en funció de la durada de les pràctiques. Ara bé, com a orientació general es pot recomanar que l'estudiantat realitze les activitats següents:

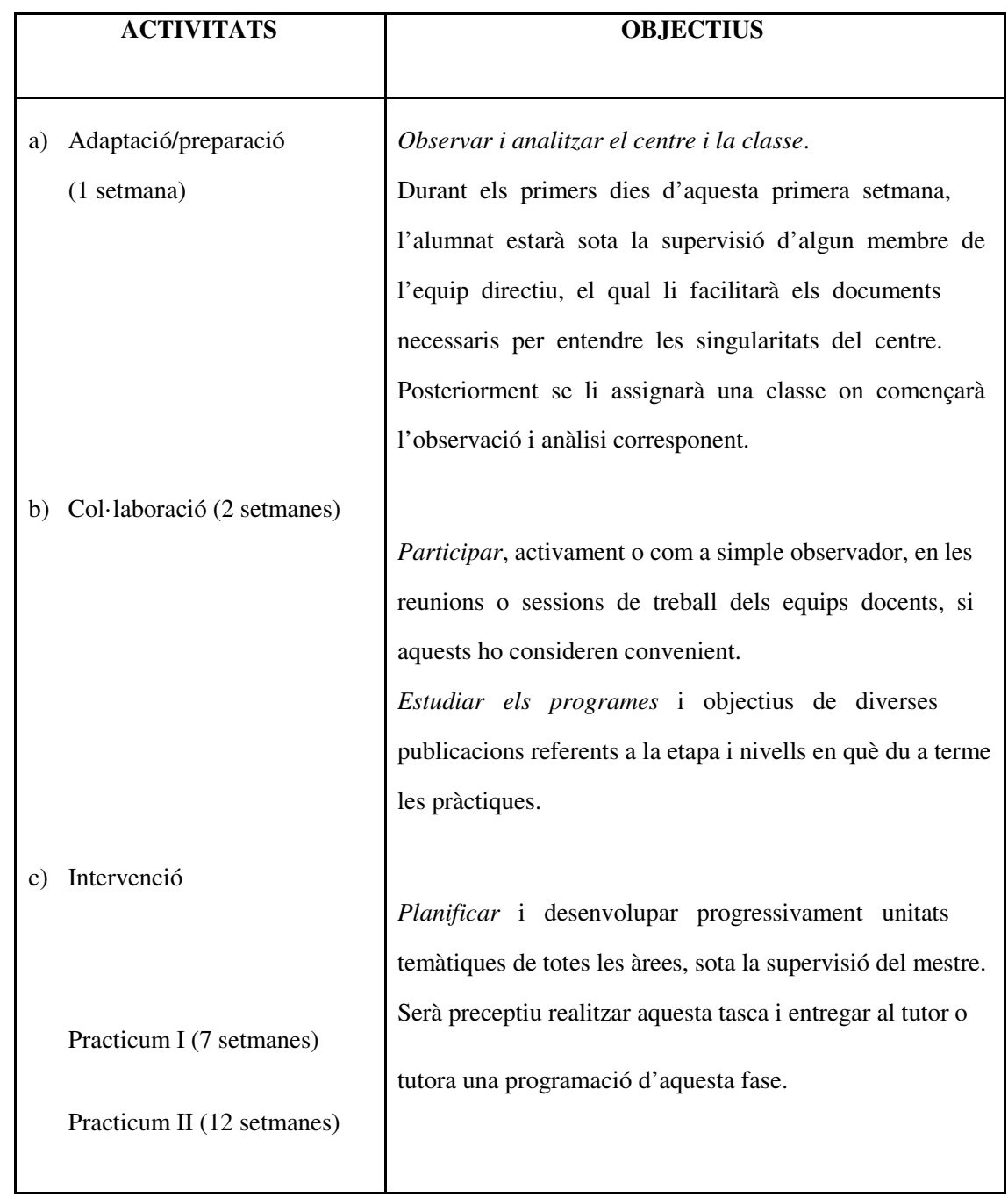

\section{CRITERIS PER A L'AVALUACIÓ}

\subsection{Aspectes generals}

a) L'assistència és obligatòria per a tot l'estudiantat i, per tant, és preceptiu justificar totes les faltes d'assistència o les absències en horari lectiu. La coordinació estudiarà, no obstant això, els casos que requereixen un tractament especial. 
b) Es permetrà un màxim de tres dies d'absència justificada, seguint els mateixos criteris que s'apliquen en l'àmbit laboral (no es consideren justificades les reunions amb el tutor de TFG o de Practicum). En el cas de situacions sobrevingudes, en el que l'absència siga superior als tres dies, caldrà recuperar tot el temps, sense allargar l'estància més enllà del 31 de maig. És obligatòria aquesta recuperació per a poder ser avaluat per part del mestre/a supervisor/a i el tutor/a.

c) La valoració de l'adquisició de les competències del punt 2 es farà a partir de l'avaluació de l'informe global del supervisor o supervisora, la programaciómemòria entregada al tutor o tutora en el termini establert i el seguiment de les sessions de tutorització. Per a realitzar aquesta avaluació es proposen els Annexos 5 i 9 d'aquest document.

d) Si existeix un informe negatiu per part del supervisor, tutor o coordinador de pràctiques o s'incompleix alguna de les directrius per un adequat funcionament dins del centre (apartat 9), es podria interrompre el període de l'estada en pràctiques. Davant d'aquesta situació, la qualificació de l'assignatura seria de suspens.

\subsection{Qualificació}

La qualificació final del Practicum serà la següent:

\begin{tabular}{|l|c|}
\hline \multicolumn{1}{|c|}{ Tipus de prova } & Ponderació \\
Mestre-Supervisor: Informe (Annex 5) & 50 \\
Tutor UJI: & \\
Memòries i informes de pràctiques (Annex 9) & 50 \\
Participació en Seminaris i/o Tutories que el professorat organitza per al seu & \\
estudiantat & \\
& \\
\end{tabular}

Les notes parcials es puntuaran sobre 10 i per obtenir la nota final s'aplicarà la ponderació establerta, sempre que estiguen totes aprovades (nota igual o major que 5).

El Tutor-UJI determinarà, a més de la valoració de la memòria de pràctiques, les tasques y activitats en les quals l'estudiant ha de participar per valorar el 50\% de la nota de Practicum que té assignat.

\section{DIRECTRIUS PER A UN ADEQUAT FUNCIONAMENT DINS DEL CENTRE DE PRÀCTIQUES}

1. L'adjudicació dels Centres de Pràctiques i la relació institucional amb els mateixos correspon a la Comissió de Pràctiques Externes (GMEI i GMEP). Els estudiants no podran fer pel seu compte cap gestió organitzativa en els Centres, de manera que no podran dirigir-se als mateixos per sol-licitar plaça, ni per presentar reclamació alguna sobre les qualificacions que allí emetin. 
2. Els col·legis i supervisors acullen a l'alumnat voluntària i gratuïtament; per tant, l'alumne no pot exigir res al centre.

3. Les dificultats que puguin sorgir durant les pràctiques es tractaran directament amb el professor Tutor de la UJI que és l'interlocutor autoritzat per gestionar les pràctiques en el col·legi, i si no hi ha altre remei amb la Comissió de Practicum.

4. Els estudiants no van als col-legis a emetre judicis sobre el seu funcionament o l'actuació dels seus professors, sinó a aprendre des del respecte i la valoració del treball que allí es realitza.

5. Els estudiants en pràctiques han d'integrar-se en la vida del centre, participant en les diferents activitats, però tenint en compte que no són professors, sinó estudiants en pràctiques.

6. L'escola confia en que les actituds dels estudiants UJI seran sempre de disponibilitat, respecte, diàleg, col·laboració, agraïment i, per descomptat, responsabilitat en les tasques que se'ls encomanin.

7. L'actitud i presència dels estudiants de pràctiques, a l'aula i en el centre docent ha de caracteritzar-se per l'adequació del vocabulari i modals, ajustant-se a pautes de discreció.

8. Tots els estudiants en pràctiques es comprometen a observar i respectar totes les normes de funcionament del centre.

9. Recordem que cal desconnectar a l'aula els telèfons mòbils i segons Llei 28/2005, i la Llei 42/2010 no està permès fumar en les dependències i recintes dels centres docents.

10. Està absolutament prohibit fotografiar o gravar en vídeo als nens, ni individualment ni en grup, de no ser amb el permís dels seus professors i dels seus pares.

11. És molt important l'assistència i la puntualitat. Les faltes d'assistència han de comunicar-se al centre i al professor tutor de la UJI en la forma que estableixi cada professor.

12. Confidencialitat, es recomana llegir l'Annex 1, la informació del centre i/o les converses mantingudes entre col-legues del centre, s'han de tractar amb prudència evitant comentaris que puguin crear conflictes o desvelen dades privades de qualsevol membre de la comunitat educativa.

El no tenir en compte aquestes recomanacions o els procediments establerts en el document de pràctiques poden ser causa d'una prevenció, la qual pot ser sol-licitada pel centre de pràctiques (supervisor o equip directiu) o el seu tutor UJI. La Comissió de Coordinació de Practicum valorarà els arguments i disposarà de les accions oportunes. Segons la gravetat de la situació o la reiteració de prevencions la Comissió Coordinació de Practicum podrà considerar aquestes faltes com a causes suficients per suspendre el practicum, la qual cosa significa que hauran de tornar a cursar-lo. 


\section{GUIÓ DE LA MEMÒRIA}

La memòria no es només un resum de les activitats realitzades a l'aula i al centre al llarg del període de pràctiques. És a dir, ha de ser una autoavaluació, una reflexió i una anàlisi personal dels aspectes didàctics i metodològics relacionats amb el clima de la classe, dels problemes trobats $\mathrm{i}$ de les solucions aportades; recollirà de forma tècnica $\mathrm{i}$ reflexiva la realitat de l'aula i del període d'actuació, i evitarà el caràcter merament descriptiu.

Per a desenvolupar la memòria es proposa el següent esquema:

\section{ASPECTES CONTEXTUALS I ANÀLISI METODOLÒGICA}

Descripció i reflexió sobre les característiques generals del centre (ubicació, projectes especials, instal-lacions, etc.) i de l'aula o l'espai on s'imparteixen les assignatures (nivells, característiques de l'alumnat, materials de l'aula, agrupaments, etc.). A més de l'anàlisi metodològica, és a dir, l'ús de materials i recursos, clima d'aula, models d'ensenyament-aprenentatge, etc.

Aquest apartat no hauria d'ocupar més de 4-5 fulls amb una redacció personal de l'estudiantat. Si cal afegir algun organigrama o detall que ajude a la comprensió d'aquest apartat es pot incloure. Es recomana que aquest apartat es complete durant les tres primeres setmanes.

Amb l'objectiu de que l'alumnat adquireixi competències per dissenyar i regular espais d'aprenentatge en contextos de diversitat, en l'assignatura de practicum hi haurà especial atenció sobre aquest tema. Aquest fet implicarà l'observació i reflexió de les singulars necessitats educatives de l'alumnat del centro on es realitzin les pràctiques, l'anàlisi de les intervencions per fomentar la igualtat de gènere, l'equitat $i$ el respecte als drets humans.

\section{PROJECTE-PROGRAMACIÓ}

Ubicació de la programació, descripció de la programació i avaluació de la seua implementació.

La programació respectarà i s'ajustarà a la planificació de totes les matèries impartides pel supervisor i comprendrà una part important de la fase d'intervenció. En la memòria es recollirà aquesta programació estructurada per matèries tenint en compte tots els elements d'aquesta:

I. Plantejament d'objectius, continguts i competències

II. Metodologia

III. Temporalització

IV. Activitats, recursos didàctics i metodològics, mesures d'atenció a la diversitat i igualtat de gènere (el desenvolupament de les activitats podrien estar com a annexos).

V. Avaluació

VI. Anàlisi/ Reflexió i valoració

VII. Proposta d'innovació (executada o no a l'aula)

La programació és un document que s'ha d'elaborar a priori a la pràctica real.

\section{VALORACIÓ DEL PRACTICUM}

Valoracions sobre les relacions establertes amb el centre, companys/es, tutor/a, xiquets/es, 
famílies, etc.

En el cas del Practicum II, la valoració inclourà una reflexió crítica i una comparació entre Practicum I y II, tenint en compte l'evolució de les pròpies competències docents i la teoria desenvolupada durant tota la formació.

\section{CONCLUSIONS SOBRE L'ESTADA EN PRÀCTIQUES}

Practicum I: Valoració de les activitats programades: Anàlisi i reflexions de la seua vinculació amb el context, dels recursos metodològics utilitzats per a l'atenció a la diversitat, de la realització de tasques integrades (continguts interdisciplinars...). Conclusions finals.

Practicum II: Valoració del disseny i desenvolupament del currículum: aspectes metodològics, de planificació e innovació educativa realitzada dins l'aula. Propostes de millora plantejades per l'alumnat. Conclusions finals.

\section{BIBLIOGRAFIA I ALTRES RECURSOS}

Totes les referències bibliogràfiques i documentals es faran d'acord amb la normativa APA, que es pot consultar en la següent adreça electrònica: http://normasapa.net/normas-apa-2016/

\section{ASPECTES FORMALS DE LA MEMÒRIA}

La memòria cal presentar-la degudament enquadernada o amb format digital (segons les directrius del tutor), amb una extensió que no supere els 50 fulls (s'exclouen d'aquest còmput els documents annexos, la portada i l'índex), escrita a ordinador. Cal cuidar la bona presentació, redacció i ortografia. És aconsellable que la memòria la signe també el professorat supervisor del centre al qual ha estat adscrit l'estudiantat en pràctiques. En el cas que es presente en pdf, el supervisor enviarà una nota al tutor amb el seu vist i plau.

En la portada cal que apareguen les següents dades:

Nom i cognoms, denominació del grau que es cursa i assignatura, col-legi, població, mestre/a supervisor/a del centre, professorat tutor de la Universitat, curs acadèmic i data d'entrega.

La memòria haurà d'incloure un índex on s'especifiquen els diferents apartats amb els seus corresponents $n^{\circ}$ de pàgines.

\section{Normes per a la redacció de la memòria}

1. Format de lletra: Times New Roman 12.

2. Format de pàgina: marges superior, inferior, esquerre i dret de $2 \mathrm{~cm}$.

3. Interlineat 1,15 .

4. Els apartats aniran numerats i en negreta.

5. Les pàgines han d'estar numerades.

Els possibles annexos aniran al final de la memòria. Aquests han de tindre un vincle estret amb els continguts desenvolupats prèviament. Per tant, també hauran d'estar indicats en el cos del text. 
El plagi és un acte fraudulent, inacceptable i subjecte a sancions. La còpia d'idees, textos, gràfics, etc., d'altres autors sense referenciar-los degudament empobreix la nostra feina i posa en perill el procés d'aprenentatge.

L'avaluació de la memòria per part del tutor/a es farà segons l'Annex 9.

\section{RECONEIXEMENTS}

\subsection{Estudiants amb altres titulacions}

Es reconeixerà l'assignatura de Practicum I (MI1025 i MP1026) a l'estudiantat que haja cursat les pràctiques de les titulacions que apareixen en la taula d'equivalències

L'assignatura MI1025 es convalidarà a corresponent al Cicle Formatiu de Grau Formació en Centres de Treball.

l'alumnat que presente la documentació Superior en Educació Infantil. PràctiquesL'òrgan responsable del procés: Servei de Gestió de la Docència i Estudiantat.

\subsection{Estudiants amb experiència professional.}

L'estudiantat amb les titulacions que figuren a continuació i d'acord amb la Normativa General de Practiques Externes de l'UJI (Annex I, article 11) podrà sol-licitar l'exempció de part de les seues pràctiques:

- Llicenciats i llicenciades en Pedagogia, Psicopedagogia i Psicologia que estiguen treballant en un centre escolar (únicament quan desenvolupen les funcions relacionades amb les nomenades llicenciatures: psicòlegs, psicopedagogs...): realitzaran sols la fase d'intervenció.

- Llicenciats i llicenciades en altres titulacions que estiguen treballant en un centre de secundària i hagen ocupat un càrrec directiu durant un període no inferior a un curs acadèmic en els últims quatre anys: realitzaran sols la fase d'intervenció.

Aquest reconeixement se sol-licitarà a través d'una plaça nominativa (veure apartat 4.2).

Tot l'estudiantat que no es trobe en cap dels dos casos descrits haurà de fer el Practicum corresponent de manera íntegra.

Per tal de garantir els criteris de qualitat de les pràctiques fixats per la titulació, no es contempla la possibilitat de reconèixer les pràctiques extracurriculars com a pràctiques curriculars.

\section{PRACTICUM EN PROGRAMES D'INTERCANVI}

L'estudiant podrà realitzar les pràctiques mitjançant programes d'intercanvi. Les pràctiques de Practicum I s'han de realitzar dins del sistema educatiu espanyol.

1. Programa Erasmus + o Programa SICUE. Cal contactar amb els coordinadors de programes d'intercanvi dels Graus en Mestres d'Educació Infantil i d'Educació Primària. No obstant això, realitzar les pràctiques a través d'aquesta modalitat és 
complicat, degut a la dificultat de trobar plans d'estudis d'altres universitats nacionals o estrangeres amb el mateix nombre de crèdits que el pla d'estudis de l'UJI.

2. Programa Pràctiques Externes. Cal contactar amb el responsable d'aquest programa de la Facultat o amb el tècnic de la OIPEP. Degut a la singularitat d'aquest Grau i de les seues pràctiques, l'estudiantat podria realitzar la proposta del centre.

3. Pràctiques solidaries en països empobrits. Cal contactar a l'Oficina de Cooperació al Desenvolupament i Solidaritat.

4. Realitzar les pràctiques curriculars en centres fora de l'àmbit d'influència dels programes anteriors. En aquests casos no hauria beca i s'haurien de realitzar convenis específics. Cal contactar amb la coordinació de Practicum.

\section{INFORMACIÓ ADDICIONAL}

\subsection{Protocols d'actuació davant incidències i dubtes durant el període de practicum.}

Si durant el període de pràctiques sorgeixen incidències, els passos que cal realitzar són els següents:

\subsubsection{Estudiantat}

El primer pas davant de qualsevol incidència o dubte seria posar-se en contacte amb el tutor del Practicum. En segona instància es pot posar en contacte amb la coordinació de pràctiques.

E-mail practicum_mestre@uji.es.

\subsubsection{Supervisors}

El primer pas davant de qualsevol incidència o dubte seria contactar amb el tutor de

Practicum. En segona instància s'haurà de posar en contacte amb la direcció del centre, el qual contactarà amb la coordinació de pràctiques.

E-mail practicum_mestre@uji.es

\subsubsection{Tutors}

Per a qualsevol incidència o dubte posar-se en contacte amb la coordinació de Practicum.

E-mail practicum_mestre@uji.es

\subsection{On trobar més informació}

La guia docent de l'assignatura la trobareu al LLEU. Tota la informació general referent al Practicum de la Universitat Jaume I es gestiona des de l'OIPEP: http://www.uji.es/CA/serveis/ocie/acil/prog/estades/. 
Coordinació de pràctiques del Grau en Mestre/a d'Educació Infantil:

Colomer Diago, Carla

Górriz Plumed, Ana Belén

Sánchez-Tarazaga Vicente, Lucía

Coordinació de pràctiques del Grau en Mestre/a d'Educació Primària:

García Antolín, Robert

Ruiz Bernardo, Paola

Mateu Pérez, Rosa

Escobedo Peiro, Paula

NOTA 1: AQUEST DOCUMENT HA ESTAT APROVAT EN LA COMISSIÓ DE TITULACIÓ DEL GRAU EN MESTRE/A D'EDUCACIÓ INFANTIL I DE MESTRE/A D'EDUCACIÓ PRIMÀRIA, EL 25 DE MAIG DE 2016. 


\section{ANNEXOS}

ANNEX 1. Acord de confidencialitat

Castelló, a .... de .... de 201_

\section{REUNITS}

L'estudiant amb DNI , en condició d'alumne

de Practicum del Grau en mestre d'Educació. de la Universitat Jaume I, i el docent amb DNI , en condició de mestre supervisor del

\section{EXPOSEN}

1. Que ambdues parts desitgen iniciar una col-laboració mútua d'àmbit acadèmic, amb l'objectiu de portar a terme les pràctiques necessàries per a la formació de l'alumne de l'esmentada universitat.

2. Que, durant el procés, ambdues parts intercanviaran informació i material, i que estan interessades a regular la seua confidencialitat mitjançant les següents:

\section{CLÀUSULES}

\section{Finalitat}

L'objectiu d'aquest acord és fixar les condicions sota les quals les parts mantindran la confidencialitat de la informació subministrada entre elles. Es considerarà confidencial aquella informació susceptible de ser revelada per escrit, de paraula o per qualsevol mitjà o suport, tangible o intangible. S'hi inclou la informació rebuda de les reunions amb les famílies, les juntes d'avaluació, els claustres i qualsevol altra que es porte a terme durant el període de pràctiques.

\section{Vigència}

Cada part es compromet a mantenir el compromís de confidencialitat de forma indefinida una vegada finalitzada l'estada en pràctiques.

\section{Confidencialitat}

Ambdues parts es comprometen a facilitar tota la informació i el material que siga necessari i, en cas de ser confidencial, a utilitzar-lo de forma reservada, a no divulgar-lo i a impedir la seua còpia o revelació a tercers. 


\section{Drets de propietat}

Tota informació intercanviada és de propietat exclusiva de la part d'on procedisca, i no és necessària la concessió de llicència per a aquest intercanvi. Cap de les parts utilitzarà informació de l'altra part per al seu propi ús, excepte que s'autoritze el contrari.

\section{Protecció de dades}

Ambdues parts es comprometen a no publicar en cap lloc (tampoc en la memòria de pràctiques, en el cas de l'alumnat) qualsevol material fotogràfic, escrit o d'un altre tipus que poguera contravenir la Llei Orgànica 15/1999 de 13 de desembre, de Protecció de Dades de Caràcter Personal, sempre que no hi haja una autorització expressa que permeta fer-ho.

I com a prova de conformitat, signen aquest document per duplicat, en el lloc i la data assenyalats a l'encapçalament.

(Nom i cognoms de l'alumne)

(Nom i cognoms del mestre supervisor) 
ANNEX 2. Full per a sol·licitar plaça nominativa (a reomplir per l'estudiantat)

\begin{tabular}{|c|c|c|c|c|c|}
\hline \multirow[t]{2}{*}{ SEGELL REGISTRE } & \multicolumn{2}{|c|}{$\begin{array}{l}\text { RESOLUCIO } \\
\text { PROVISIONAL }\end{array}$} & \multicolumn{2}{|c|}{$\begin{array}{l}\text { RESOLUCIO } \\
\text { DEFINITIVA }\end{array}$} & \multirow[t]{2}{*}{$\mathrm{N}^{\mathrm{o}}$} \\
\hline & $\begin{array}{l}\square_{\text {FAVORABLE }} \\
\square_{\text {DESFAVORABLE }} \\
\square_{\text {Fòra de termini }} \\
\sqcup_{\text {No Procedeix }}\end{array}$ & Motiu & $\begin{array}{l}\square_{\text {FAVORABLE }} \\
\square_{\text {DESFAVORAB }} \\
\square_{\text {Fòra de termini }} \\
\sqcup_{\text {No Procedeix }}\end{array}$ & Motiu & \\
\hline
\end{tabular}

\section{COORDINACIÓ PRACTICUM MESTRE / No Plaça: COORDINACIÓN PRACTICUM MAESTRO}

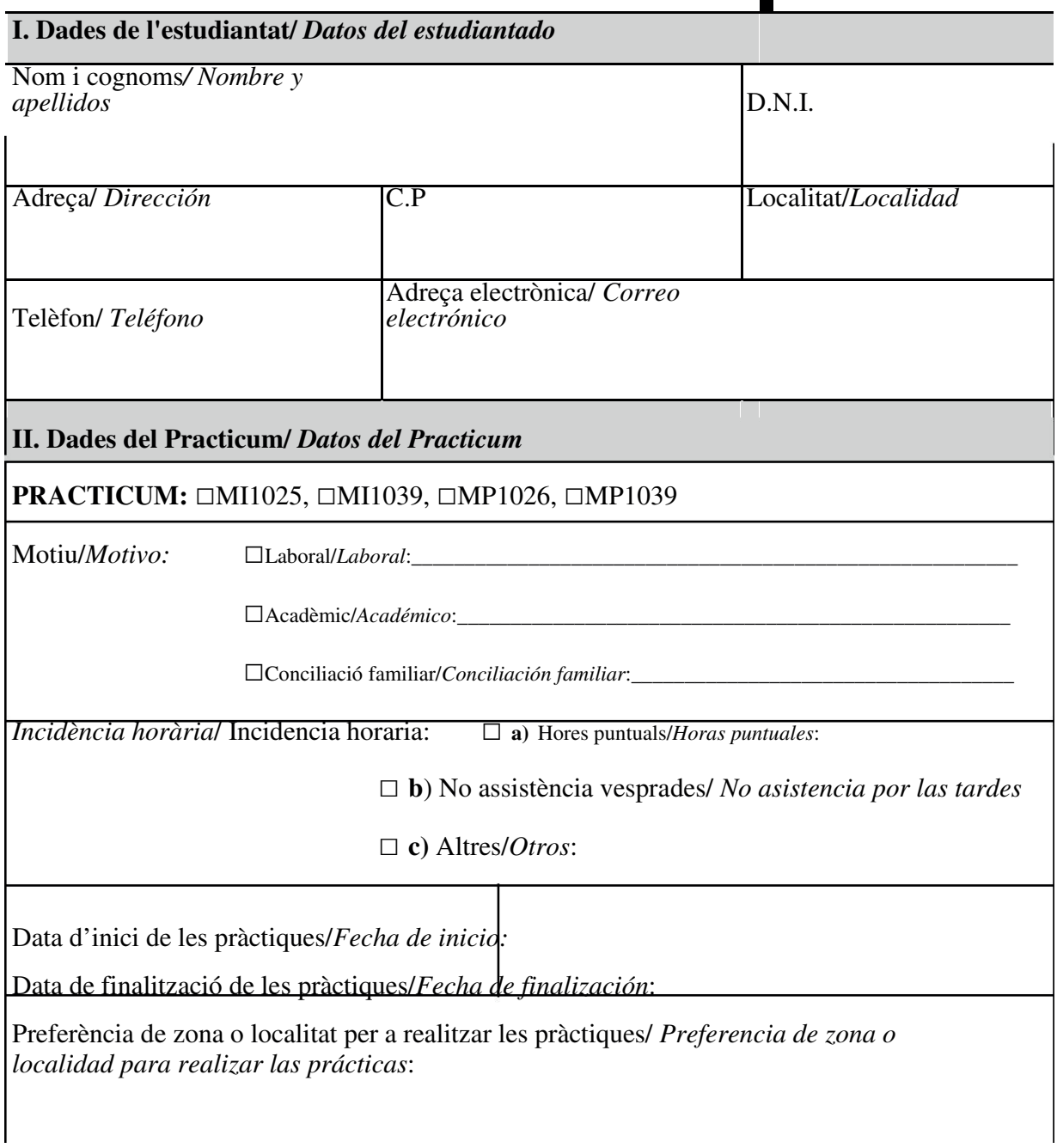


* En cap cas l'estudiant anirà a parlar directament amb un centre concret. Serà la Comissió de Coordinació de Practicum qui decidirà en última instancia el centre de pràctiques i qui contactarà amb els centres seleccionats basant-se en la proposta de l'alumne/a./ En ningún caso será el estudiante el que vaya a hablar directamente con un centro concreto. Será la Comisión de Coordinación de Practicum quien decidirá en útima instacia el centro de prácticas y quien contactarà con los centros seleccionados basandose en la propuesta del alumno/a.

Es obligatori omplir tots els apartats d'aquest full, si no s'omplin, la sol-licitud es considerarà desfavorable/ Es obligatoria la cumplimentación de todos los apartados de esta hoja, si no se cumplimenta alguno, la solicitud se considerará desestimada. 


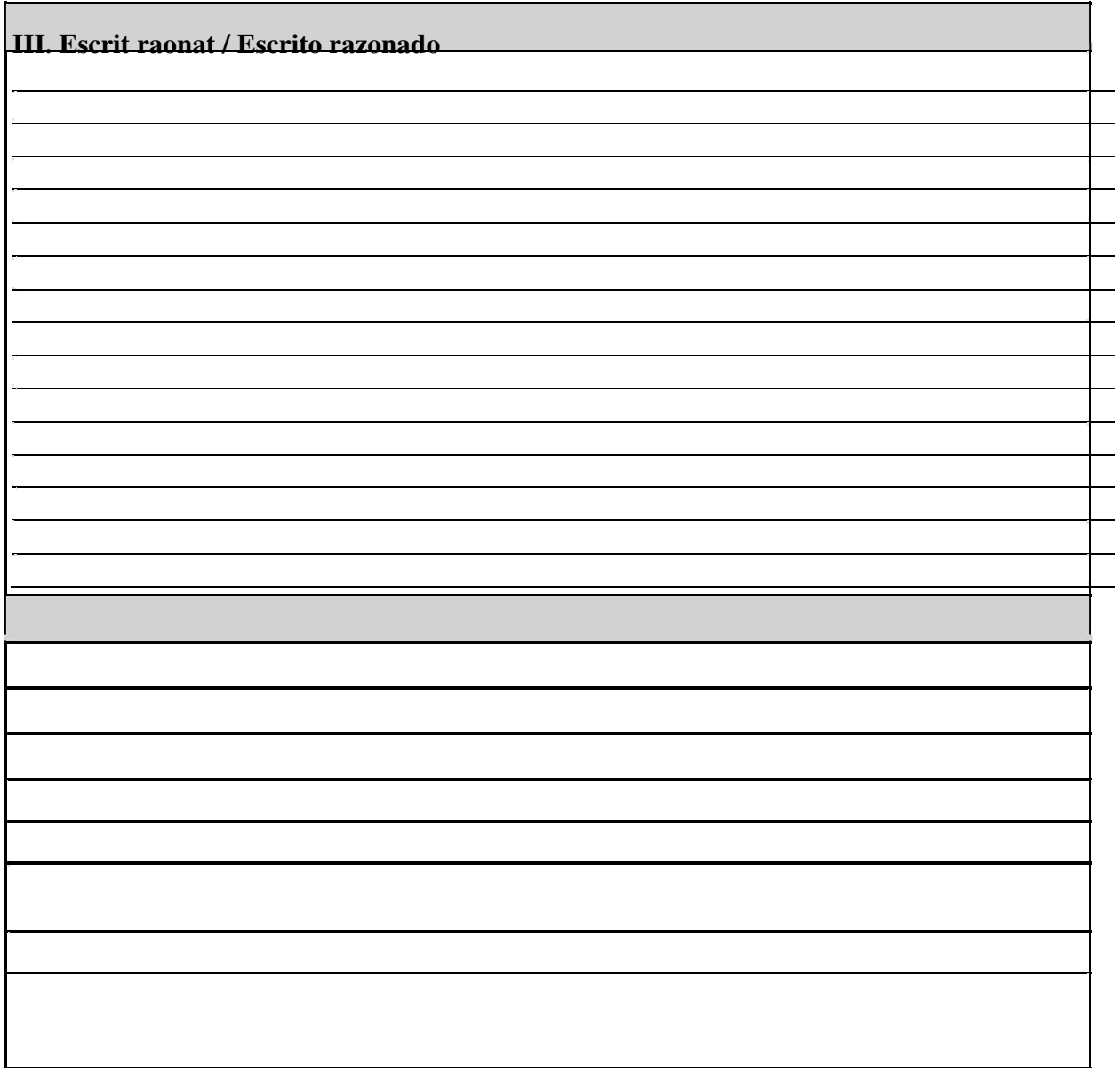

\section{Documentació/ Documentación}

Còpia del full de matrícula /Copia de la hoja de matrícula

$\square$

Proposta de calendari (Annex 3) / Propuesta de calendario (Anexo 3)

$\square$

Horari laboral o d'estudis / Horario laboral o de estudio

$\square$ Contracte laboral o justificant oficial corresponent/Contrato laboral o justificante oficial correspondiente

$\square$ Certificat de qualificacions / Certificado de notas

$\square$ Certificat de l'organisme responsable de l'intercanvi de l'UJI / Certificado del organismo responsable del intercambio de la UJI

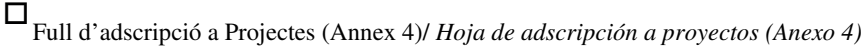

$\square$ Altres/Otros: 
(*)Presenteu aquest document emplenat, firmat i segellat en el Registre General de la Universitat Jaume I /Presentar este documento debidamente cumplimentado, firmado y sellado en el Registro General de la Universitat Jaume I.

Les dades personals d'aquest document quedaran incloses en el fitxer automatitzat de la Universitat Jaume I, que es compromet a no fer-ne ús distint d'aquell per al qual han estat demanades, d'acord amb la Llei orgánica 15/1999, de 13 de desembre, de protecció de les dades. Podeu exercir, per escrit, els drets d'accés, rectificació, cancel-lació i, si escau, d'oposició, davant de la Secretaria General d'aquesta Universitat.

Los datos personales de este documento quedarán incluídos en el archivo automatizado de la Universitat Jaume I, que se compromete a no hacer un uso distinto a aquel por el cual han sido solicitados, en conformidad con la Ley orgánica 15/1999, de 13 de diciembre, de protección de datos. Se puedenejercer, por escrito, los derechos de acceso, rectificación, cancelación y si cabe, de oposición, ante la Secretaria General de esta Universidad.

Signatura de l'estudiant / Firma del estudiante

Castelló, a d de $20 \ldots$ 


\section{ANNEX 3. Proposta de calendari per a desenvolupar les pràctiques (plaça}

nominativa)

Omplir el següent calendari marcant l'horari i els dies d'assistència al centre. Aportar el còmput d'hores de cadascuna de les setmanes marcades i el total d'hores d'assistència. Aspectes a tindre en compte:

1) En cap cas les pràctiques podran començar abans del 9 de gener (a excepció de tancament d'expedient i de casos que per motius de falta d'hores disponibles podran començar a partir de l'1 de desembre) ni realitzar-se més enllà del 31 de maig de 2017.

2) L'horari lectiu de cada centre és de 6 hores al dia, normalment de 9.00 a $13.30 \mathrm{~h}$ i de 15.30 a $17.00 \mathrm{~h}$ o de 9.00 a $15.00 \mathrm{~h}$. (però pot dependre de la ubicació i tipologia del centre)

3) S'han de complir mínim de tres setmanes d'intervenció consecutiva en horari complet en la part final del Practicum.

S'hauran de marcar i tindre en compte pel còmput d'hores els dies festius de la localitat.

Horari a realitzar (cal especificar l'horari concret que es realitzarà cada

dia al

centre):

\begin{tabular}{|c|c|c|c|c|c|c|}
\hline \multicolumn{5}{|c|}{ Gener 2017} & \multirow{2}{*}{ Especificar horari de cada dia } & \multirow{2}{*}{$\begin{array}{c}\text { Hores } \\
\text { setmanal } \\
\mathrm{s}\end{array}$} \\
\hline Dll & Dm & Dc & $\mathrm{Dj}$ & Dv & & \\
\hline 2 & 3 & $\overline{4}$ & 5 & 6 & & \\
\hline 9 & 10 & 11 & 12 & 13 & & \\
\hline 16 & 17 & 18 & 19 & 20 & & \\
\hline 23 & 24 & 25 & 26 & 27 & & \\
\hline 30 & 31 & & & & & \\
\hline
\end{tabular}

\begin{tabular}{|c|c|c|c|c|c|c|}
\hline \multicolumn{5}{|c|}{ Febrer 2017} & \multirow{2}{*}{ Especificar horari de cada dia } & \multirow{2}{*}{$\begin{array}{c}\text { Hores } \\
\text { setmanal } \\
\mathrm{s}\end{array}$} \\
\hline Dll & $\mathrm{Dm}$ & $\mathrm{Dc}$ & $\mathrm{Dj}$ & Dv & & \\
\hline & & 1 & 2 & 3 & & \\
\hline 6 & 7 & 8 & 9 & 10 & & \\
\hline 13 & 14 & 15 & 16 & 17 & & \\
\hline 20 & 21 & 22 & 23 & 24 & & \\
\hline 27 & 28 & & & & & \\
\hline
\end{tabular}

\begin{tabular}{|c|c|c|c|c|c|c|}
\hline \multicolumn{5}{|c|}{ Març 2017} & \multirow{2}{*}{ Especificar horari de cada dia } & \multirow{2}{*}{$\begin{array}{c}\text { Hores } \\
\text { setmanal }\end{array}$} \\
\hline Dll & Dm & Dc & $\mathrm{Dj}$ & Dv & & \\
\hline & & 1 & 2 & 3 & & \\
\hline
\end{tabular}




\begin{tabular}{|c|c|c|c|c|c|c|}
6 & 7 & 8 & 9 & 10 & & \\
\hline 13 & 14 & 15 & 16 & 17 & & \\
\hline 20 & 21 & 22 & 23 & 24 & & \\
\hline 27 & 28 & 29 & 30 & 31 & & \\
\hline
\end{tabular}

\begin{tabular}{|c|c|c|c|c|c|c|}
\hline \multicolumn{4}{|c|}{ Abril 2017 } & & \multirow{2}{*}{ Especificar horari de cada dia } & Hores \\
setmanal \\
Dl1 & Dm & Dc & Dj & Dv & & \\
\hline 3 & 4 & 5 & 6 & 7 & & \\
\hline 10 & 11 & 12 & 13 & 14 & & \\
\hline 17 & 18 & 19 & 20 & 21 & & \\
\hline 24 & 25 & 26 & 27 & 28 & & \\
\hline
\end{tabular}

\begin{tabular}{|c|c|c|c|c|c|c|}
\hline \multicolumn{5}{|c|}{ Maig 2017} & \multirow{2}{*}{ Especificar horari de cada dia } & \multirow{2}{*}{$\begin{array}{c}\text { Hores } \\
\text { setmanal } \\
\mathrm{s}\end{array}$} \\
\hline Dll & Dm & Dc & Dj & Dv & & \\
\hline 1 & 2 & 3 & 4 & 5 & & \\
\hline 8 & 9 & 10 & 11 & 12 & & \\
\hline 15 & 16 & 17 & 18 & 19 & & \\
\hline 22 & 23 & 24 & 25 & 26 & & \\
\hline 29 & 30 & 31 & & & & \\
\hline
\end{tabular}

Total d'hores d'assistència: (Practicum I: 300 hores; Practicum II: 450 hores) 
ANNEX 4. Document places nominatives - Projecte d'investigació o innovació acadèmica-. (a reomplir per l'alumne i el tutor UJI)

\section{DADES DEL TUTOR I DEL PROJECTE:}

Nom:

Departament:

Àrea:

Crèdits de pràcticum en POD:

Grup d'Investigació:

Projecte (codi i nom):

Finançament (UJI, entitats públiques o entitats privades):

\section{DADES DE L'ALUMNE:}

Nom i cognoms:

E-mail:

Titulació:

Tasques a realitzar en el projecte:

Tasques a realitzar en el centre (relacionades amb el projecte):

\section{DADES DEL CENTRE DE PRÀCTIQUES:}

Nom i cognoms del supervisor:

E-mail:

Nivell (aula):

Nom i cognoms del responsable de l'equip directiu:

E-mail:

Signatures:

\begin{tabular}{|l|l|l|l|}
\hline Alumne/a & Tutor UJI & Supervisor centre & Equip directiu \\
\hline & & & \\
& & & \\
& & & \\
\hline
\end{tabular}

En (data) 
ANNEX 5. Full d'avaluació del Practicum

(Document a reomplir pel supervisor/a del centre)

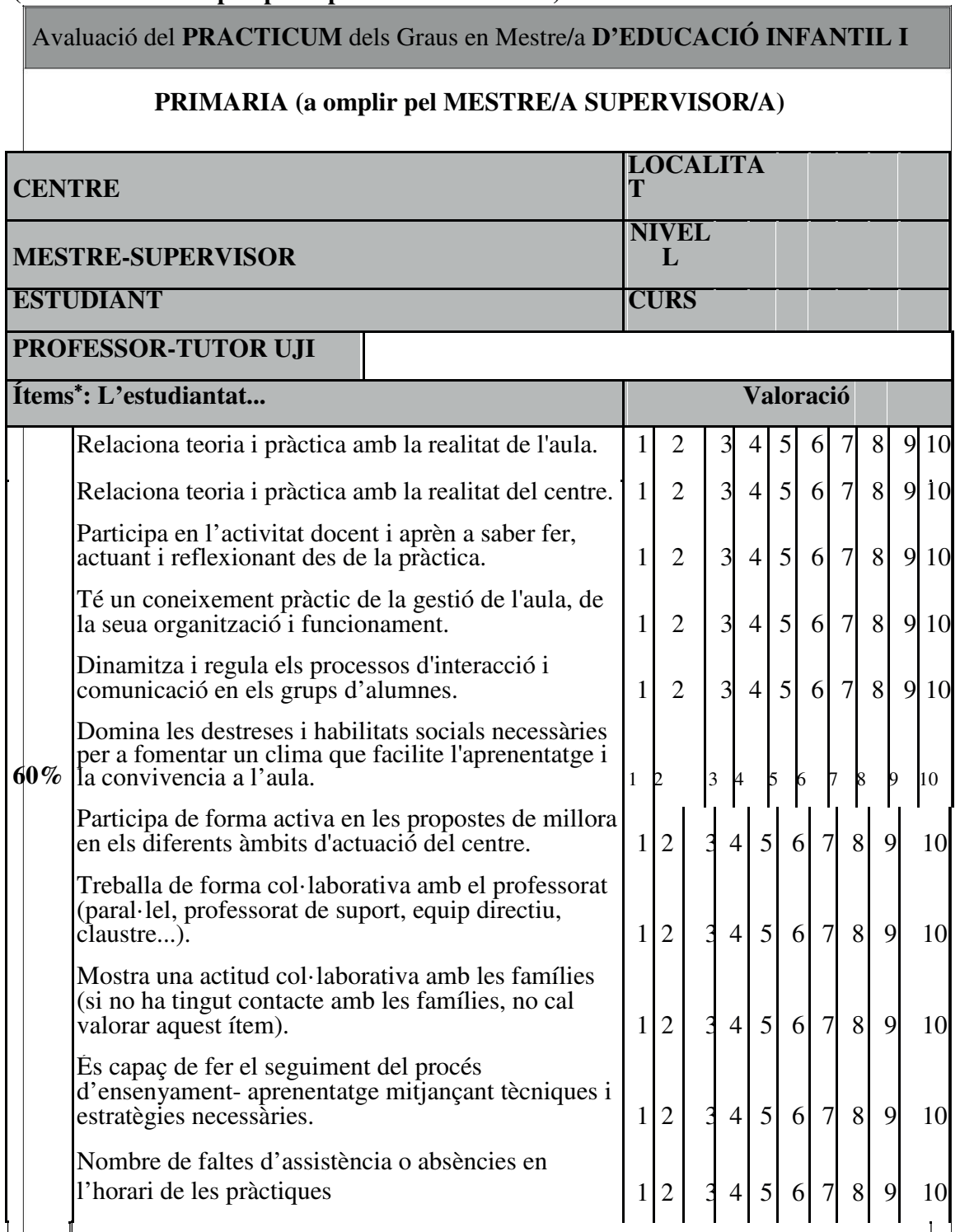

\section{VALORACIÓ QUALITATIVA DE L'ESTUDIANT}

*VALORACIÓ: 1= Mal .....10 = Excel.lent 
ANNEX 6. Orientacions per al tutor/a a l'hora de fer les visites als centres educatius

Aquestes són unes orientacions per a les diferents visites que es van a realitzar en el centre.

\begin{tabular}{|c|c|c|}
\hline Visita & Objectius & Aspectes que cal tenir en compte \\
\hline $\begin{array}{l}\text { Primera (inicial i } \\
\text { presa de contacte) }\end{array}$ & $\begin{array}{l}\text { - Realitzar la primera presa de } \\
\text { contacte amb el centre i els mestres } \\
\text { supervisors. } \\
\text { - Agrair als supervisors i al centre } \\
\text { l'acolliment d'alumnat de } \\
\text { Practicum. } \\
\text { - Conèixer com s'han iniciat les } \\
\text { pràctiques } \\
\text { - Explicar el funcionament de les } \\
\text { pràctiques a través del document de } \\
\text { Practicum als supervisors. } \\
\text { - Resoldre els dubtes que puguin } \\
\text { sorgir del Practicum tant als } \\
\text { supervisors com als alumnes. }\end{array}$ & $\begin{array}{l}\text { - És aconsellable a l'hora de les } \\
\text { visites saludar i agrair (primera } \\
\text { visita), tant a la direcció del centre } \\
\text { com als supervisors, el fet que } \\
\text { estiguin sota la seva tutela els } \\
\text { alumnes de Practicum. } \\
\text { - En primera reunió és } \\
\text { important que el tutor done el seu } \\
\text { correu als supervisors per a } \\
\text { qualsevol dubte que puga sorgir } \\
\text { en el transcurs del Practicum. }\end{array}$ \\
\hline $\begin{array}{l}\text { Segona } \\
\text { (desenvolupament } \\
\text { de les pràctiques) }\end{array}$ & $\begin{array}{l}\text { - Conèixer el desenvolupament de } \\
\text { les pràctiques. } \\
\text { - Resoldre els dubtes que puguin } \\
\text { sorgir de la memòria del Practicum } \\
\text { tant als supervisors com als } \\
\text { alumnes. }\end{array}$ & $\begin{array}{l}\text { - Les visites als centres s'han de } \\
\text { concertar prèviament amb els } \\
\text { supervisors }\end{array}$ \\
\hline $\begin{array}{ll}\text { Tercera (final } & \mathrm{i} \\
\text { desenvolupament } & \mathrm{i} \\
\text { avaluació de les } & \\
\text { pràctiques) } & \end{array}$ & $\begin{array}{l}\text { - Conèixer el desenvolupament i } \\
\text { l'avaluació dels alumnes de } \\
\text { Practicum per part dels mestres } \\
\text { supervisors }\end{array}$ & \\
\hline
\end{tabular}




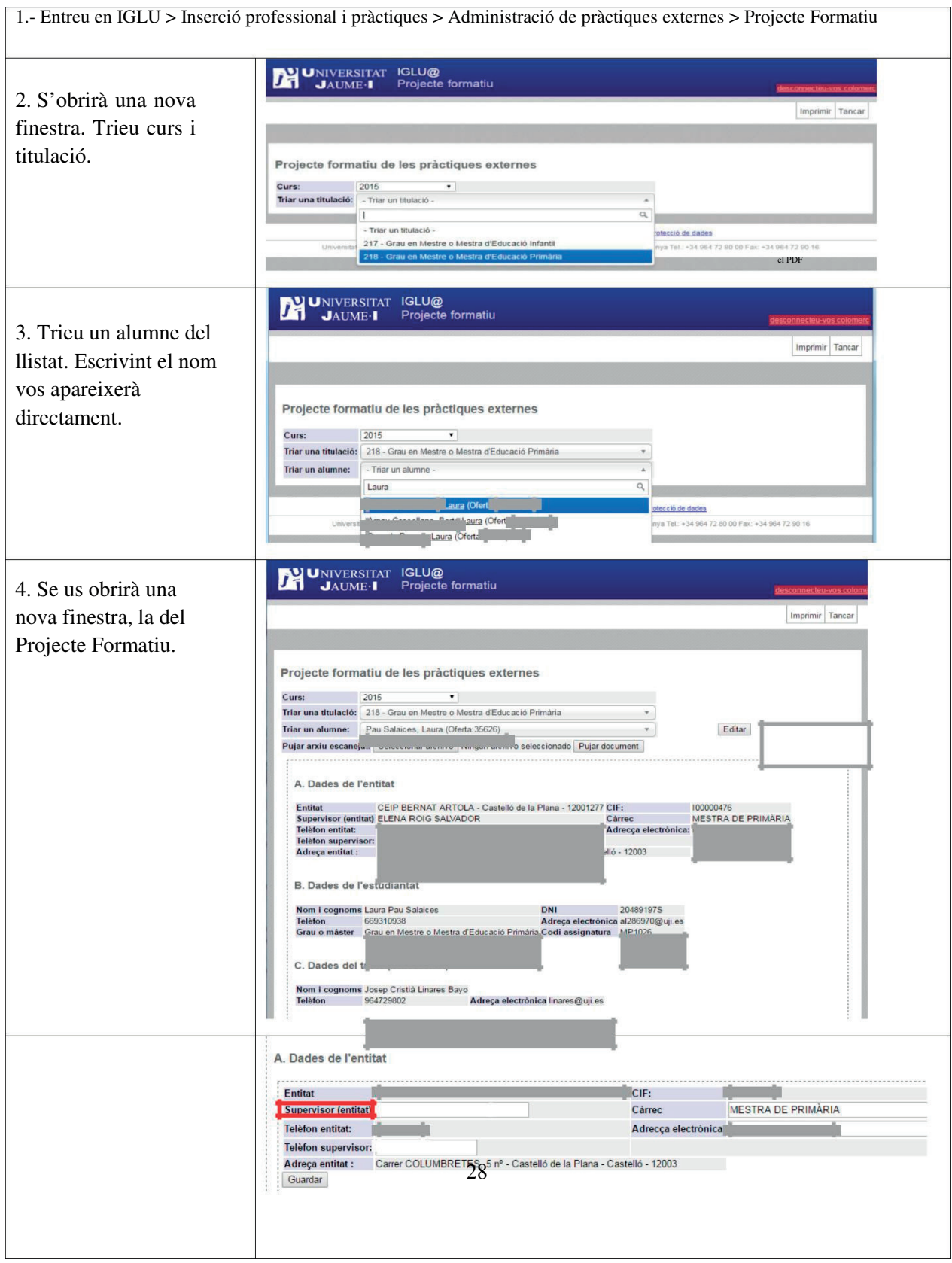


6. Empleneu l'apartat E segons la imatge. Deixeu els camps que veieu en blanc, sense emplenar.

\section{GUARDEU}

*Practicum I: 300 hores. (inici: 1 de març; fi: 24 de maig 2017) *Practicum II: 450 hores. (inici: 23 gener; fi: 24 de maig 2017)

7. Empleneu l'apartat F, segons la imatge.

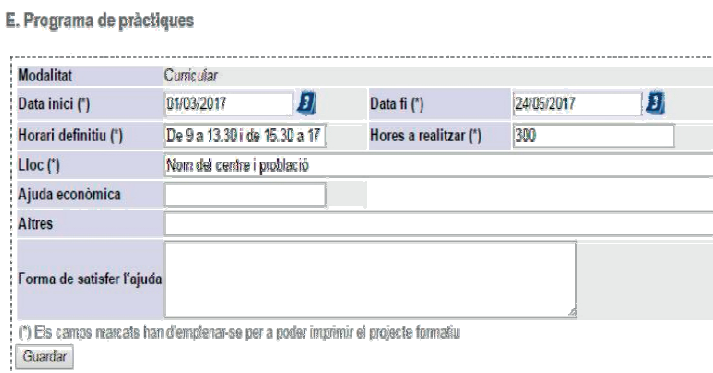

\section{En l'apartat “Altres} habilitats transversals que es desenvolupen", podeu assenyalar les que cregueu convenients (podeu optar per NO assenyalar-ne cap). De tota manera estan pràcticament totes recollides a les competències que figuren al Projecte Formatiu.

\section{Altres habilitats transversals que es desenvoluparan}

$\square$ Habilitats interpersonals / Habilidades interpersonales

$\square$ Resolució de problemes / Resolución de problemas

Capachat de comunicació / Capacidad de comunicación

QPianificació i gestío del temps / Planílicación y gestión del tiempo

Presa de decisions / Toma de decisiones

Hablitats de gestió de la informacio / Habilidades de gestion de la información

Responsabilitat social i ètica / Responsabilidad social y ética

$\square$ Capachat de generar noves idees (creatvitav) / Capacidaz de generar nuevas ideas (creatsidad)

Capacitat per aplicar els coneixements en la pràctica / Capacidad para aplicar los conocimientos a la

Capacitat per adaptar-se a noves situacions / Capacidad para adaptarse a nuevas situaciones

Capachat per aprendre / Capacidad para aprender

Preccupació per la qualitat / Preocupación por la calidad

Habiltat per treballar de maneta autónoma / Habliţad para trabajar de manera autónoma

Treball en equig / Trabajo en equipo

Iniciativa i esperit emprenedors / Iniciativa y espiritu emprendedor

C Coneixement de llengules estrangeres / Conocimiento de lenguas estranjeras

QCapacitat critica I autocritica / Canacidad critica y autocritica

D Habilitats bảsiques en el maneig de lordinador / Habilidades básicas en el manejo del ordenador

Capacitat per treballar en un equip interdisciplinat / Capacidad para trabajar en un equipo interdiscip

Compromis organitzacional/Compromiso organizacional

$\square$ Capacitat d'anallisi i de sintesi / Capacidad de analisis y de sintesis

Motivació d'èxit / Mothyación de éxito 
9. Ompliu de l'apartat F les activitats a realitzar, segons la imatge.

Ompliu també l'idioma, i si hi ha alguna observació.

\section{GUARDEU}

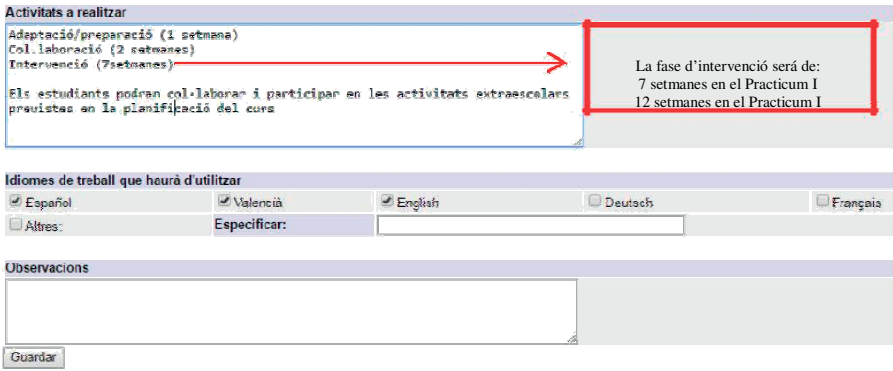

10. Premeu [Finalitzar Ediclóf. és un botó que us eixirà al principi de la pàgina del PF, on abans havíeu punxat en "Editar". Si tot ha estat correcte us deixarà imprimir.

11. Imprimiu 1 exemplar, el qual deurà signar-se per:

L'estudiant

El tutor

El mestre/a supervisor

12. Una vegada signat per cada firmant, s'escaneja tot el projecte (totes les fulles), la guardeu al vostre ordinador en format pdf, i se puja a T'TGLU des de la mateixa finestra deI Projecte Formatiu de la següent manera, on diu [Pujar arxiu escanejat]:

$>$ Seleccioneu el document pdf a pujar amb el botó [Navega]

$>$ Pugeu-lo amb el botó [Puja el document]

Finalment l'heu d'enviar per correu intern a l'OIPEP.

Una vegada que heu pujat l'arxiu escanejat, ja no podreu tornar a editar-lo: si voleu fer modificacions, haureu d'esborrar-lo punxant en l'aspa roja que us eixirà i seguir el mateix procés: editar-lo, imprimir-lo, firmar-lo tots (enviar el l' exemplar a l'OIPEP novament, indicant que modifica un PF anterior) i pujar el document a l'e-ujier.

13. A continuació torneu a procedir des del punt 2 del present tutorial per a cada estudiant que tingueu assignat, en cada titulació de la que tingueu POD de Practicum.

14. Si teniu algun dubte o incidència, consulteu els coordinadors de pràctiques: practicum_mestre@uji.es . Si es tracta d'una incidència informàtica, haureu de fer un CAU: http://cau.uji.es/

*Important: el Projecte Formatiu formarà part del procés de seguiment per a la renovació dels títols, a més és necessari per a què els coordinadors/es de pràctiques puguen generar el certificat acreditatiu de les pràctiques per a cada estudiant en compliment de la normativa estatal. 


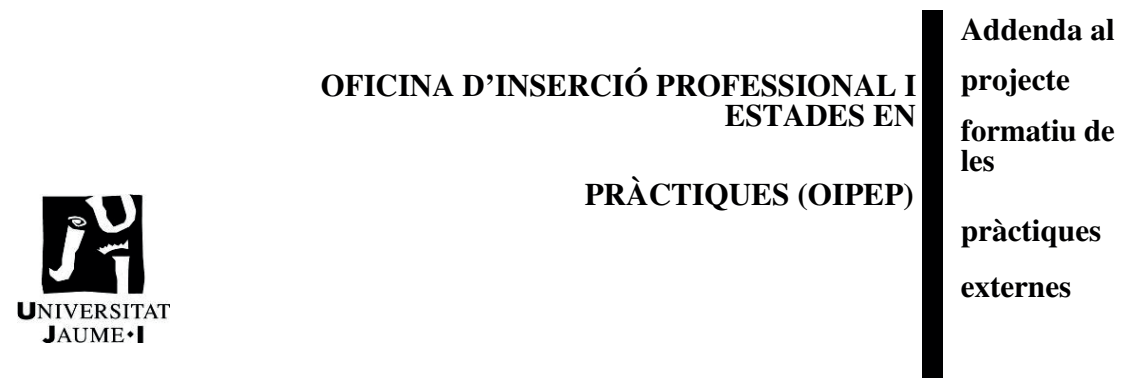

\section{Addenda al projecte formatiu de les pràctiques externes curriculars de l' estudiant} en el CEIP (

Les parts acorden que, durant la baixa mèdica del supervisor designat inicialment (nom i cognoms del supervisor inicial), les pràctiques de l'estudiant seran supervisades pel mestre que el substitueix (nom i cognoms del supervisor substitut), respectant en tot moment les condicions i contingut acordats al corresponent projecte formatiu.

El professor tutor

Nom i cognoms

Nom i cognoms
El supervisor substitut

Nom i cognoms

Vist i plau del director del centre

Nom i cognoms

En Castelló de la Plana, a dd/mm/aaaa 


\begin{tabular}{|c|c|c|c|c|c|c|c|c|c|c|}
\hline CENTRE & & & & & & & & & & \\
\hline MESTRE-SUPERVISOR & & & & & & & & & & \\
\hline ESTUDIANT & & JRS & & & & & & & & \\
\hline Ítem* & & ALC & DR & $\overline{\mathbf{A C}}$ & & & & & & \\
\hline & 1 & 2 & 3 & 4 & 5 & 6 & 7 & 8 & 9 & 10 \\
\hline $\begin{array}{l}\text { Projecte- programació(I): Plantejament } \\
\text { 2.d'objectius, continguts i competències }\end{array}$ & 1 & 2 & 3 & 4 & 5 & 6 & 7 & 8 & 9 & 10 \\
\hline 3.Projecte- programació(II): Metodologia & 1 & 2 & 3 & 4 & 5 & 6 & 7 & 8 & 9 & 10 \\
\hline 4.Projecte- programació(III): Temporalització & 1 & 2 & 3 & 4 & 5 & 6 & 7 & 8 & 9 & 10 \\
\hline $\begin{array}{l}\text { Projecte- programació(IV): Activitats, recursos } \\
\text { 5.didàctics I metodològics }\end{array}$ & 1 & 2 & 3 & 4 & 5 & 6 & 7 & 8 & 9 & 10 \\
\hline 6.Projecte- programació(V): Avaluació & 1 & 2 & 3 & 4 & 5 & 6 & 7 & 8 & 9 & 10 \\
\hline $\begin{array}{l}\text { Projecte- programació (VI): Anàlisi / reflexió i } \\
\text { 7.valoració }\end{array}$ & 1 & 2 & 3 & 4 & 5 & 6 & 7 & 8 & 9 & 10 \\
\hline $\begin{array}{l}\text { 8. Projecte- programació (VII): Proposta } \\
\text { d'innovació }\end{array}$ & 1 & 2 & 3 & 4 & 5 & 6 & 7 & 8 & 9 & 10 \\
\hline 9. Valoració del Practicum I/II & 1 & 2 & 3 & 4 & 5 & 6 & 7 & 8 & 9 & 10 \\
\hline 10. Conclusions sobre l'estada en pràctiques & 1 & 2 & 3 & 4 & 5 & 6 & 7 & 8 & 9 & 10 \\
\hline 11. Bibliografia i altres recursos & 1 & 2 & 3 & 4 & 5 & 6 & 7 & 8 & 9 & 10 \\
\hline 12. Aspectes formals de la memòria & 1 & 2 & 3 & 4 & 5 & & 7 & 8 & 9 & 10 \\
\hline OBSERVACIONS* Obligatori omplir aquest apartat amb & & 0 & & & & & & & & \\
\hline
\end{tabular}




\section{Apéndice 1}

\section{Certificado participación para el grupo control:}

D. ${ }^{a} \quad M^{a}$ Ángeles Llopis Nebot, con DNI 19005506-P, Profesora Asociada del Departamento de Educación de la Universitat Jaume I,

\section{HACE CONSTAR}

Que con DNI ha colaborado en la investigación "Pensamiento reflexivo en el Grado de Maestro en Educación Primaria", para lo cual ha realizado tareas tales como entrevistas reflexivas así como la elaboración de un diario reflexivo durante su estancia de Practicum I.

Para que conste a los efectos oportunos,

Castellón a __ de de 2015

\section{Certificado de participación del grupo experimental:}

D. ${ }^{a} \quad M^{a}$ Ángeles Llopis Nebot, con DNI 19005506-P, Profesora Asociada del Departamento de Educación de la Universitat Jaume I,

\section{HACE CONSTAR}

Que con DNI ha colaborado en la investigación "Pensamiento reflexivo en el Grado de Maestro en Educación Primaria", para lo cual ha asistido al Taller de Formación en Pensamiento Reflexivo, de 3 horas de duración, realizado en la Universitat Jaume I de Castellón durante el curso académico 2014-2015. Además ha realizado tareas tales como entrevistas reflexivas así como la elaboración de un diario reflexivo durante su estancia de Practicum I.

Para que conste a los efectos oportunos,

Castellón a de de 2015 


\section{Apéndice 2}

\section{CONSENTIMIENTO INFORMADO ${ }^{3}$}

$M^{a}$ Ángeles Llopis, como investigadora de la tesis doctoral "Pensamiento reflexivo en el Grado de Maestro en Educación Primaria", redacto este documento de Consentimiento Informado con la intención de dejar constancia por escrito de las características de dicho proyecto. Mediante este documento solicito su colaboración y consentimiento en este estudio así como su autorización para el análisis de los datos recogidos.

Para ello le expongo la siguiente información:

- Esta investigación forma parte de la tesis doctoral de la profesora $M^{a}$ Ángeles Llopis, dirigida por los profesores Jordi Adell y Lidón Moliner.

- El objetivo general de esta investigación es analizar el impacto que una intervención específica puede tener en la reflexión de los estudiantes de Practicum I del Grado de Maestro en Educación Primaria. Nos planteamos además, el desarrollo de una serie de sugerencias para maximizar las oportunidades de aprendizaje reflexivo crítico en sus asignaturas.

- La información será recogida a lo largo de todo el proceso a través de instrumentos de investigación tales como entrevistas, grupos de discusión, diarios de campo, etc.

- El equipo de investigación se compromete a que no aparezcan datos que revelen la identidad de la persona participante sin consentimiento previo de la misma. Sus datos personales son confidenciales y están protegidos por la Ley Orgánica de Protección de Datos 15/1999.

- Usted autoriza que los resultados obtenidos puedan ser utilizados en informes y publicaciones correspondientes a la difusión de la investigación.

Para finalizar, el equipo de investigación agradece su colaboración en este proyecto así como la confianza depositada en éste. A través de este documento, la persona

\footnotetext{
3 Solicitud de consentimiento según capítulo II del REAL DECRETO |720/2007, de 2 I de diciembre, por el que se aprueba el Reglamento de desarrollo de la Ley Orgánica 15/1999, de 13 de diciembre, de protección de datos de carácter personal.
} 
colaboradora se compromete a participar activa y voluntariamente en esta investigación.

De esta forma se procede a la firma de este consentimiento informado:

Yo,

como colaborador, declaro estar informado y autorizo a los miembros del equipo de investigación del proyecto a la recopilación, custodia y tratamiento de los datos necesarios para el desarrollo de este estudio.

En Castellón, a de de 2015

Colaborador/a en la investigación Investigador Principal

Fdo: Fdo:

DNI $n^{\circ}$ DNI $n^{\circ}$ 


\section{Apéndice 3}

\section{PARTE I}
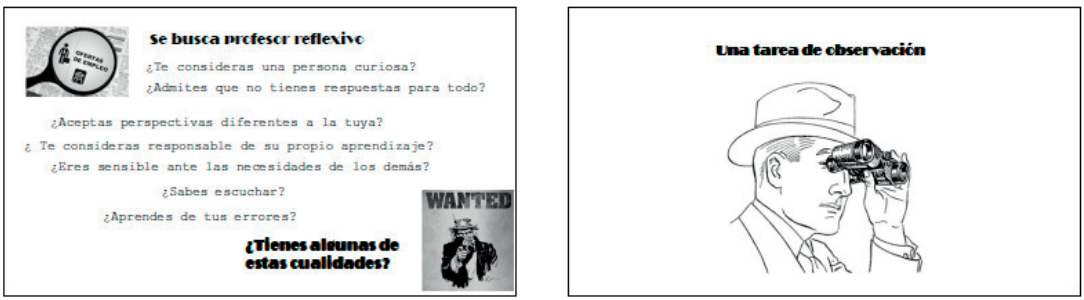

\section{¿Lcr qué se necesitan profesicnales reflevivcs?}

Porque sus actos educativos son informados, justificados y

Porque revisan creencias y las ponen a pruebs.

Porque tiene mejor control emocional dentro -y fuera-del aula.

porque ofrecen al alumnado un modelo abierto, sequro, retador.
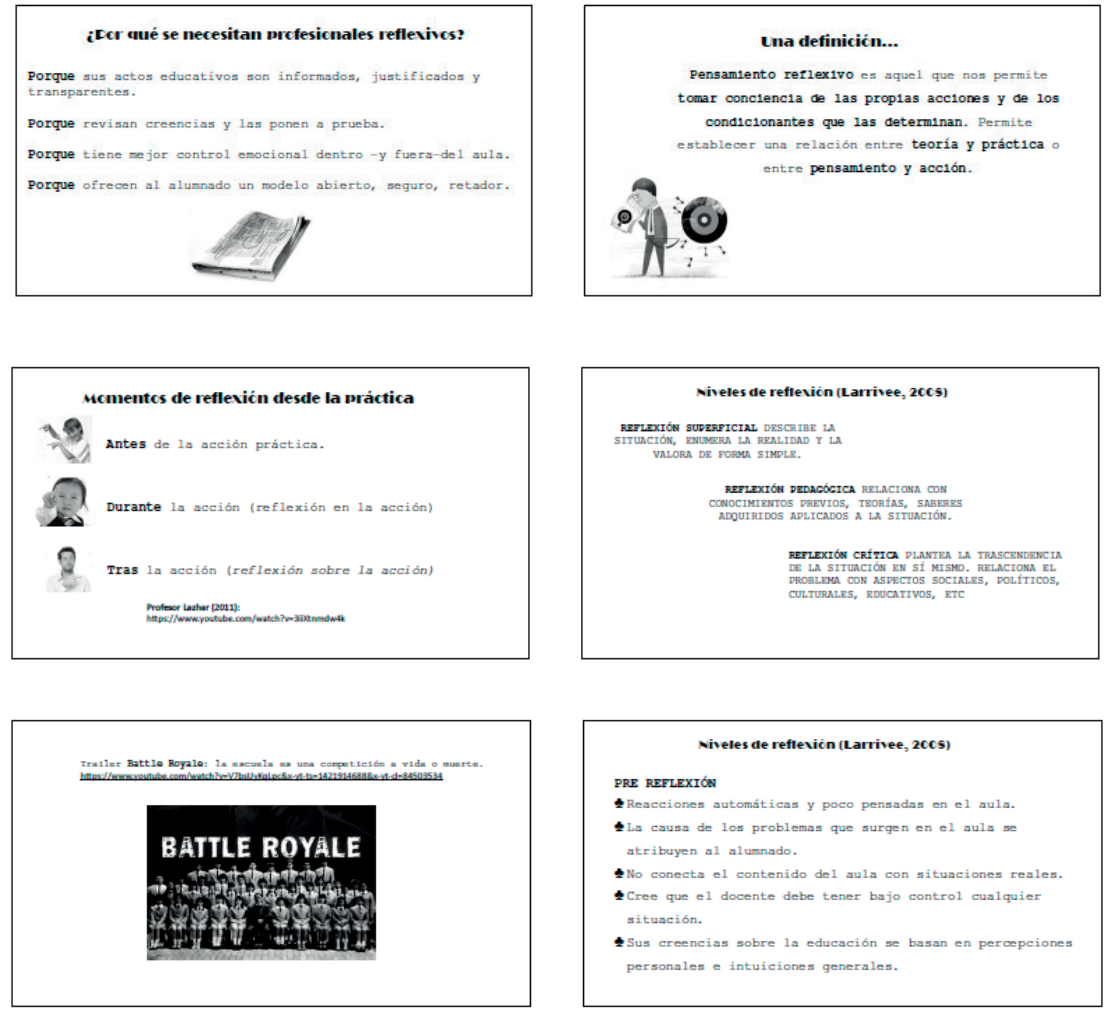

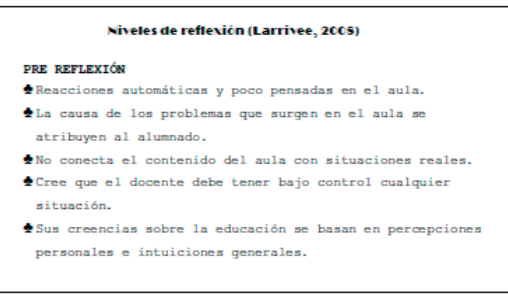

Pag. 262 Apéndice 3 

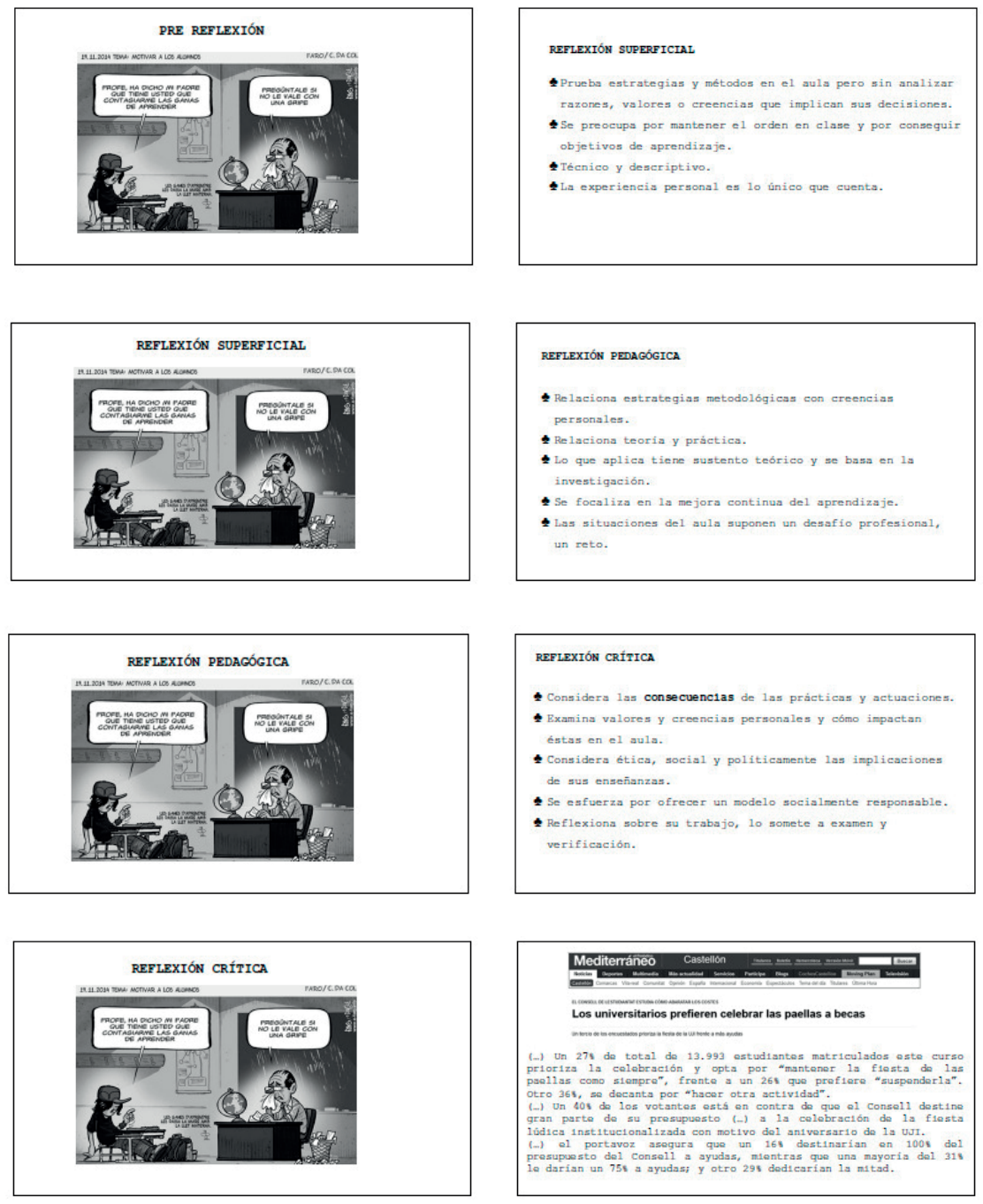

SESIÓN 2:

Traer pensado/redactado un incidente crítico sucedido en el centro escolar 


\section{PARTE II}

\section{EJERCICIO DE ROL PLAY PARA LA OBSERVACIÓN REFLEXIVA DESCRIPCIÓN:}

La profesora sacará un alumno voluntario junto con el cual desarrollará una escena de aula en la cual sucederá un conflicto.

El aula se dividirá en dos partes, los que observarán sin más la escena y los que observarán con unas mínimas pautas reflexivas.

Finalmente compararán las observaciones de ambos grupos.

Grupo A: Sin pautas.

Grupo B: deben entender qué tipo de concepción de la enseñanza tiene esta profesora, cómo es el proceso enseñanza-aprendizaje, cómo es el aprendizaje del alumnado, si está de acuerdo o no con este sistema y qué propondría a cambio. Si esta escena es actual o no lo es y por qué. En qué repercute esta escena en la concepción de la enseñanza que la sociedad tiene hoy en día.

\section{ESCENA: Proceso de enseñanza-aprendizaje en una escuela.}

Reparto de Roles:

1) Profesora => adoptará el rol docente.

2) Alumna=> adoptará el rol del alumnado de primaria.

Desarrollo: La alumna se sienta en un pupitre atendiendo a la profesora. La profesora comienza la clase y va dando instrucciones.

PROF: Buenos días a todos.

ALUM (responde): buenos días profesora.

PROF: Hoy vamos a hablar del verbo y su importancia en la oración. Abrid el libro por la página 34 y leed la definición del recuadro.

ALUM: Abre y lee:

\section{VERBO}

Es aquella palabra que expresa acción, proceso, estados o existencia que afectan a las personas o las cosas. Puede variar en el tiempo, aspecto, modo, voz, número y persona y funciona como núcleo del predicado. Son ejemplos de verbos caer, dormir, buscar o querer. PROF: Como veo que se entiende bien, vais a copiar en el cuaderno la definición.

ALUM (copia)

PROF: A continuación vais a resolver los ejercicios I, 2, 3 y 4 del tema y al final de clase los revisaremos.

A continuación cada grupo debe exponer lo que más le llama la atención de la escena. 


\section{Apéndice 4}

\section{GUÍA PARA ELABORAR EL DIARIO REFLEXIVO}

Este documento constituye una guía para el alumnado que participa en la investigación sobre pensamiento reflexivo. Las orientaciones que aquí figuran sólo pretenden orientar para que cada cual tome ideas respecto a lo que puede escribir en su diario.

La guía está dividida en tres momentos, coincidentes con la propia estructura del Practicum I:
a) Adaptación/ preparación (1 semana)
b) Colaboración ( 2 semanas)
c) Intervención (7 semanas)

Se debe redactar una entrada semanal que deberéis subir al aula virtual, en la que se reflexionará sobre algún hecho crítico (positivo o negativo) que haya sucedido a lo largo de esa semana de prácticas. Esa entrada será de carácter privado, es decir, ningún otro miembro del grupo podrá leerla. No hay extensión predeterminada de cada entrada pero se aconseja no hacerla demasiado extensa.

\section{SEMANA DE ADAPTACIÓN}

Aspectos sobre los que se puede reflexionar: un hecho que te haya llamado la atención sobre la organización del centro o del aula, algo que haya chocado con las expectativas previas que llevabas, algo que haya modificado alguna de tus creencias sobre la educación o que te haya hecho aprender algo sobre ti mismo/a. Aspectos que te creen inseguridad o temor, aspectos donde te has visto seguro/a y a gusto.

\section{SEMANAS DE COLABORACIÓN}

Aspectos sobre los que se puede reflexionar: situaciones que te han llamado la atención de las clases: metodología, actividades, control del aula, planificación de las tareas, etc. ídem pero sobre contextos externos (patios, pasillos, salas de profesores), relaciones entre alumnado y profesorado, incidentes que hayan hecho modificar creencias personales sobre la educación o la docencia o también sobre uno mismo como profesional y como persona. Aspectos que te creen inseguridad o temor, aspectos donde te has visto seguro/a y a gusto.

\section{SEMANAS DE INTERVENCIÓN}

Aspectos sobre los que se puede reflexionar: sobre tu propio desempeño, por ejemplo, qué materia te ha sorprendido, qué conocimientos teóricos te están siendo útiles, qué te está pareciendo el trabajo del docente, qué están aprendiendo los niños y niñas (contenidos, actitudes, procedimientos, valores, etc.), de qué modo aprenden, cómo se trabaja la diferencia, qué rol docente estás adoptando, cómo llevas el control de la disciplina, incidentes que modifiquen tus creencias. Aspectos que te creen inseguridad o temor, aspectos donde te has visto seguro/a y a gusto. 


\section{Apéndice 5}

Apéndice 5. Entrevista reflexiva validada

\section{ENTREVISTA SEMIESTRUCTURADA SOBRE PENSAMIENTO REFLEXIVO}

El objetivo de la entrevista es valorar el pensamiento reflexivo del alumnado y categorizarlo según los niveles de reflexión establecidos por diversos autores:

1) Reflexión superficial: descriptiva, narrativa pero sin ahondar ni establecer relaciones.

2) Reflexión pedagógica: establece conexiones con teorías, conocimientos previos, paradigmas.

3) Reflexión crítica o social: establece una visión personal y crítica de la repercusión o trascendencia social, política y/o económica.

\section{A) SOBRE LOS ESTUDIOS Y LA PROFESIÓN DE MAESTRO}

1) ¿Por qué elegiste estudiar la titulación de maestro primaria?

2) ¿Qué actividades te han llevado con mayor frecuencia a reflexionar sobre la profesión docente?

3) ¿Qué tipo de profesorado te ha llevado con mayor frecuencia a reflexionar sobre la profesión docente?

4) Como docente, ¿qué te gustaría enseñar/transmitir a tus futuros alumnos?

5) Expresa lo que para ti significa "ser un buen maestro".

6) Tu idea sobre lo que es la educación y la enseñanza ¿se mantiene igual que cuando iniciaste la carrera?

7) ¿Qué valor crees que tiene la profesión de maestro?

8) ¿Cómo crees que afecta la situación económica actual en España a la educación?

\section{B) SOBRE EL CONCEPTO O IDEA DE REFLEXIÓN}

1. ¿La palabra "reflexión" qué significado tiene para ti?

2. ¿Crees que tienes capacidad de reflexión? (Justifica tu respuesta)

3. ¿Cómo crees que se puede desarrollar la capacidad reflexiva?

4. ¿Establecerías alguna diferencia entre "reflexión" y "reflexión crítica"?

5. ¿Encuentras alguna relación entre la reflexión y la práctica docente?

6. ¿Podrías contar un hecho o suceso durante tu formación que te haya hecho reflexionar hasta el punto de cambiar tu forma de pensar respecto a algún tema?

\section{C) SOBRE LAS EXPECTATIVAS PREVIAS RESPECTO AL PRACTICUM}

1. ¿Qué experiencias personales crees que te pueden ayudar a mejorar como docente en el Practicum?

2. ¿Qué objetivos personales y/o profesionales te planteas conseguir con el Practicum?

3. ¿Qué cualidades posees como docente que te ayudarán a llevar bien el Practicum?

4. ¿Qué competencias adquiridas durante la titulación crees que te han preparado mejor para el Practicum?

5. Cuando des clase durante el Practicum, ¿qué metodología didáctica emplearás?

6. ¿Qué recursos didácticos consideras imprescindibles en las aulas? 



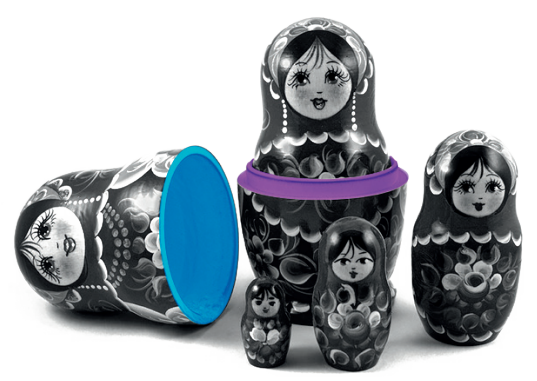

